JÚLIA COUTINHO AMARAL

ANÁLISE DA COMPLEXIDADE DA MALHA VIÁRIA PARA DISTRIBUIÇÃO DE ÚLTIMA MILHA EM ÁREAS URBANAS

SÃO PAULO 
JÚLIA COUTINHO AMARAL

ANÁLISE DA COMPLEXIDADE DA MALHA VIÁRIA PARA
DISTRIBUIÇÃO DE ÚLTIMA MILHA EM ÁREAS URBANAS

Dissertação apresentada à Escola

Politécnica da Universidade de São Paulo para obtenção do Título de Mestre em Ciências

SÃO PAULO 
JÚLIA COUTINHO AMARAL

\section{ANÁLISE DA COMPLEXIDADE DA MALHA VIÁRIA PARA DISTRIBUIÇÃO DE ÚLTIMA MILHA EM ÁREAS URBANAS}

Dissertação apresentada à Escola Politécnica da Universidade de São Paulo para obtenção do título de Mestre em Ciências

Área de Concentração:

Engenharia de Transportes

Orientador: Prof. Livre-Docente

Cláudio Barbieri da Cunha

\section{SÃO PAULO}




\section{FICHA CATALOGRÁFICA}

Amaral, Júlia Coutinho Amaral

ANÁLISE DA COMPLEXIDADE DA MALHA VIÁRIA PARA DISTRIBUIÇÃO

DE ÚLTIMA MILHA EM ÁREAS URBANAS / J. C. A. Amaral -- São Paulo, 2018. $164 \mathrm{p}$.

Dissertação (Mestrado) - Escola Politécnica da Universidade de São Paulo. Departamento de Engenharia de Transportes.

1.Distribuição de mercadorias 2.Transporte urbano I.Universidade de São Paulo. Escola Politécnica. Departamento de Engenharia de Transportes II.t. 


\section{AGRADECIMENTOS}

Ao meu orientador Prof. Dr. Claudio Barbieri da Cunha, pelo direcionamento, atenção, confiança e apoio demonstrados durante todo período da orientação.

Aos amigos do mestrado cujo apoio e convivência me motivaram longo deste processo: Bruno Uberti, Fábio Emanuel, Guilherme Bandones, Janaína Carli, Luiz Felipe, Maurício Souza, Patrícia Laranjeiro, Priscila Coutinho, Renan Sallai, Renato Arbex e Rodrigo Ajauskas.

Aos meus pais, Márcia Cristina Peixoto Coutinho e Luiz Arthur Roberto de Souza Ferreira Amaral, pelo amor e suporte para a realização deste trabalho. 


\section{RESUMO}

O objetivo deste trabalho é apresentar um método que possibilite a avaliação e a comparação de áreas urbanas quanto à dificuldade imposta pela malha viária à circulação dos veículos que realizam a distribuição de última milha Busca-se um método automatizado que seja global, ou seja, que possa ser aplicado em qualquer cidade do mundo, não dependa de dados de campo nem de informações cujo acesso é restrito. A relevância deste trabalho é justificada pela carência de ferramentas que auxiliem a tomada de decisões relacionadas a políticas de transporte e planejamento da distribuição de última milha em cidades. Primeiro, é feita uma revisão bibliográfica de métodos e métricas de avaliação de cidades e redes viárias e de transportes, a fim de identificar quais podem ser adaptadas para o problema da distribuição de carga urbana. Em seguida é apresentado o procedimento do método proposto, que contempla as duas partes da distribuição de última milha: circulação local e acesso/regresso ao distrito de entrega. O método avalia a malha viária quanto a influência da sua infraestrutura nas distâncias das viagens através de um índice de "retilinidade" baseado em uma métrica revisada da literatura, e avalia a influência da ocupação viária nos tempos de viagem através das velocidades médias estimadas em dados históricos. O método ainda contempla a possibilidade do uso de veículos não motorizados nas entregas, adicionando a topografia da área urbana estudada à avaliação realizada. Os dados de entrada necessários para a aplicação do método são estabelecidos pelo usuário com base na região e no tipo de cadeia de suprimentos que se deseja estudar e as informações necessárias para a análise são obtidas através das ferramentas Google Maps Directions API e Open Street Map, cumprindo os objetivos de generalidade e automação desejados. Para a parte da circulação local, são apresentados resultados da aplicação do método proposto em seis áreas urbanas de seis cidades diferentes (São Paulo, Rio de janeiro, Bogotá, Nova lorque, Londres e São Francisco), e, para a parte do acesso/regresso ao distrito de entrega, são apresentados resultados para quatro potenciais locais de Centro de Distribuição e uma área de entrega em São Paulo. Os resultados consistem em uma coletânea de métricas, gráficos e mapas que permitem a avaliação e comparação das áreas urbanas estudadas, como proposto. Adicionalmente são apresentadas as correlações entre as métricas estruturais das malhas viárias e as métricas associadas ao desempenho da distribuição de última milha, a fim de identificar possíveis causalidades entre elas. Por fim, os resultados obtidos são discutidos e são sugeridos próximos passos para a continuação deste trabalho.

Palavras-chave: Distribuição de mercadorias; Transporte urbano. 


\begin{abstract}
The goal of this thesis is to introduce a method that allows the evaluation and comparison of urban areas regarding the difficulty imposed by the road network to the circulation of vehicles that perform the last mile distribution. The method must be automated and global, meaning that it can be applied in any city and does not rely on field data or restricted information. This thesis is motivated by the scarcity of supporting tools for elaborating transport policies and planning the last mile distribution operations in cities. Firstly, a literature review is conducted to identify urban and road network metrics that can be applicable to urban freight distribution analysis. Next, the proposed method is presented. It analyses two parts of the last mile distribution: local distribution and line-haul. The method evaluates the influence of the road network infrastructure on travel distances through a straightness index based on metric found in the literature review, and it evaluates the influence of road occupation on travel times through estimated speeds based on historical data. All inputs required for the application of the method are defined by the user and are based on the characteristics of the study area and type of supply chain. The information required for the analysis is obtained through the Google Maps Directions API and Open Street Map tools, which fulfill the automation premise of the method. For the local distribution, a study case is conducted in six urban areas from six cities (Sao Paulo, Rio de Janeiro, Bogota, New York, London and San Francisco). For the line-haul, the case study includes four potential distribution center locations and a delivery area in Sao Paulo. The results are a collection of metrics, graphs and maps that allow the evaluation and the comparison of the six urban areas, as proposed. Additionally, the correlations between the structural metrics of the road networks and the drivers of the last mile distribution are presented, in order to identify possible causalities between them. Finally, the results are discussed and further steps for this work are suggested.
\end{abstract}

Keywords: Freight distribution; Urban transport. 


\section{SUMÁRIO}

1 INTRODUÇÃO .1

1.1 A Distribuição de Última Milha em Áreas Urbanas .....................................1

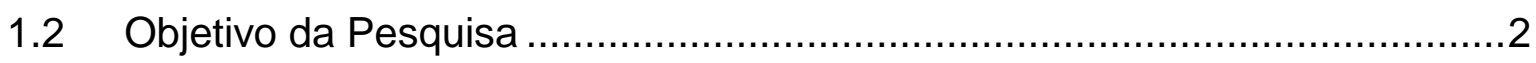

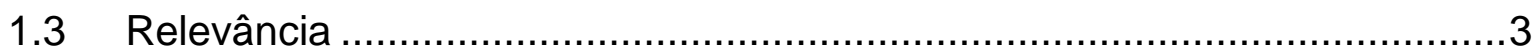

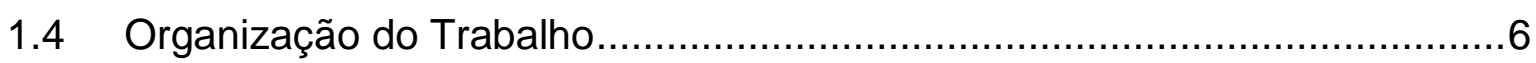

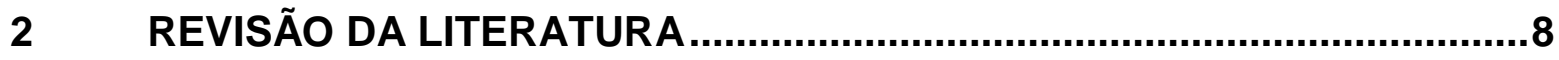

2.1 Evolução e Análise de Forma de Áreas Urbanas .......................................

2.2 Análise de Redes Viárias e de Transportes ...........................................12

2.2.1 Eficiência de Rede ................................................................... 12

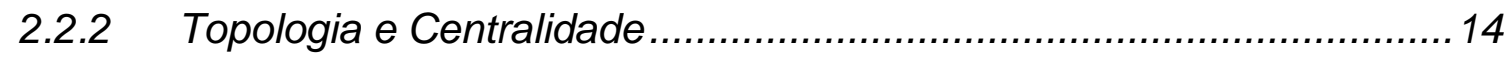

2.3 Métricas para Análise do Transporte Urbano de Passageiros ....................21

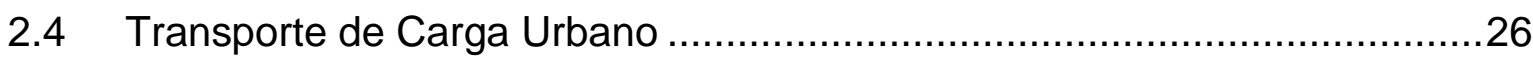

2.5 Conclusão da Revisão da Literatura ...........................................................

3 MÉTODO PARA AVALIAÇÃO DA COMPLEXIDADE DA DISTRIBUIÇÃO

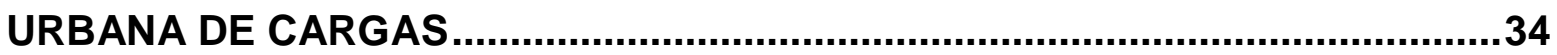

3.1 Escolha e Caracterização da Área de Estudo.........................................42

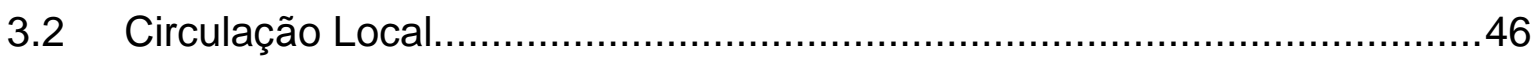

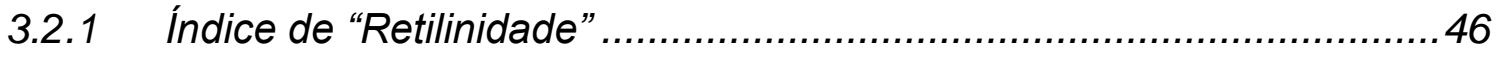

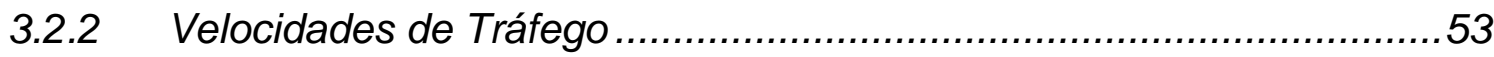

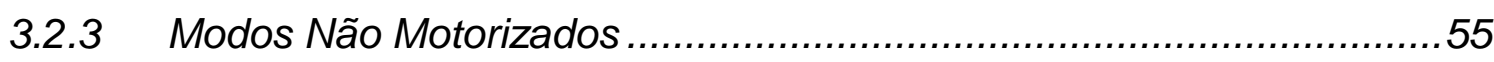

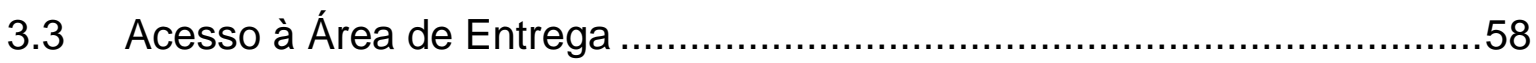

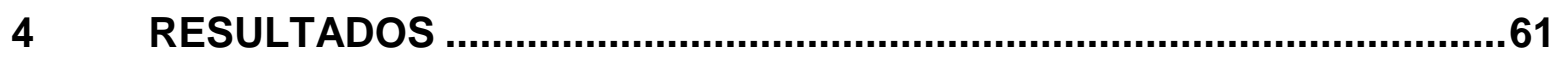

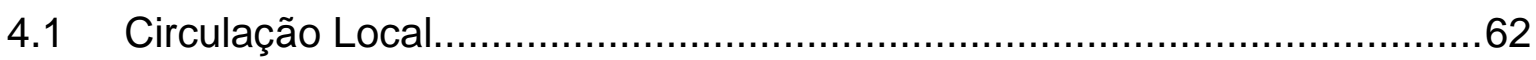

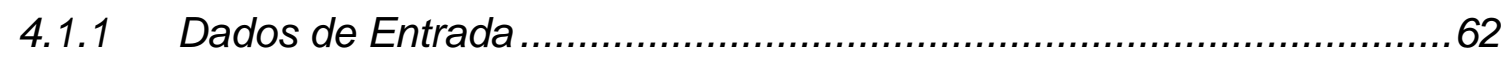

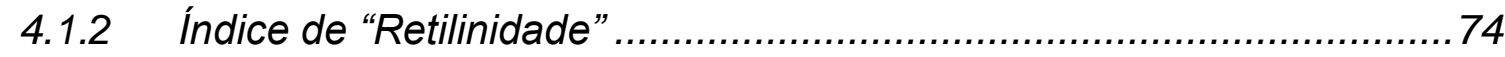




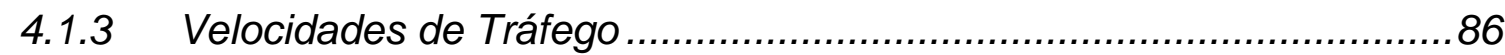

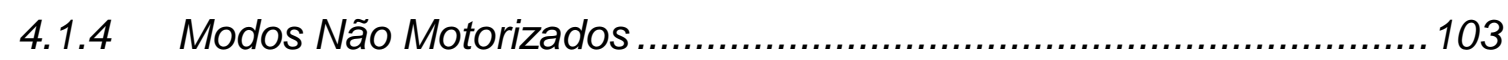

4.2 Acesso à Área de Entrega .............................................................117

4.3 Comentários Gerais .....................................................................123

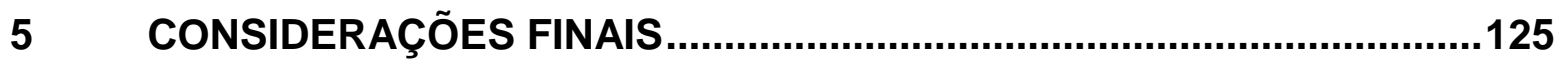

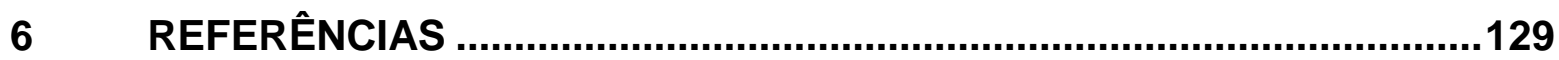

ANEXO A: RESUMO DAS MÉTRICAS ENCONTRADAS NA LITERATURA.....133

ANEXO B: ÍNDICE DE "RETILINIDADE” - ESTUDO DE CASO EM TRÊS BAIRROS DE SÃO PAULO .........................................................................137

ANEXO C: AGRUPAMENTO DE PONTOS DE ENTREGA UTILIZANDO O ALGORITMO K-MEANS ...........................................................................142

ANEXO D: ANÁLISE DO ACESSO À ÁREA DE ENTREGA UTILIZANDO

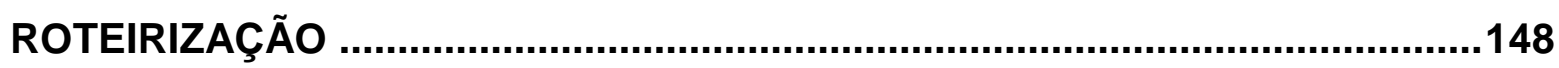

ANEXO E: COMPARAÇÃO DE RESULTADOS - GOOGLE MAPS X OPEN STREET MAP. 160 


\section{LISTA DE FIGURAS}

Figura 2.1: Evolução da rede viária de Sheffield; (a) histograma circular da orientação das vias; (b) histograma tradicional com número de ruas $(\mathrm{N})$ e entropia da orientação (S); (c) cumulativo da distribuição dos comprimentos de via (Mohajeri e Gundmunson, 2014)

Figura 2.2: Os quatro grupos de cidades; a esquerda a distribuição dos fatores de forma (Ф); a direita, exemplos de configuração típica para cada grupo (Louf e Barthelemy, 2014). 12

Figura 2.3: índices de centralidade dos nós de um recorte da malha viária de Veneza (Itália); (1) centralidade de proximidade; (2) centralidade de intermediação; (3) centralidade de "retilinidade"; (4) centralidade de informação; a escala de cinzas representa multiplicadores do desvio padrão a partir da média (Crucitti et al., 2006).

Figura 2.4: Processo de densificação e expansão da malha viária de região do norte de Milão, Itália (Strano et al., 2012) 16

Figura 2.5: (a) rede viária do bairro Sätra em Gavle, Suécia; (b) rede dual correspondente (Jiang e Claramunt, 2004). 19

Figura 2.6: (1) o sistema urbano; (2) a rede primal; (3) a rede dual; (A) rede dual construída de acordo com o critério da linearidade das vias; (B) rede dual construída pelo critério de nomenclatura; (C) rede dual construída utilizando o critério de continuidade das vias (Porta et al., 2006)

Figura 2.7: Exemplo de divisão de distritos resultante do modelo matemático proposto por Novaes et al. (2000).

Figura 3.1: Duas alternativas de divisão de uma região em seis distritos de entrega (Daganzo, 1984) .38

Figura 3.2: Exemplo de configuração de distritos de entrega com barreira urbana em São Paulo. .38

Figura 3.3: Exemplo alternativo de configuração de distritos de entrega em São Paulo 
Figura 3.4: A Avenida Paulista com seu canteiro central, exemplo de via que é considerada de mão única pelo OSM.

Figura 3.5: A Avenida Angélica, exemplo de via mão dupla.

Figura 3.6: Exemplo de distância euclidiana máxima para cálculo de caminho entre pontos.

Figura 3.7: Representação de oito caminhos com origem no ponto central da circunferência.

Figura 3.8: Exemplo de origem e destino com representação gráfica das distâncias.

Figura 3.9: Possibilidades de caminhos entre dois pontos variando o modo de transporte.

Figura 4.1: Área selecionada para análise na cidade de São Paulo. .63

Figura 4.2: Área selecionada para análise na cidade do Rio de Janeiro. .64

Figura 4.3: Área selecionada para análise na cidade de Bogotá. .64

Figura 4.4: Área selecionada para análise na cidade de Nova lorque. .65

Figura 4.5: Área selecionada para análise na cidade de Londres. .65

Figura 4.6: Área selecionada para análise na cidade de São Francisco. .66

Figura 4.7: Rede viária contida na área analisada em São Paulo. 69

Figura 4.8: Rede viária contida na área analisada no Rio de Janeiro. .70

Figura 4.9: Rede viária contida na área analisada em Bogotá. .71

Figura 4.10: Rede viária contida na área analisada em Nova lorque .72

Figura 4.11: Rede viária contida na área analisada em Londres. .73

Figura 4.12: Rede viária contida na área analisada em São Francisco. .73

Figura 4.13: Distribuição IR x Distância Euclidiana de São Paulo. .74

Figura 4.14: Distribuição IR x Distância Euclidiana do Rio de Janeiro. .75

Figura 4.15: Distribuição IR x Distância Euclidiana de Bogotá. .75

Figura 4.16: Distribuição IR x Distância Euclidiana de Nova lorque. .76

Figura 4.17: Distribuição IR x Distância Euclidiana de Londres. .76

Figura 4.18: Distribuição IR x Distância Euclidiana de São Francisco. .77 
Figura 4.19: Boxplots dos IRs para veículos motorizados por cidade e faixa de distância euclidiana.

Figura 4.20: Mapa com os IRs para veículos motorizados em São Paulo. .83

Figura 4.21: Mapa com os IRs para veículos motorizados no Rio de Janeiro... .83

Figura 4.22: Mapa com os IRs para veículos motorizados em Bogotá. .84

Figura 4.23: Mapa com os IRs para veículos motorizados em Nova lorque. .84

Figura 4.24: Mapa com os IRs para veículos motorizados em Londres. 85

Figura 4.25: Mapa com os IRs para veículos motorizados em São Francisco. 85

Figura 4.26: Velocidade Média de Circulação x Horário. .87

Figura 4.27: Velocidades de tráfego em São Paulo a 1h. 91

Figura 4.28: Velocidades de tráfego em São Paulo as 8h. 91

Figura 4.29: Velocidades de tráfego em São Paulo as 13h. .92

Figura 4.30: Velocidades de tráfego em São Paulo as 18h. .92

Figura 4.31: Velocidades de tráfego no Rio de Janeiro a $1 \mathrm{~h}$. .93

Figura 4.32: Velocidades de tráfego no Rio de Janeiro as 8h. .93

Figura 4.33: Velocidades de tráfego no Rio de Janeiro as $13 \mathrm{~h}$. .94

Figura 4.34: Velocidades de tráfego no Rio de Janeiro as $18 \mathrm{~h}$. .94

Figura 4.35: Velocidades de tráfego em Bogotá a 1h. .95

Figura 4.36: Velocidades de tráfego em Bogotá as 8h. .95

Figura 4.37: Velocidades de tráfego em Bogotá as 13h. .96

Figura 4.38: Velocidades de tráfego em Bogotá as 18h. .96

Figura 4.39: Velocidades de tráfego em Nova lorque a $1 \mathrm{~h}$. .97

Figura 4.40: Velocidades de tráfego em Nova lorque as $8 \mathrm{~h}$. .97

Figura 4.41: Velocidades de tráfego em Nova lorque as 13h. .98

Figura 4.42: Velocidades de tráfego em Nova lorque as $18 \mathrm{~h}$. .98

Figura 4.43: Velocidades de tráfego em Londres a $1 \mathrm{~h}$. .99

Figura 4.44: Velocidades de tráfego em Londres as 8h. .99

Figura 4.45: Velocidades de tráfego em Londres as $13 \mathrm{~h}$. 100

Figura 4.46: Velocidades de tráfego em Londres as 18h. 100

Figura 4.47: Velocidades de tráfego em São Francisco a 1h. 101 
Figura 4.48: Velocidades de tráfego em São Francisco as 8h. .............................101

Figura 4.49: Velocidades de tráfego em São Francisco as 13h. .............................102

Figura 4.50: Velocidades de tráfego em São Francisco as 18h. ...........................102

Figura 4.51: Distribuição IRbicicleta $x$ Distância Euclidiana de São Paulo...................103

Figura 4.52: Distribuição IRbicicleta $x$ Distância Euclidiana do Rio de Janeiro.............104

Figura 4.53: Distribuição IRbicicleta $x$ Distância Euclidiana de Nova lorque................104

Figura 4.54: Distribuição IRbicicleta X Distância Euclidiana de Londres.......................105

Figura 4.55: Distribuição IRbicicleta $x$ Distância Euclidiana de São Francisco.............105

Figura 4.56: Boxplots dos IRs para bicicleta por cidade e faixa de distância euclidiana.

Figura 4.57: Distribuição IRa péx Distância Euclidiana de São Paulo. .....................108

Figura 4.58: Distribuição $I R_{a}$ pé $X$ Distância Euclidiana do Rio de Janeiro................109

Figura 4.59: Distribuição IRa péx Distância Euclidiana de Bogotá. ..........................109

Figura 4.60: Distribuição IRa pé X Distância Euclidiana de Nova lorque. ..................110

Figura 4.61: Distribuição IRa pé X Distância Euclidiana de Londres.........................110

Figura 4.62: Distribuição IRa péx Distância Euclidiana de São Francisco. ................111

Figura 4.63: Boxplots dos IRs para caminhada por cidade e faixa de distância

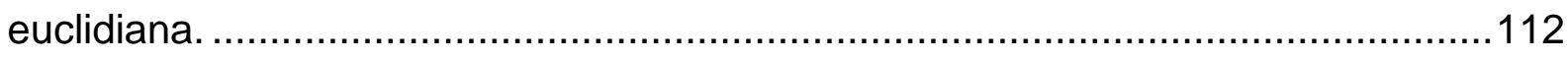

Figura 4.64: Declividades das vias em São Paulo. ..........................................114

Figura 4.65: Declividades das vias no Rio de Janeiro........................................115

Figura 4.66: Declividades das vias em Bogotá....................................................115

Figura 4.67: Declividades das vias em Nova lorque. .......................................116

Figura 4.68: Declividades das vias em Londres..............................................116

Figura 4.69: Declividades das vias em São Francisco .....................................117

Figura 4.70: Traçados dos trajetos com origem nos potenciais locais de CD e destino

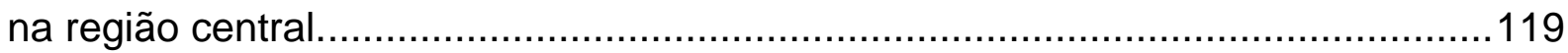

Figura 4.71: Traçados dos trajetos com origem na região central e destino nos

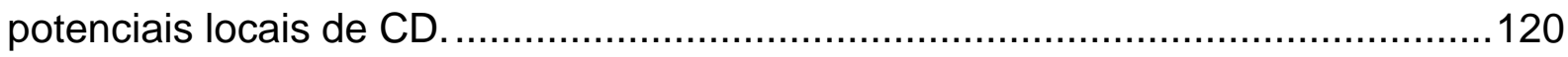

Figura 4.72: Perfis de velocidade para os trajetos com sentido centro. ..................121 
Figura 4.73: Perfis de velocidade para os trajetos com sentido aos potenciais locais de centro de distribuição.

Figura B.1: Localização das regiões estudadas.

Figura B.2: Potenciais pontos de entrega na região da Paulista/Consolação.

Figura B.3: Potenciais pontos de entrega em Pinheiros

Figura B.4: Potenciais pontos de entrega na Vila Carrão.

Figura B.5: Comparação das distâncias reais com as distâncias euclidianas.

Figura B.6: Comparação do índice de "retilinidade" com as distâncias euclidianas.

Figura C.1: Resultado do agrupamento para k = 3 com distâncias euclidianas......144

Figura C.2: Resultado do agrupamento para $\mathrm{k}=3$ com distâncias reais. 145

Figura C.3: Resultado do agrupamento para $\mathrm{k}=5$ com distâncias euclidianas......145

Figura C.4: Resultado do agrupamento para $\mathrm{k}=5$ com distâncias reais. 146

Figura D.1: Dados de entrada para a análise de velocidades: distrito de entrega, locais de entrega e locais dos centros de distribuição. 150

Figura D.2: Resultado do sequenciamento das rotas para o grupo de pontos 1 .....151

Figura D.3: Resultado do sequenciamento das rotas para o grupo de pontos 2.....151

Figura D.4: Resultado do sequenciamento das rotas para o grupo de pontos $3 \ldots . . .152$ Figura D.5: Perfis de velocidade para etapa de line-haul até o local de entrega para o grupo de pontos 1 . 155

Figura D.6: Perfis de velocidade para etapa de line-haul até o local de entrega para o grupo de pontos 2 . 155

Figura D.7: Perfis de velocidade para etapa de line-haul até o local de entrega para o grupo de pontos 3. 156

Figura D.8: Perfis de velocidade para etapa de circulação entre locais de entrega para o grupo de pontos 1. 156

Figura D.9: Perfis de velocidade para etapa de circulação entre locais de entrega para o grupo de pontos 2 .

Figura D.10: Perfis de velocidade para etapa de circulação entre locais de entrega para o grupo de pontos 3 . 
Figura D.11: Perfis de velocidade para etapa de line-haul de retorno para o centro de distribuição para o grupo de pontos 1 . 158

Figura D.12: Perfis de velocidade para etapa de line-haul de retorno para o centro de distribuição para o grupo de pontos 2 . 158

Figura D.13: Perfis de velocidade para etapa de line-haul de retorno para o centro de distribuição para o grupo de pontos 3 . 159

Figura E.1: Variação do IR Google Maps x OSM em São Paulo. 162

Figura E.2: Variação do IR Google Maps x OSM no Rio de Janeiro. 162

Figura E.3: Variação do IR Google Maps x OSM em Bogotá 163

Figura E.4: Exemplo de caminhos em Bogotá. 164 


\section{LISTA DE TABELAS}

Tabela 2.1: Métricas e autores revisados.

Tabela 4.1: Valores das Áreas e número de pontos gerados para cada cidade. 63

Tabela 4.2: Métricas das redes viárias.

Tabela 4.3: Correlação entre as métricas das redes viárias.

Tabela 4.4: Índices de "Retilinidade" Médios para veículos motorizados. .79

Tabela 4.5: Correlação entre métricas da rede viária e IRM para veículos motorizados.

Tabela 4.6: Velocidades Médias $(\mathrm{km} / \mathrm{h})$ de circulação. .86

Tabela 4.7: Correlação entre métricas da rede viária e velocidades médias de circulação.

Tabela 4.8: Porcentagem de quilometragem de vias com tráfego em determinadas faixas de velocidade a $1 \mathrm{~h}$ .89

Tabela 4.9: Porcentagem de quilometragem de vias com tráfego em determinadas faixas de velocidade as $8 \mathrm{~h}$. .90

Tabela 4.10: Porcentagem de quilometragem de vias com tráfego em determinadas faixas de velocidade as $13 \mathrm{~h}$. .90

Tabela 4.11: Porcentagem de quilometragem de vias com tráfego em determinadas faixas de velocidade as $18 \mathrm{~h}$. .90

Tabela 4.12: Índices de "Retilinidade" Médios para bicicleta. 106

Tabela 4.13: Correlação entre métricas da rede viária e IR para veículos bicicleta. 108

Tabela 4.14: Índices de "Retilinidade" Médios para caminhada. 111

Tabela 4.15: Correlação entre métricas da rede viária e IR para caminhada. 113

Tabela 4.16: Razão entre IRM dos modos motorizado e bicicleta. 113

Tabela 4.17: Razão entre IRM dos modos motorizado e caminhada. 113

Tabela 4.18: Porcentagem de quilometragem de vias em determinadas faixas de declividade. 
Tabela 4.19: Características dos trajetos de acesso à Região A partir dos potenciais locais de centro de distribuição.

Tabela 4.20: Características dos trajetos de regresso aos potenciais locais de centro de distribuição a partir da Região $A$.

Tabela A.1: Métricas encontradas na literatura. 133

Tabela B.1: Médias dos valores obtidos por região estudada. 139

Tabela D.1: Resultados da etapa 1 - line-haul. 153

Tabela D.2: Resultados da etapa 2 - circulação local. 153

Tabela D.3: Resultados da etapa 3 - line-haul..................................................154

Tabela E.1: Porcentagem (\%) de observações em cada variação de IR. 163 


\section{INTRODUÇÃO}

\subsection{A Distribuição de Última Milha em Áreas Urbanas}

Segundo Lindner (2011, apud Yuen et al., 2018), distribuição de última milha (do inglês, last mile distribution ou last mile delivery) é a expressão utilizada para o último segmento de um processo de entrega, que envolve uma série de atividades necessárias para processo de entrega do último ponto de transbordo até o destino final de entrega.

A distribuição de última milha nas cidades consiste no transporte de bens e mercadorias de centros de distribuição (CDs), armazéns e fábricas localizados na periferia da região metropolitana até os pontos de demanda (restaurantes, farmácias, supermercados, domicílios, etc.) localizados em áreas urbanas mais centrais. Devido ao fracionamento da carga, cada veículo atende múltiplos locais de entrega, tornando o problema de sequenciamento de pontos de entrega de extrema importância para o bom desempenho da operação de entregas. A fim de reduzir os custos de transporte (aumentar a eficiência da distribuição urbana de última milha), o sequenciamento de pontos de entrega busca minimizar a frota utilizada e a distância total percorrida pelos veículos, ao mesmo tempo em que atende a restrições de jornadas de trabalho, janelas de entrega, etc.

Sendo assim, a eficiência da distribuição de última milha está relacionada com as distâncias percorridas e com os tempos necessários para completar os roteiros de entrega; quanto menor a distância percorrida e o tempo necessário para atendimento de todos os pontos de entrega, mais eficiente é a operação de distribuição de última milha. Distância e tempo estão diretamente relacionados à oferta de malha viária, que é a infraestrutura para a circulação dos veículos, e ao trânsito presente nas vias, que impacta as velocidades de tráfego e consequentemente os tempos de viagem. A dificuldade de circulação imposta pela malha viária aos veículos que realizam entregas se dá devido a trajetos sinuosos causados pela eventual escassez de vias que liguem uma dada origem a um destino de maneira mais eficiente, ou a leis de trânsito (mão de direção, restrição de circulação, etc.) que podem ocasionar longos 
desvios, ou ainda a formação de gargalos no trânsito devido à falta de alternativas de trajetos, causando congestionamentos e baixas velocidades de tráfego.

\subsection{Objetivo da Pesquisa}

O objetivo deste trabalho é apresentar um método que possibilite a avaliação e a comparação de áreas urbanas quanto à dificuldade imposta à circulação dos veículos que realizam a distribuição de última milha, a partir de uma revisão da literatura sobre o assunto. A ideia é que o método proposto permita identificar áreas cuja oferta viária e cuja ocupação cotidiana do sistema viário (trânsito) imponham dificuldades à circulação de veículos que realizam a distribuição de última milha, permitindo que tanto planejadores do transporte de carga urbano quanto formuladores de políticas públicas possam priorizá-las e investigá-las com mais detalhes, possibilitando a proposição de estratégias específicas para melhorar o desempenho da distribuição de última milha nesses locais.

Tanto as características físicas da malha viária quanto a sua ocupação afetam diretamente a eficiência da operação de última milha, portanto há a necessidade de incluir ambas análises nesta pesquisa. Neste trabalho busca-se investigar a eficiência da malha viária disponível em conectar regiões periféricas onde se localizam os CDs aos polos de demanda de entrega e também a eficiência da malha viária disponível que possibilita conectar os pontos de entrega entre si, pois é através da malha viária que os deslocamentos são realizados, afetando diretamente as distâncias percorridas. A ocupação do sistema viário também é contemplada, pois afeta diretamente os tempos de deslocamento, prolongando-os e aumentando sua variabilidade, impactando diretamente a eficiência do transporte de carga.

A malha viária disponível e as regras de trânsito locais afetam ainda mais a as distâncias e os tempos de deslocamento para a realização das entregas quando se considera que, devido a imprevistos, nem sempre os veículos conseguem cumprir o roteiro planejado, o que causa alterações no caminho e na sequência de pontos de entrega atendidos. Imprevistos como bloqueios de vias, acidentes, falta de vaga de estacionamento ou cliente não disponível para recebimento no momento da chegada do veículo são comuns no processo de distribuição, e forçam o motorista a sair do 
roteiro previsto, gerando desvios inesperados que aumentam a distância total percorrida e o tempo de deslocamento, impactando diretamente na eficiência da operação.

O objetivo é que o método proposto permita a caracterização de uma área urbana definida pelo usuário, na qual pressupõe-se que estão contidos os locais de entrega, quanto a dificuldade da realização da distribuição de última milha através de um atlas de métricas urbanas associadas ao desempenho do transporte de carga urbano, a fim de fornecer dados, mapas e gráficos relevantes para o planejamento das operações de distribuição. Além de permitir a comparação entre áreas urbanas distintas, ferramenta importante quando há importação de estratégias operacionais ou de políticas públicas relacionadas ao transporte de carga urbano.

Sendo assim, busca-se um método que seja geral para que possa ser aplicado a qualquer cidade, sem depender de coleta de dados em campo, ou de dados específicos de obtenção restrita. Além disso, o método deve ser mais automatizado possível, ou seja, não pode depender de manipulação ou aplicação manual, de modo a permitir a aplicação em áreas de grande amplitude geográfica que requerem processamento de grande volume dados.

\subsection{Relevância}

A distribuição urbana de mercadorias, ou distribuição de última milha urbana, é uma atividade essencial para a dinâmica das cidades, já que as atividades econômicas, sociais e até mesmo a sobrevivência dos habitantes das cidades dependem do uso e consumo de mercadorias, como alimentos, combustíveis, bens de consumo em geral, itens de vestuário, etc. Mesmo assim, conforme apontam Lindholm e Blinge (2014), o transporte de carga não ocupa posição de destaque nos planos de mobilidade urbana em comparação com o transporte urbano de passageiros. Ainda segundo os autores, apesar do número de pesquisas relacionadas à sustentabilidade do transporte urbano de mercadorias estar aumentando, as políticas de mobilidade urbana ainda são baseadas na associação direta da distribuição de carga com os impactos negativos gerados pela circulação de veículos de grande porte, detalhados a seguir, levando as autoridades a, muitas vezes, 
adotarem políticas restritivas que nem sempre contribuem para eficiência da distribuição de última milha.

Os principais impactos negativos associados ao transporte de carga são os congestionamentos, a poluição sonora e visual e a emissão de poluentes no ar. Inicialmente, esses impactos são potencializados pela natureza dos veículos que realizam o transporte de carga, pois possuem maiores dimensões e, em geral, desenvolvem menores velocidades que os veículos que transportam passageiros (Zambuzi, 2015). Considerando as características negativas dos veículos que realizam entregas de carga, as políticas adotadas pelas autoridades visam restringir a circulação de determinados veículos de carga em horários e regiões da cidade, principalmente àquelas com altas taxas de congestionamento e poluição, a fim de priorizar o fluxo de passageiros (Merchan et al., 2015). Porém, como discutido por Holguín-Veras et al. (2017), a implantação de políticas de restrição de circulação de veículos de carga não resulta na redução dos congestionamentos e da poluição como é esperado, já que as entregas continuam sendo realizadas por veículos menores que substituem os que foram restringidos, levando ao aumento do número total de quilômetros percorridos por veículos de carga e gerando ainda mais congestionamentos e poluição.

O conflito entre fluxos de carga e passageiros em áreas urbanas tende a se intensificar com o processo de urbanização (Merchan et al., 2015). Como destacado pelas projeções de urbanização mundial da Organização das Nações Unidas (2014), a população urbana aumenta a taxas maiores que o crescimento populacional mundial. A população urbana mundial passou de 746 milhões em 1950 para 3,9 bilhões em 2014 e, de acordo com as projeções, até 2050 será acrescida de mais 2,5 bilhões de pessoas. Já existem 27 cidades com mais de 10 milhões de habitantes, as chamadas megacidades, e a tendência aponta que o número de megacidades continue crescendo, chegando a 41 megacidades em 2030, reforçando a existência de um processo de urbanização a nível mundial.

Além da dificuldade imposta pela concorrência nos planos de mobilidade das cidades com o transporte de passageiros, as operações de distribuição da última milha sofrem com obstáculos (congestionamentos, restrições de circulação, barreiras físicas, falta de vaga de estacionamento, etc.) impostos pelo ambiente urbano. $\mathrm{O}$ 
histórico de urbanização e os padrões de desenvolvimento mudam de cidade para cidade e geram ambientes urbanos distintos. Por exemplo, as megacidades da Ásia, África e América do Sul são muito diferentes das megacidades dos países desenvolvidos. As taxas de densidade demográfica são mais altas e a desigualdade também, portanto, os veículos de entrega têm que atender áreas ricas e pobres; bairros prósperos com rede viária consolidada e também vizinhanças mais pobres, bairros periféricos com infraestrutura temerária, construída de maneira informal, sem a ação do Estado. É importante ressaltar que, de acordo com as projeções de urbanização mundial da Organização das Nações Unidas (2014), das 41 megacidades que se estima existirem em 2030, apenas seis estão localizadas em países desenvolvidos, sendo que as demais estão em países em desenvolvimento, em que há carência de recursos e infraestrutura, o que leva ao crescimento rápido e não planejado, à degradação ambiental e a padrões insustentáveis de produção e consumo, prejudicando ainda mais a qualidade de vida da população.

Por se tratar de uma atividade que gera impactos negativos ao ambiente, é importante estudar os aspectos que influenciam a distribuição da última milha, a fim de buscar a minimização dos seus impactos negativos e aumentar a sua eficiência. Fatores como uso do solo, disponibilidade de áreas para estacionamento dos veículos de carga, a malha viária existente, distribuição das atividades comerciais e políticas de restrição de circulação de veículos atingem diretamente a eficiência das entregas, gerando impactos negativos à população que necessita de insumos e que sofre as consequências de um trânsito congestionado.

Devido ao grande número de externalidades, a tarefa de analisar as cidades e os desafios da logística urbana são complexos e extensos. Essa complexidade chama atenção para a necessidade do uso de métodos e modelos que permitam uma análise objetiva do ambiente em questão, auxiliando no diagnóstico de problemas e direcionando a criação de propostas e políticas que aumentem a eficiência da distribuição na última milha, contribuindo assim para a melhoria da condição de vida dos habitantes nas grandes cidades.

Como destacado por Oliveira et al. (2018), políticas de transporte urbano de carga devem ser definidas localmente, pois não há uma solução definitiva e única para diferentes cidades. Sendo assim, a obtenção de dados que embasem a tomada de 
decisões contempla interesses público e privado. Para o setor privado, a identificação de áreas críticas em termos da complexidade da distribuição na última milha pode significar atenção maior atenção no planejamento e na programação das operações nessas áreas. O setor público pode elaborar políticas a partir da identificação de regiões críticas, a fim de planejar e realizar ações direcionadas a fim de mitigar as dificuldades observadas.

Adicionalmente, um mecanismo de análise comparativa da complexidade da distribuição urbana entre diferentes cidades também possibilita uma melhor avaliação das similaridades e diferenças entre as áreas urbanas investigadas, contribuindo para a sondagem no caso de importação de estratégias operacionais e de políticas públicas voltadas para o transporte de carga urbano; fornecendo informações que contribuem para o sucesso dessas iniciativas, evitando que sejam adotadas em ambientes muito distintos daqueles para as quais foram propostas inicialmente.

Por fim, existe também a relevância da contribuição acadêmica deste trabalho. Como foi identificado na revisão da literatura, foi encontrado apenas um artigo que analisa malhas viárias urbana do ponto de vista da distribuição de última milha, porém parte do método descrito pelos autores necessita de coleta de dados em campo, tornando sua aplicação limitada. O Capítulo 2 deste trabalho apresenta a coletânea de artigos revisados, onde se comprova que as métricas de análise de redes viárias urbanas presentes na literatura são utilizadas majoritariamente em aplicações geográficas gerais ou em transporte de passageiros.

\subsection{Organização do Trabalho}

O texto deste trabalho está organizado em cinco capítulos. O Capítulo 2 apresenta uma revisão bibliográfica sobre os temas relevantes para o problema deste trabalho: (ii) evolução e análise de forma de áreas urbanas, (iii) análise de redes viárias e de transportes, (iv) métricas para análise do transporte urbano de passageiros e (v) transporte urbano de carga.

O Capítulo 3 discorre sobre o método proposto com o seu procedimento e o Capítulo 4 apresenta resultados da aplicação do método em áreas urbanas de seis cidades: São Paulo, Rio de Janeiro, Bogotá, Nova lorque, Londres e São Francisco. 
Por fim, o Capítulo 5 apresenta as considerações finais sobre os resultados obtidos e os objetivos atingidos neste trabalho e recomendações para trabalhos futuros. 


\section{REVISÃO DA LITERATURA}

O objetivo principal desta revisão bibliográfica é identificar métricas e métodos que possam ser utilizados no problema da distribuição da última milha. Este capítulo está dividido em cinco seções; as quatro primeiras dividem os artigos revisados em quatro tópicos:

(i) Evolução e Análise de Forma de Áreas Urbanas

(ii) Análise de Redes Viárias e de Transportes

(iii) Métricas para Análise do Transporte de Passageiros

(iv) Transporte de Carga Urbano

A última seção apresenta as conclusões do panorama geral da literatura relevante para o assunto deste trabalho.

O Anexo A apresenta uma lista com todas as métricas identificadas na revisão bibliográfica com sua descrição e autores que a citaram.

\subsection{Evolução e Análise de Forma de Áreas Urbanas}

Esta seção abrange trabalhos encontrados na literatura que tratam, genericamente, da ocupação territorial das cidades. Os trabalhos analisados utilizam métricas para analisar a configuração de cidades quanto ao ambiente inserido e o processo de organização.

Taubenböck et al. (2012) utilizam dados de sensoriamento remoto para monitorar a expansão territorial de megacidades utilizando uma abordagem sistemática multi-temporal. As imagens são obtidas pelos satélites Landsat e TerraSAR-X. As áreas urbanas são identificadas através de uma análise de imagens orientada a objetos e baseada em pixels. As cidades analisadas foram monitoradas por um período de 40 anos com intervalos de 10 anos, mostrando as diferentes dimensões territoriais e os padrões geográficos de evolução da ocupação territorial ao longo do tempo. Algumas cidades, como Londres e Nova lorque, praticamente não tiveram aumento das suas áreas urbanas. Outras, como a Cidade do México, Manila 
(Filipinas), Karashi (Paquistão) ampliaram muito a área urbana. O método proposto é direto e pragmático, permitindo aplicações em diversas áreas, porém não permite uma análise tridimensional do desenvolvimento urbano e depende da disponibilidade de imagens de satélite, que podem não ser facilmente acessíveis e disponíveis de maneira universal. Além disso, os autores focam na evolução temporal de manchas urbanas, enquanto a proposta deste trabalho é focada nos efeitos da oferta de malha viária e sua ocupação na circulação de veículos que realizam a distribuição de última milha.

Mohajeri e Gudmundsson (2014) também propõem um método para acompanhar o crescimento de cidades ao longo do tempo, porém utilizando informações da malha viária. O método quantifica as características geométricas da malha viária e é aplicado na análise da evolução geográfica das malhas de três cidades: Sheffield (Reino Unido), Khorramabad (Irã) e Kerman (Irã). As três cidades possuem relevo diferentes: Sheffield está localizada em uma região de colinas e vales com poucas restrições de relevo; Khorramabad possui a maior restrição geográfica por estar localizada em um vale estreito; e Kerman está localizada em uma região desértica plana que não apresenta restrições físicas para seu desenvolvimento espacial. Os autores utilizaram orientação (azimutes) e comprimento dos segmentos das vias (trechos entre interseções) para caracterizar o crescimento das cidades ao longo tempo e os resultados sugerem que a distribuição da malha viária é diretamente afetada pela morfologia do local.

Observando a Figura 2.1, é possível identificar a evolução da cidade de Sheffield quanto a orientação e comprimento dos segmentos de via através dos histogramas da orientação dos segmentos de via e das curvas de distribuição dos comprimentos dos segmentos de via. Os autores calcularam a entropia (S) das distribuições obtidas para orientação e comprimento dos segmentos de via. A entropia é uma maneira de avaliar se a distribuição obtida é uniforme; quanto maior a entropia, mais uniforme é a distribuição. Khorramabad, a cidade com maior restrição geográfica apresentou maior aumento na entropia da orientação das vias e menor aumento na entropia do comprimento dos segmentos de via, o contrário de Kerman, a cidade localizada na área desértica sem barreiras físicas para seu desenvolvimento. Isso significa que, devido a topografia do local que limita a expansão territorial da cidade, os segmentos de via em Khorramabad surgem em orientação mais variada que em 
Kerman, que não tem restrições para sua expansão e consegue manter a malha viária em forma de grade, ou seja, com segmentos de via predominantemente perpendiculares e paralelos entre si.

(a)
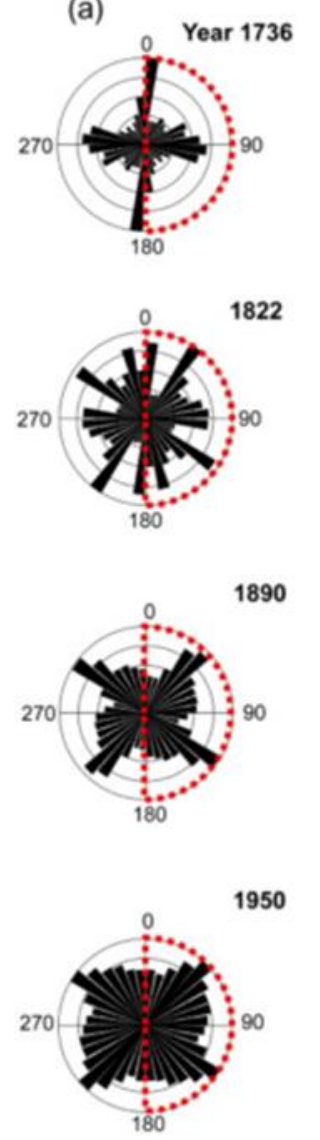

2010

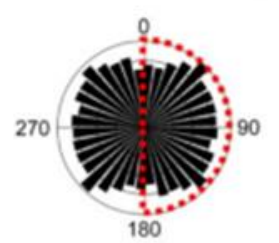

(b)
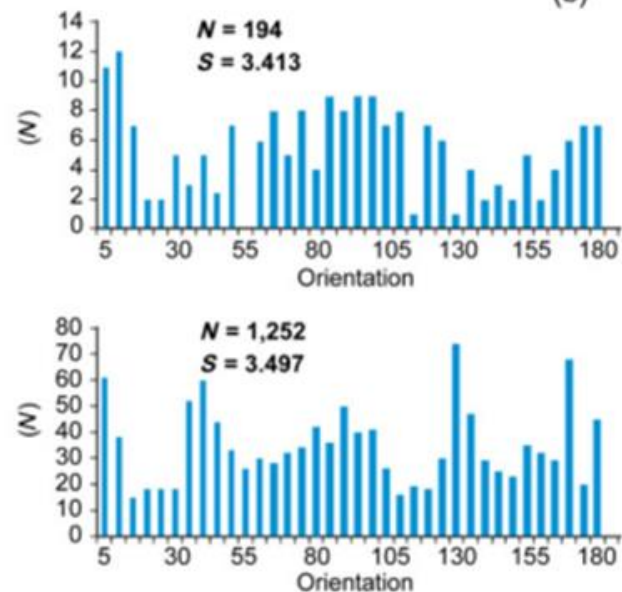

$N=4,552$
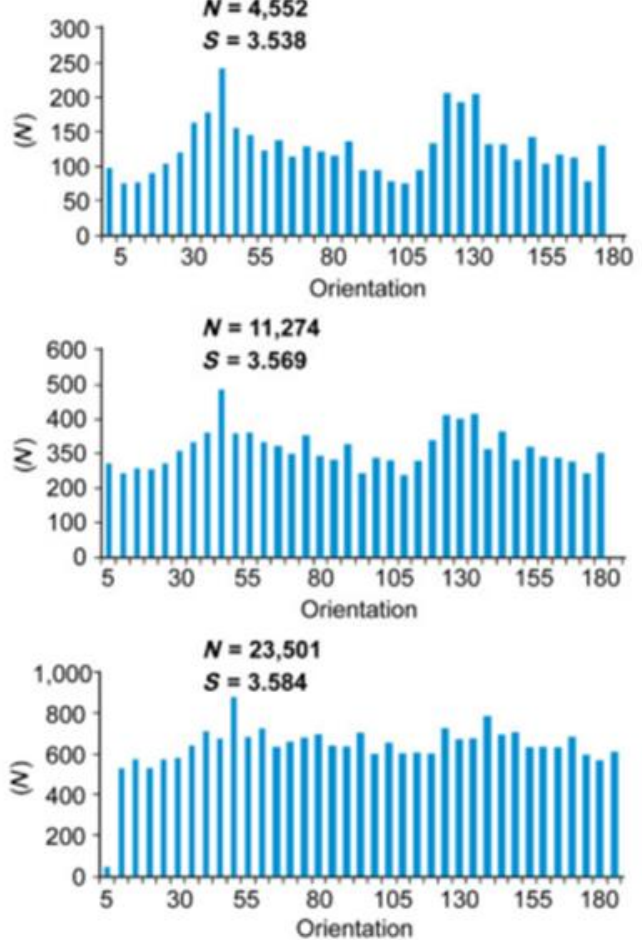

(c)
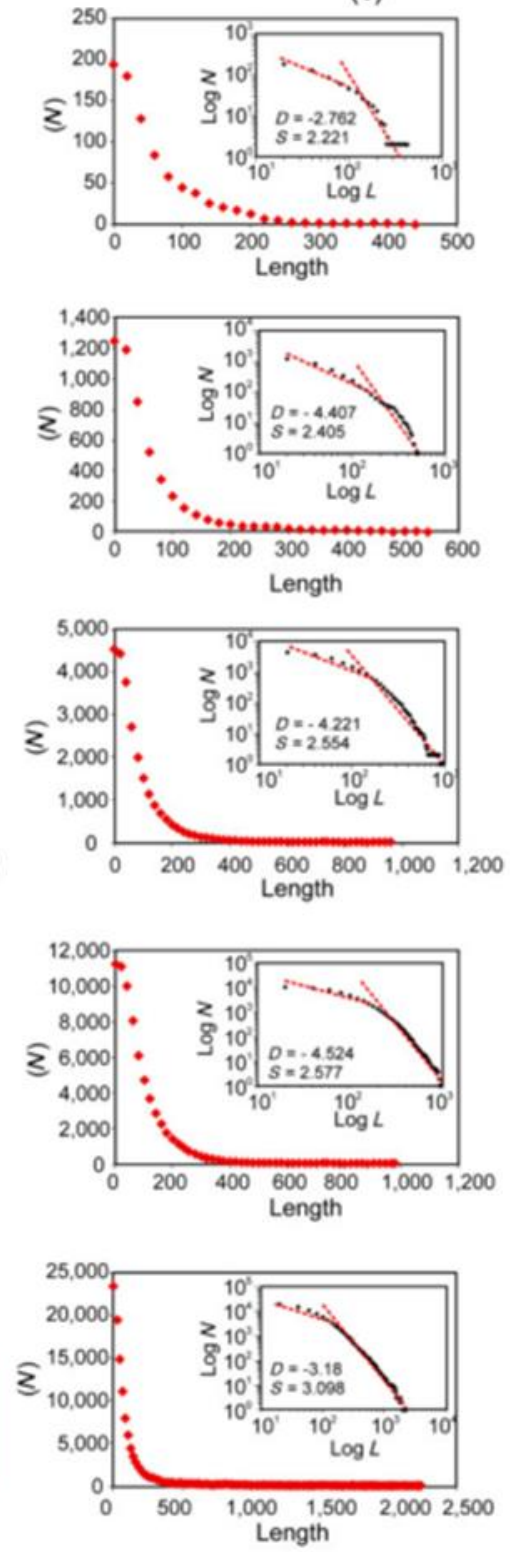

Figura 2.1: Evolução da rede viária de Sheffield; (a) histograma circular da orientação das vias; (b) histograma tradicional com número de ruas $(\mathrm{N})$ e entropia da orientação (S); (c) cumulativo da distribuição dos comprimentos de via (Mohajeri e Gundmunson, 2014).

Quanto à diferença observada de entropia de comprimento, significa que em Kerman foi observado o aparecimento de segmentos de vias mais longos do que em Khorromabad, o que também é esperado quando não há limitações para expansão territorial. Sheffield que possui relevo intermediário em relação às duas cidades do Irã 
apresentou resultados intermediários em relação às entropias de orientação e de comprimento. Os resultados do método mostraram-se coerentes com as características geográficas das cidades analisadas e corroboram a ideia que a topografia influencia no desenvolvimento da cidade. Mohajeri e Gudmundsson (2014) utilizam as características espaciais das malhas viárias para avaliar expansão territorial das cidades, diferentemente de Taubenböck et al. (2012) que utilizam apenas área da macha urbana. Porém, ainda assim, Mohajeri e Gudmundsson (2014) não discutem a influência das malhas viárias nos deslocamentos realizados nas cidades estudadas, apenas relacionam as características espaciais das malhas viárias à topografia local.

Louf e Barthelemy (2014) propõem um método quantitativo para caracterizar cidades de acordo com o padrão do sistema viário. A proposta é utilizar as características dos quarteirões para constituir uma espécie de impressão digital da cidade, ou seja, um atributo único para cada cidade. O primeiro passo é calcular um fator de forma para os quarteirões, que consiste na razão entre a área do quarteirão e a área do círculo que o circunscreve. A distribuição de probabilidades dos fatores de forma é o que define impressão digital da cidade. Os autores aplicaram esse método para 131 cidades e, através de análise de cluster hierárquica, identificam grupos de cidades com características semelhantes; são identificadas quatro principais famílias caracterizadas pela abundância de quarteirões de determinada área e forma. A Figura 2.2 ilustra as "impressões digitais" resultantes para cada um dos quatro grupos propostos, ou seja, a distribuição de probabilidades dos fatores de forma das quadras, e exemplos de configurações típicas esperados em cada grupo. Os autores destacam o fato de que a maioria das cidades norte-americanas e europeias estão alocadas em grupos diferentes, respectivamente grupo 3 e grupo 2 , evidenciando quantitativamente as diferenças dos padrões urbanos típicos das regiões. O método apresenta uma maneira direta e simples de caracterizar cidades, porém, assim como Mohajeri e Gudmundsson (2014), os autores não exploram se as diferentes configurações de malhas viárias influenciam os deslocamentos realizados nas cidades, o que dificulta a sua aplicação para os objetivos deste trabalho. 

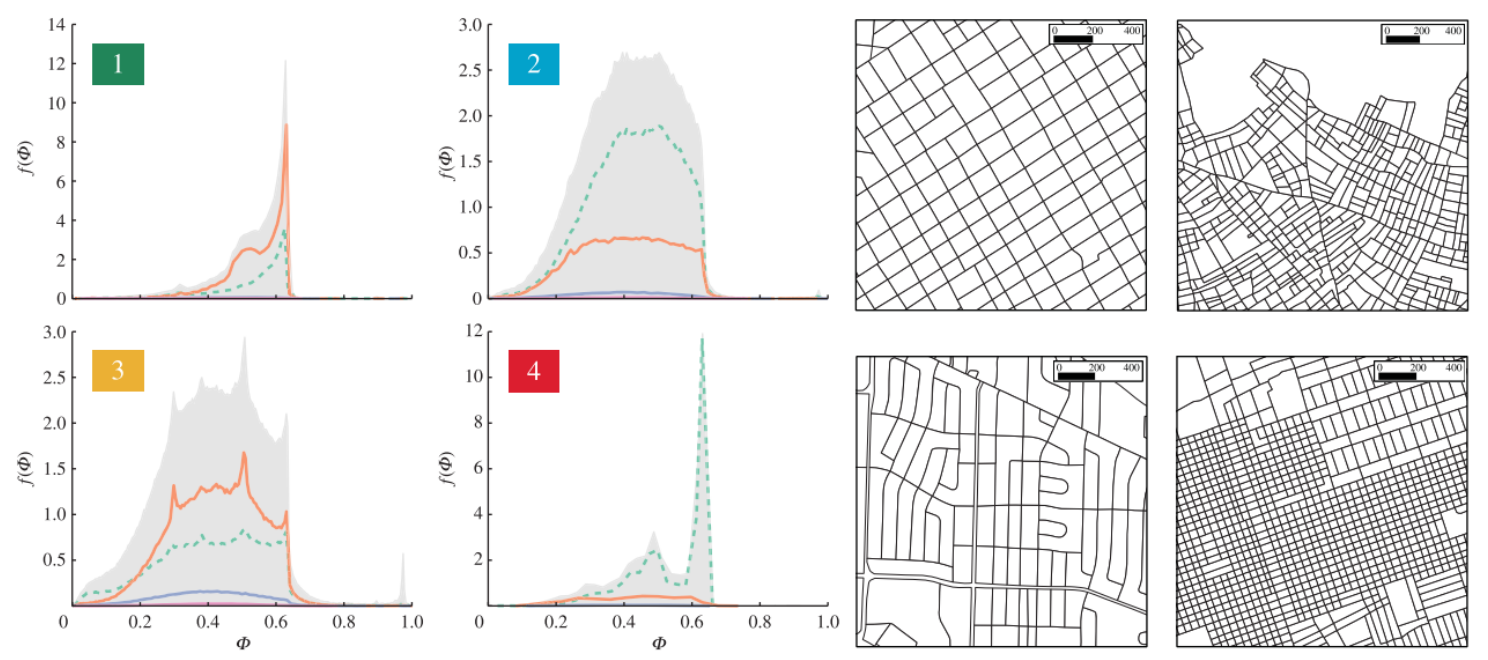

Figura 2.2: Os quatro grupos de cidades; a esquerda a distribuição dos fatores de forma (Ф); a direita, exemplos de configuração típica para cada grupo (Louf e Barthelemy, 2014).

\subsection{Análise de Redes Viárias e de Transportes}

As redes viárias são representações gráficas da malha viária de um local, podendo conter simplificações dependendo das análises desejadas. Sendo assim, define-se malha viária como o conjunto completo das vias de um local e rede viária sua representação gráfica, podendo ser simplificada ou completa. Nesta seção são revisados artigos cujo tema principal contempla algum tipo de análise de redes de transporte (redes viárias ou de transporte público). Estes artigos estão divididos em dois grupos, primeiro os que tratam de eficiência de redes e, em seguida, os que tratam de questões topológicas e de centralidade. Apesar de muitas das aplicações serem genéricas, estes são os artigos mais importantes para a revisão deste trabalho, pois procura-se identificar algum método de análise de malha viária que seja aplicável ao problema do transporte urbano de carga.

\subsubsection{Eficiência de Rede}

Latora e Marchiori (2001) definem o conceito de eficiência global de redes em geral de acordo com a eficiência de troca de "informações" que proporcionam, por exemplo, em uma rede de transporte a "informação" é a distância física entre os nós, na internet, o número de links que devem ser acessados para conectar uma página a partir de outra. Os autores destacam o fato de qualquer sistema complexo poder ser representado por uma rede, em que os nós são os elementos do sistema e os arcos, 
as interações entre os elementos. São citados como exemplos de representações: redes neurais, rede de comunicação e uma rede de um sistema de transporte público. A rede de transporte público é a que mais se assemelha ao foco deste trabalho. Para computar a sua eficiência, os autores consideram como "informação" da rede as distâncias entre as estações de um sistema de metrô e comparam as distâncias entre estações do sistema existente com uma rede ideal em que estações são todas ligadas entre si por túneis diretos e retilíneos, ou seja, há ligação direta entre todas as estações através da menor distância possível. A rede fictícia seria o cenário com $100 \%$ de eficiência e é usada como parâmetro para determinar a eficiência global da rede real, através da razão entre o cenário com 100\% eficiência e o cenário real. Por fim, pode-se concluir que a aplicação do conceito de eficiência global de rede é uma forma prática de se fazer uma análise quantitativa do fluxo de informações em uma rede. $A$ aplicação para o problema do transporte de carga urbano pode ser inviabilizada devido ao grande número de interseções e segmentos de vias das malhas viárias das grandes cidades que seriam respectivamente os nós e os arcos em uma representação em rede análoga à proposta pelos autores, pois seria necessária alta capacidade de processamento computacional para computar a eficiência global da rede levando em consideração todos os nós da malha, podendo ser aplicada para recortes de áreas da cidade e para redes viárias simplificadas. Porém, ainda fica o questionamento se este tipo de cálculo de eficiência é relevante para caracterizar o desempenho da operação de entregas nas cidades, já que os veículos de entrega trafegam entre CDs e locais de entrega especificamente e o resultado da eficiência proposta pelos autores traduziria a eficiência entre interseções da malha viária.

Ballou et al. (2002) discutem a eficiência de redes de rodovias. Os autores aplicam o conceito de fator de "circuicidade" (do inglês circuity), razão entre distância real (distância em rede) e distância linear, entre cidades de 26 países localizados nas Américas, Europa, Ásia e África, resultando em um fator de "circuicidade" médio por país. Os resultados variam entre 1,12 e 2,10 e são reflexo das características geográfica dos países estudados e da infraestrutura rodoviária. Os autores conduzem o estudo como uma forma preliminar de discutir os fatores de correção de distâncias aplicados em problemas de transporte de carga, nos quais as distâncias são estimadas através da distância linear multiplicada por um fator de correção. Ao contrário da análise que foi realizada por esses autores, no presente trabalho buscam- 
se métodos que avaliem os deslocamentos urbanos, dentro de uma mesma cidade; portanto, essa aplicação seria útil para os objetivos desta pesquisa, mas necessitaria de adaptações para ser utilizada no problema de distribuição urbana.

\subsubsection{Topologia e Centralidade}

Crucitti et al. (2006) estudaram malhas viárias de cidades levando em consideração as suas dimensões espaciais e propõem quatro índices de centralidade espaciais para caracterizar as estruturas das malhas viárias. São eles: (i) centralidade de proximidade (closeness centrality), que mede a proximidade de um nó em relação aos demais através dos caminhos mais curtos; (ii) centralidade de intermediação (betweenness centrality), que mede a participação de um nó na ligação entre todos os outros nós da rede; (iii) centralidade de "retilinidade" (straightness centrality), que é a razão entre a distância em linha reta (euclidiana) e a distância real na rede, também chamada de "circuicidade" por outros autores; e (iv) centralidade de informação (information centrality), que mede a diferença de eficiência da rede no caso de desligamento/desconsideração de um nó. São calculados os índices de centralidade para os nós (interseções) de redes viárias de 18 recortes de tamanho correspondente a uma milha quadrada para diferentes cidades. A Figura 2.3 mostra o exemplo da aplicação para a cidade de Veneza na Itália. Na sequência, são analisados agrupamentos de cidades baseados na distribuição das centralidades. $O$ resultado aponta a existência de duas principais classes de cidade, que são as cidades que cresceram em decorrência de algum processo histórico e sem controle de nenhum tipo de agência reguladora, e as cidades planejadas, que costumam apresentar um padrão de grade (do inglês grid) regular. A análise é feita em malhas contidas em áreas de uma milha quadrada devido à grande quantidade de nós presentes em uma área urbana completa, fazendo com que a aplicação para o problema deste trabalho, que almeja analisar áreas maiores, seja inviabilizada. Além disso, os índices de centralidade não são usados para investigar a influência da malha viária nos deslocamentos realizados nas cidades, apenas para caracterizá-las. 


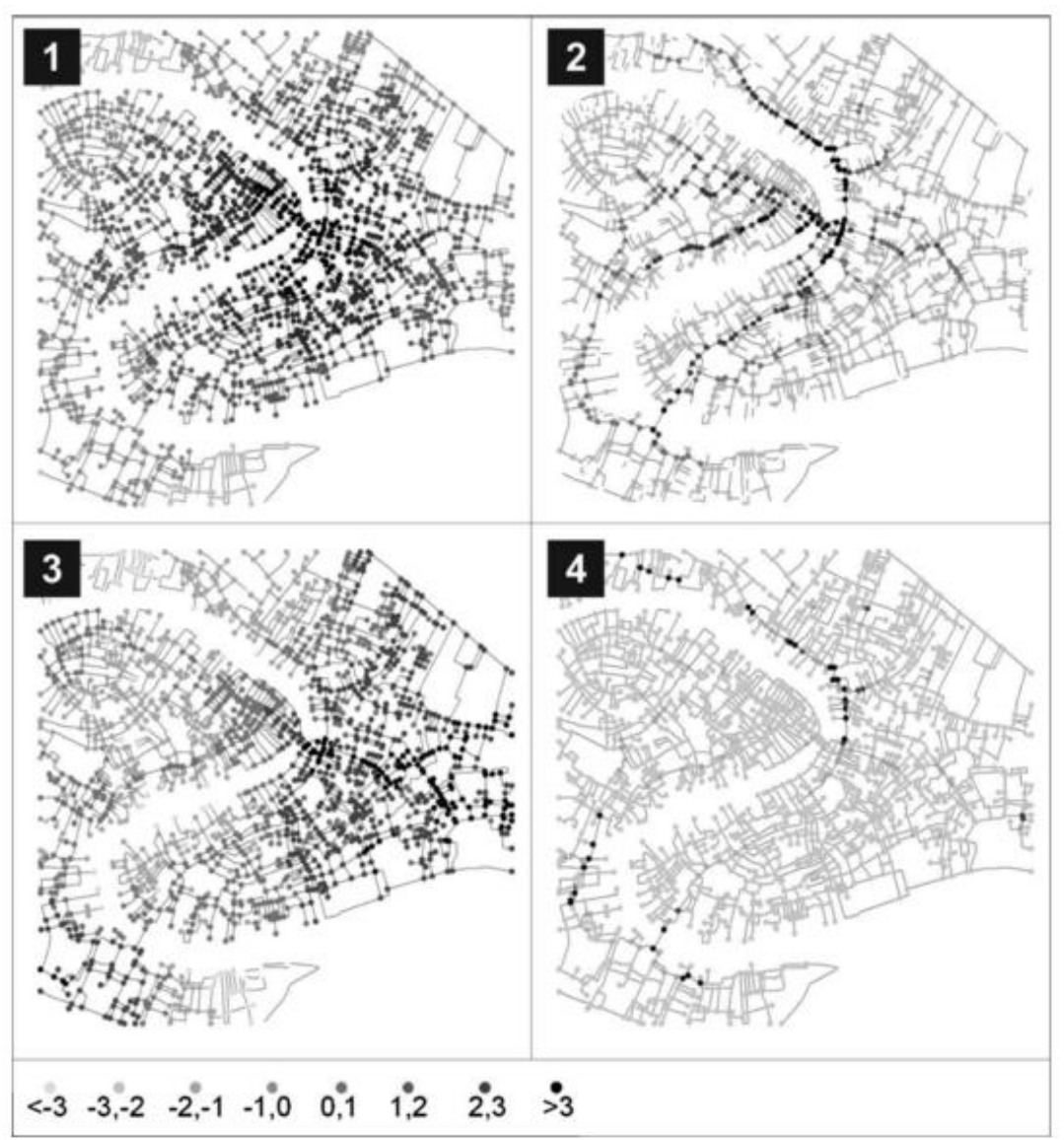

Figura 2.3: índices de centralidade dos nós de um recorte da malha viária de Veneza (Itália); (1) centralidade de proximidade; (2) centralidade de intermediação; (3) centralidade de "retilinidade"; (4) centralidade de informação; a escala de cinzas representa multiplicadores do desvio padrão a partir da média (Crucitti et al., 2006).

Strano et al. (2012) utilizam índices de centralidade para caracterização hierárquica de vias. Os autores apontam a falta de uma maneira adequada para caracterizar o processo de urbanização quantitativamente, mas especificamente o processo de expansão das malhas viárias das cidades. Dessa forma, sugerem a utilização de índices de centralidade para identificar vias de "alta centralidade", ou seja, as vias principais de uma região urbana. A área de estudo é a região norte de Milão (Itália), com a evolução de sua malha viária de 1833 a 2007. Os resultados apontam que as vias de alta centralidade são estáveis, pois permanecem as mesmas ao longo dos anos, como uma espinha dorsal para o desenvolvimento urbano, e confirmam a importância das raízes históricas para o desenvolvimento da cidade. Além disso, identifica-se que o processo de urbanização é marcado pela densificação de vias, que corresponde ao surgimento de novas vias locais nas regiões urbanas, e pela evolução do uso do solo impulsionada pelo surgimento dessas novas vias. A Figura 2.4 ilustra esses fenômenos na região estudada; cada imagem apresenta em 
verde e vermelho as vias que surgiram em determinado período de tempo, as vias em verde representam o processo de densificação da malha viária e as em vermelho, o processo de expansão. Apesar do método proposto não tratar diretamente de uma aplicação para o problema de distribuição urbana, foco deste trabalho, a identificação empírica desse mecanismo simples e elementar do processo de urbanização sugere a existência de mecanismos gerais para o processo de urbanização (expansão e densificação) e abre portas para a possibilidade de um modelo quantitativo para descrever as cidades através da análise histórica das centralidades das vias.
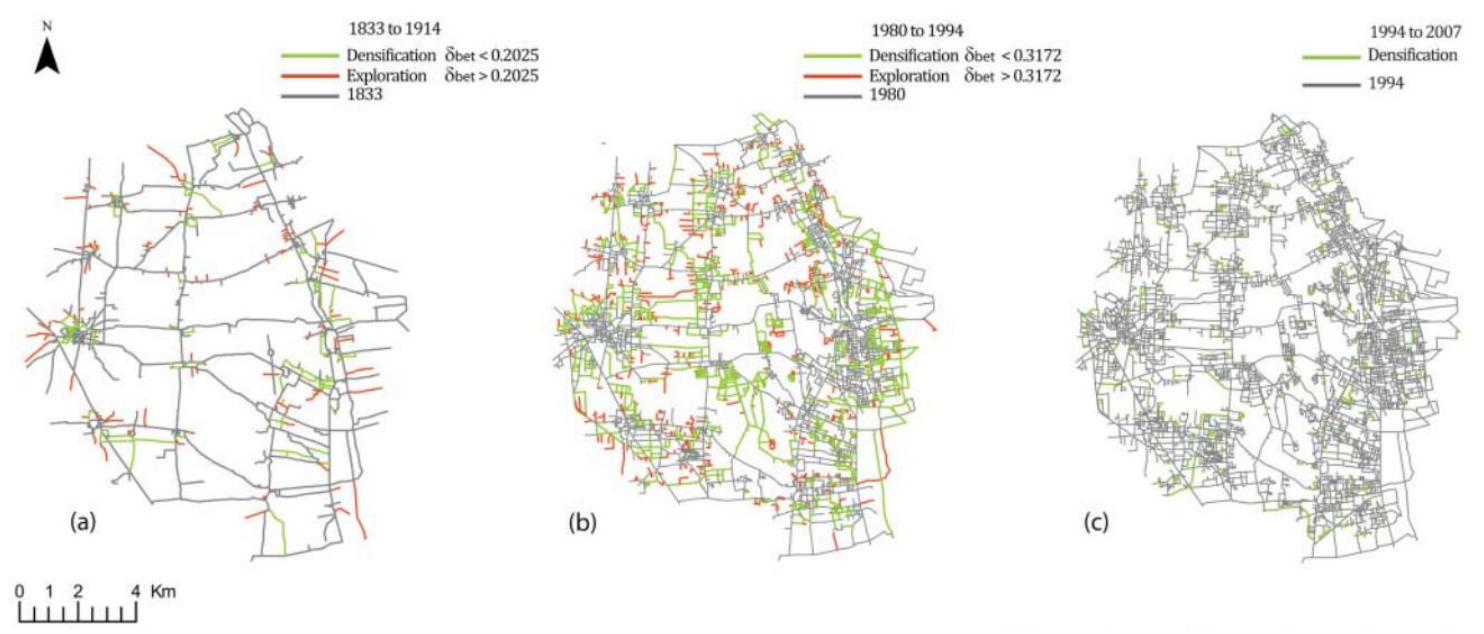

Figura 2.4: Processo de densificação e expansão da malha viária de região do norte de Milão, Itália (Strano et al., 2012).

As vias principais também foram estudadas por Porta et al. (2014), que ressaltam a importância de uma rede de vias principais como forma de representação gráfica simplificada da malha viária. Os autores buscam encontrar padrões nas redes de vias principais de acordo com a origem histórica da cidade e investigam se a "regra dos 400 metros", que diz que as cidades, antes do advento do automóvel, criavam uma configuração em que as vias principais (mesmo conceito de vias principais utilizados por Strano et al., 2012) eram interceptadas, no máximo, a cada 400 metros, é válida. Para tanto, foi conduzido um estudo de caso envolvendo 100 cidades, em que as vias principais são identificadas através de heurísticas visuais. O procedimento foi repassado para alunos que realizaram a identificação dos trechos. A conclusão extraída do estudo é que há fortes indícios que a regra dos 400 metros se aplica a cidades mais antigas, porém as cidades planejadas com diretrizes modernistas a partir século XX apresentam segmentos em média duas vezes maiores que as mais antigas, podendo ser explicado pela popularização do automóvel. Cidades com planejamento 
informal também apresentam segmentos de vias principais menores, como as mais antigas. Apesar desse artigo apresentar um método de difícil reprodução por ser trabalhoso e não ser automatizável, os resultados apontam para uma diferença significativa do comprimento de vias sem interceptações principais nas cidades, reforçando a necessidade da realização de estudos sobre a influência da malha viária nas atividades urbanas, como a distribuição de carga foco deste trabalho.

Zhang et al. (2015) investigam o papel da topologia de uma rede de transportes e o comportamento do sistema de transportes em caso de desastres. Para tanto, parte-se da hipótese de que os atributos topológicos, ou propriedades geométricas e espaciais, de um sistema de transportes afetam sua resiliência em caso de desastre. O conceito de resiliência não considera apenas a habilidade do sistema de se manter em funcionamento no caso de interferências externas, mas também a eficiência e eficácia das possíveis ações de mitigação após um evento desastroso. Foram conduzidos experimentos em 17 redes fictícias de transportes, caracterizadas de acordo com o grau médio (ou número médio) de ligações de um nó, diâmetro (maior caminho conectando dois nós) e ciclicidade. A ciclicidade é obtida pela geração de caminhos aleatórios que saem de qualquer nó da rede e terminam quando não há mais opções para seguir em frente ou quando retornam para um nó já visitado; calculase a proporção de caminhos que retornam a um nó já visitado em relação a todos os caminhos aleatórios gerados. A resiliência dos sistemas foi quantificada em termos do fluxo, conectividade e distância recíproca média. O fluxo é definido como a capacidade de transmissão de informação de uma rede, ou seja, no caso de uma rede representando um sistema de transportes, pode ser a distância necessária para conectar dois lugares. A conectividade é definida como o número de pares origemdestino que permanecem conectados pelo caminho mínimo em uma situação de desastre. A distância média recíproca é a média entre as distâncias entre dois locais, alternando-se apenas a origem com o destino. Foram considerados cenários com e sem benefícios de ações de prevenção e de recuperação. A relação da resiliência com o impacto a danos dos componentes do sistema também é investigada. Uma análise sistemática desses dados serve para caracterizar redes com topologia de alta resiliência e identificar atributos que podem causar para mal funcionamento dos sistemas. Os resultados apontam que as medidas de resiliência aumentam quanto maior o grau médio de ligações de um nó e maior ciclicidade, mas diminuem quanto 
maior o diâmetro da rede. O estudo é relevante por relacionar topologia de rede e funcionamento do sistema de transportes, porém considera apenas situações atípicas de funcionamento e não o desempenho corriqueiro. Além disso, os experimentos foram feitos apenas em redes fictícias.

Freiria et al. (2015) também utilizam topologia para analisar desastres e interrupções nas redes de transporte, mais especificamente em rodovias. O principal objetivo dos autores é identificar as vias mais importantes em uma rede, para que, em caso de interrupções, sejam alocadas ações de mitigação de impactos. Os autores propõem um modelo para avaliação das vias mais importantes na rede, através da identificação de atributos e padrões de conectividade. O primeiro passo do método é a caracterização da rede utilizando as seguintes métricas: (i) índice alpha, que reflete o número de circuitos fechados dentro da rede; (ii) centralidade de intermediação (betweenness), número de caminhos mínimos que utilizam um nó; (iii) potência de Bonacich, que avalia a conectividade de um nó de acordo com o número de ligações presentes e o número de ligações dos vizinhos; (iv) índice de "clusterização", que é a probabilidade de que um nó estar associado à outro; (v) pontos de corte, número de nós que se excluídos desconectam parte da rede; (vi) grau de conexão do nó, que é o número de ligações de um nó; e (vii) fragmentação, definida pela proporção de pares de vértices que não são ligados pela rede. Após a caracterização das rodovias da rede estudada através das métricas, é realizada uma "biclusterização", a fim de agrupar as observações (rodovias) com atributos topológicos mais parecidos entre si. Resultados apontam o índice alpha como medida topológica estatisticamente mais significante e que interrupções em vias com mais conectividade têm maiores consequências no funcionamento da rede do que interrupções nas vias com menor conectividade. A abordagem proposta é uma boa reflexão da dinâmica de redes no âmbito dos transportes. Esse trabalho é útil para ações de mitigação de riscos que precisam alocar recursos e definir áreas de prioridade e também é útil para planejamento da rede e mais uma vez ressalta a relação direta entre características topológicas e desempenho do sistema, porém, foi realizado apenas em redes rodoviárias cujas características diferem das redes urbanas que se pretende estudar neste trabalho.

Jiang e Claramunt (2004) propõem uma análise topológica de redes urbanas através de uma representação gráfica dual. Apesar de ser contra intuitiva, nessa forma de representação, os nós correspondem às ruas e os arcos aos cruzamentos de ruas. 
A Figura 2.5 apresenta um exemplo de construção de rede dual, na qual é possível perceber que a rua que circunda o bairro e que apresenta o maior número de interseções é representada como nó central na rede dual. Para analisar a estrutura da rede viária a partir dessa representação são computadas algumas medidas topológicas como conectividade das vias, comprimento médio de caminho e coeficiente de aglomeração. Os experimentos foram realizados para três cidades, mostrando que as redes urbanas apresentam características de redes de "mundo pequeno", ou seja, redes em que poucos nós possuem muitos vizinhos, mas o número médio de ligações necessárias para conectar dois nós quaisquer é baixo. Além disso, as redes urbanas não exibem características de redes sem escala, isto é, redes em que as ligações seguem uma lei de potência, e nós com alto grau de conectividade têm a tendência de se conectarem entre si. Essas propriedades topológicas são de interesse para estudos em áreas urbanas, porém a representação gráfica depende da maneira como as ruas são identificadas, dificultando a padronização do método e limitando as possibilidades de comparação entre locais diferentes, já que a identificação de vias e suas nomenclaturas são reflexos da cultura local. Além disso, o processo é manual, com dificuldade de automatização, dificultando sua aplicação de maneira mais generalizada para diferentes cidades.

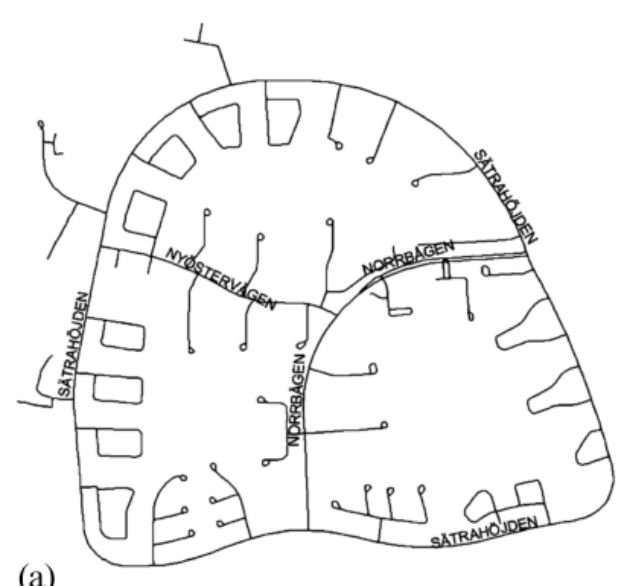

(a)

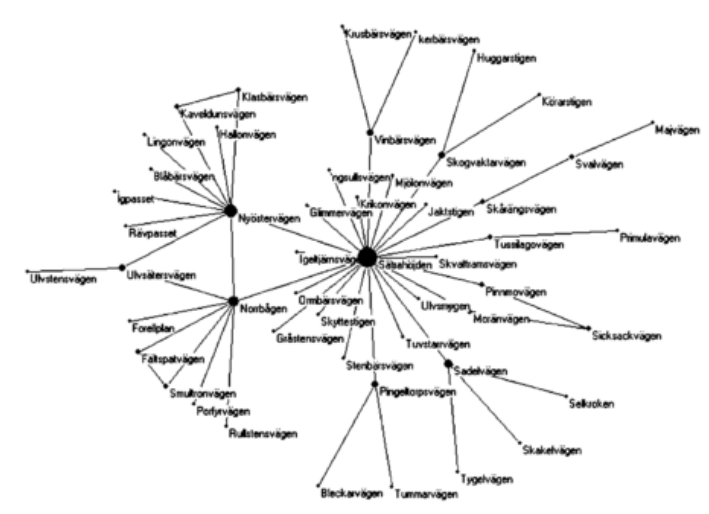

(b)

Figura 2.5: (a) rede viária do bairro Sätra em Gavle, Suécia; (b) rede dual correspondente (Jiang e Claramunt, 2004).

Assim como Jiang e Claramunt (2004), Porta et al. (2006) propõem a construção do grafo dual; porém, constroem o grafo com base em uma identificação da continuidade das vias e não na nomenclatura das ruas, que não detecta situações em que uma mesma via pode ter mais de um nome. Foram analisadas seis cidades 
com origens históricas, desenvolvimento urbano e padrões de distribuição viária diferentes. São elas: Ahmedabad (Índia), Barcelona, São Francisco, Veneza, Viena e Walnut Creek (Califórnia, EUA). Os autores discutem as metodologias adotadas para a construção dos grafos duais e as diferenças nos resultados gerados por cada uma delas. Também realizaram um estudo comparativo de algumas propriedades estruturais dos grafos gerados como, por exemplo, número total de nós e arcos e número médio de ligações por nós. A Figura 2.6 ilustra os grafos resultantes para uma mesma malha viária utilizando as três metodologias discutidas pelos autores.

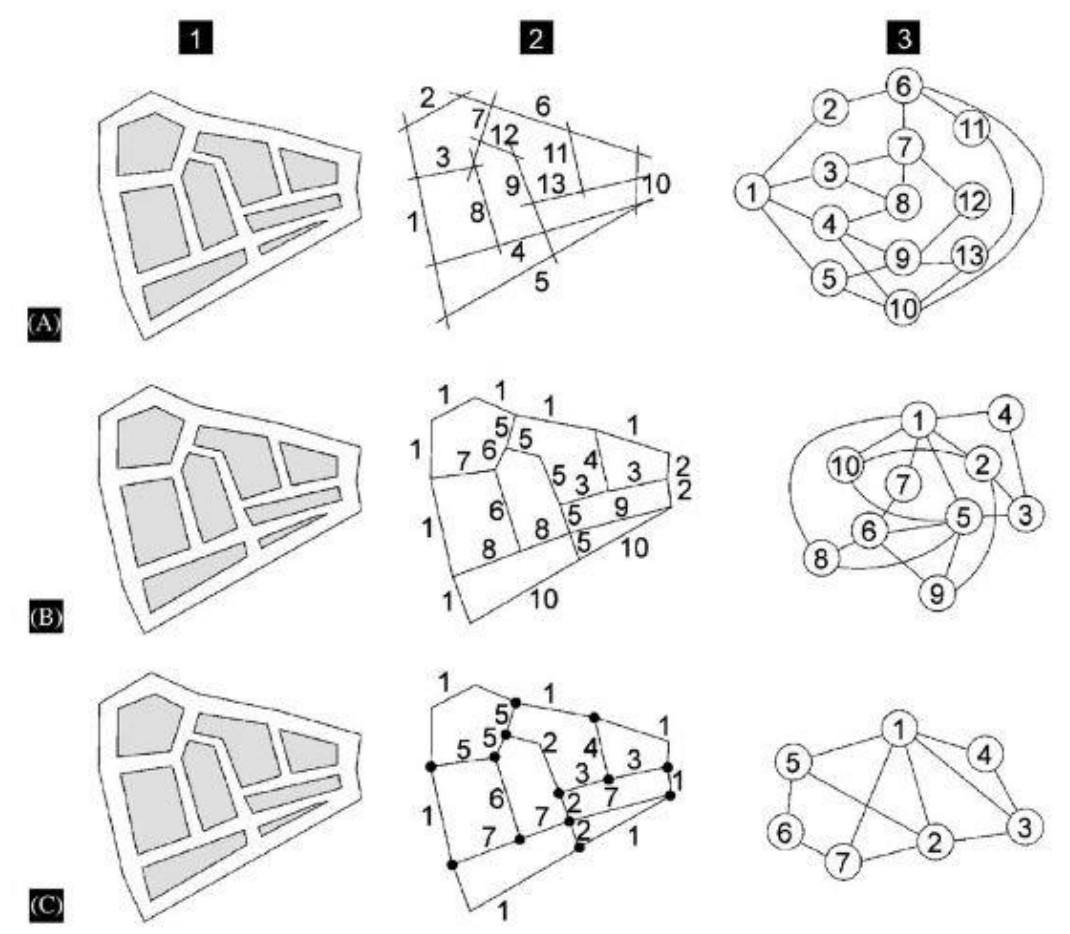

Figura 2.6: (1) o sistema urbano; (2) a rede primal; (3) a rede dual; (A) rede dual construída de acordo com o critério da linearidade das vias; (B) rede dual construída pelo critério de nomenclatura; $(\mathrm{C})$ rede dual construída utilizando o critério de continuidade das vias (Porta et al., 2006).

Por fim, são gerados grafos das seis cidades e diversas técnicas de análise de redes são aplicadas: (i) comprimento de caminho médio, que é a média do comprimento de todos os caminhos entre todos os nós da rede; (ii) correlação de grau, que é a correlação do grau (número de ligações) de um nó com o grau dos nós vizinhos; (iii) coeficiente de aglomeração, que é calculado através da razão de arcos que existem sobre a quantidade máxima de arcos que seria possível na rede dividida pela quantidade nós da rede; e (iv) eficiência global e local, os autores utilizam a mesma definição de Latora e Marchiori (2001). Os resultados mostram que as redes 
urbanas analisadas têm propriedades características de redes "de mundo pequeno", assim como os resultados de Jiang e Claramunt (2004). Contudo, neste caso, os resultados apontam que as redes urbanas também têm características de redes sem escala, devido a uma tendência hierárquica em que poucas ruas e avenidas principais possuem muitas conexões e outras vias menos importantes são menos conectadas. Esse estudo considera apenas topologia, desconsiderando a grandeza das distâncias reais entre os nós, o que torna o método pouco apropriado para problemas reais, como o de distribuição urbana de mercadorias. Os autores concluem que a abordagem dos grafos duais complementa estudos que utilizam apenas a rede espacial.

\subsection{Métricas para Análise do Transporte Urbano de Passageiros}

As métricas de conectividade são aplicadas a diversos campos, incluindo transportes, planejamento urbano e geografia, como detalhado na seção 2.3. Nesta seção estão apresentados os artigos que aplicam métricas de conectividade em análises do transporte urbano de passageiros, já que das aplicações revisadas na literatura essa é a que mais se assemelha da proposta deste trabalho, visto que não foram encontrados artigos que tratem do uso de métricas no problema específico do transporte de carga urbano.

Dill (2004) compila e resume métricas com o objetivo de avaliar cidades quanto à facilidade de deslocamento por meios não motorizados: bicicleta e a pé. As métricas discutidas são as seguintes:

i) média do comprimento dos quarteirões;

ii) tamanho dos quarteirões, definido por média das áreas e dos perímetros;

iii) densidade de quarteirões;

iv) densidade de interseções;

v) densidade de vias, comprimento de vias em determinada área;

vi) proporção de nós conectados, razão entre número de interseções e número total de nós, incluindo interseções e extremidades de ruas sem saída; 
vii) razão entre segmentos de vias e nós da malha;

viii) padrão de grade, variável binária que identifica se a malha existente forma um padrão de grade $(=1)$ ou não $(=0)$;

ix) "retilinidade" das rotas feitas a pé; razão entre a distância da rota e a distância euclidiana dos pontos de origem e destino;

x) área de caminhada efetiva, na qual define-se um ponto de origem e a área de caminhada efetiva é a razão entre a área que pode ser alcançada a partir desse ponto caminhando-se um quarto de milha e a área do círculo com um quarto de milha de raio.

Quatro métricas são escolhidas devido à facilidade de aplicação através de software GIS para um estudo de caso na cidade de Portland (Estados Unidos), com o objetivo de identificar a mais adequada para caracterizar a cidade quanto a facilidade de deslocamentos por modos de transporte não motorizados. A cidade é analisada de acordo com a divisão de áreas do censo (setores censitários), visto que esta apresenta dimensões compatíveis com deslocamentos a pé e de bicicleta. Os resultados apontam que as quatro métricas escolhidas para o estudo de caso (densidade de vias, proporção de nós conectados, densidade de interseções e razão entre segmentos de vias e nós da malha) apresentam resultados inconclusivos para as áreas estudadas, indicando que seria necessário compará-las com dados de viagem para um resultado mais sólido. Apesar do trabalho ser preliminar e o estudo de caso pouco conclusivo, as métricas apresentadas não dependem de coleta de dados em campo, podem ser adaptadas para descrever outros tipos de deslocamento nas cidades. A facilidade de aplicação e obtenção de dados para aplicar as métricas tornam-nas promissoras para investigação em outras pesquisas.

Levinson e El-Geneidy (2009) usam a "circuicidade" da rede viária para entender melhor o comportamento das pessoas em relação às viagens por motivo trabalho. O objetivo é demonstrar que a topologia da rede faz parte do processo de seleção da rota das viagens e da escolha do local da moradia em função do local de trabalho, assim como outros fatores já conhecidos como distância casa-trabalho, valor dos imóveis e preferências pessoais relativas a acessibilidade a escolas, lazer e outras amenidades. São utilizados dois métodos para definir os pares origem-destino 
estudados: o primeiro utiliza como dados de entrada viagens reais obtidas através de pesquisa origem-destino e o segundo consiste na geração aleatória de pontos na cidade, uma abordagem interessante para gerar dados de entrada sem a necessidade de coleta em campo, como a pesquisa origem-destino. O método é aplicado em 20 regiões metropolitanas dos Estados Unidos. Os resultados mostram que a "circuicidade" das viagens com origem e destino aleatórios é maior do que das viagens reais, sendo 25\% maior para o caso de Minneapolis-St. Paul (Minnesota, EUA) e 17\% maior para Portland (Oregon, EUA), dando indícios que a topologia da rede influência as decisões dos locais de moradia das pessoas e o seu comportamento em relação às viagens e, portanto, é um fator que deve ser considerado em modelos de planejamento. $O$ estudo propõe ainda um modelo de regressão linear para relacionar características da rede como número de cruzamentos e comprimento total de oferta viária (número de quilômetros de vias) com os fatores de "circuicidade" obtidos. Apesar dos resultados serem coerentes, os indicadores do modelo indicam que têm baixa significância estatística. Em geral, o método aplicado é de fácil reprodução e automação, com exceção dos dados provenientes de pesquisas origem-destino; com alguns ajustes, apresenta potencial para ser aplicado em outros tipos de deslocamento de viagens como, por exemplo, a distribuição de carga, foco deste trabalho Portanto, o método apresentado no capítulo seguinte utiliza algumas métricas que foram utilizadas por Levinson e El-Geneidy (2009).

Parthasarathi e Levinson (2010) comparam métricas de estrutura de redes com medidas de desempenho do sistema de transporte urbano rodoviário para identificar possíveis correlações. As métricas escolhidas para caracterização da rede viária são:

i) treeness, que quantifica quantas partes da rede, se isoladas, formam uma estrutura de árvore, ou seja, ramificada, sem a formação de circuitos fechados;

ii) completude, que mede a porcentagem existente da rede em relação a rede completa que é a rede na qual todos os nós são ligados entre si por no máximo uma ligação direta, sem passar por outros nós intermediários;

iii) densidade de vias, comprimento total de vias $(\mathrm{km})$ dividido pela área total da rede $\left(\mathrm{km}^{2}\right)$; 
iv) densidade de vias expressas, análogo a densidade de vias, porém só leva em conta o comprimento das vias classificadas como expressas;

v) "circuicidade" média, que consiste na razão entre a soma das distâncias em rede de todas as viagens realizadas e a soma de todas as distâncias euclidianas entre origens e destinos;

vi) acessibilidade, que nesse estudo relaciona a área de uma isócrona referente a um tempo de viagem de 30 minutos com a densidade da população local.

O desempenho do sistema é expresso através dos níveis de uso (quilômetros percorridos per capita por dia) e de congestionamento de veículos (horas anuais de atraso), de maneira que foram feitos dois modelos de regressão para explicar essas variáveis em função das características da rede. Foram coletados dados de 50 regiões metropolitanas dos Estados Unidos para aplicação do método. Os resultados apontam que a topologia das malhas viárias tem influência no desempenho do transporte urbano rodoviário, sendo treeness a variável que mais contribui para congestionamento, e completude e densidade de vias as variáveis que mais contribuem para o número de quilômetros percorridos por habitante por dia. Apesar dos dados do estudo contemplarem apenas viagens de passageiros pelo modo veículo privado, esses resultados corroboram a hipótese de que a oferta de infraestrutura viária afeta o desempenho do sistema de transporte urbano rodoviário e reforçam a necessidade da realização de uma análise similar para outros tipos de sistemas, como o do transporte de carga.

Levinson (2012) compara o desempenho geral dos sistemas com a estrutura da rede de transporte de 50 cidades dos Estados Unidos, com o objetivo de identificar variáveis que ajudem no planejamento de redes de transporte. A discussão central gira em torno da relação do tamanho das cidades, nesse caso definida pela população residente, com a conectividade provida pelos sistemas de transporte disponíveis. A caracterização das redes é feita através de (i) índice beta, razão entre número de arcos e nós; (ii) "circuicidade", razão entre distância em rede e distância euclidiana; (iii) acessibilidade, parâmetro que determina número de locais de trabalho acessados em determinado tempo de viagem a partir de uma origem; (iv) e entropia, que quantifica a heterogeneidade das vias que compõe a malha da cidade quanto a classificação hierárquica (local, arterial, expressa, etc.). Os resultados apontam que 
cidades mais populosas têm viagens motivo trabalho mais longas e ocorrem mais atrasos nos sistemas de transporte; ao mesmo tempo, são mais conectadas e acessíveis através de transporte público. O autor utiliza variáveis interessantes, como a "circuicidade" e o índice beta, para a caracterização das redes, pois podem ser obtidas de forma automatizada e sem dependência de dados de difícil acesso, porém o estudo é focado para transporte de pessoas, em especial viagens com motivo trabalho e, portanto, os dados demográficos utilizados para a comparação com as características das redes têm o viés para o estudo desse tipo de viagem específico.

Parthasarathi et al. (2013) avaliam a relação entre a percepção das pessoas quanto aos tempos de viagem, coletados de uma pesquisa de base domiciliar, e as características estruturais da rede viária. Através da revisão da literatura, os autores ressaltam a imprecisão dos modelos de previsão de demanda e a justificam devido à dificuldade de prever o comportamento dos viajantes. Quando as pessoas escolhem a rota a ser percorrida, nem sempre escolhem a que realmente representa o menor tempo de viagem, e sim aquela que as pessoas têm a percepção de oferecer o menor tempo de viagem. Os autores utilizam informações coletadas em pesquisas origemdestino de base domiciliar, formulários e dados de GPS da cidade de Minneapolis (Estados Unidos) para identificar trajetos cotidianos casa-trabalho feitos de carro e os respectivos tempos de viagem. As métricas utilizadas para a caracterização da malha viária visam quantificá-la quanto a hierarquia das vias, a topologia e a morfologia. São elas: (i) descontinuidade relativa, que captura as diferenças de classes de vias utilizadas em uma viagem; (ii) proporção de vias expressas; são consideradas expressas as vias que têm acesso de entrada e saída controlado; (iii) treeness; (iv) "circuicidade"; (v) densidade de vias; (vi) densidade de interseções; e (vii) "P2A", razão entre o perímetro do polígono que contorna a malha ao quadrado e a sua área. $\mathrm{Na}$ análise foram comparados os tempos de viagens reais com os informados nas entrevistas, apontando que quanto maior o tempo de viagem real, mais subestimado o mesmo é; e quanto menor o tempo de viagem real, mais superestimado ele é, de acordo com a percepção dos viajantes. Sendo assim, as observações são divididas em dois grupos: a de tempos subestimados e a de tempos superestimados. Para cada grupo é realizado um modelo linear em que a razão entre o tempo percebido e o tempo real é a variável explicada e as variáveis explicativas são as métricas referentes a rede. Em ambos os modelos, a descontinuidade relativa e a densidade de vias são as 
variáveis mais significativas, ou seja, contribuem para uma má percepção no tempo de viagem. Como conclusão, esse trabalho relacionou as métricas de rede com outro fator de impedância das viagens urbanas realizadas em carros particulares além das distâncias, que é o tempo de viagem; e apesar do tempo de viagem estar relacionado a distâncias, existem outros fatores que o afetam, já que as velocidades médias de deslocamento na cidade não são as mesmas para todas as viagens realizadas. Os modelos de regressão não obtiveram valores estatísticos excelentes do ponto de vista da explicação do tempo através das características descritas, mas são suficientes para confirmar os indícios que a infraestrutura viária disponível afeta a duração dos deslocamentos urbanos.

Huang e Levinson (2015) utilizam conceitos de teoria de redes para estudar a "circuicidade" de redes de transporte público urbano. Os autores comparam os resultados da "circuicidade" para viagens realizadas de carro e por transporte público, com o intuito de correlacionar o parâmetro com a escolha de modo de transporte dos usuários. São estudados pares origem-destino reais, ou seja, retirados de uma pesquisa origem-destino, e também outros gerados aleatoriamente. O método foi aplicado em 36 regiões metropolitanas dos Estados Unidos e os resultados indicam que as viagens realizadas por transporte público possuem média de "circuicidade" maior que viagens por carro. Além disso, os autores identificam maiores valores para os pares origem - destino gerados aleatoriamente, mas apontam que mesmo apresentando valores maiores, o recurso de geração de origens e destinos aleatórios é útil quando não se tem acesso a informações de viagens reais. Por fim, os autores conseguem identificar correlações entre "circuicidade", tempos de viagem e acessibilidade das áreas estudadas, mostrando que a "circuicidade" pode explicar a divisão modal em áreas metropolitanas. O método apresenta a vantagem de ser completamente automatizado, porém, em uma adaptação para o problema do transporte de carga, existiria uma dificuldade na obtenção de dados de viagens reais, visto que ainda é deficiente a obtenção de dados de origem destino de carga.

\subsection{Transporte de Carga Urbano}

Nas seções anteriores não foram identificados trabalhos com foco no transporte de carga urbano, portanto, o objetivo desta seção é identificar as abordagens 
existentes para o tratamento do transporte de carga urbano. Esta seção contempla trabalhos relacionados à estimativa de distâncias de entregas sem a necessidade de resolver problemas complexos de roteirização de veículos, um método de divisão de áreas em distritos de atendimento por veículos e uma proposta de construção de atlas logístico cujo objetivo é concentrar métricas e ferramentas que auxiliem a elaboração de políticas públicas voltadas ao transporte de carga urbano.

Daganzo (1984) propõe um método para estimar a distância total percorrida em uma rota de distribuição urbana baseando-se na área e forma do distrito de entrega, no número de pontos de entrega e na localização do distrito em relação ao centro de distribuição. O método propõe que primeiro seja feito o agrupamento dos locais de entrega que devem ser percorridos por cada veículo e, depois, elaboradas as rotas. O agrupamento de pontos a serem atendidos é a consolidação dos distritos de entrega, o que segundo o autor é um fator determinante nas distâncias totais percorridas. A fórmula que estima a distância percorrida por um veículo de distribuição é dividida em duas partes: a primeira é a distância de line-haul, distância entre o centro de distribuição e o distrito de entrega, e a segunda é a soma das distâncias entre os pontos de entrega, chamadas de distâncias locais. Com a fórmula, o autor ressalta a influência do formato dos distritos de entrega na distância de line-haul e que as distâncias locais dependem exclusivamente das condições do local. Estas distâncias são estimadas através de um fator de correção aplicado às distâncias lineares entre os pontos de entrega do percurso do veículo, e este fator deve ser calibrado para cada local em que é aplicado. O método retorna uma estimativa da distância percorrida de uma maneira simples que não depende de muitos dados de entrada, porém considera poucas características do local onde são realizadas as entregas. Ainda, o método não inclui fatores determinantes no desempenho das rotas (como, por exemplo, barreiras geográficas) e devido à época que foi proposto, não utiliza ferramentas computacionais úteis que hoje são de fácil acesso, como mapas digitais e softwares de informação geográfica, para o processamento de dados espaciais para a determinação das rotas. Desta forma, o método proposto por Daganzo (1984) pode gerar números subestimados para a distância real percorrida e não aproveita os recursos tecnológicos disponíveis atualmente.

Outra abordagem para definição de distritos de entrega é o modelo de otimização apresentado por Novaes et al. (2000). O referido modelo permite 
determinar fronteiras de distritos de entrega e a frota de veículos necessária a fim de minimizar custos diários da distribuição de mercadorias. Um distrito é definido pela área atendida por um veículo. Os tempos de viagem consideram a densidade dos pontos de entrega e uma distância de viagem total aproximada, que é calculada através de um fator de correção coerente com o local em que as entregas ou coletas são realizadas baseado em Daganzo (1984). Cada distrito é formado de acordo com restrições de custo máximo, de horário, de capacidade do veículo, de forma do distrito e de homogeneidade dos roteiros, ou seja, tempos de viagem similares para realização do roteiro. Os distritos de entrega são formados radialmente, ou seja, o modelo de otimização retorna ângulos e raios, e as áreas são delimitadas através de coordenadas polares onde o centro de distribuição é a origem, como mostra Figura 2.7. Esse tipo de abordagem para problemas de roteamento é interessante pois não exige tanta capacidade computacional quanto a resolução do VRP (Vehicle Routing Problem) (Braekers et al., 2016) tradicional e chama a atenção para a necessidade da caracterização dos distritos e regiões de entrega a fim de se obter resultados satisfatórios. Apesar dessa abordagem automatizar do processo através de um algoritmo genético, assim como Daganzo (1984) não são discutidas barreiras geográficas na formação dos distritos de entrega ou outras características locais que possam gerar resultados práticos de distância percorrida muito maiores que as estimadas, reforçando a necessidade de uma melhor caracterização e identificação de áreas problemáticas para a circulação de veículos no espaço urbano, afim de incluílas no planejamento dos roteiros de entrega, tornando-os mais compatíveis com a realidade local. 


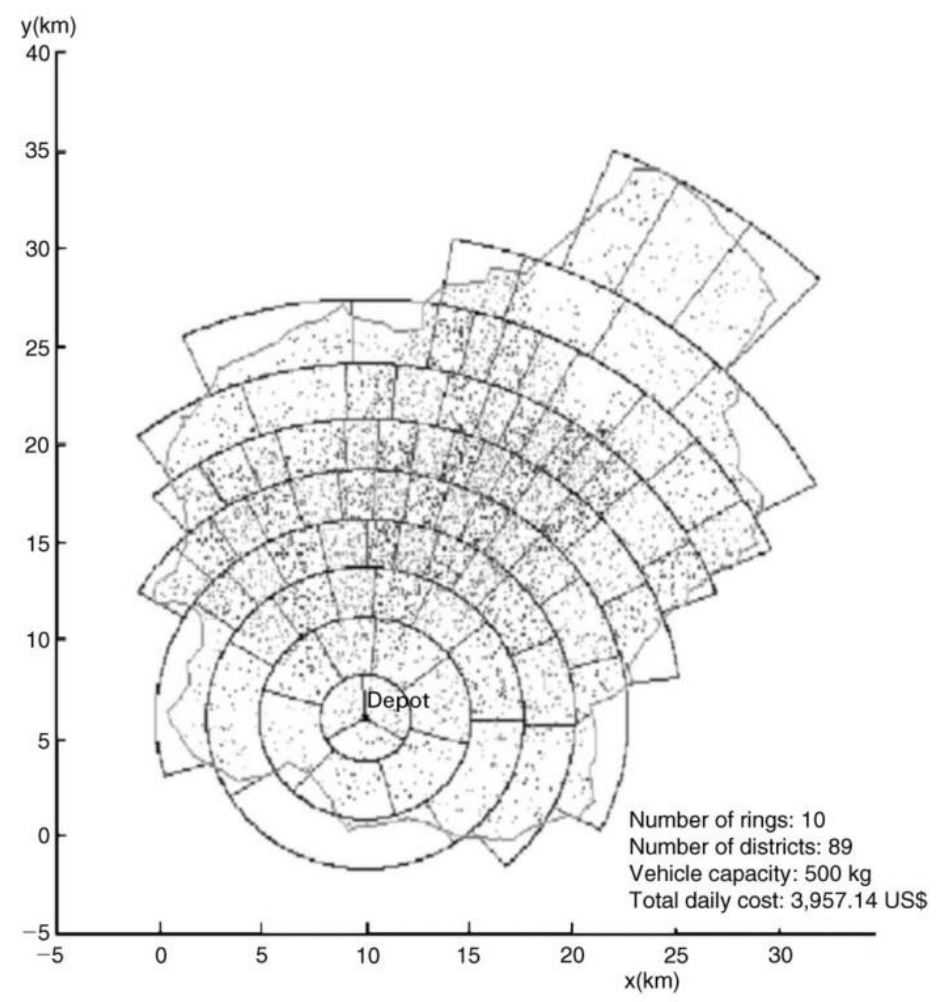

Figura 2.7: Exemplo de divisão de distritos resultante do modelo matemático proposto por Novaes et al. (2000).

Merchan et al. (2015) propõem a construção de um atlas que concentre todas as métricas referentes à eficiência da distribuição de carga nas cidades, afim de auxiliar o processo de tomada de decisão de agentes públicos na elaboração de políticas públicas relativas ao transporte de carga urbano. Os autores propõem um atlas online (disponível em http://lastmile.mit.edu/km2) o qual apresenta dados coletados em oito cidades (Pequim, Kuala Lumpur, Madrid, Cidade do México, São Paulo, Rio de Janeiro, Bogotá e Santiago). Em cada cidade foi selecionada uma área quadrada de $1 \mathrm{~km}^{2}$ localizada em região comercial, pois os autores afirmam que a dificuldade de operações de entrega de carga é maior em regiões urbanas centrais com intensa atividade comercial.

Os dados coletados foram divididos em cinco categorias: (i) atividade comercial, (ii) malha viária e regulações de trânsito, (iii) operações de entrega, (iv) interrupções no tráfego e (v) trânsito. Para as duas primeiras categorias, foram coletados dados em todo o $\mathrm{km}^{2}$, para as outras três, apenas em um segmento de via considerado mais relevante. Algumas das métricas extraídas através de observação em campo são: tipos de comércio, comprimento de fachada do comércio, espaço disponível para descarga de veículos, número de faixas de cada via, dimensão das 
calçadas, dimensão das vagas de estacionamento para veículos de carga, tipo de veículos utilizados nas entregas, tamanho da entrega, distância entre veículo estacionado e loja, número de lojas atendidas em uma parada por veículo, duração da entrega, número de interrupções no tráfego de veículos e pedestres causadas por veículos de carga, número de faixas bloqueadas, fluxo de tráfego de pedestres, fluxo de tráfego de veículos motorizados, etc.

Com essas informações, os autores calcularam a densidade de lojas por tipo de atividade comercial (alimentação, vestuário, etc.) e número médio de entregas recebidas diariamente por loja para cada tipo de atividade comercial. Os autores ainda ressaltam a importância do uso de métricas para a caracterização da oferta malha viária na área estudada e propõem o uso do fator de "circuicidade". O fator de "circuicidade" é calculado através da computação de trajetos aleatórios que passam por 10 lojas localizadas dentro do $\mathrm{km}^{2}$, para cada trajeto obtém-se a distância em rede que deve ser percorrida por um veículo obedecendo todas as restrições de trânsito e a soma das distâncias lineares entre as lojas. Em seguida, calcula-se a razão entre distância real e distância linear para $n$ trajetos aleatórios gerados e define-se o fator de "circuicidade" para região como a soma das razões obtidas divididas por n. Os autores destacam que o fator de "circuicidade" pode ser utilizado como coeficiente de correção em abordagens que utilizam aproximações de distâncias, como a de Daganzo (1984). Em geral, os autores concluem que os dados coletados foram úteis para a comparação das cidades estudas e destacam que tais informações seriam úteis no processo de tomada de decisão de estratégias e políticas voltadas para o transporte de carga urbano.

De todos os trabalhos revisados, Merchan et al. (2015) é o que mais se assemelha ao objetivo desta pesquisa, porém o método proposto pelos autores exige coleta de dados em campo, dificultando a sua replicação, sua automação e a sua aplicação em áreas maiores que $1 \mathrm{~km}^{2}$. Apesar de ser destacado que a dificuldade da distribuição urbana de carga é maior em regiões comerciais, justificando a análise em áreas localizadas, $1 \mathrm{~km}^{2}$ é uma área muito limitada para caracterização de megacidades, que têm múltiplos centros comerciais que ultrapassam facilmente o tamanho sugerido pelos autores, por exemplo, o centro do Rio de Janeiro, um dos principais bairros comerciais da cidade, tem $5,7 \mathrm{~km}^{2}$. E, por fim, o foco em regiões com 
atividades comerciais exclui a possibilidade de analisar a dificuldade de realizar entregas de comércio eletrônico, cujo destino final também inclui domicílios.

\subsection{Conclusão da Revisão da Literatura}

Através da revisão da literatura realizada neste trabalho, identifica-se uma carência de estudos que relacionem características urbanas com a eficiência da distribuição de carga de última milha. Os métodos e métricas investigados são utilizados em análises geográficas ou espaciais gerais; quando aplicados a operações de transportes, contemplam apenas o transporte de passageiros. Além disso, apenas a abordagem descrita por Merchan et al. (2015) ressalta a importância da investigação de aspectos da infraestrutura das cidades, como a oferta de mala viária, no uso do planejamento da operação da última milha. Ainda assim, diferentemente do método proposto neste trabalho, o atlas logístico proposto por Merchan et al. (2015) exige coleta de dados em campo tornando impossível a sua automação, reforçando a relevância deste trabalho.

O panorama geral das métricas encontradas na literatura é apresentado na Tabela 2.1, onde estão listadas todas as métricas revisadas e os respectivo autores que as citaram. Os autores que fazem referência à aplicação em transportes estão destacados em azul. Percebe-se que a métrica mais citadas e utilizada em aplicações de transportes é o fator de "circuicidade", ou "retilinidade" (destaque em amarelo), o que é esperado já que é uma métrica de eficiência que relaciona distância, aspecto importante para qualquer problema de transportes. Outras métricas que também são bastante utilizadas em problemas de transporte são conectividade, densidade de vias e densidade de interseções, porém, utilizadas para complementar a análise de "circuicidade" com características de infraestrutura viária.

Muitas métricas são genéricas e não agregam quantitativamente em problemas de transportes, como por exemplo, as medidas topológicas que geram uma interpretação muito limitada da configuração da rede devido a impossibilidade de expressarem suas características espaciais. Outras métricas são obtidas por processos de difícil automação, tornando seu uso inviável para problemas milha que contemplam grandes áreas urbanas com malhas viárias extensas, como é o caso das 
entregas urbanas; um exemplo é a ciclicidade que requer a geração de caminhos conectando todos os nós da rede entre si.

Outra questão a ser destacada é que muitas dessas métricas são altamente correlacionadas e o seu uso concomitante não agrega novas informações a análise, já que descrevem aspectos similares. É o caso, por exemplo, da ciclicidade e treeness; a primeira descreve a quantidade de ciclos que a estrutura da rede forma e o segundo a quantidade de ramificações, ou seja, são valores que apresentam correlação negativa, pois uma rede com mais ciclos é uma rede com menos ramificações e viceversa. 
Tabela 2.1: Métricas e autores revisados.

\begin{tabular}{|c|c|c|c|c|c|c|c|c|c|c|c|c|c|c|c|c|c|c|}
\hline & 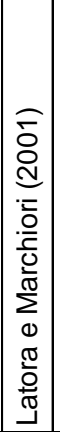 & 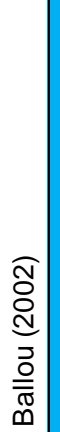 & 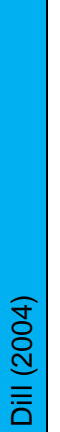 & 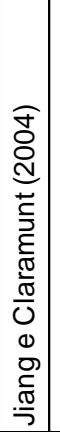 & 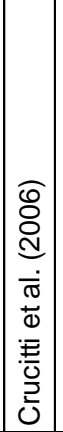 & 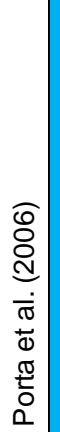 & 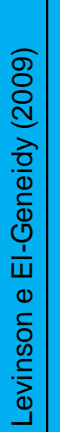 & 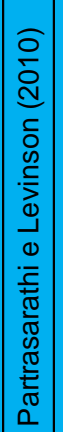 & 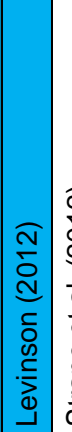 & 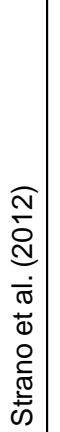 & 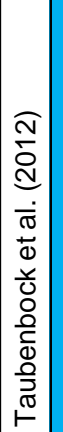 & 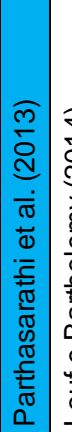 & 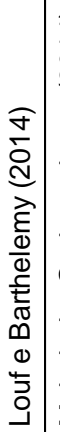 & 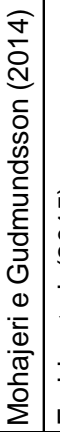 & 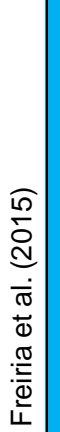 & 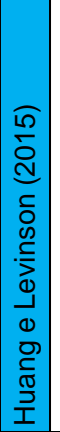 & 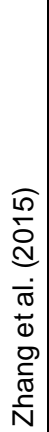 & 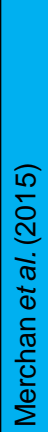 \\
\hline Área de caminhada efetiva & & & $\mathrm{X}$ & & & & & & & & & & & & & & & \\
\hline Área do quarteirão & & & $\mathrm{X}$ & & & & & & & $\mathrm{X}$ & & & $\mathrm{X}$ & & & & & \\
\hline Área urbana & & & & & & & & & & & $\mathrm{X}$ & & & & & & & \\
\hline Centralidade de informação & & & & & $\mathrm{X}$ & & & & & & & & & & & & & \\
\hline Centralidade de intermediação & & & & & $\mathrm{X}$ & & & & & $\mathrm{X}$ & & & & & $\mathrm{X}$ & & & \\
\hline Centralidade de proximidade & & & & & $\mathrm{X}$ & & & & & & & & & & & & & \\
\hline Ciclicidade & & & & & & & & & & & & & & & & & $\mathrm{X}$ & \\
\hline "Circuicidade" / Índice de "retilinidade" & & $\mathrm{X}$ & $\mathrm{X}$ & & $\mathrm{X}$ & & $\mathrm{X}$ & $\mathrm{X}$ & $\mathrm{X}$ & & & $\mathrm{X}$ & & & & $\mathrm{X}$ & & $\mathrm{X}$ \\
\hline "Circuicidade" média & & & & & & & & $\mathrm{X}$ & & & & & & & & & & \\
\hline Coeficiente de aglomeração & & & & $\mathrm{X}$ & & $\mathrm{X}$ & & & & & & & & & $\mathrm{X}$ & & & \\
\hline Completude & & & & & & & & $\mathrm{X}$ & & & & & & & & & & \\
\hline Comprimento médio dos segmentos de via & & & $\mathrm{X}$ & & & & & & & & & & & $\mathrm{X}$ & & & & \\
\hline Comprimento médio de caminho & & & $\mathrm{X}$ & & & $\mathrm{X}$ & & & & & & & & & & & & \\
\hline Comprimento total de vias & & & & & & & $\mathrm{X}$ & & & $\mathrm{X}$ & & & & & & & & \\
\hline Conectividade & & & & $\mathrm{X}$ & & $\mathrm{X}$ & & & $\mathrm{X}$ & & & & & & & & $\mathrm{X}$ & \\
\hline Correlação de grau & & & & & & $\mathrm{X}$ & & & & & & & & & & & & \\
\hline Densidade de interseções & & & $\mathrm{X}$ & & & & $\mathrm{X}$ & & & & & $x$ & & & & & & \\
\hline Densidade de quarteirões & & & $\mathrm{X}$ & & & & & & & & & & & & & & & \\
\hline Densidade de vias & & & $\mathrm{X}$ & & & & & $\mathrm{X}$ & & & & $x$ & & & & & & \\
\hline Descontinuidade relativa & & & & & & & & & & & & $x$ & & & & & & \\
\hline Diâmetro & & & & & & & & & & & & & & & & & $\mathrm{X}$ & \\
\hline Distribuição de grau & & & & & & $\mathrm{X}$ & & & & & & & & & & & & \\
\hline Eficiência global & $\mathrm{X}$ & & & & & $\mathrm{X}$ & & & & & & & & & & & & \\
\hline Eficiência local & $\mathrm{X}$ & & & & & $\mathrm{X}$ & & & & & & & & & & & & \\
\hline Fator de forma do quarteirão & & & & & & & & & & $\mathrm{X}$ & & & $\mathrm{X}$ & & & & & \\
\hline Fragmentação & & & & & & & & & & & & & & & $\mathrm{X}$ & & & \\
\hline índice alpha & & & & & & & & & & & & & & & $\mathrm{X}$ & & & \\
\hline Número de arcos & & & & & & $\mathrm{X}$ & & & & $\mathrm{X}$ & & & & & & & & \\
\hline Número de nós & & & & & & $\mathrm{X}$ & & & & $\mathrm{X}$ & & & & & & & & \\
\hline Orientação das vias & & & & & & & & & & & & & & $\mathrm{X}$ & & & & \\
\hline P2A & & & & & & & & & & & & $x$ & & & & & & \\
\hline Padrão de grade & & & $\mathrm{X}$ & & & & & & & & & & & & & & & \\
\hline Perímetro dos quarteirões & & & $\mathrm{X}$ & & & & & & & & & & & & & & & \\
\hline Pontos de corte & & & & & & & & & & & & & & & $\mathrm{X}$ & & & \\
\hline Potência de Bonacich & & & & & & & & & & & & & & & $\mathrm{X}$ & & & \\
\hline Proporção de nós conectados & & & $\mathrm{X}$ & & & & & & & & & & & & & & & \\
\hline Proporção de vias expressas & & & & & & & & & & & & $x$ & & & & & & \\
\hline Razão entre segmentos de vias e nós & & & $\mathrm{X}$ & & & & & & & & & & & & & & & \\
\hline "Treeness" & & & & & & & & $x$ & & & & $x$ & & & & & & \\
\hline
\end{tabular}




\section{MÉTODO PARA AVALIAÇÃO DA COMPLEXIDADE DA DISTRIBUIÇÃO URBANA DE CARGAS}

Neste capítulo é proposto e detalhado um método para avaliar áreas urbanas quanto à complexidade e dificuldade de realização de operação de distribuição urbana de carga de última milha. Além da caracterização da área estudada quanto à sua complexidade, o procedimento proposto também possibilita a comparação entre áreas distintas, de uma mesma cidade ou de cidades diferentes. O método proposto parte da premissa de não depender de coleta de dados em campo, e nem de dados de obtenção restrita (tais como imagens de satélite, banco de dados de estabelecimentos comerciais, etc.), e também de não requerer cálculos ou análises manuais, possibilitando sua aplicação em qualquer área urbana de qualquer tamanho, com facilidade.

Como foi apresentado sucintamente no capítulo inicial, a operação da distribuição urbana de carga de última milha consiste no transporte de bens e mercadorias desde centros de distribuição (CD), depósitos, armazéns ou fábricas, entre outros pontos de origem, que usualmente ficam afastados dos grandes centros urbanos, até os pontos de demanda, tipicamente estabelecimentos comerciais (tais como lojas, bares, restaurantes, escritórios, supermercados, etc.) ou residências, que se localizam dentro da área urbana, onde se desenvolvem as atividades econômicas. É importante observar que a valorização imobiliária, decorrente do crescimento das cidades, é um fenômeno mundial, que tem acarretado um afastamento das instalações logísticas em relação aos centros urbanos, fenômeno esse conhecido como espraiamento logístico, do inglês logistic sprawl (Dablanc et al., 2014). Por exemplo, em Paris a distância média dos terminais logísticos para o centro da metrópole foi de 5km em 1974 para 16km em 2008 (Dablanc e Rakotonarivo, 2010); em Belo Horizonte, foi de 17,8km para 19km no período entre 1995 e 2015 (Oliveira et al., 2017). Em São Paulo, alguns centros de distribuição que atendem prioritariamente a sua Região Metropolitana estão distantes até cerca de 60 a 80 km do centro da cidade, como no caso, por exemplo, do CD do Magazine Luiza (rede varejista de bens duráveis), localizado no km 68 da Rodovia dos Bandeirantes ou do 
Mercado Livre (empresa do setor de comércio eletrônico), localizado no km 72 da Rodovia Anhanguera, ambos a mais de $60 \mathrm{~km}$ do centro da cidade.

Outra característica importante da distribuição urbana de última milha é o tamanho médio das entregas em termos de peso e volume (também conhecido como drop size). A tendência de estabelecimentos comerciais com espaços de estocagem cada vez menores devido à valorização imobiliária, a popularização do e-commerce e a perecibilidade dos insumos são alguns dos fatores característicos da distribuição de carga nas cidades que contribuem para o tamanho reduzido dos pedidos, levando ao fracionamento das entregas e à necessidade de agrupar múltiplos destinos de entrega no roteiro de um veículo, o que torna imperativo otimizar o conjunto de rotas para os veículos utilizados.

O problema de agrupamento e sequenciamento dos pontos de entrega a serem atendidos por cada veículo de forma eficiente (isto é, minimizando a frota utilizada e a distância total percorrida no atendimento de todos os pontos de entrega) é conhecido na literatura como Problema de Roteamento de Veículos (do inglês Vehicle Routing Problem ou VRP) (Braekers et al., 2016). É um problema de natureza combinatória, de enorme complexidade, sendo objeto de um número muito grande de pesquisas científicas (Cunha, 2006).

Normalmente os roteiros são programados de forma a otimizar as distâncias percorridas, utilizando-se para isso algum software ou pacote de roteirização (Partyka e Hall, 2018). Entretanto, tais programações não contemplam eventuais imprevistos que podem ocorrer na prática, durante o percurso dos veículos, particularmente a eventual impossibilidade de realizar uma entrega na sequência e horário programados. Isso pode decorrer, por exemplo, de alguma dificuldade de um estabelecimento em receber a carga naquele momento que foi programado, ou do cliente não se encontrar em seu domicílio (no caso de entregas B2C no comércio eletrônico), o que obriga o veículo a seguir para a próxima entrega, para posteriormente retornar a esse local para uma nova tentativa de entrega. Nesse contexto, é importante avaliar e estimar quantitativamente o impacto desses imprevistos que obrigam o retorno não programado a alguns locais de entrega, na eficiência dos roteiros realizados. 
Daganzo (1984) propõe uma forma simplificada para estimar as distâncias totais percorridas nos roteiros de entrega tendo por base uma análise da melhor configuração das regiões de entrega em termos de seu formato. O autor divide 0 percurso de um roteiro de entrega em duas partes: o trecho line-haul e a circulação local. O trecho do roteiro denominado line-haul consiste no trajeto de acesso e regresso à área de entrega a partir da sua origem, onde não ocorrem paradas para entregas; já o trecho de circulação local consiste nos deslocamentos feitos entre pontos consecutivos de entrega de um roteiro. No acesso/regresso, é usual deslocamentos mais longos devido à distância dos CDs de onde partem os veículos para as áreas urbanas onde se localizam os pontos de demanda. Esta parte do trajeto depende de infraestrutura normalmente rodoviária e pressupõe-se que grande parte do trajeto seja realizado em vias expressas cujas principais características são, tipicamente, rodovias com múltiplas faixas de rodagem, poucas interseções em nível e limites de velocidade mais elevados (acima de $60 \mathrm{~km} / \mathrm{h}$ ) que causam poucas interferências no fluxo de tráfego. Já na circulação local, esperam-se deslocamentos mais curtos, entre os pontos de demanda, ou seja, a distância está sujeita a densidade média dos pontos de entrega na região, que varia de acordo com o tipo de carga em questão (por exemplo, bebidas sendo entregues em bares, remédios em farmácias, alimentos em supermercados, encomendas postais em domicílios, etc.). Este trajeto entre pontos de entrega consecutivos usualmente ocorre no ambiente urbano, onde encontram-se predominantemente vias locais e arteriais, cujas interseções são frequentes e as velocidades máximas permitidas nas vias mais baixas (até $50 \mathrm{~km} / \mathrm{h}$ ), além de serem mais estreitas que vias expressas e estarem sujeitas a mais restrições de trânsito como conversões proibidas e mão-única de direção, o que causa maior impedância nos fluxos de tráfego.

A recomendação de Daganzo (1984) é formar distritos de entrega (aglomeração de pontos de entrega atendidos por um veículo) alongados em relação ao depósito, a fim de minimizar as distâncias de line-haul, pois não há diferença significativa entre as distâncias percorridas na parte da circulação local. A Figura 3.1 ilustra essa recomendação; percebe-se que das duas configurações apresentadas, a que tem distritos de entrega mais alongados (retangulares) gera distâncias de linehaul menores que a configuração com distritos de entrega mais próximos do formato quadrado. Em ambos os casos, dada uma mesma densidade de pontos de entrega, a 
distância total entre pontos de entrega pode ser considerada a mesma. Como foi visto na revisão da literatura, Novaes et al. (2000) propõem um método de definição de distritos de entrega, um para cada veículo, que se baseia nessa metodologia proposta por Daganzo (1984).

Apesar desse tipo de abordagem (Figura 3.1) ser uma alternativa à resolução do VRP para definir agrupamentos de entrega, deve-se atentar que não são levadas em consideração eventuais barreiras urbanas que afetar a eficiência, na prática, do cumprimento dos roteiros de entrega definidos a partir de agrupamentos de pontos em distritos seguindo a proposta de Daganzo (1984). A Figura 3.2 e a Figura 3.3 exemplificam o que ocorreria na definição desses agrupamentos para um caso da cidade de São Paulo onde há barreira urbana natural, o rio Pinheiros. Mais especificamente na Figura 3.2, cada um dos distritos é formado por áreas não contíguas, uma vez que não há pontes que possibilitam a ligação dessas áreas. Em outras palavras, a o Rio Pinheiros impõe uma barreira para a circulação local, o que faz com que as distâncias percorridas na circulação local variem conforme a configuração dos distritos de entrega, ao contrário da premissa do autor. A Figura 3.3 apresenta um exemplo de configuração de distritos de entregas mais adequada à região em questão, em que se observa não haver barreiras para a circulação dos veículos dentro de um distrito de entrega, e sim que as barreiras compõem as fronteiras dos distritos.

Deve-se notar que não é apenas um corpo d'água como o Rio Pinheiros o único tipo de barreira que afeta a circulação de veículos em um roteiro de entregas: barreiras naturais ou artificiais, como parques, florestas, lagos, vias férreas, rodovias, e até mesmo grandes avenidas podem representar um obstáculo para a circulação dos veículos que realizam as entregas de última milha. 

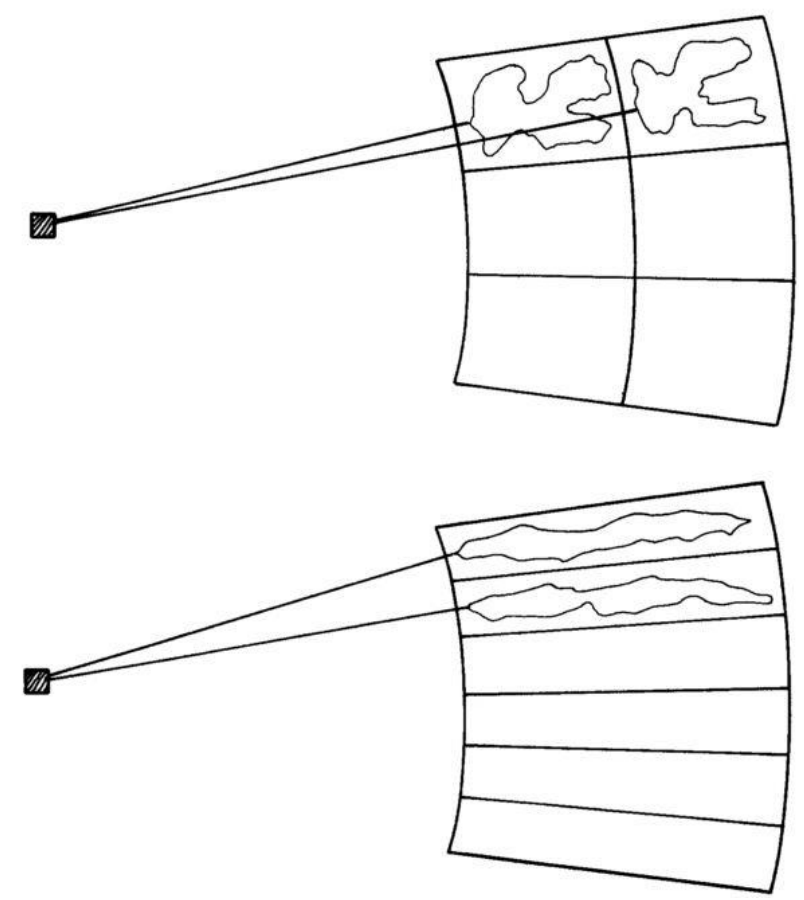

Figura 3.1: Duas alternativas de divisão de uma região em seis distritos de entrega (Daganzo, 1984).

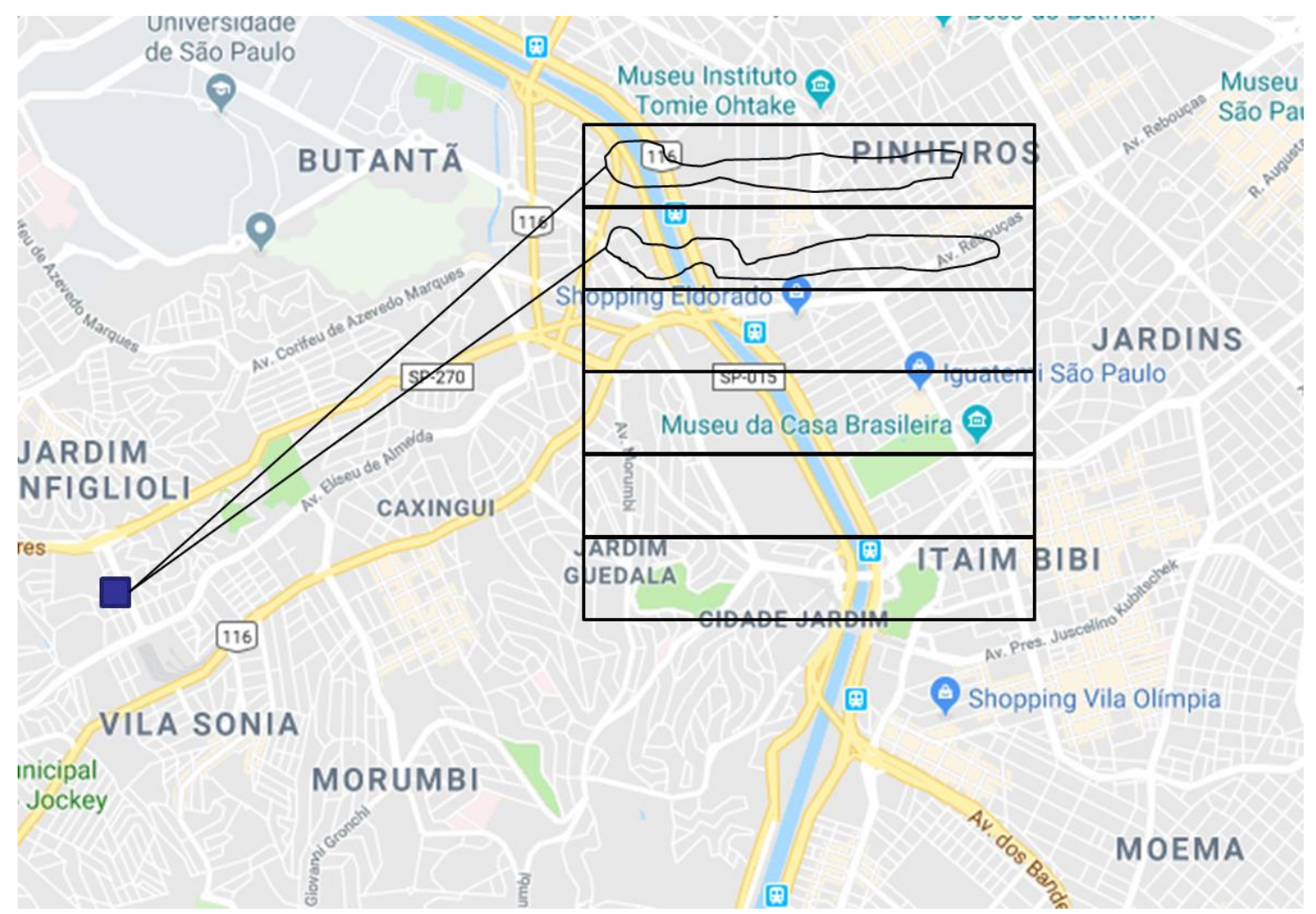

Figura 3.2: Exemplo de configuração de distritos de entrega com barreira urbana em São Paulo. 


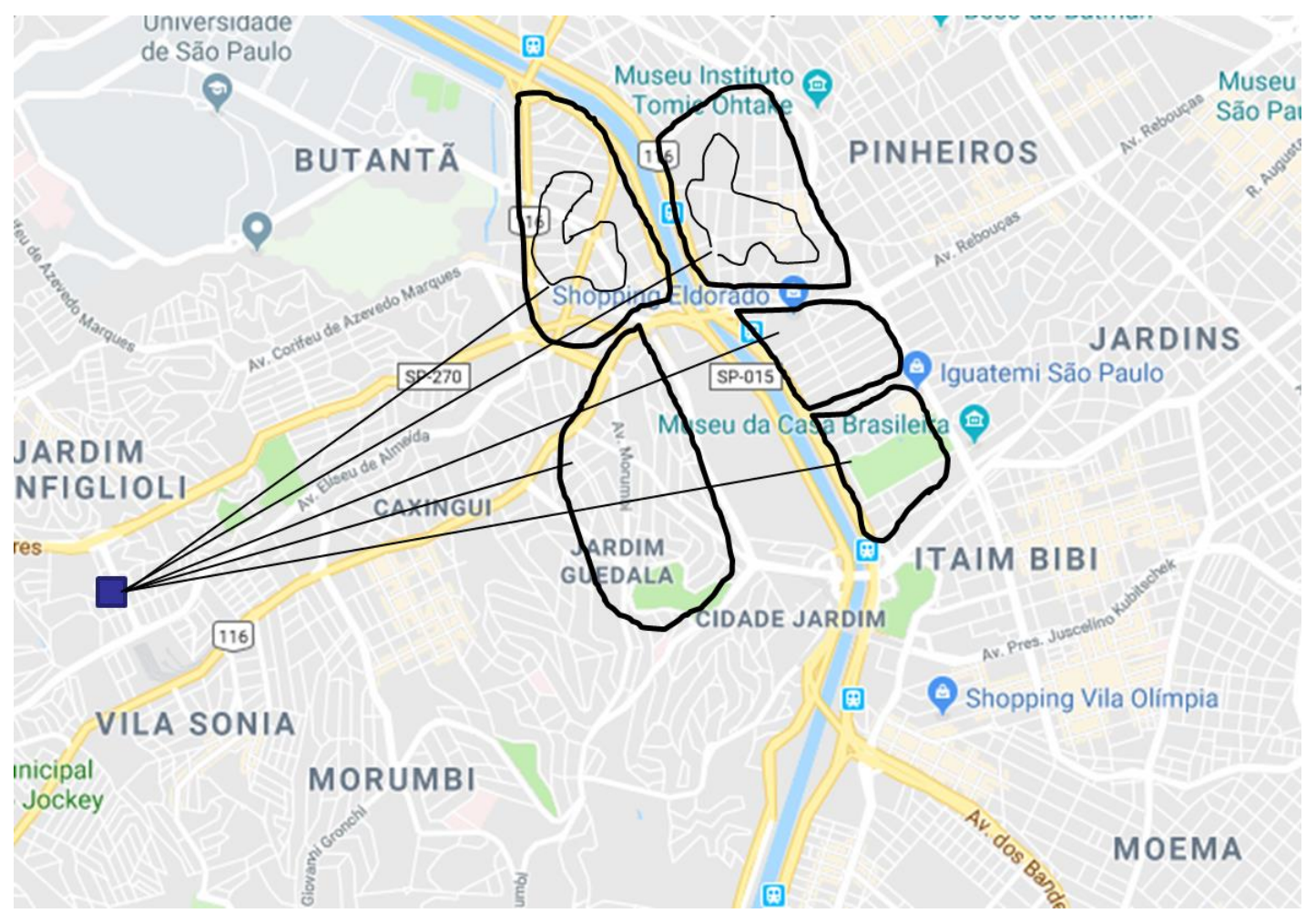

Figura 3.3: Exemplo alternativo de configuração de distritos de entrega em São Paulo

Com base no que foi exposto acima, o método aqui proposto para a análise das áreas urbanas quanto à complexidade e dificuldade de realização de operação de distribuição urbana de carga de última milha considera duas partes de um roteiro de entregas, como sugerido por Daganzo (1984): line-haul, acesso e regresso do CD ao distrito de entrega, e circulação local, deslocamentos entre pontos de demanda. Essa divisão se faz necessária devido à diferente natureza dos deslocamentos em cada parte.

Assim, propõe-se investigar as distâncias e os tempos de deslocamento que influenciam ambas as partes de um roteiro de entregas e seu efeito na produtividade dos veículos e aumentam os custos da operação. A disponibilidade de vagas de estacionamento para operações de carga e descarga, e os tempos efetivamente despendidos na realização de cada uma das entregas, com os veículos estacionados, apesar de também afetarem diretamente a produtividade das entregas, não serão contemplados nesta proposta tendo em vista a ausência de dados que possam ser coletados para a análise.

O procedimento proposto contempla veículos motorizados e não-motorizados, focando na oferta da infraestrutura viária e da sua utilização/ocupação. Mais 
especificamente, procura-se avaliar o quanto que a oferta de malha viária afeta as distâncias percorridas tanto no acesso/regresso do distrito de entrega (line-haul), quanto no percurso entre pontos de entrega consecutivos (circulação local). Pressupõe-se que quanto maiores as distâncias percorridas, menor a produtividade das entregas e por consequência, maiores custos de operação. Porém, distâncias por si só não são suficientes para caracterizar a dificuldade imposta a operação de última milha, daí a necessidade de também procurar analisar tanto a sinuosidade dos trajetos e quanto os tempos de viagem levando em consideração as condições de circulação causados por congestionamentos, gerando a necessidade de investigar não só a oferta de malha viária como também a sua ocupação cotidiana através do histórico de velocidades de deslocamento observado nas vias, pois a variação da quantidade de veículos nas vias afeta diretamente as velocidades desenvolvidas.

A inclusão de veículos não-motorizados no método se dá pela tendência mundial de reduzir os impactos ambientais do transporte de carga através da substituição de veículos de transporte tradicionais (caminhões) por veículos de transporte menores e com menor emissão de poluentes, como carrinhos-de-mão, bicicletas, triciclos, etc, além de veículos elétricos (Gruber e Kihm, 2016; Marujo et al., 2018). Portanto, julgou-se importante investigar como a oferta de malha viária afeta as distâncias percorridas para os modos bicicleta e a pé, já que cada modo de transporte dispõe de seu próprio espaço viário para a circulação e deve seguir percurso respeitando diferentes regras e restrições de trânsito. Diferentemente de veículos motorizados, não são observadas quantidades de bicicletas ou pedestres críticas nas cidades a ponto de afetar suas velocidades de deslocamento, o que faz com que os tempos de viagem por modos não-motorizados sejam relativamente estáveis e, portanto, não são considerados nesta análise. Por outro lado, o uso de modos não-motorizados é afetado pela topografia da área; como declividades elevadas podem até mesmo inviabilizar seu uso, este método se propõe a também considerar as declividades das vias.

O método é baseado na caracterização de uma região urbana que é selecionada pelo usuário, na qual se pressupõe que será realizada a distribuição de última milha, e, portanto, estejam localizados os pontos onde são realizadas as entregas. A possibilidade do método ser aplicado em uma área de livre escolha elimina a necessidade de realizar a análise em áreas de municípios inteiros, o que permite 
que o usuário foque em uma região urbana específica em que de fato estão localizados os pontos de demanda, diminuindo o tempo necessário para análise e a capacidade de processamento necessária, e também não restringe a aplicação do método a um padrão ou forma de área específica, tais como bairros ou distritos, que podem compor uma mesma área de entrega.

A fim de evitar a necessidade de obtenção de dados de localização de pontos de entrega, que variam para cada cadeia de suprimentos e podem não estar necessariamente disponíveis, adotou-se o procedimento de geração de pontos de entrega localizados aleatoriamente de maneira uniforme dentro da área analisada. Essa é uma maneira simples e prática de simular a localização e distribuição de locais de entrega, pois a densidade dos pontos de entrega (pontos $/ \mathrm{km}^{2}$ ) pode ser facilmente estimada pelo usuário dependendo do tipo de serviço que se deseja analisar. Como já foi dito, a distância entre os locais de entrega depende do tipo de carga em questão, tendo em vista que bens e produtos diferentes tem padrões de demanda diferentes. Assim, o usuário pode definir a densidade de pontos que melhor se adeque a distribuição espacial dos pontos de demanda que deseja analisar.

Em seguida, procura-se avaliar como a oferta e a ocupação da malha viária presente dentro da área estudada afetam os deslocamentos entre os pontos de entrega (circulação local) e como o posicionamento da região de estudo na cidade, a oferta e o nível de ocupação da malha viária no entorno afetam o percurso entre o centro de distribuição e a área (line-haul). Conforme apresentado no capítulo anterior, a revisão da literatura indicou que a maioria das métricas encontradas na literatura são utilizadas em aplicações geográficas gerais. Dessa forma, optou-se pelo uso da métrica que mais foi utilizada em aplicações em transportes, o Índice de "Retilinidade" (Crucitti et al., 2006), uma forma de quantificar a eficiência das malhas viárias quanto as distâncias percorridas; em outras palavras, o quanto a configuração da malha viária aumenta as distâncias percorridas na cidade. Já o nível de ocupação viário e sua influência nos tempos de deslocamento serão avaliados pelas velocidades de tráfego esperadas.

Por se tratar de uma análise exploratória, a consolidação do método descrito a seguir foi desenvolvida após a realização de algumas análises iniciais, nas quais foram testadas fontes de dados e procedimentos diversos. A descrição dessas 
análises, que serviram de apoio, porém acabaram não sendo incorporadas ao método proposto, bem como seus resultados são discutidos mais adiante e detalhados nos Anexos B, C, D e E.

O restante deste capítulo está dividido em três subseções. A primeira contempla o procedimento para obtenção dos dados de entrada necessários para a aplicação do método; as duas seções seguintes discorrem sobre o processo de avaliação da influência da malha viária e seu carregamento na circulação local e na acessibilidade da região, respectivamente.

\subsection{Escolha e Caracterização da Área de Estudo}

O primeiro passo é a seleção de uma área de estudo, que pode ser uma região ou até mesmo uma cidade inteira, dependendo do seu porte/tamanho e do interesse do usuário. A área de estudo deve ser delimitada por um polígono em um arquivo do tipo shapefile. Este tipo de arquivo é compatível com softwares de sistema de informação geográfica (GIS) e pode ser facilmente gerado manualmente pelo usuário através da definição dos vértices do polígono ou importado de alguma base aberta de dados espaciais, como, por exemplo, a Zona Máxima de Restrição de Circulação de São Paulo (ZMRC) (Companhia de Engenharia de Tráfego, 2018), que foi utilizada nas análises apresentadas no Anexo D para a cidade de São Paulo. Os resultados são interessantes, pois incluem ambas as partes da operação já discutidas (line-haul e circulação local), possibilitando a análise das velocidades médias esperadas nos roteiros

Como tais arquivos podem não ser disponíveis, a criação de um polígono definido pelo usuário elimina a necessidade do uso de informações específicas. Apenas com o polígono, já é possível obter métricas que caracterizam a malha viária contida na área de interesse através da biblioteca OSMnx (Boeing, 2017) em Python. A biblioteca permite o download da base Open Street Map (OSM) (OpenStreetMap, 2018), uma base aberta de mapas digitais desenvolvida de maneira colaborativa. Através de um comando é possível obter a rede viária baseada em OSM contida em um polígono definido em um arquivo do tipo shapefile, e extrair as métricas da rede. Neste caso, utiliza-se o termo rede e não malha, pois são feitas algumas 
simplificações para sua representação gráfica, por exemplo, a rede viária não apresenta o número de faixas de rolagem das vias, pois as representa como segmentos bidimensionais. Sugere-se a obtenção das seguintes métricas através do OSMnx: extensão total das vias $(\mathrm{m})$, extensão média dos segmentos de via $(\mathrm{m})$, número de interseções e comprimento total de vias de mão única $(m)$. Com esses valores, mais a área, são calculados os seguintes indicadores para caracterização da área de estudo:

(i) densidade de vias $\left(\mathrm{m} / \mathrm{km}^{2}\right)$, extensão total de vias contidas no polígono dividido pela área;

(ii) extensão média do segmento de via $(\mathrm{m})$, extensão média dos trechos de via entre interseções;

(iii) densidade de interseções $\left(\mathrm{km}^{2}\right)$, número total de interseções contidas no polígono dividida pela área;

(iv) proporção de extensão de vias de mão única $(\mathrm{m} / \mathrm{m})$, extensão de vias de mão única dividida pela extensão total de vias contidas no polígono.

É importante ressaltar que o OSM considera avenidas com canteiro central como duas vias de mão única. Portanto, para a via ser considerada de mão dupla, não pode haver separação física entre as faixas de tráfego de sentidos opostos. A Figura 3.4 e a Figura 3.5 apresentam exemplos, respectivamente, da Avenida Paulista, considerada pelo OSM como duas vias de mão única devido a presença do canteiro central e da Avenida Angélica, cuja separação entre as faixas de tráfego de sentidos opostos é feita apenas pela sinalização horizontal, sendo, portanto, considerada via de mão dupla pelo OSM. 


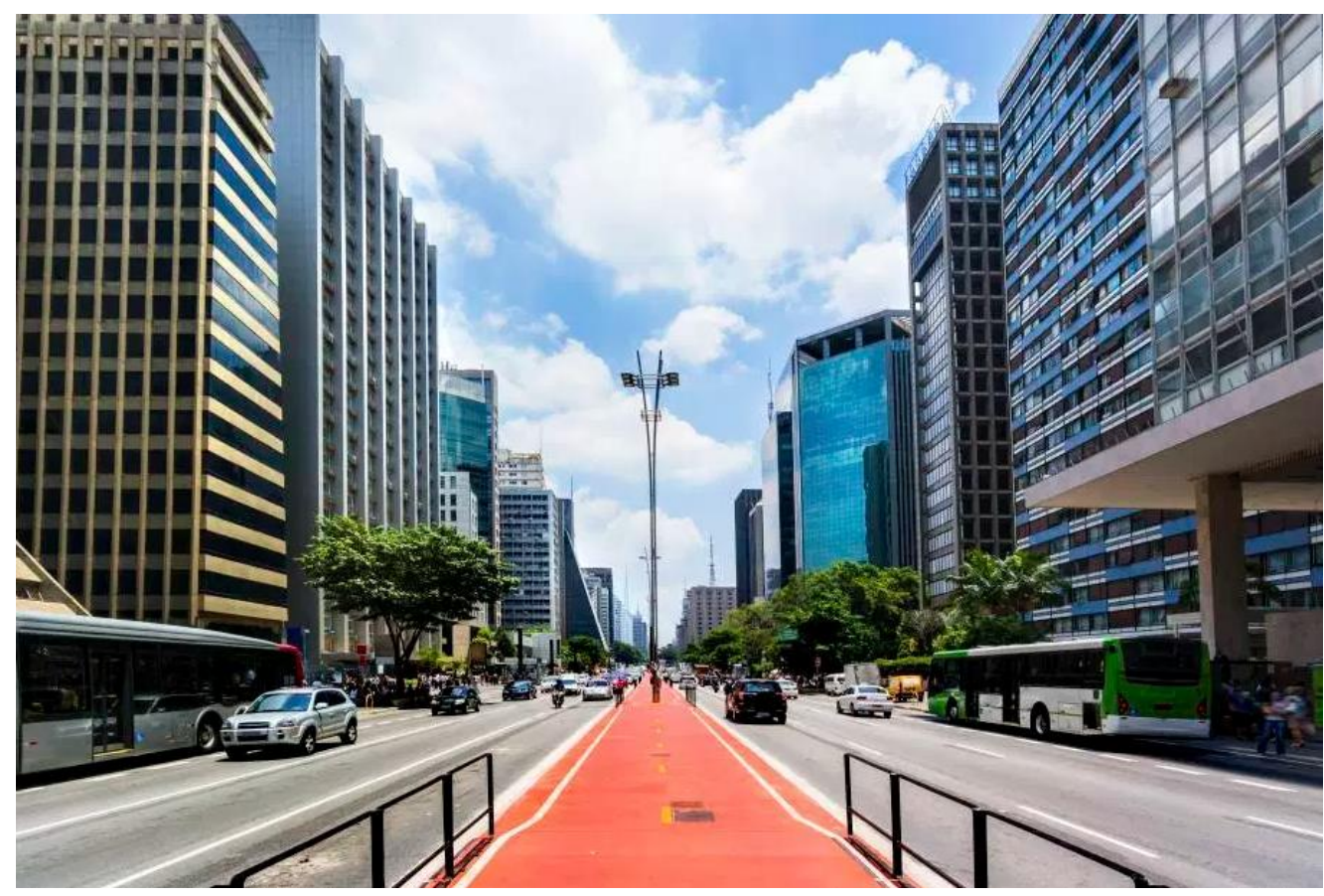

Figura 3.4: A Avenida Paulista com seu canteiro central, exemplo de via que é considerada de mão única pelo OSM.

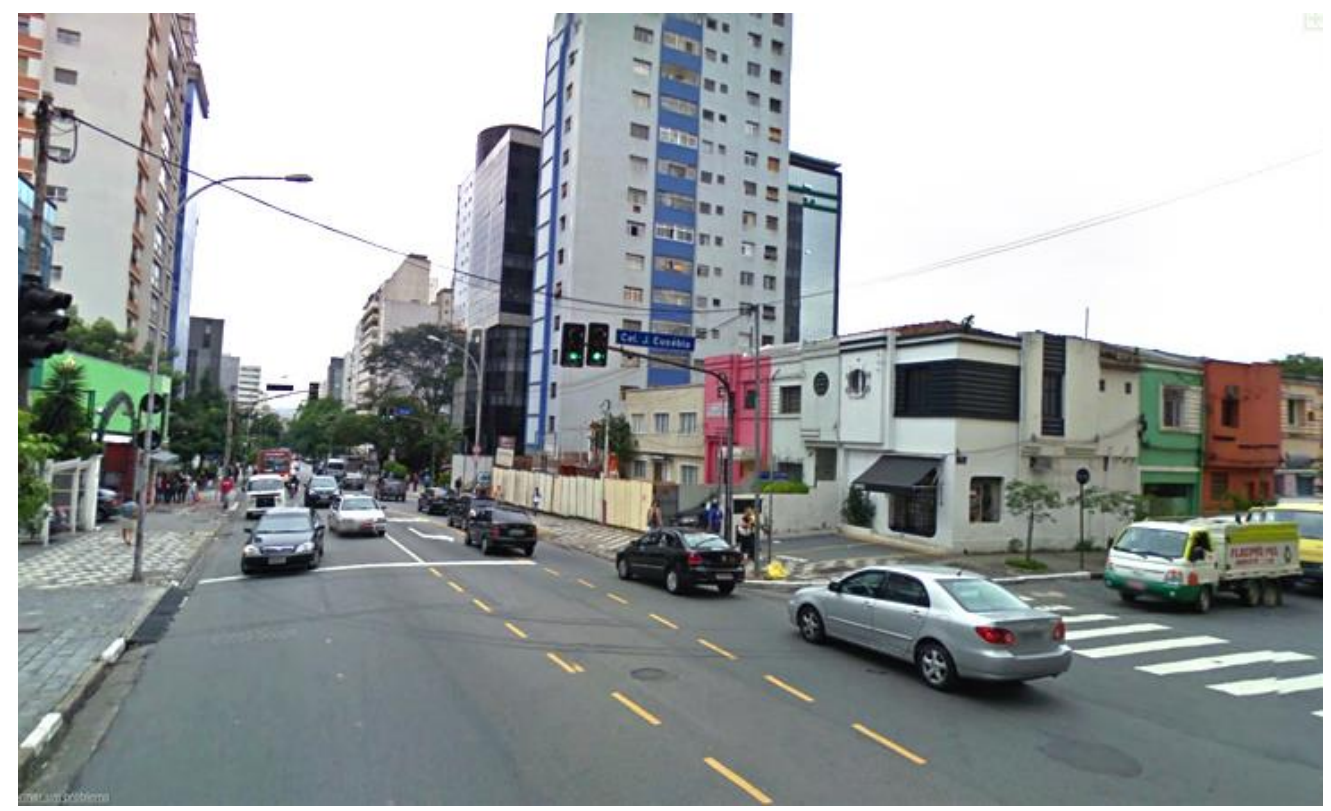

Figura 3.5: A Avenida Angélica, exemplo de via mão dupla.

Em seguida, é necessário gerar pontos aleatórios dentro da área de estudo. Como mencionado acima, esse artifício é uma maneira de eliminar a necessidade de obtenção de dados de localização de locais de entrega, já que não existe uma base de dados unificada de estabelecimentos comerciais ou de destinatários finais de encomendas. Dessa maneira, é possível simular a localização dos pontos de entrega através da geração aleatória de pontos, pois o usuário tem o controle da densidade 
(pontos $/ \mathrm{km}^{2}$ ) e distância mínima dos pontos aleatórios para que tenham valores semelhantes a distribuição de pontos de entrega reais.

Esse procedimento é semelhante ao proposto por Huang e Levinson (2015) em sua análise comparativa entre viagens feitas por carro particular e transporte público, que destacam que a geração de origens e destinos aleatórios é uma abordagem útil quando não se tem acesso aos dados de viagens reais. Analogamente, para o transporte de carga, a geração de pontos aleatórios é uma maneira simples de simular pontos de entrega em uma região da cidade por não depender de nenhum tipo de coleta ou pesquisa de dados, bastando apenas estipular a densidade de pontos de entrega do tipo de cadeia de suprimentos que se deseja estudar na área em questão para gerar a localização dos pontos.

Os pontos aleatórios são obtidos através de um algoritmo em Python, o qual gera um conjunto de pontos distribuídos em uma área dados:

(i) um polígono que defina a área;

(ii) a densidade de pontos desejada (pontos $/ \mathrm{km}^{2}$ );

(iii) distância mínima entre os pontos.

O resultado do algoritmo é um arquivo do tipo csv contendo um banco de dados em que cada observação representa um ponto, caracterizado por um número de identificação e por coordenadas geográficas (latitude e longitude).

Como o método também inclui a questão do acesso à área estudada, também é necessário identificar uma ou mais possíveis localizações para o armazém ou centro de distribuição de onde partem os veículos que realizarão as entregas. Se esses locais não são conhecidos, podem ser facilmente identificados com pesquisas simples na internet. Para o método, basta fornecer coordenadas geográficas (latitude e longitude) para cada local de origem de onde partem os veículos de entrega.

É importante destacar que também se avaliou a possível utilização de locais reais de entrega obtidos a partir de algum tipo de banco de dados, como do site Kekanto (Guia Kekanto, 2016), um guia colaborativo para localização e avaliação de serviços tais como bares, restaurantes, lojas, hotéis. Porém, o uso desse tipo de fonte de dados pode comprometer a proposta de caráter geral do método, uma vez que o 
Kekanto é restrito ao Brasil, e não existe nenhum tipo de base de estabelecimentos comerciais universal que agregue diversas partes do mundo, limitando a aplicação do método somente para locais onde tais dados estão disponíveis. Por exemplo, o FourSquare (Foursquare, 2018), semelhante ao Kekanto e que auxilia o usuário a encontrar lugares tais como restaurantes, bares, lojas e é muito utilizado na América do Norte e em partes da Europa Ocidental, é muito pouco usado e conhecido no Brasil, fazendo com que a sua base de estabelecimentos seja incompleta, o que prejudicaria a aplicação do método proposto, por não permitir identificar e localizar estabelecimentos que represente a realidade do sistema de distribuição que se pretende representar. Além disso, surge a dificuldade de aplicar o método para diferentes tipos de cadeias de suprimentos, como, por exemplo, entregas de materiais em escritórios ou o comércio eletrônico (e-commerce). As análises descritas nos Anexos B e C utilizaram localização de estabelecimentos comerciais (restaurantes) do site Kekanto. No Anexo B os estabelecimentos utilizados na análise foram escolhidos de maneira aleatória e no Anexo $\mathrm{C}$ foram selecionados através de um filtro do tipo de serviço.

\subsection{Circulação Local}

\subsection{1 Índice de "Retilinidade"}

O processo a seguir sumariza a parte do método que busca analisar a disponibilidade, flexibilidade e eficiência da malha viária existente para a circulação local segundo o critério de impedância de distância. Ao seu final, o resultado é um banco de dados no qual cada observação corresponde a uma combinação origem e destino definidos pelos pontos gerados aleatoriamente, além do Índice de "Retilinidade" associado. Com esses dados é possível elaborar gráficos e mapas a fim de visualizar as áreas onde a malha viária é menos eficiente. Além dos índices atribuídos aos pares origem e destino, é possível gerar Índices de "Retilinidade" Médios para caracterizar a região estudada como um todo.

Conforme detalhado no Anexo $\mathrm{B}$, foram realizados experimentos iniciais realizados em três bairros da cidade de São Paulo a fim de investigar o uso do Índice de "Retilinidade" na avaliação da eficiência da malha viária disponível do ponto de 
vista das distâncias percorridas nas viagens urbanas. Os resultados obtidos foram promissores, pois os Índices de "Retilinidade" obtidos são proporcionais a percepção de dificuldade de circulação em cada bairro.

O procedimento proposto pode ser sumarizado da seguinte forma: uma vez gerados os pontos que simulam locais de entrega, o primeiro passo do método é analisar a influência da malha viária existente nas distâncias percorridas na circulação local. Isso é feito através de uma análise dos os trajetos que correspondem aos menores caminhos que conectam os pontos de entrega. Como os roteiros de entrega resultantes de software de roteirização costumam agrupar locais próximos a fim de minimizar a distância e o tempo despendido com deslocamentos, não há a necessidade de analisar os caminhos ligando todos os pares de pontos do banco de dados, e sim apenas os pontos que estão próximos entre si, uma vez que é pouco provável que os veículos de entrega tenham que se deslocar entre pontos muito distantes do roteiro de entrega. Sendo assim, propõe-se um parâmetro de entrada que define um raio máximo, medido através de uma distância linear máxima entre paradas consecutivas. Dessa forma, cada ponto de entrada gerado aleatoriamente é visto como centro desse raio de busca e como origem do trajeto, permitindo determinar os demais pontos que estão dentro do raio pré-estabelecido e que podem ser destinos.

Efetivamente, antes de computar o percurso em rede entre um ponto de origem e outro de destino, verifica-se a distância linear entre os pontos; se for menor que a distância máxima pré-estabelecida, o percurso entre aquele par de pontos é computado. Esse procedimento é aplicado para cada um dos pontos gerados, fazendo com que o resultado seja uma matriz de distâncias incompleta, na qual as origens e os destinos são os pontos que compõe os dados iniciais e as células vazias correspondem aos pares de pontos cujas distâncias lineares (ou seja, em linha reta) estão que estão acima do raio máximo.

A Figura 3.6 e a Figura 3.7 ilustram um exemplo deste procedimento para uma distância máxima de 500 metros. A Figura 3.6 mostra o detalhe de pontos gerados aleatoriamente no espaço urbano através do procedimento descrito acima. O ponto central da circunferência de raio de 500 metros destacada em amarelo será a origem dos trajetos cujos destinos são os outros pontos contidos na circunferência. A Figura 3.7 ilustra o traçado destes trajetos de veículos na malha viária. 


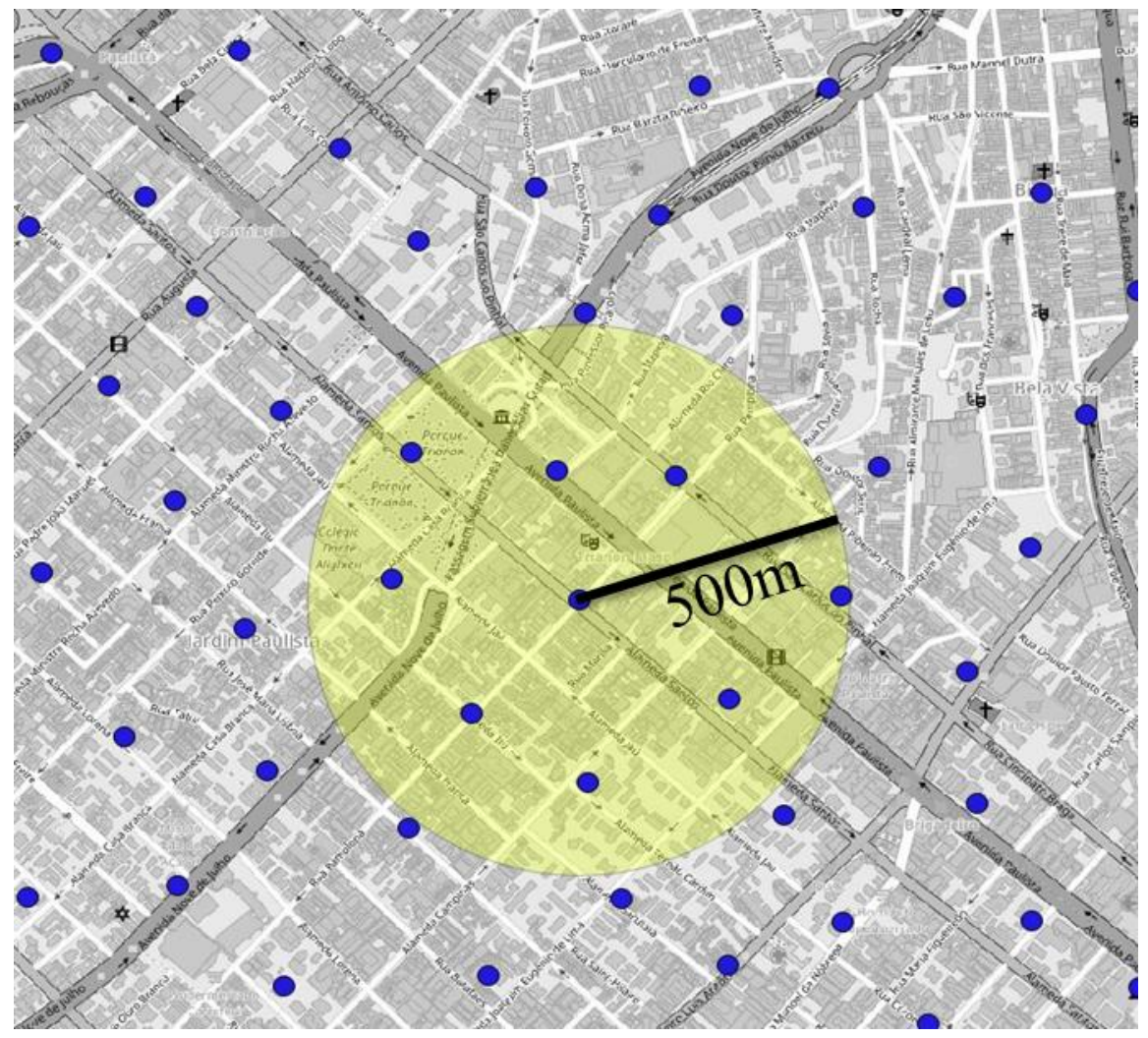

Figura 3.6: Exemplo de distância euclidiana máxima para cálculo de caminho entre pontos.

Este procedimento em que se estabelece uma distância linear máxima entre os locais de entrega é uma forma simples de considerar na análise apenas os deslocamentos entre pontos próximos entre si, como em uma espécie de aglomeração. Como mencionado anteriormente, foi também feita uma tentativa de agrupar os pontos de entrega através do algoritmo de "clusterização" k-means (MacQueen, 1967), que é detalhada no Anexo C. Esse algoritmo é muito utilizado em estudos estratégicos de logística para dividir um conjunto de pontos de entregas em agrupamentos compactos, que podem ser designados, cada um deles, a um veículo, bastando então determinar sequenciamento (ou roteiro) dos pontos. Foram efetuados testes de agrupamentos de pontos de entrega utilizando distâncias euclidianas e distâncias reais a fim de comparar a influência da oferta da malha viária, que leva em consideração barreiras geográficas e restrições ao tráfego (tais como vias de mão única, restrições de conversão e cruzamento) na configuração das aglomerações (clusters) resultantes. Visualmente, percebe-se pelos resultados que há muitas diferenças nos grupos formados utilizando o critério de distâncias reais dos grupos formados utilizando o critério de distâncias euclidianas. Porém, há uma limitação nesse tipo de abordagem, pois não é fornecida nenhuma forma quantitativa de 
avaliação dos resultados, já que a avaliação é feita somente pela observação dos grupos formados.

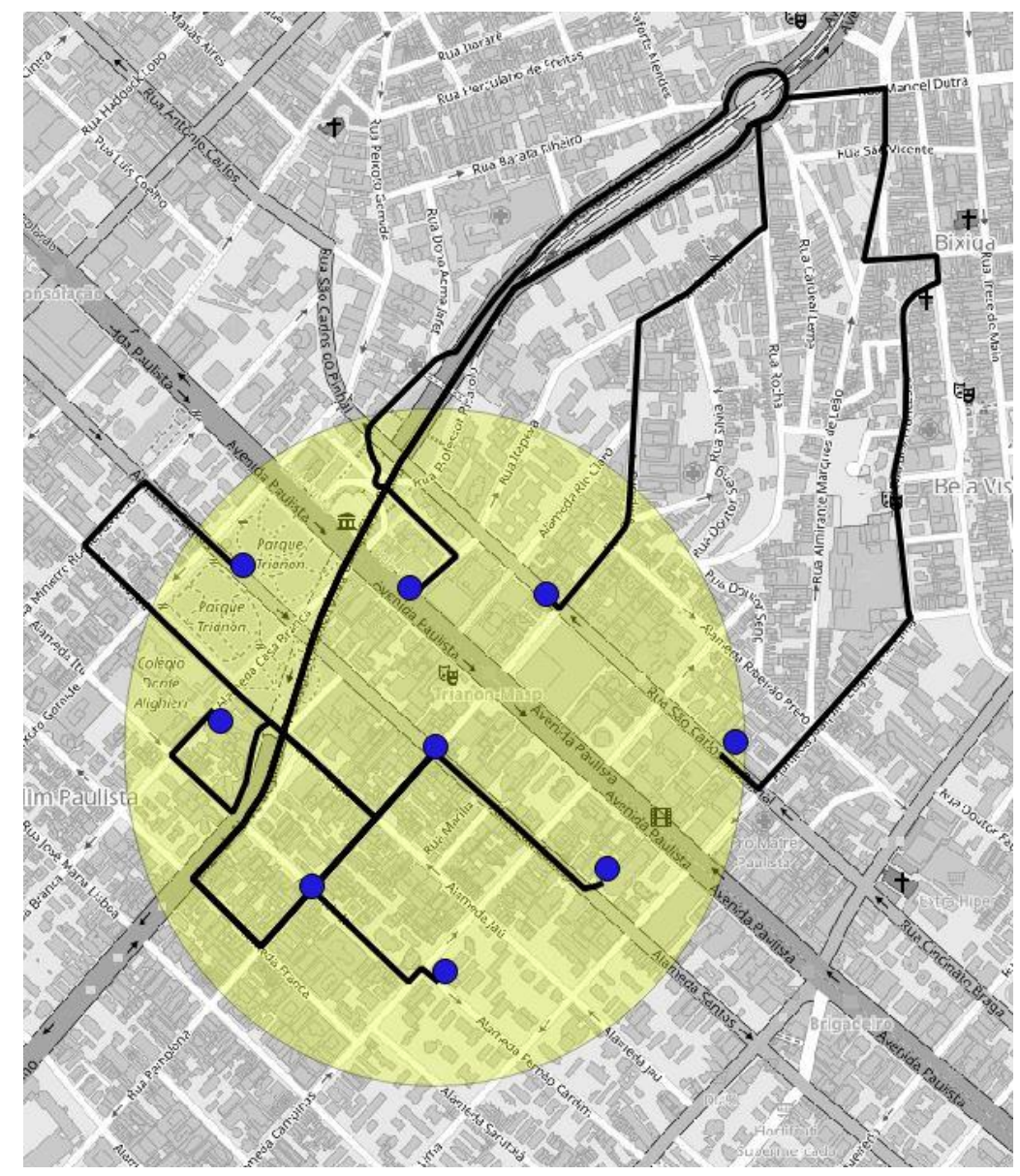

Figura 3.7: Representação de oito caminhos com origem no ponto central da circunferência.

Assim, essa alternativa foi descartada por não garantir a homogeneidade entre os grupos formados, e por exigir a computação completa da matriz de distâncias entre os pontos, exigindo uma maior capacidade de processamento, podendo até inviabilizar o método dependendo do número de pontos gerados aleatoriamente. Os resultados desta aplicação do algoritmo k-means estão no Anexo C.

Os trajetos em rede e suas respectivas distâncias são computados através da ferramenta Google Maps Directions API (Google Maps APIs, 2017), que recebe como dados de entrada as coordenadas geográficas do par de pontos de origem e de destino e o modo de transporte desejado (carro, bicicleta, a pé ou transporte público) para a realização do percurso, e retorna todos os parâmetros referentes ao trajeto em questão: distância percorrida, tempo de viagem e traçado. Vale ressaltar que é possível fornecer as coordenadas geográficas dos pontos gerados aleatoriamente 
mesmo que eles estejam distantes do espaço viário, pois a API identifica o trajeto que chega o mais próximo o possível dos locais exatos fornecidos.

Apesar da API do Google Maps apresentar a desvantagem de ter um limite diário de solicitações gratuitas, ela foi escolhida em detrimento de qualquer ferramenta de Open Street Map (OSM) para a obtenção das distâncias em rede devido à confiabilidade dos resultados que podem ser obtidos. Mais especificamente, o Anexo E apresenta a comparação de resultados de Índices de "Retilinidade" obtidos utilizando a base Open Street Map (OSM) e API do Google Maps (Google Maps APIs, 2017). Esses testes foram realizados a fim de identificar qual seria a melhor base de mapas digitais. O OSM é uma base de mapas aberta que é desenvolvida por uma comunidade voluntária de mapeadores. Sua principal vantagem é o acesso ilimitado, por ser uma base aberta, porém os resultados apresentados no Anexo $E$ indicam que existem falhas na atualização de dados, o que às vezes gera resultados muito diferentes dos obtidos por Google Maps. As bases do OSM não são necessariamente atualizadas quanto às restrições de conversão e mãos de direção das vias pois dependem de colaboradores voluntários. O registro incorreto das restrições de trânsito resulta em caminhos que na realidade são inviáveis ou são estimadas distâncias de percurso maiores do que as observadas na realidade, enviesando a análise. O Anexo E contém resultados de análises envolvendo caminhos computados com OSM e a comparação dos resultados com a API do Google Maps.

Retornando ao procedimento do método, as distâncias reais obtidas pela ferramenta do Google Maps são usadas para calcular os Índices de "Retilinidade", do inglês straightness centrality index. A aplicação deste índice é uma adaptação de aplicações da literatura (Ballou, 2002; Dill, 2004; Crucitti et al., 2006; Levinson e ElGeneidy, 2009; Levinson, 2012; Parthasarathi et al., 2013; Huang e Levinson, 2015), também denominado de fator de "circuicidade", do inglês circuity factor. O nome Índice de "Retilinidade" adotado neste trabalho é inspirado em Crucitti et al. (2006). A aplicação sugerida neste trabalho difere das revisadas na literatura por aplicar o índice em trajetos esperados na distribuição de carga.

Assim, dados dois pontos i e j, o Índice de "Retilinidade" (IR) consiste no cálculo do quociente (ou razão) entre a distância real em rede (para o transporte individual) entre i e j $\left(d_{i j}^{r}\right)$ e a distância euclidiana $\left(d_{i j}^{E u c l}\right)$, conforme mostrado na expressão 3.1 . 


$$
I R=\frac{d_{i j}^{r}}{d_{i j}^{E u c l}}
$$

O Índice de "Retilinidade" é uma forma de quantificar a eficiência de um caminho entre dois pontos utilizando distância como critério de impedância. A distância euclidiana representa a menor distância espacial possível entre dois pontos. Sendo assim, os valores do quociente $\left(d_{i j}^{r} / d_{i j}^{E u c l}\right)$ são sempre maiores ou iguais a 1 , sendo que quanto mais próximos a unidade, maior a "eficiência" (ou alternativamente menor a "impedância") da rede viária disponível para conectar os pontos em questão quanto as distâncias percorridas. Em outras palavras, quanto maior o percurso real em relação à distância em linha reta, menos "direto" e mais sinuoso é esse traçado, ocasionado tanto pela menor oferta da malha viária, obrigando a desvios, quanto por restrições ao movimento dos veículos tais como vias de mão única e proibição de conversões.

Definidas as distâncias reais, assim como as distâncias euclidianas correspondentes a cada percurso, basta calcular os quocientes que equivalem aos IRs para cada par de pontos. Deve-se destacar que cada par de pontos tem dois índices de "retilinidade". Isso se dá ao fato de que a distância real de i para j não é a mesma que a distância real de j para i, uma vez que é afetada por restrições de mão de direção de tráfego permitida nas vias e de conversão e cruzamentos permitidos.

Além disso, o Índice de "Retilinidade" pode ser calculado como uma média ponderada dos índices de diversos percursos em uma mesma região a fim de caracterizar um indicador de eficiência global da malha viária da região em questão. Este índice é denominado Índice de "Retilinidade" Médio (IRM). Para tanto, dado um conjunto com $n(0,1,2, \ldots, k, \ldots, n)$ observações que representam viagens em uma mesma região, caracterizadas por uma origem i, um destino j, distância euclidiana $\left(d_{k}^{E u c l}\right)$, distância real $\left(d_{k}^{r}\right)$ e Índice de "Retilinidade" $\left(I R_{k}\right)$, o Índice de "Retilinidade" médio da região pode ser calculado pela expressão 3.2.

$$
I R M=\frac{\sum_{k=0}^{n}\left(I R_{k} \times d_{k}^{E u c l}\right)}{\sum_{k=0}^{n} d_{k}^{E u c l}}=\frac{\sum_{k=0}^{n} d_{k}^{r}}{\sum_{k=0}^{n} d_{k}^{E u c l}}
$$

Foram conduzidos testes em três regiões da cidade de São Paulo com características de malhas viárias distintas a fim de verificar se os valores obtidos para o IRM seriam significantemente diferentes nas três regiões. Os resultados fornecem 
indícios de que é um bom indicador para quantificar as a dificuldade imposta pela malha viária disponível e pelas regras de trânsito na circulação de veículos em cada região e estão presentes no Anexo $B$.

É importante ressaltar que a distância euclidiana utilizada no quociente do IR não é a distância linear entre os pontos do conjunto inicial, pois como os pontos são gerados de maneira aleatória, os mesmos não estão necessariamente localizados sobre ou adjacentes na malha viária. Essa característica da base de dados não resulta um impasse para a aplicação da ferramenta do Google Maps que identifica a rota chegando o mais próximo o possível do local exato indicado, porém, devido à ordem de grandeza das distâncias estudadas neste método, torna-se necessário utilizar a distância euclidiana entre os pontos extremos do trajeto fornecido para não enviesar a interpretação dos índices calculados. O processo é simples e consiste em extrair as coordenadas geográficas (latitude e longitude) das extremidades do caminho fornecido pela API do Google Maps e, em seguida, calcular a distância euclidiana $\left(d_{i j}^{E u c l}\right)$ correspondente através da aproximação da fórmula de Haversine, que permite calcular a distância entre dois pontos em uma esfera (Robusto, 1957).

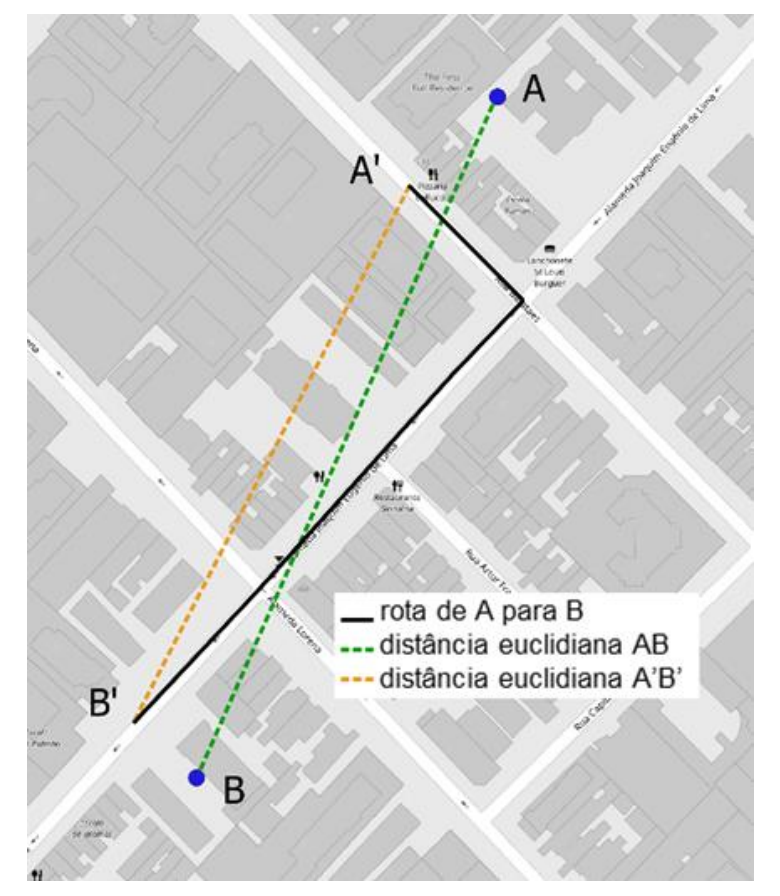

Figura 3.8: Exemplo de origem e destino com representação gráfica das distâncias.

A Figura 3.8 ilustra o conceito explicado acima de distância euclidiana utilizado no cálculo do IR; os pontos A e B são exemplos do conjunto aleatório utilizado na 
análise e estão localizados a certa distância do viário; os pontos A' e B' são os locais mais próximos com acesso à malha viária. A rota fornecida pelo Google Maps tem os pontos A' e B' em seus extremos e é com esses extremos que se determina a distância euclidiana, ilustrada na Figura 3.8 pelo tracejado laranja, e que é utilizada como denominador no cálculo do IR. Esse processo garante que os valores obtidos pela divisão entre distância real e euclidiana sejam sempre maiores ou iguais a um.

\subsubsection{Velocidades de Tráfego}

O objetivo desta etapa do método é avaliar a velocidade de tráfego $(\mathrm{km} / \mathrm{h})$ esperada para cada segmento de via contido na área estudada em determinados horários de um dia útil típico. Entende-se por segmentos de via os trechos entre interseções. Essa informação permite: (i) a elaboração de mapas temáticos para identificação dos trechos com velocidades críticas (inferiores a $10 \mathrm{~km} / \mathrm{h}$ ), a fim de serem evitados, (ii) o cálculo da velocidade média de circulação esperada na área estudada em determinado horário do dia, a fim de comparar os valores obtidos para horários diferentes ao longo do dia, e (iii) computar a porcentagem de quilômetros de vias em que se deve esperar velocidades de circulação críticas.

Para analisar a circulação local quanto aos tempos de viagem observados, selecionam-se horários ao longo do dia para se estimar a velocidade média dos deslocamentos. A Google Maps Directions API permite a realização de solicitações de rota definindo-se um horário de saída específico; o resultado é o trajeto de menor tempo previsto para aquele momento, segundo um modelo baseado em dados observados. Além das coordenadas da origem e do destino, deve-se adicionar à solicitação um valor para o horário de saída desejado no formato "epoch" (segundos transcorridos desde 01 de janeiro de 1970). Portanto, o usuário deve escolher uma data futura que represente um dia útil típico para assegurar não enviesar a interpretação dos dados previstos pelo Google Maps. Como há um limite diário de solicitações à API, sugere-se as solicitações sejam feitas apenas em alguns horários do dia, como por exemplo os horários de pico manhã e tarde de forma a representar períodos típicos que se deseja analisar.

O fato de o Google Maps possibilitar a estimativa dos tempos de viagem baseados em dados reais de tráfego observados é mais um motivo para a sua adoção neste método. Os tempos de viagem retornados pelo OSM são baseados em limites 
máximos de velocidade associados a categorias de vias, gerando valores extremamente subestimados para os tempos de deslocamento nas cidades, em que na prática é impossível trafegar próximo do limite máximo permitido devido ao volume de tráfego.

Nesta parte do método, pretende-se identificar velocidades médias de circulação em determinada área, ou até mesmo identificar trechos específicos do espaço viário em que o nível de ocupação histórico indique velocidades baixas. Para que seja possível este tipo de interpretação dos dados obtidos pelo Google Maps, é necessário identificar as coordenadas (latitude e longitude) das intersecções entre as vias, ou nós da rede, e a informação referente a conectividade entre as intersecções, em outras palavras, se há ligação viária direta entre as intersecções, ligação também conhecida como arco da rede. Os arcos da rede representam os segmentos da malha viária que se deseja identificar.

Portanto, o primeiro passo desta etapa é extração das informações da rede viária (nós e arcos) da área de estudo. Sugere-se o uso a biblioteca OSMnx (Boeing, G. 2017) em Python, pois com alguns comandos simples é possível extrair as informações desejadas do Open Street Map: uma lista com a informação de todos os arcos da rede viária contida em uma área fornecida pelo usuário definidos por número de identificação dos nós das extremidades, e uma lista com todos os nós da rede viária com um número de identificação e coordenadas geográficas. Para cada arco da rede, é feita uma solicitação de caminho para a API do Google Maps, utilizando como dados de entrada de origem e destino do caminho as coordenadas dos nós das extremidades do arco e o horário de saída desejado.

O resultado obtido do Google Maps consiste no tempo de viagem considerando o trânsito previsto para o horário de saída solicitado e a distância total da viagem. Note que para esta parte do método, a distância fornecida pela API deve coincidir com o comprimento do respectivo arco na base do Open Street Map. A biblioteca OSMnx possui um comando que retorna o comprimento dos arcos. Sendo assim, é possível comparar se o resultado do Google Maps é de fato correspondente ao segmento, ou arco, desejado.

Estipula-se que as distâncias obtidas apresentem no máximo 10\% de variação em relação ao comprimento do arco do Open Street Map para considerar que de fato 
o caminho fornecido pela API corresponde ao segmento desejado. Caso a distância não atenda o critério de variação máxima estabelecido, uma nova solicitação de caminho é feita à API, porém alternando a origem e o destino, ou seja, o nó que havia sido utilizado como origem passa a ser o destino e o nó que havia sido utilizado como destino passa a ser a origem. Esta segunda solicitação se faz necessária devido ao caráter direcional das vias. Em um trecho de via mão única, é possível trafegar em apenas um sentido, logo uma solicitação de rota cuja origem e cujo destino não coincidam com a mão de direção permitida resulta em um percurso que envolve outras vias, gerando um resultado de distância de trajeto maior do que o comprimento do arco em questão.

A distância obtida pela segunda solicitação à API deve ser novamente comparada com o comprimento do arco extraído do OSM. Caso a distância ainda seja incompatível de acordo com o critério de $10 \%$ de variação estabelecido, os resultados para o arco em questão devem ser descartados. Tais resultados ocorrem devido a incompatibilidades da base de OSM com a morfologia real das vias existentes ou por ajustes automáticos realizados pela API do Google Maps. Ainda assim, este método permite a obtenção de resultados coerentes para a maioria dos arcos da rede viária, não afetando a análise proposta.

O resultado do procedimento descrito acima é a obtenção do tempo de viagem esperado para um determinado horário de saída para cada trecho, ou arco, da rede viária estudada. Como o comprimento de tais trechos são conhecidos, é possível computar a velocidade média de percurso para cada trecho, calculando a razão entre comprimento do arco $(\mathrm{km})$ e tempo de viagem estimado (h). Além disso, é possível calcular a velocidade média de circulação para a área, basta calcular a razão entre a soma dos comprimentos de todos os arcos da rede viária e a soma de todos os tempos estimados.

\subsubsection{Modos Não Motorizados}

Como a distribuição de carga urbana de última milha não precisa ser feita exclusivamente por modo motorizado, é importante estudar a circulação local para outros modos de transporte: bicicleta e a pé. Como mencionado anteriormente, esses modos seguem percurso respeitando diferentes regras e restrições de circulação e trânsito. O objetivo desta etapa é analisar a eficiência da rede viária disponível para 
deslocamentos não-motorizados, para que tais modos sejam comparados quantitativamente com o modo motorizado tradicional e seja viável estimar possíveis ganhos de eficiência (menores distâncias percorridas) no uso de um em detrimento do outro.

A Figura 3.9 ilustra um exemplo de como os modos de transporte modificam o resultado dos trajetos entre origem e destino. Percebe-se que o trajeto a pé utiliza caminhos por dentro de um parque, gerando a menor distância percorrida dentre os três modos.

Para analisar a eficiência dos trajetos feitos de bicicleta ou a pé, é proposto o mesmo procedimento já apresentado para modo motorizado: o Índice de "Retilinidade". A obtenção do IR para bicicleta e a pé é feita de maneira análoga a descrita anteriormente, com a diferença de que deve ser adicionado um novo parâmetro à solicitação feita à API do Google Maps. Além das coordenadas geográficas de origem e destino, nesta etapa adiciona-se a escolha do modo de transporte: bicycling para bicicleta ou walking para a pé. Para modos motorizados não há a necessidade de especificar o modo de transporte, pois a API considera "carro" o modo padrão para a elaboração dos percursos em rede. Com a especificação de um modo diferente do padrão, o Google Maps retorna os caminhos mínimos compatíveis com o modo em questão, ou seja, levando em consideração a disponibilidade de espaço viário adequado (calçadas e ciclofaixas, por exemplo) e as respectivas regras de trânsito que devem ser respeitadas.

A possibilidade do uso de meios de transporte não motorizados reforça a necessidade de se estabelecer uma distância linear máxima entre origem e destino para a computação dos caminhos em rede, pois caminhar ou pedalar exigem esforço físico dos entregadores e tais limitações de esforço impedem que longos trajetos sejam feitos por meios não motorizados. Na proposta aqui apresentada são consideradas distâncias lineares máximas de $1 \mathrm{~km}$ para rotas feitas a pé e de $3 \mathrm{~km}$ para rotas feitas de bicicleta. 


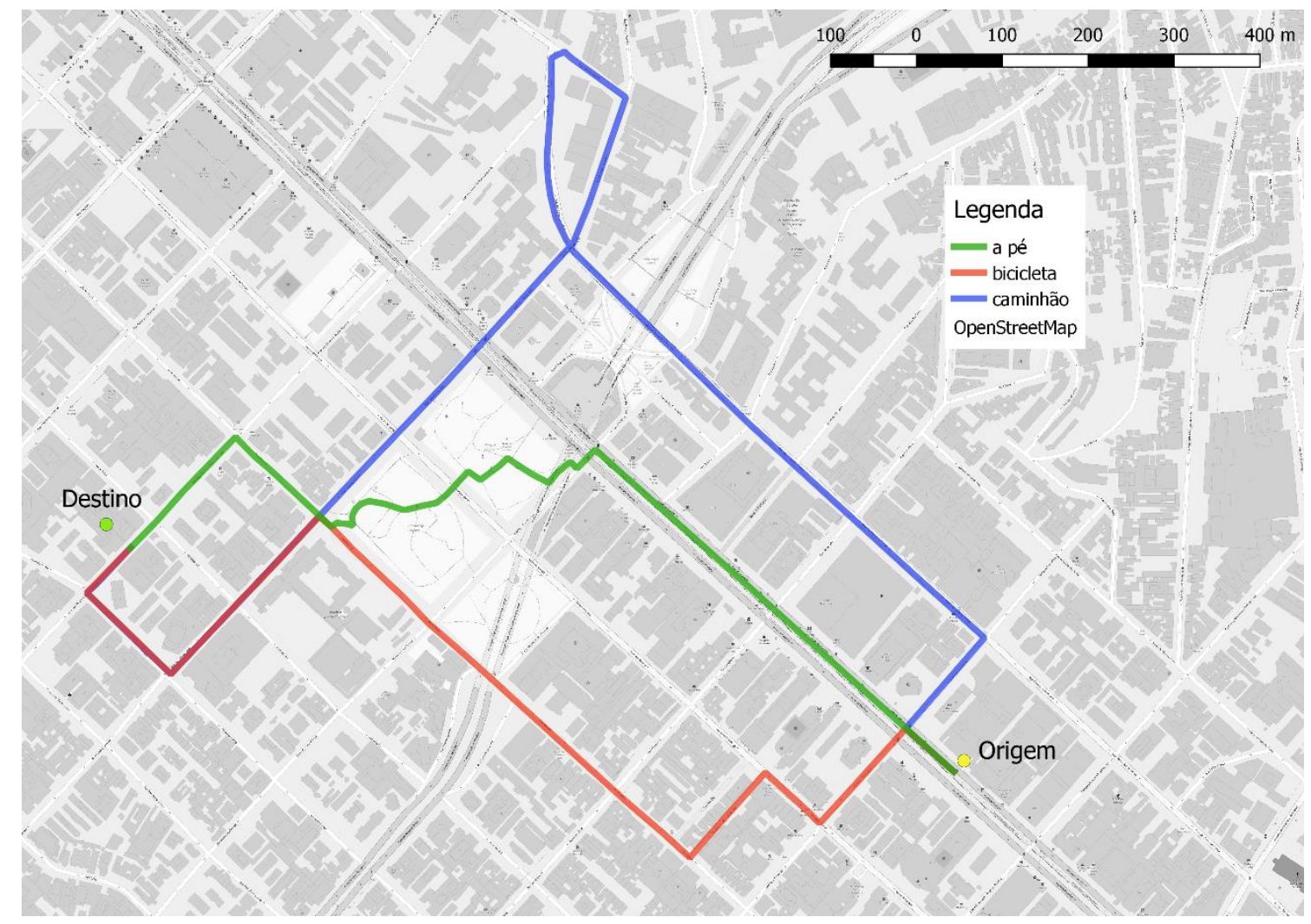

Figura 3.9: Possibilidades de caminhos entre dois pontos variando o modo de transporte.

Outro fator que limita a viabilidade de uso de meios de transporte não motorizados por afetar o esforço físico empregado pelos entregadores é a topografia da área de entrega. Portanto, este método também contempla a análise das declividades das vias contidas na área de estudo. Pretende-se determinar a proporção de vias cujas declividades são adequadas para modos não motorizados e elaborar mapas temáticos para a visualização da topografia do local, a fim de identificar se a área analisada está apta para o uso de meios de transporte não motorizados.

Segundo Broach et al. (2012), ciclistas tendem a modificar suas rotas de viagem para evitar declividades maiores que $2 \%$; ou seja, os ciclistas estão dispostos a enfrentar maiores distâncias e tempos de viagem em detrimento do desconforto físico por enfrentar declividades superiores a $2 \%$. Já para pedestres, a declividade máxima confortável para se caminhar qualquer distância é 5\% (Hopper, 2012). Baseado nessas diretrizes de conforto, consideraram-se três faixas de declividades para a análise da topografia da área de estudo: entre 0 e $2 \%$, cenário ideal para meios não motorizados; entre 2 e 5\%, confortável para pedestres e limitante para ciclistas; e maior que $5 \%$, não recomendada para transporte não motorizado. 
O objetivo desta etapa é atrelar a declividade a cada segmento da malha viária contida na área de estudo, de maneira análoga como foi feito com as velocidades de tráfego. Portanto, o primeiro passo é obter as informações da rede através da biblioteca OSMnx em Python. Com a informação das coordenadas geográficas dos nós, é possível solicitar a elevação de cada nó através da Google Maps Elevation API (Google Maps APIs, 2018). Esta API retorna a elevação de um ponto, dadas latitude e longitude. Sendo assim, adiciona-se a informação da elevação de cada nó da rede, e como a biblioteca OSMnx também fornece informações sobre a conectividade da rede, é possível calcular a declividade de cada segmento de via.

O resultado da etapa de análise da topografia do método é um arquivo $c s v$, em que cada observação é um arco da rede viária estudada, com informações das coordenadas geográficas das suas extremidades, seu comprimento e a sua declividade.

\subsection{Acesso à Área de Entrega}

A próxima etapa do processo consiste em verificar o Índice de "Retilinidade" dos trajetos de acesso e regresso à área estudada. Pretende-se avaliar a eficiência da oferta viária em conectar regiões centrais da cidade, onde se concentram as demandas de entrega, com a periferia da região metropolitana, onde se encontram os CDs e armazéns. O objetivo desta etapa do método é calcular o IR para os trajetos de acesso/regresso do distrito de entrega e avaliar o efeito do nível de ocupação viária nos tempos de viagem.

Em uma operação real de entregas, é feita a roteirização dos pontos de entrega através de algum algoritmo para o VRP ou da implementação de alguma heurística, e assim é possível identificar o trecho de acesso ao distrito de entrega como o primeiro trecho da rota, ou seja, que tem origem no centro de distribuição e destino no primeiro local de atendimento. De forma análoga, é identificado o trecho de regresso ao centro de distribuição, ou seja, o último trecho da rota. No Anexo D são apresentados resultados da análise de acesso à área de entrega utilizando roteirização, porém, essa abordagem limita a aplicação do método, pois exigiria uma grande capacidade de processamento para a ordem de grandeza de número de pontos que se exige. Sendo 
assim, a roteirização foi descartada e a proposta é que os trajetos de acesso à área de estudo e regresso ao centro de distribuição sejam identificados como os trajetos mais curtos entre o centro de distribuição e a área, e vice-versa, como forma de simplificação.

Com a localização dos potenciais locais de centro de distribuição em mão, através da Google Maps Directions API, computa-se o trajeto com origem nesses locais até os pontos gerados aleatoriamente dentro da região estudada. Seleciona-se o trajeto com menor tempo ou com menor distância como acesso do CD ao distrito de entrega, ou seja, seleciona-se o ponto que foi usado de destino para o trajeto de menor tempo ou menor distância. O mesmo procedimento deve ser feito para o retorno ao centro de distribuição, computando-se os trajetos com origem nos pontos da região estudada e destino nos potenciais locais de centro de distribuição. Desta maneira, para cada local potencial de centro distribuição são atribuídos dois pontos do conjunto de pontos aleatórios, um que funciona como destino no caminho de ida e outro que funciona como origem na volta, ambos escolhidos através do critério de menor distância ou menor tempo e, assim, o IR de cada trajeto pode ser facilmente calculado através dos resultados extraídos da API.

Assim, como foi discutido anteriormente na seção 3.2, os Índices de "Retilinidade" calculados refletem a eficiência da malha viária disponível em conectar pontos de origem e destino utilizando distância como critério de impedância, porém o tempo de viagem também é um fator importante a ser considerado, e para a análise dos tempos de viagem, propõe-se o cálculo das velocidades médias de deslocamento.

Sugere-se a criação de perfis de velocidade ao longo do dia para os trajetos estudados. Os tempos de viagens para o cálculo das velocidades médias são obtidos através de solicitações a Google Maps Directions API, especificando o horário de saída desejado. Como o número de trajetos na análise de acesso à área é baixo comparado com a análise da circulação local, sugere-se que se solicitem tempos de viagem estimados para as 24 horas do dia. Dessa maneira, para cada local de centro de distribuição são atribuídos dois trajetos e para cada trajeto são realizadas 24 solicitações à API do Google Maps, incrementando em 1 hora o horário de saída desejado a cada solicitação. No fim deste processo, é possível determinar a 
velocidade média esperada para cada trajeto ao longo de 24 horas para a elaboração dos perfis de velocidade. 


\section{RESULTADOS}

Este capítulo apresenta os resultados da aplicação do método descrito no Capítulo 3. Os resultados estão divididos em duas seções, a primeira (seção 4.1) contempla os resultados obtidos para o procedimento descrito na seção 3.2, a parte de circulação local da distribuição de última milha, e a segunda seção (seção 4.2) apresenta os resultados para o procedimento descrito na seção 3.3, a parte do acesso/regresso ao distrito de entrega (line-haul). Por fim, a seção 4.3 apresenta os comentários gerais dos resultados obtidos.

Para a análise da circulação local, foram escolhidas seis cidades: São Paulo, Rio de Janeiro, Bogotá, Nova lorque, Londres e São Francisco. Pretende-se observar os valores de IR obtidos para cada cidade, tanto para veículos motorizados quanto não-motorizados, a fim de identificar se há diferenças nos valores obtidos em cada cidade, se em alguma das cidades espera-se maiores distâncias de percurso e se existem locais específicos onde as distâncias de percurso são maiores devido a barreiras geográficas. Ainda, pretende-se observar as velocidades de tráfego esperadas nas seis cidades em quatro horários do dia diferentes (1h, $8 \mathrm{~h}, 13 \mathrm{~h}$ e 18h), a fim de calcular a velocidade média de tráfego em cada horário, se existem vias específicas que apresentam velocidades de tráfego mais baixas, se as velocidades esperadas variam ao longo do dia e em qual cidade espera-se velocidades de tráfego mais baixas. Por fim, deseja-se investigar se as características das malhas viárias das cidades influenciam nos valores obtidos para IR e velocidade e para tal calcula-se a correlação entre os valores de IR e velocidade obtidos com as métricas que caracterizam a malha viária (densidade de vias, extensão média do segmento de via, densidade de interseções e proporção de extensão de vias de mão única).

Para o acesso e regresso ao distrito de entrega, analisou-se apenas São Paulo, devido à familiaridade com os locais que concentram instalações logísticas (CDs, armazéns, etc.) na região metropolitana paulista. Foram apontados quatro locais cada um a margem de uma rodovia diferente que dá o acesso à capital, são elas: Dutra, Castelo Branco, Anhanguera e Raposo Tavares. O objetivo desta análise é calcular o IR de cada um dos quatro locais até o distrito de entrega e apresentar os perfis de velocidade esperadas ao longo do dia tanto para o acesso ao distrito de entrega, 
quanto para o regresso ao CD, a fim de identificar as variações de velocidades ao longo do dia e se alguma rodovia apresenta piores condições de tráfego (menor velocidade esperada).

\subsection{Circulação Local}

\subsubsection{Dados de Entrada}

Foram analisadas seis áreas urbanas de seis municípios diferentes: São Paulo, Rio de Janeiro, Bogotá, Nova lorque, Londres e São Francisco. Estas cidades foram escolhidas devido a familiaridade da autora deste trabalho com as mesmas, o que possibilitou a definição de áreas centrais onde se concentram as atividades econômicas. Além disso, as cidades foram escolhidas pela diversidade que apresentam na configuração da malha viária, por exemplo, Nova lorque, Bogotá e São Francisco são cidades planejadas que apresentam malha viária quadricular, já São Paulo, Rio de Janeiro e Londres apresentam vias curvas e que não se encontram necessariamente em ângulos retos devido ao histórico de desenvolvimento das cidades e a topografia dos locais.

As áreas escolhidas são regiões centrais das cidades, em que estão presentes polos de atividades econômicas. Para todos os municípios com exceção de Londres, as áreas foram definidas por polígonos criados pelo usuário em um software GIS, seguindo o procedimento descrito na seção 3.1. Procurou-se delimitar regiões em cada cidade que concentrassem atividades comerciais, seguindo a recomendação de Merchan et al. (2015) de que maior complexidade de operações de carga urbanas costuma ser concentradas em locais específicos da cidade como distritos comerciais centrais. No caso de Londres, foi obtido um shapefile da zona de pedágio urbano, chamada Congestion Charge Zone (Pope, 2017), pois essa área já delimita a região central de Londres que se deseja analisar e por estar em um shapefile elimina a necessidade da criação de um polígono pelo usuário.

Na sequência, foram gerados pontos aleatórios com densidade aproximada de 15 pontos $/ \mathrm{km}^{2}$ e $150 \mathrm{~m}$ de distância mínima entre si. As Figuras 4.1 a 4.6 a seguir contém mapas com as áreas analisadas e os pontos gerados e a Tabela 4.1 os valores das áreas e número de pontos gerados para cada cidade. 
Tabela 4.1: Valores das Áreas e número de pontos gerados para cada cidade.

\begin{tabular}{cccc}
\hline & Área $\left(\mathrm{km}^{2}\right)$ & Número de Pontos & Densidade $\left(\right.$ pontos $\left./ \mathrm{km}^{2}\right)$ \\
\hline São Paulo & 22,42 & 335 & 14,94 \\
Rio de Janeiro & 19,67 & 300 & 15,25 \\
Bogotá & 22,00 & 334 & 15,18 \\
Nova lorque & 21,88 & 325 & 14,85 \\
Londres & 21,43 & 314 & 14,65 \\
São Francisco & 13,44 & 199 & 14,80 \\
\hline
\end{tabular}

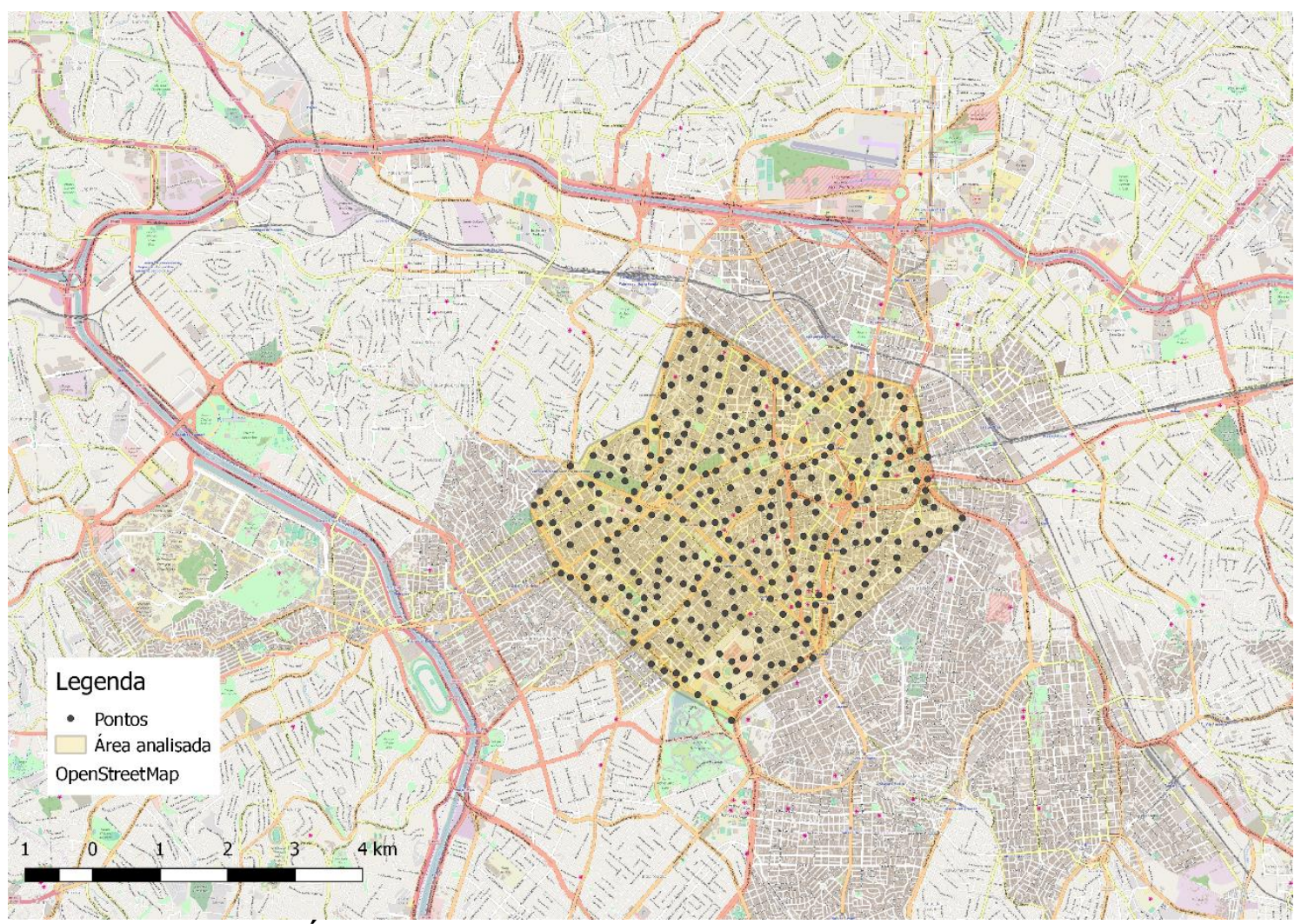

Figura 4.1: Área selecionada para análise na cidade de São Paulo. 


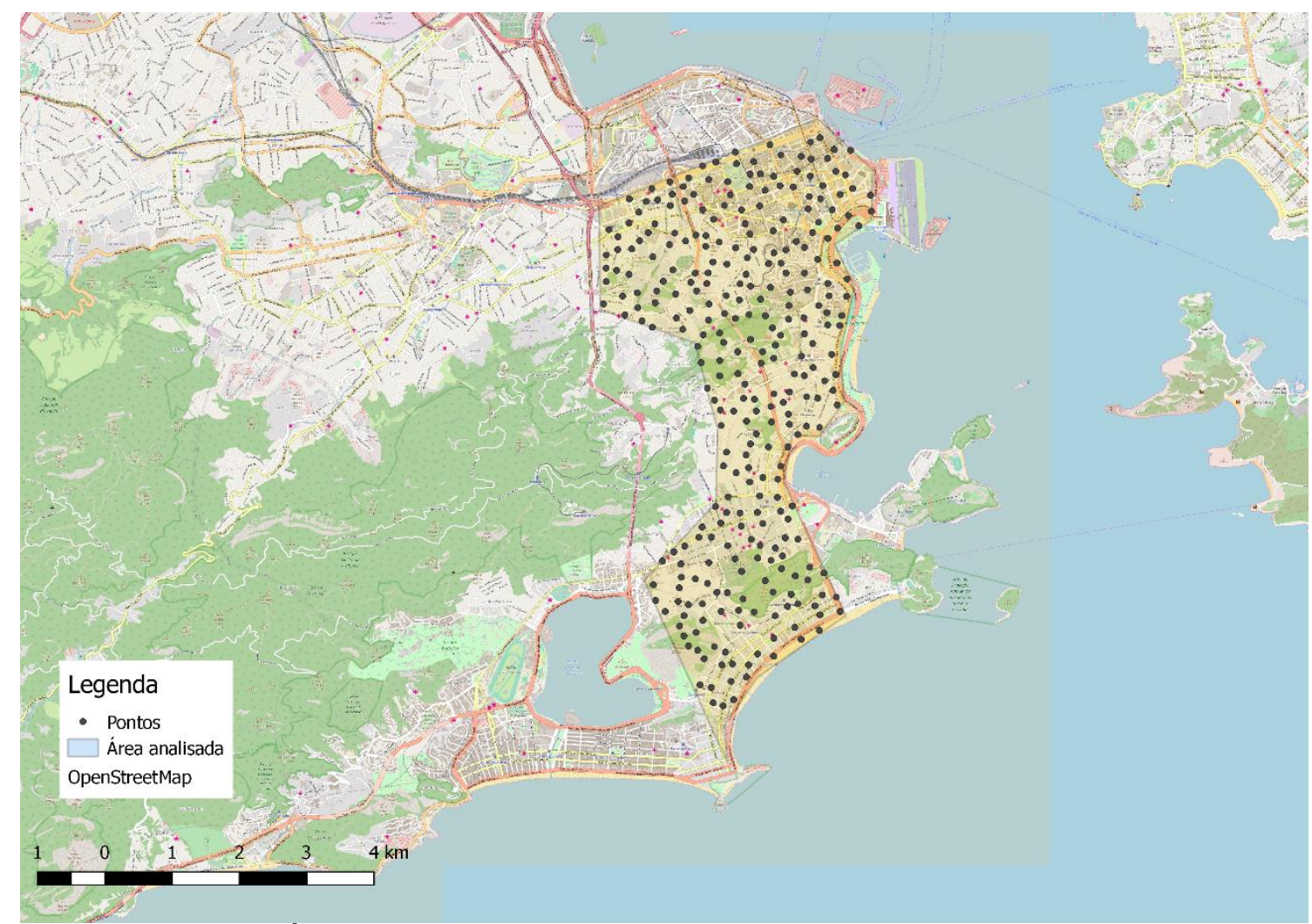

Figura 4.2: Área selecionada para análise na cidade do Rio de Janeiro.

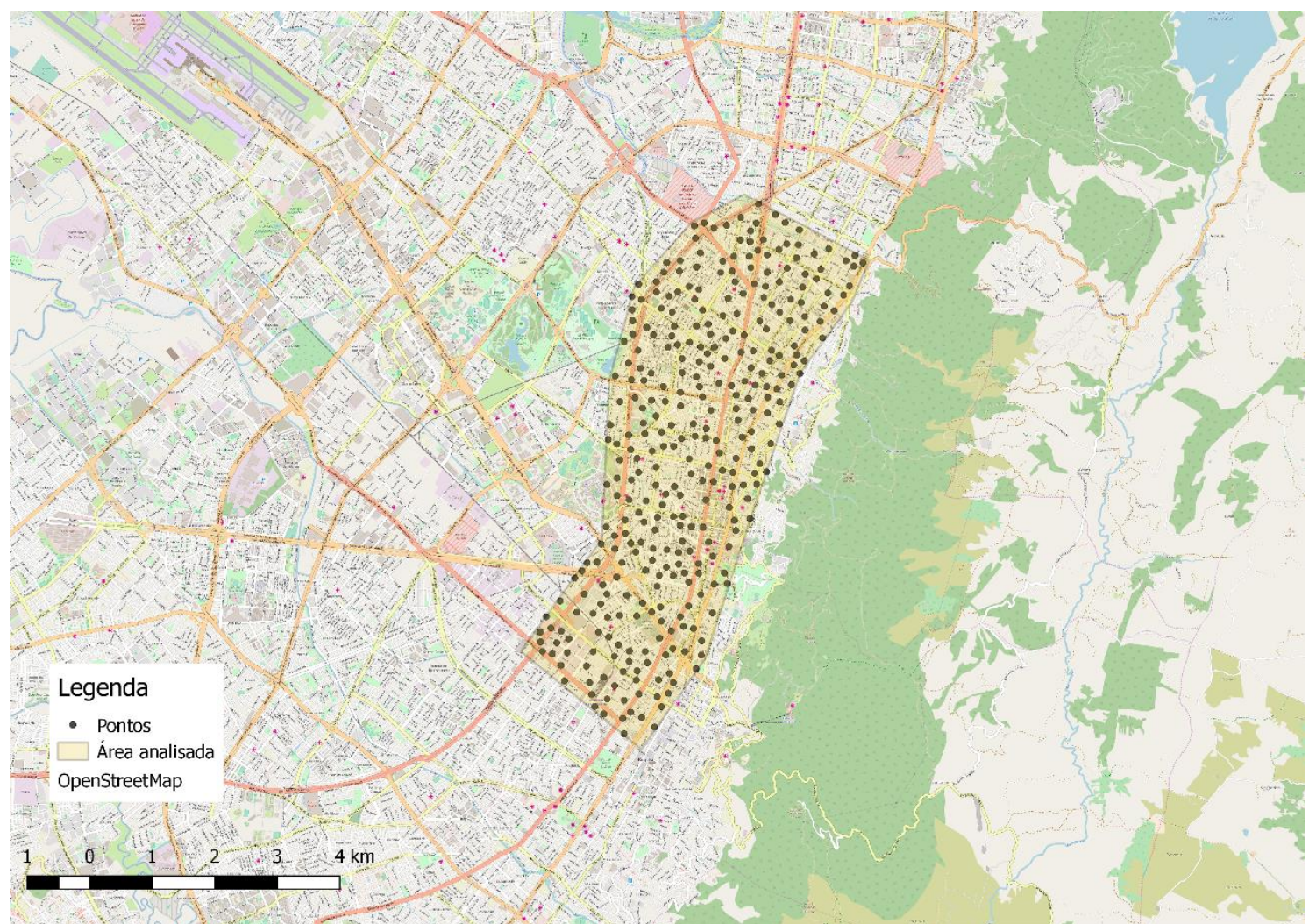

Figura 4.3: Área selecionada para análise na cidade de Bogotá. 


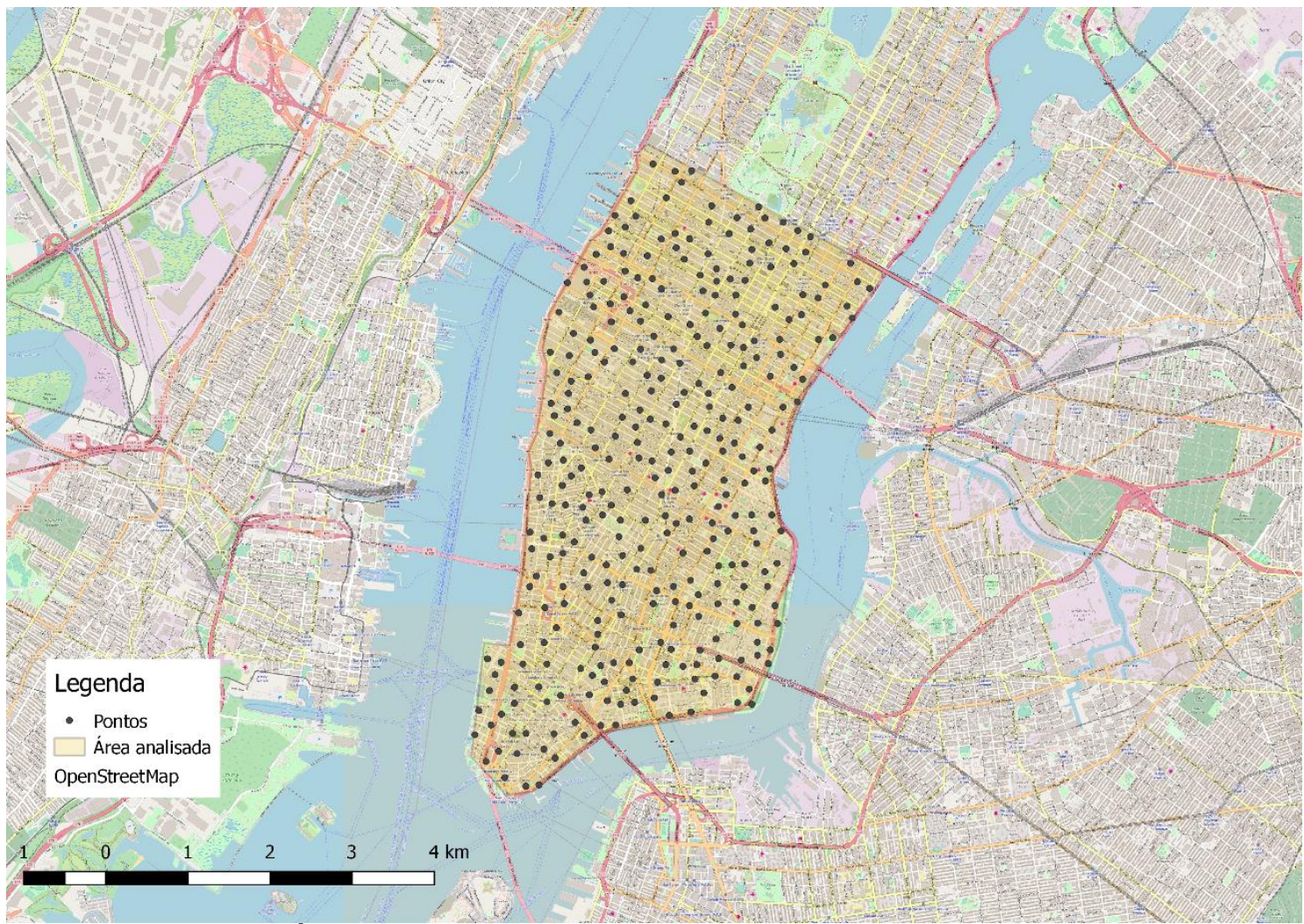

Figura 4.4: Área selecionada para análise na cidade de Nova lorque.

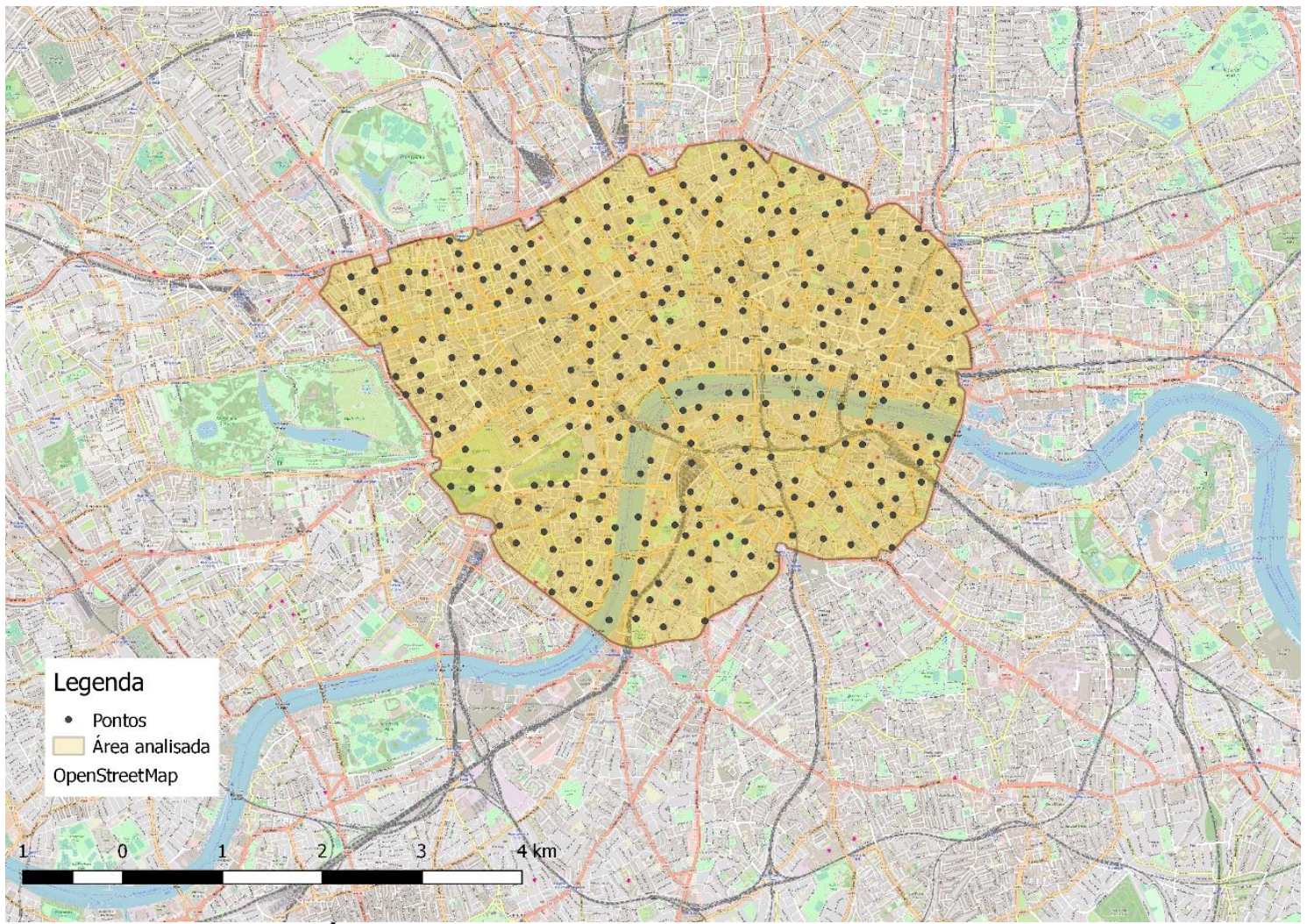

Figura 4.5: Área selecionada para análise na cidade de Londres. 


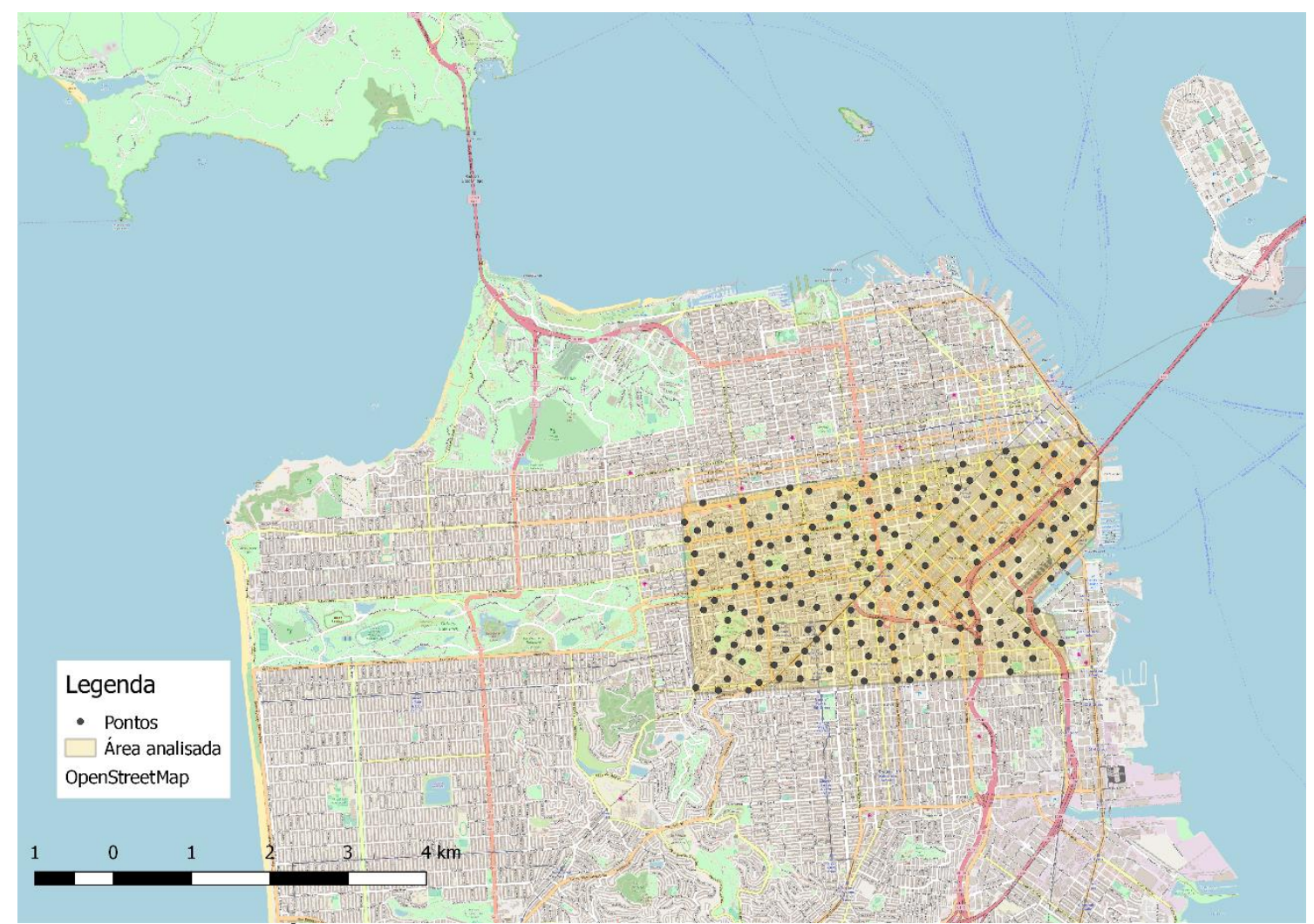

Figura 4.6: Área selecionada para análise na cidade de São Francisco.

Também foram extraídas métricas das redes viárias contidas nas áreas selecionadas. Através do OSM foram obtidos: extensão total das vias $(m)$, extensão média dos segmentos de via $(\mathrm{m})$, número de interseções e extensão total de vias de mão única $(\mathrm{m})$. Com esses valores, mais as áreas, foram calculados os seguintes indicadores: densidade de vias $\left(\mathrm{m} / \mathrm{km}^{2}\right)$, densidade de interseções $\left(\mathrm{km}^{-2}\right)$ e proporção de extensão de vias de mão única $(\mathrm{m} / \mathrm{m})$. Os resultados para cada cidade estão apresentados na Tabela 4.2 e a correlação entre as métricas na Tabela 4.3.

Percebe-se na Tabela 4.2 que Londres apresenta o maior valor de densidade de interseções e o menor valor de extensão média do segmento de via, enquanto o contrário é observado no Rio de Janeiro, que apresenta o menor valor de densidade de interseções e o maior valor de extensão média do segmento de via. Esta constatação é esperada, pois é intuitivo pensar que um local com menos interseções terá maiores extensões de segmento de via, justamente porque o segmento de via é definido por ser um trecho sem interseções. $O$ valor de correlação obtido entre as vaiáveis "extensão média do segmento de via" e "densidade de interseções" na Tabela 4.3 corrobora a constatação, pois o módulo é um valor próximo da unidade $(0,9531)$ e é um valor negativo, o que indica que as variáveis são inversamente proporcionais. 
Tabela 4.2: Métricas das redes viárias.

\begin{tabular}{ccccccc}
\hline & $\begin{array}{c}\text { São } \\
\text { Paulo }\end{array}$ & $\begin{array}{c}\text { Rio de } \\
\text { Janeiro }\end{array}$ & Bogotá & $\begin{array}{c}\text { Nova } \\
\text { lorque }\end{array}$ & Londres & $\begin{array}{c}\text { São } \\
\text { Francisco }\end{array}$ \\
\hline $\begin{array}{c}\text { Densidade } \\
\text { de vias } \\
\left(\mathrm{m} / \mathrm{km}^{2}\right)\end{array}$ & 17615,92 & 13228,52 & 22802,68 & 19039,90 & 17115,45 & 17989,21 \\
$\begin{array}{c}\text { Extensão } \\
\text { média do }\end{array}$ & 107,12 & 120,58 & 84,09 & 112,26 & 68,61 & 113,19 \\
$\begin{array}{c}\text { segmento de } \\
\text { via (m) }\end{array}$ & & & & & & \\
$\begin{array}{c}\text { Densidade } \\
\text { de }\end{array}$ & 99,02 & 66,85 & 158,41 & 93,19 & 153,10 & 90,10 \\
$\begin{array}{c}\text { interseções } \\
\left(\mathrm{km}{ }^{-2}\right)\end{array}$ & & & & & & \\
$\begin{array}{c}\text { Proporção de } \\
\text { extensão de } \\
\text { vias de mão } \\
\text { única }(\mathrm{m} / \mathrm{m})\end{array}$ & 0,79 & 0,73 & 0,76 & 0,86 & 0,44 & 0,51 \\
\hline
\end{tabular}

Tabela 4.3: Correlação entre as métricas das redes viárias.

\begin{tabular}{|c|c|c|c|c|}
\hline & $\begin{array}{l}\text { Densidade } \\
\text { de vias } \\
\left(\mathrm{m} / \mathrm{km}^{2}\right)\end{array}$ & $\begin{array}{c}\text { Extensão } \\
\text { média do } \\
\text { segmento de } \\
\text { via }(m)\end{array}$ & $\begin{array}{c}\text { Densidade } \\
\text { de } \\
\text { interseções } \\
\left(\mathrm{km}^{-2}\right)\end{array}$ & $\begin{array}{c}\text { Proporção } \\
\text { de extensão } \\
\text { de vias de } \\
\text { mão única } \\
(\mathrm{m} / \mathrm{m})\end{array}$ \\
\hline $\begin{array}{l}\text { Densidade de } \\
\text { vias }\left(\mathrm{m} / \mathrm{km}^{2}\right)\end{array}$ & 1,0000 & $-0,4387$ & 0,6759 & 0,1952 \\
\hline $\begin{array}{l}\text { Extensão } \\
\text { média do } \\
\text { segmento de } \\
\text { via }(\mathrm{m})\end{array}$ & & 1,0000 & $-0,9531$ & 0,4762 \\
\hline $\begin{array}{l}\text { Densidade de } \\
\text { interseções } \\
\left(\mathrm{km}^{-2}\right)\end{array}$ & & & 1,0000 & $-0,3060$ \\
\hline $\begin{array}{l}\text { Proporção de } \\
\text { extensão de } \\
\text { vias de mão } \\
\text { única }(\mathrm{m} / \mathrm{m})\end{array}$ & & & & 1,0000 \\
\hline
\end{tabular}


A segundo valor de correlação mais alto observado na Tabela 4.3 é entre as variáveis "densidade de vias" e "densidade de interseções" $(0,6759)$, o que também é esperado, pois faz sentido pensar que um local com mais extensão de vias esteja sujeito a ter mais interseções também. A variável "proporção de extensão de vias de mão única" não apresenta alta correlação com nenhuma das outras variáveis, o que também tem coerência já que esta é a única das variáveis que não está ligada a estrutura da rede e sim com regras de trânsito.

As Figuras 4.7 a 4.12 trazem a representação gráfica da rede viária extraída do OSM, em que os arcos estão coloridos de acordo com as restrições de direção da via. Vermelho representa as vias de mão única e azul, as vias de mão dupla. Pelas Figuras 4.7 a 4.12 pode-se observar a origem das métricas da Tabela 4.2, em especial a "proporção de extensão de vias de mão única", por exemplo, Nova lorque (Figura 4.10) apresenta uma predominância notável de segmentos coloridos de vermelho e é a cidade com maior proporção de extensão de vias de mão única, já Londres (Figura 4.11) que é a cidade com menor proporção de extensão de vias de mão única apresenta mais segmentos coloridos de azul. Além disso, também é possível observar a configuração espacial das malhas viárias das cidades e se apresentam forma predominantemente quadricular (padrão em grade, ou grid-like, do inglês), que é o caso de Bogotá (Figura 4.9), Nova lorque (Figura 4.10) e São Francisco (Figura 4.12). 


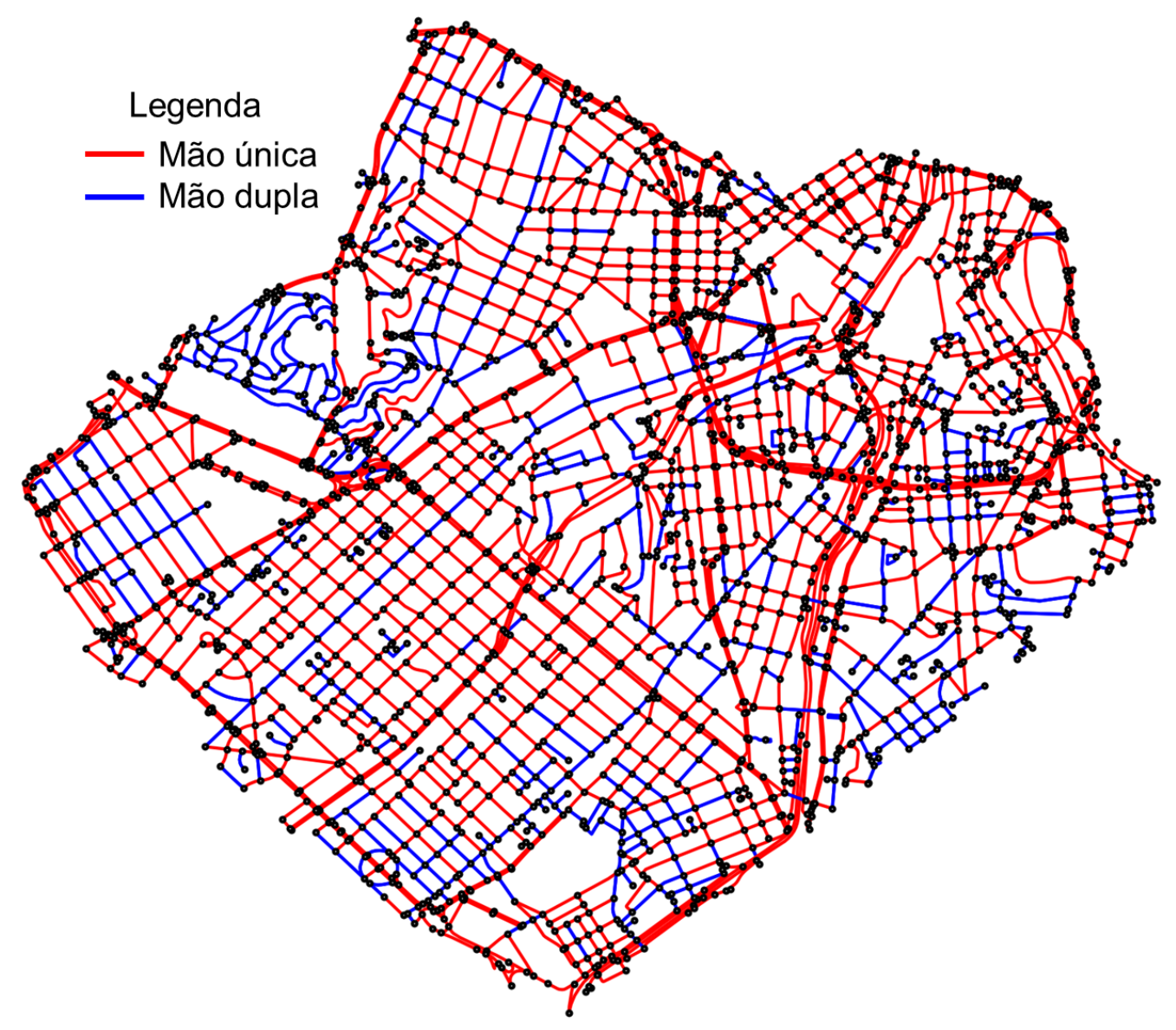

Figura 4.7: Rede viária contida na área analisada em São Paulo. 


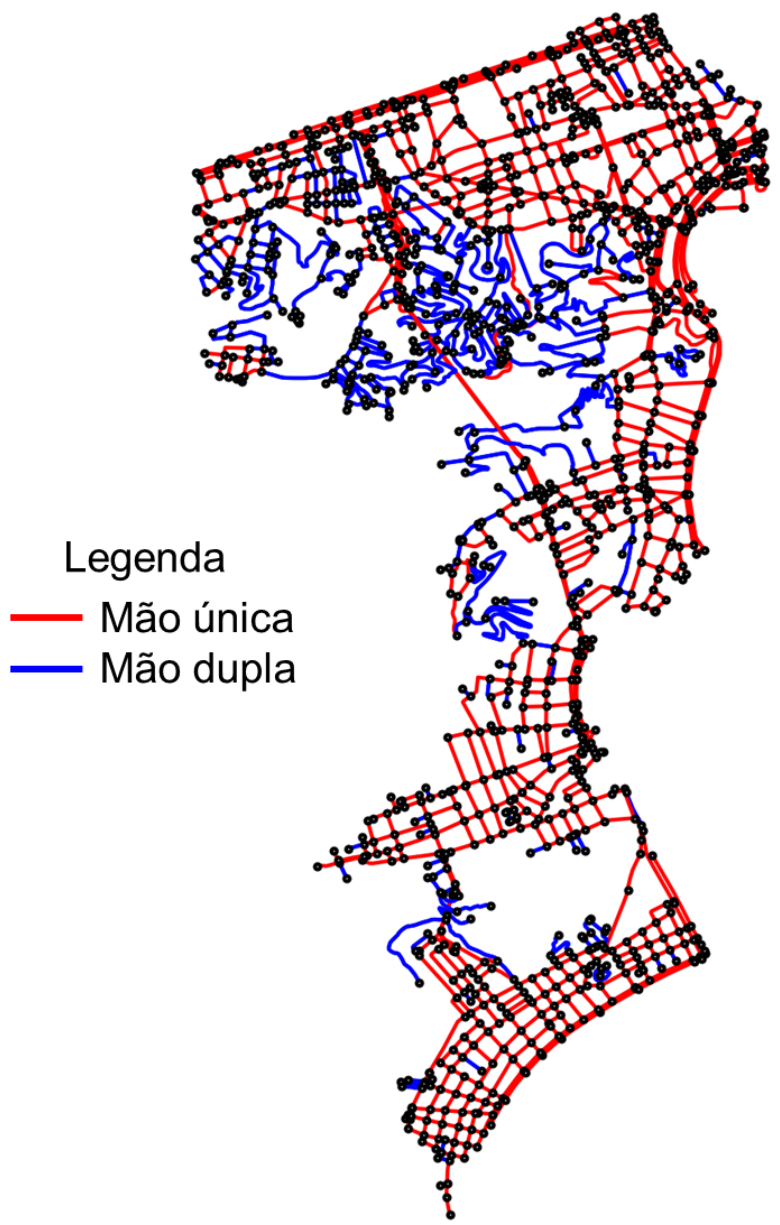

Figura 4.8: Rede viária contida na área analisada no Rio de Janeiro. 


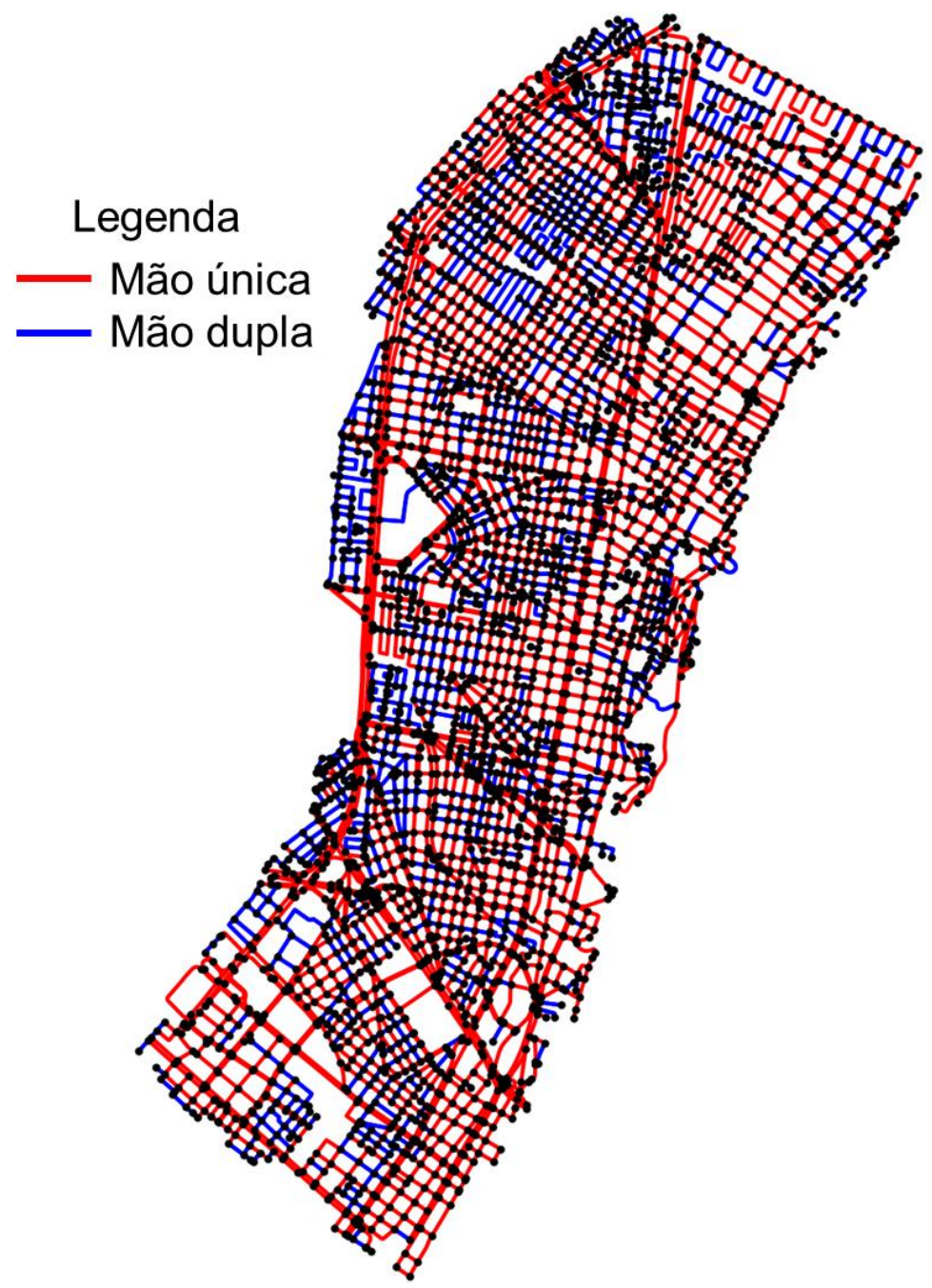

Figura 4.9: Rede viária contida na área analisada em Bogotá. 


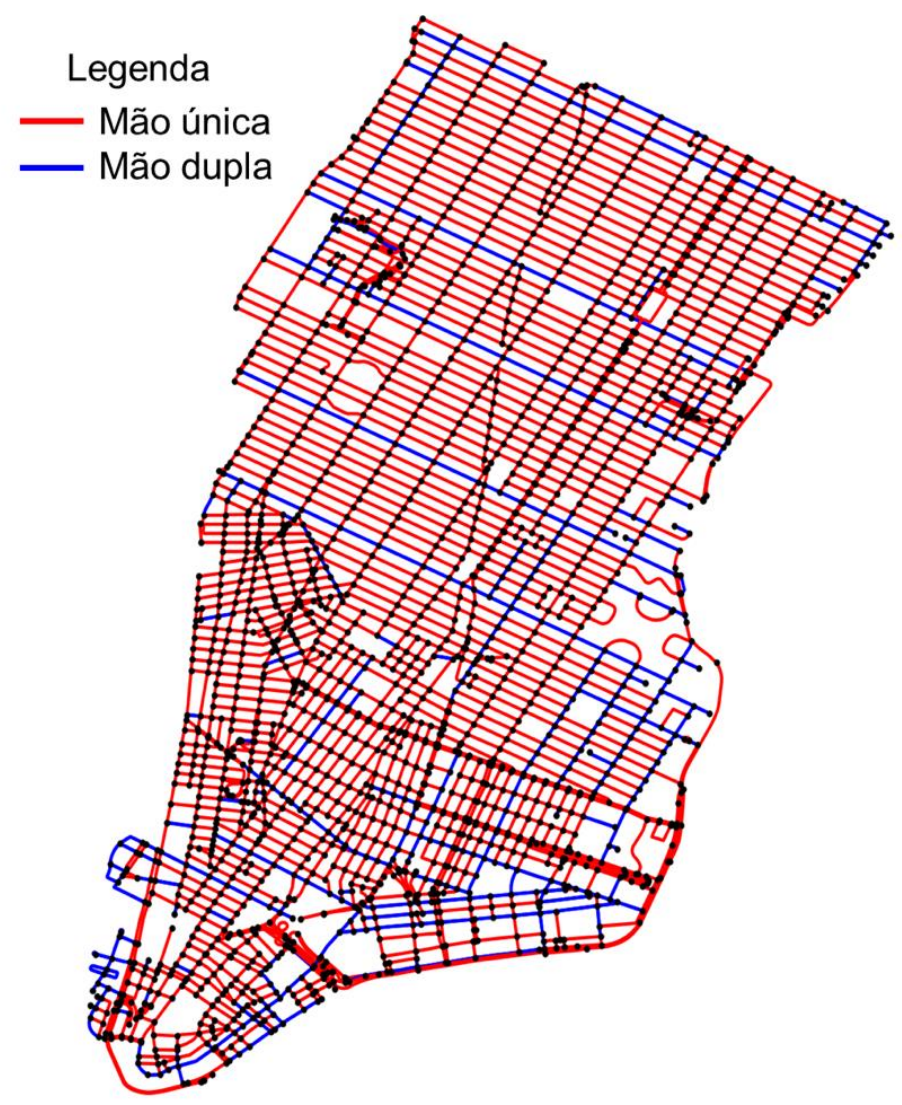

Figura 4.10: Rede viária contida na área analisada em Nova lorque. 


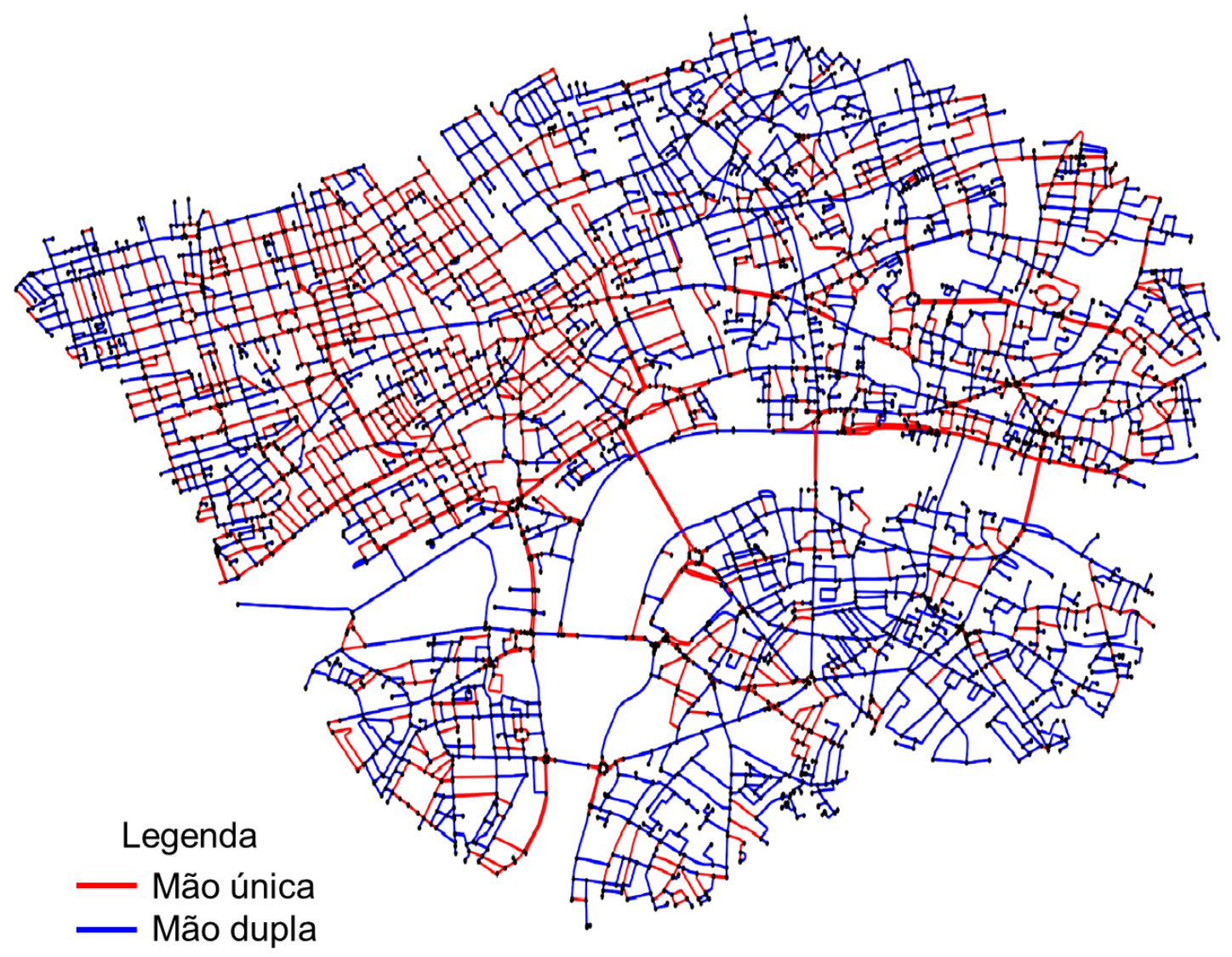

Figura 4.11: Rede viária contida na área analisada em Londres.

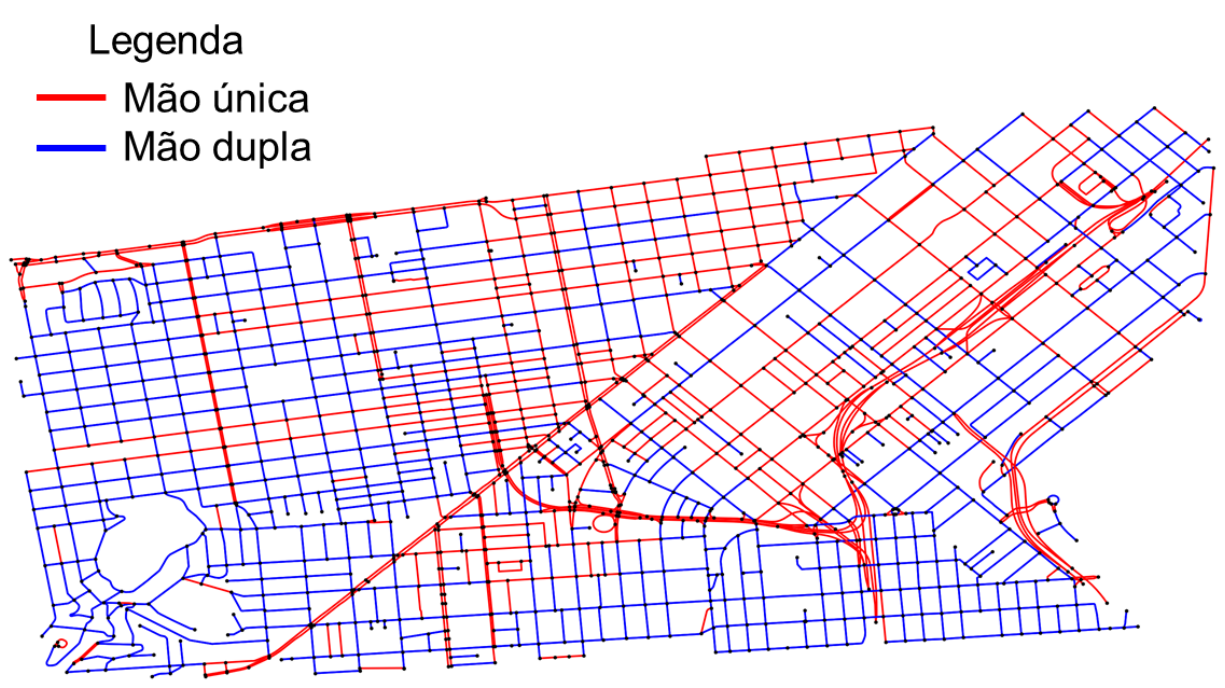

Figura 4.12: Rede viária contida na área analisada em São Francisco. 


\subsection{2 Índice de "Retilinidade"}

A seguir são apresentados os resultados referentes à análise da circulação local.

Como descrito na seção 3.2, para a aplicação do método proposto deve-se definir uma distância linear máxima entre os pontos para solicitar o caminho alocado na malha viária à API do Google Maps. Entretanto, na análise que segue, foram computados os trajetos ou itinerários entre todos os pares de pontos, sem limitação de distância máxima, a fim de se observar o comportamento do IR em relação a diferentes faixas de distâncias. Os resultados são apresentados nos gráficos das Figuras 4.13 a 4.18, em que cada ponto representa um par origem-destino

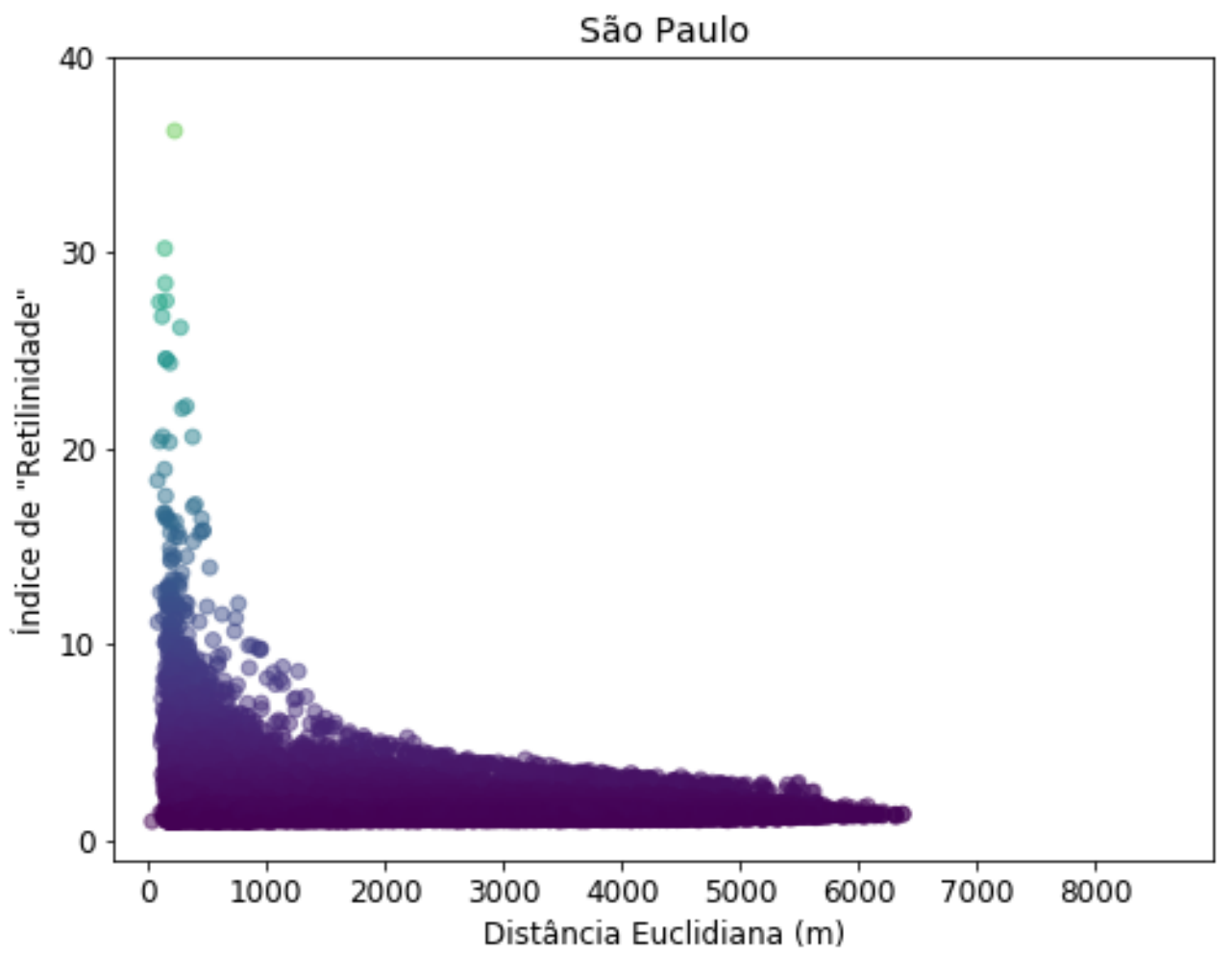

Figura 4.13: Distribuição IR x Distância Euclidiana de São Paulo. 


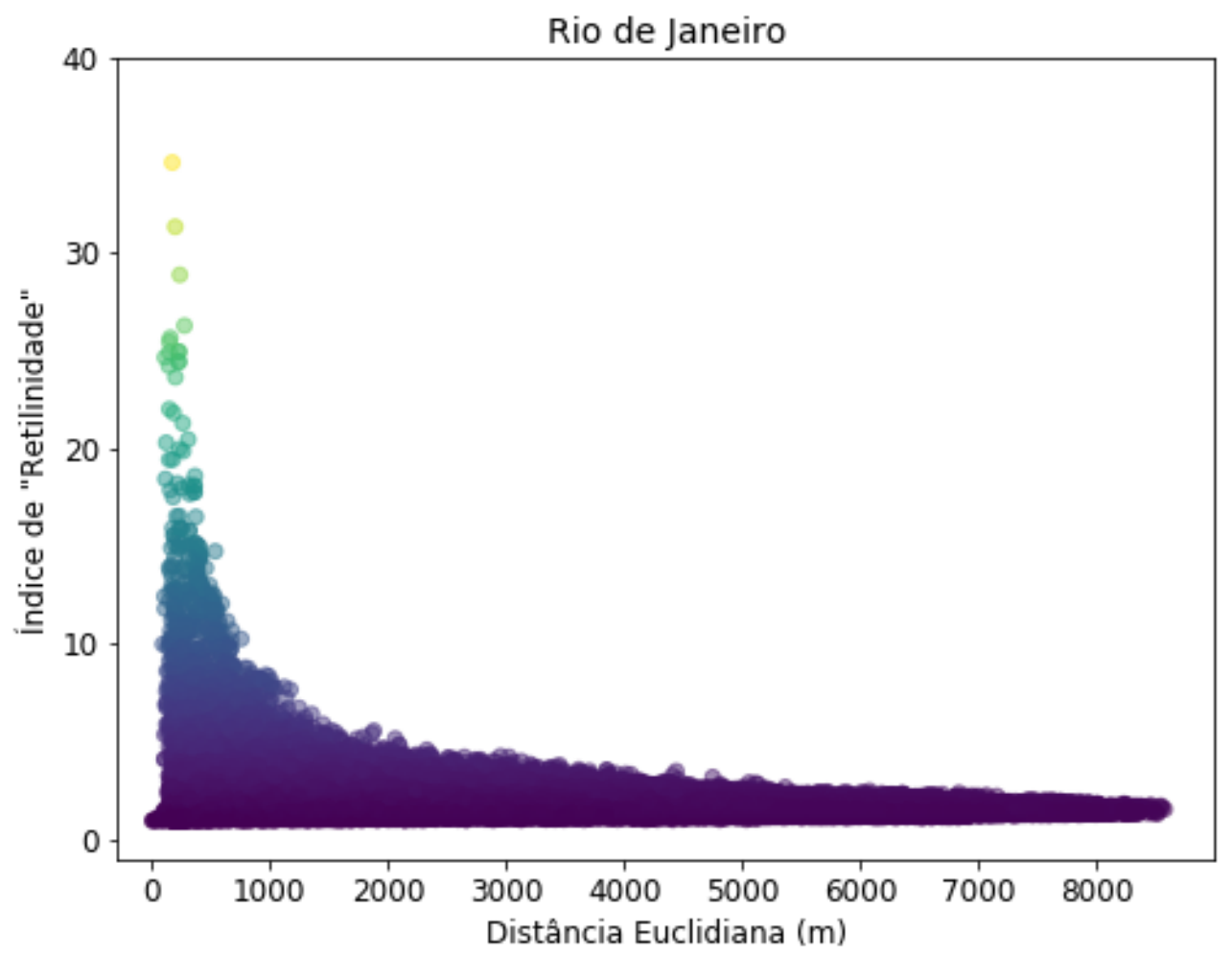

Figura 4.14: Distribuição IR x Distância Euclidiana do Rio de Janeiro.

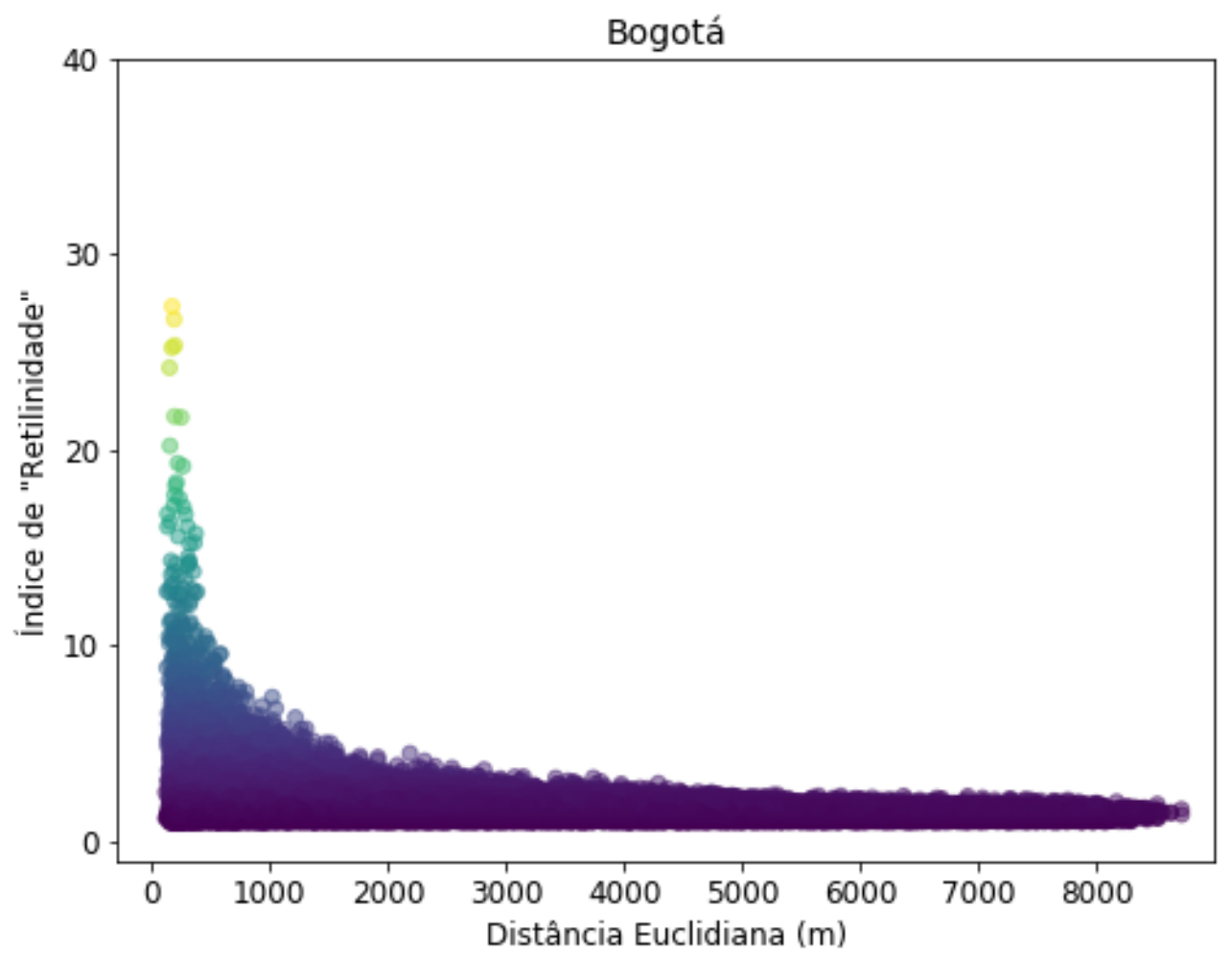

Figura 4.15: Distribuição IR x Distância Euclidiana de Bogotá. 


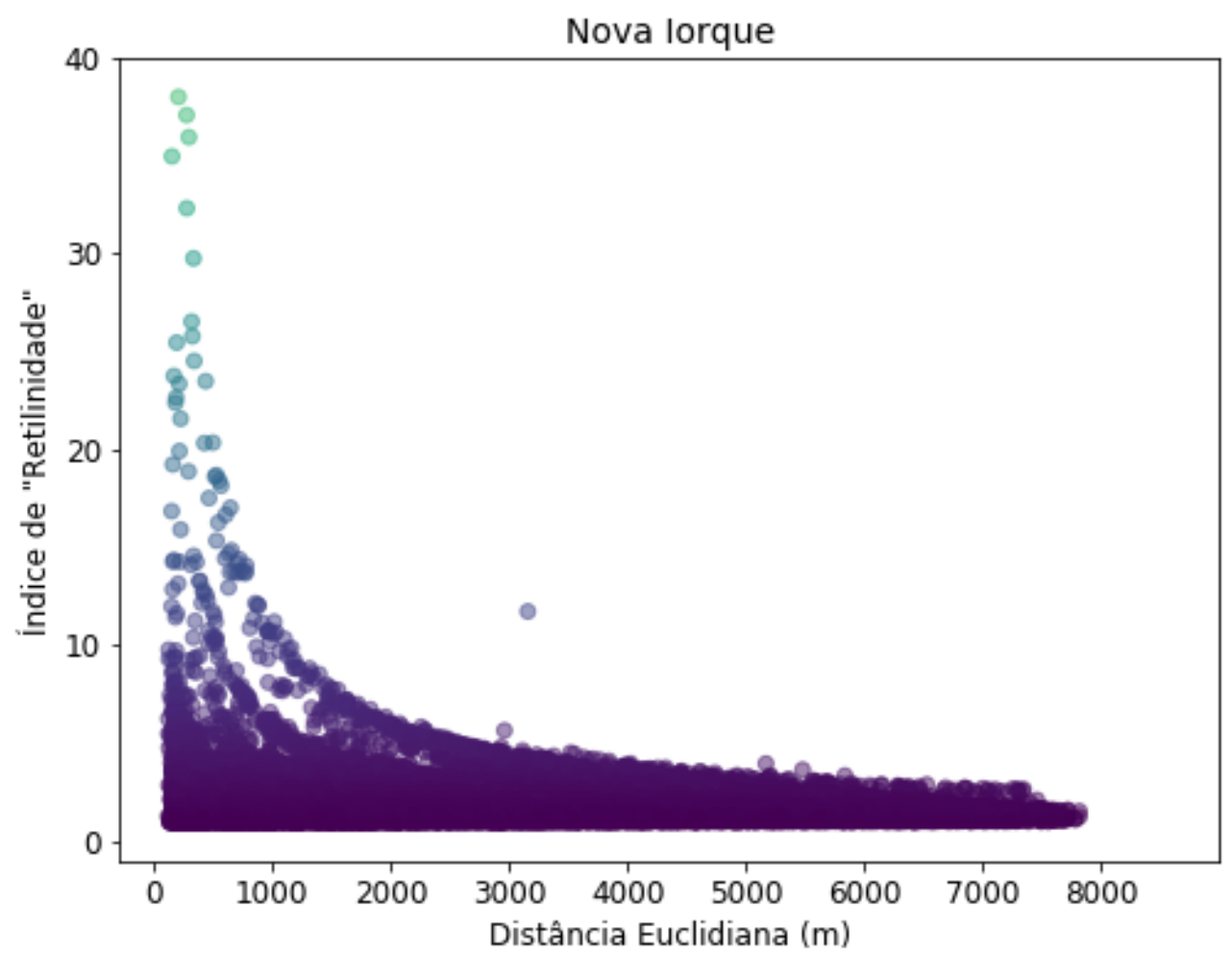

Figura 4.16: Distribuição IR x Distância Euclidiana de Nova lorque.

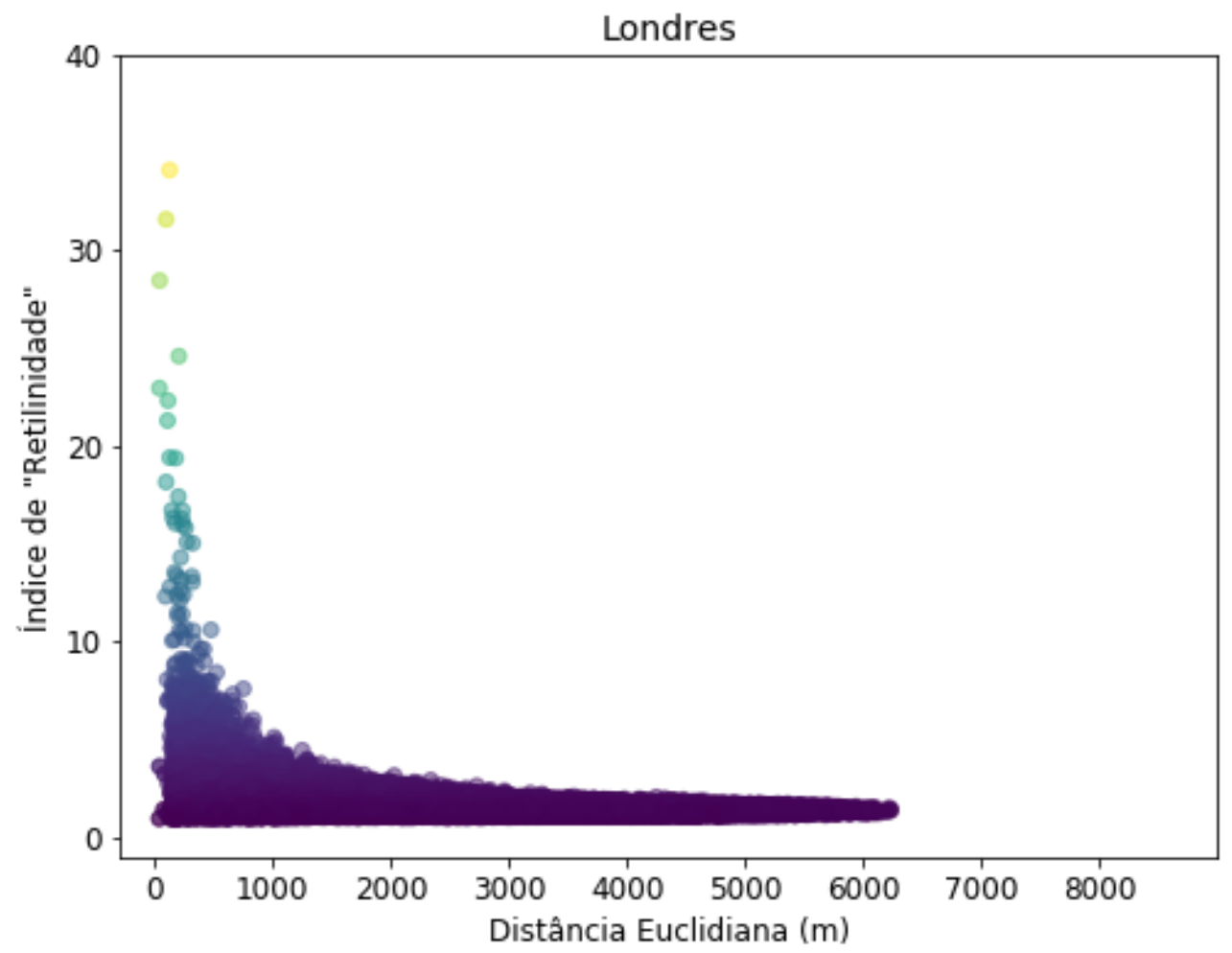

Figura 4.17: Distribuição IR x Distância Euclidiana de Londres. 


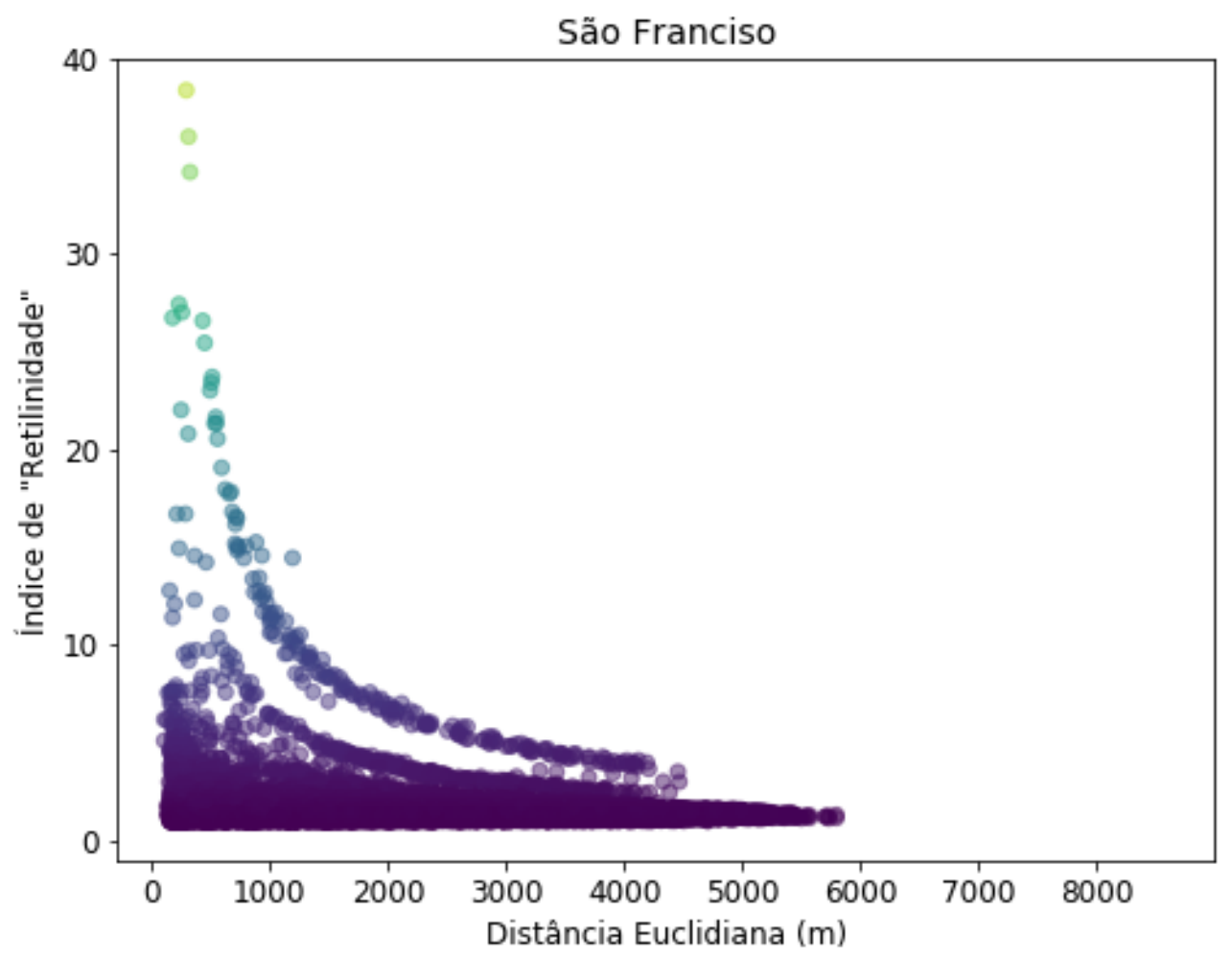

Figura 4.18: Distribuição IR x Distância Euclidiana de São Francisco.

É importante observar nas Figuras 4.13 a 4.18 que as distribuições obtidas para cada cidade são muito parecidas entre si, sendo a principal característica os altos valores de IR para distâncias euclidianas baixas e a estabilização dos valores observados de IR com o aumento da distância euclidiana (a partir de distâncias euclidianas maiores que $4000 \mathrm{~m}$ ). Percebe-se também que cada cidade apresenta uma amplitude diferente nos valores de distância euclidiana, isso se deve a diferente forma das áreas escolhidas em cada cidade, por exemplo, a distribuição do Rio de Janeiro (Figura 4.14), cujo polígono delimita uma área de estudo mais alongada, apresenta pontos com distância euclidiana superior a $8000 \mathrm{~m}$, já a distribuição de Londres (Figura 4.17), cujo polígono delimita uma área de estudo de dimensões mais proporcionais, não apresenta pontos com distância euclidiana superior a 7000m.

Ainda, as distribuições resultantes indicam que o IR tende a diminuir quanto maior a distância euclidiana entre origem e destino. Percebe-se também que para pontos próximos entre si em termos de distâncias em linha reta (euclidianas), os IRs observados chegam a valores altíssimos, acima de 10 ou 20, o que significa que o percurso de um veículo entre dois pontos muito próximos geograficamente aumenta muito. Esse fenômeno pode ser explicado pela natureza do cálculo do IR, cujo 
denominador é a distância euclidiana, sendo assim o limite do IR tende a infinito para distância euclidiana praticamente nula. Por este motivo, as observações com distância euclidiana inferior a 100m foram excluídas dos resultados apresentados a seguir. $\mathrm{O}$ valor de $100 \mathrm{~m}$ foi determinado por estar dentro da ordem de grandeza da dimensão média de segmento de via, isto é, trechos entre interseções ou cruzamentos (Tabela 4.2) das cidades analisadas. Apesar dos pontos gerados aleatoriamente estarem a uma distância mínima de 150m entre si, nos resultados obtidos, são observadas distâncias euclidianas menores que 150m entre origem e destino, já que estas são determinadas pela distância euclidiana entre as extremidades do caminho fornecido pela API do Google Maps (procedimento descrito na seção 3.2 e ilustrado na Figura 3.8).

As distribuições das Figuras 4.13 a 4.18 possibilitam pouca compreensão do comportamento dos IRs com a variação da distância euclidiana. Consequentemente, foram estabelecidos intervalos de valores de distância euclidiana, que geram seis faixas de distância euclidiana distintas e são: maiores que 100m e menores ou iguais a $500 \mathrm{~m}$, maiores que $500 \mathrm{~m}$ e menores ou iguais a $1 \mathrm{~km}$, maiores que $1 \mathrm{~km}$ e menores ou iguais a $2 \mathrm{~km}$, maiores que $2 \mathrm{~km}$ e menores ou iguais a $3 \mathrm{~km}$, maiores que $3 \mathrm{~km}$ e menores ou iguais a $4 \mathrm{~km}$ e maiores que $4 \mathrm{~km}$. Os valores para as faixas de distância foram estabelecidos pela observação das distribuições das Figuras 4.13 a 4.18, em especial devido variação do IR em função da distância euclidiana.

A Figura 4.19 apresenta os boxplots para o conjunto de dados referente a cada faixa de distância por cidade, em que é possível observar novamente a tendência de diminuição de valores de IR para distâncias euclidianas mais longas. O interessante da visualização dos boxplots é a possibilidade de comparar os resultados obtidos para cada cidade em cada faixa de distância lado a lado, o que não é possível com as distribuições das Figuras 4.13 a 4.18. Fica evidente os maiores valores de IR obtidos para o Rio de Janeiro, seguido de São Paulo e Bogotá. São Francisco, por sua vez, apresenta os menores valores de IR comparados com as outras cidades em todas as faixas de distância observadas.

Ainda sobre a Figura 4.19, os resultados obtidos indicam que quanto maior a distância entre um par origem e destino, menor a variação esperada do IR. Conforme pode ser observado, a amplitude de valores de IR nas faixas de distância euclidiana 
maiores que $2 \mathrm{~km}$ é menor que a metade da amplitude das faixas menores que $1 \mathrm{~km}$. Na prática, pode-se dizer que, em operações de entrega, quanto mais distantes entre si forem os pontos atendidos, menor a variação percentual esperada entre a distância total planejada e a distância total percorrida em caso de alteração na rota. Em outras palavras, roteiros com menos distância entre pontos consecutivos podem sofrer um acréscimo maior na distância total percorrida (e também na duração da jornada) caso um ponto tenha que ser visitado novamente ou a sequência tenha que ser alterada por algum imprevisto.

Também foi calculado o Índice de "Retilinidade" Médio (IRM) por cidade de acordo com as faixas de distância euclidiana. Os resultados estão na Tabela 4.4.

Tabela 4.4: Índices de "Retilinidade" Médios para veículos motorizados

\begin{tabular}{ccccccc}
\hline & $0.1-0.5 \mathrm{~km}$ & $0.5-1 \mathrm{~km}$ & $1-2 \mathrm{~km}$ & $2-3 \mathrm{~km}$ & $3-4 \mathrm{~km}$ & $>4 \mathrm{~km}$ \\
\hline São Paulo & 3,31 & 2,23 & 1,84 & 1,69 & 1,61 & 1,56 \\
Rio de Janeiro & 4,23 & 2,89 & 2,19 & 1,94 & 1,82 & 1,68 \\
Bogotá & 3,07 & 2,10 & 1,73 & 1,59 & 1,53 & 1,45 \\
Nova lorque & 2,55 & 1,80 & 1,55 & 1,52 & 1,55 & 1,53 \\
Londres & 2,53 & 1,92 & 1,64 & 1,51 & 1,45 & 1,43 \\
São Francisco & 2,21 & 1,71 & 1,47 & 1,41 & 1,43 & 1,41 \\
\hline
\end{tabular}

Os valores de IRM apresentados na Tabela 4.4 podem ser usados como fatores de correção de distâncias lineares, caso não seja possível computar o caminho real entre os pontos de entrega e corroboram o que já foi observado na Figura 4.19, principalmente quanto a diminuição de IR esperada com o aumento da distância geográfica entre origem e destino. Além disso, tendo em vista os IRM obtidos, também é possível inferir que, das seis cidades analisadas, são esperadas maiores distâncias percorridas na operação de distribuição de última milha no Rio de Janeiro, e são esperadas as menores distâncias percorridas em São Francisco. Esse resultado é esperado ao pensar que o Rio de Janeiro tem a menor densidade de vias dentre as cidades estudadas e alta proporção de extensão de vias de mão única, e, por outro lado, São Francisco tem a segunda menor proporção de extensão de vias de mão única. 


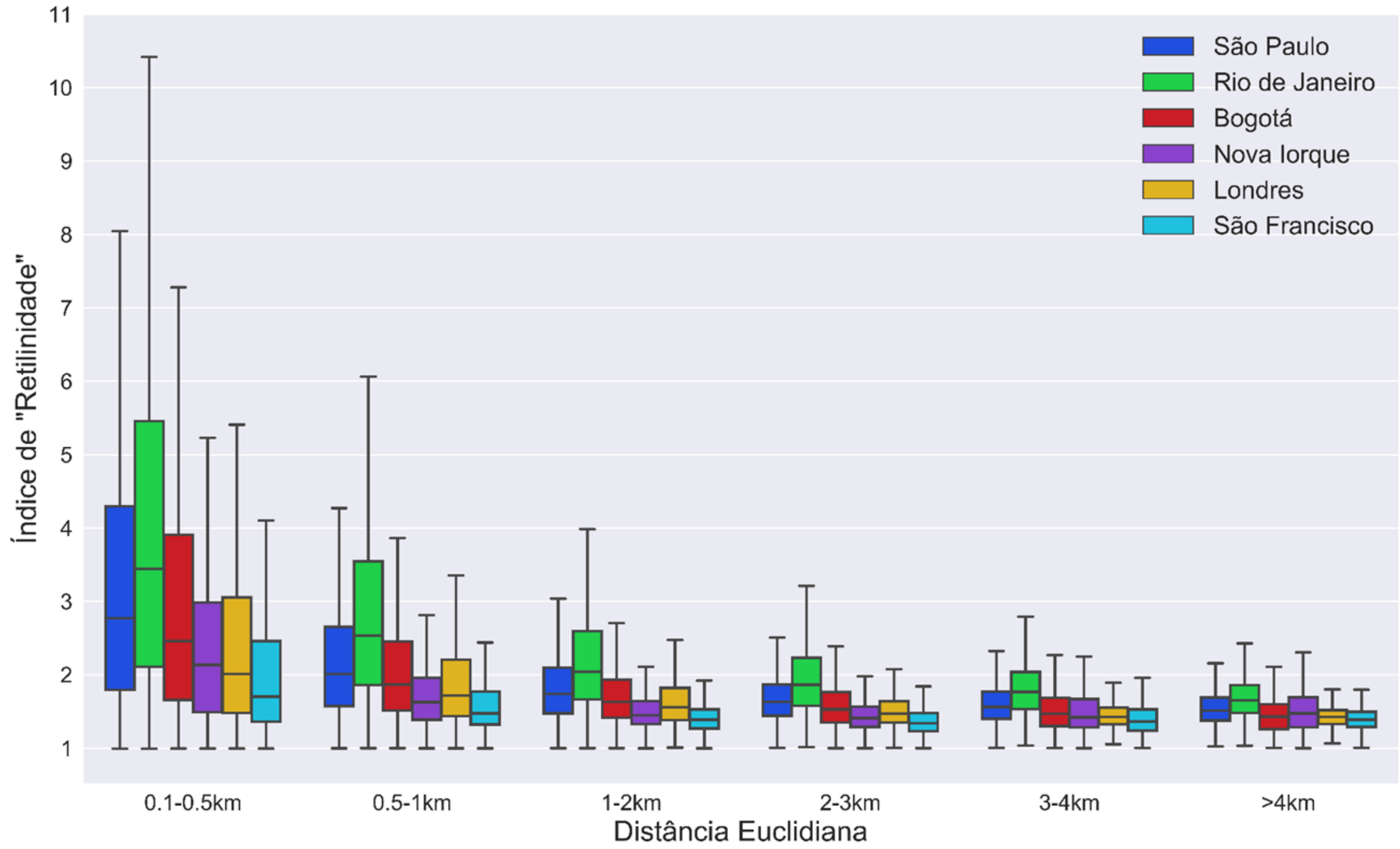

Figura 4.19: Boxplots dos IRs para veículos motorizados por cidade e faixa de distância euclidiana. 
Afim de compreender mais sobre a relação entre as características das malhas viárias das cidades e os resultados de IRM obtidos, são calculadas as correlações entre as métricas da Tabela 4.2 e os IRMs da Tabela 4.4, os resultados estão na Tabela 4.5.

Tabela 4.5: Correlação entre métricas da rede viária e IRM para veículos motorizados.

\begin{tabular}{lccccc}
\hline & & $\begin{array}{c}\text { Densidade } \\
\text { de vias } \\
\left(\mathrm{m} / \mathrm{km}^{2}\right)\end{array}$ & $\begin{array}{c}\text { Extensão } \\
\text { médio do } \\
\text { segmento de } \\
\text { via }(\mathrm{m})\end{array}$ & $\begin{array}{c}\text { Densidade } \\
\text { de } \\
\text { interseções } \\
\left(\mathrm{km}^{2}\right)\end{array}$ & $\begin{array}{c}\text { Proporção de } \\
\text { extensão de } \\
\text { vias de mão } \\
\text { única }(\mathrm{m} / \mathrm{m})\end{array}$ \\
\hline IRMmotorizado & $0.1-0.5 \mathrm{~km}$ & -0.505236 & 0.344486 & -0.370488 & 0.43462 \\
IRMmotorizado & $0.5-1 \mathrm{~km}$ & -0.599464 & 0.323869 & -0.38459 & 0.300553 \\
IRMmotorizado & $1-2 \mathrm{~km}$ & -0.587712 & 0.285153 & -0.350983 & 0.313881 \\
IRMmotorizado & $2-3 \mathrm{~km}$ & -0.591086 & 0.376641 & -0.431558 & 0.41602 \\
IRMmotorizado & $3-4 \mathrm{~km}$ & -0.601167 & 0.545344 & -0.580774 & 0.525582 \\
IRMmotorizado & $>4 \mathrm{~km}$ & -0.6517 & 0.608969 & -0.66744 & 0.571686 \\
\hline
\end{tabular}

Observa-se (Tabela 4.5) que as variáveis "densidade de vias" e "densidade de interseções" apresentam correlação negativa com os IRMs, o que significa que quanto maior as densidades, menor o valor de IR. Este resultado reforça o aspecto intuitivo de que quanto mais densa a malha, mais eficiente ela será, ou seja, menores as distâncias esperadas para conectar origens e destinos. Esperava-se maior valor no módulo de correlação entre "proporção de extensão de vias de mão única" e IRM, porém os valores são positivos, o que reforça que quanto mais vias de mão única em uma cidade, maiores IRs esperados. A extensão média dos segmentos de via apresenta correlação positiva com todos os IRMs, porém com valores absolutos relativamente baixos, o que indicam baixa influência do extensão média do segmento de via na eficiência da malha viária; observa-se uma tendência do valor absoluto da correlação ser crescente com o aumento das distâncias euclidianas, o que indica que a extensão de segmentos de via influencia mais em distâncias mais longas.

Os resultados de IR obtidos também permitem a elaboração de mapas temáticos a fim de se observar o comportamento do IR na área analisada, auxiliando no diagnóstico de áreas mais problemáticas para a circulação de veículos. Os mapas gerados para as seis cidades estão nas Figuras 4.20 a 4.25 e apresentam os resultados de IR para as rotas computadas com distância euclidiana menor que 500m. 
Cada rota é representada graficamente por um segmento de reta cujos pontos extremos são origem e destino utilizados na solicitação feita à API do Google Maps, e cuja coloração é correspondente ao IR de acordo com a escala de cores definida na legenda (verde para $1 \leq I R \leq 2$, amarelo para $2<\mid R \leq 4$, vermelho para $I R>4$ ).

Percebe-se que em todas as cidades, existem focos de concentração de segmentos de cor vermelha, ou seja, locais onde a circulação veículos é potencialmente mais problemática. Os IRs com valores maiores que 4 estão associados a locais em que existem barreiras para a circulação, como rios, morros e vias arteriais. No Rio de Janeiro (Figura 4.21) e em Londres (Figura 4.24), existem barreiras naturais que são os morros São João e Santa Marta e o rio Tâmisa, respectivamente. Nas outras cidades, percebe-se que as vias arteriais desempenham o papel de barreira para a circulação. Em São Paulo (Figura 4.20), observa-se maior concentração de segmentos vermelhos nas adjacências e também ligando pontos em lados distintos ao longo do eixo formado pela Avenida Rebouças e Rua da Consolação, da Avenida Paulista e da Avenida do Estado. Em Bogotá (Figura 4.22), é evidente a barreira formada pela Avenida Norte-Quito-Sur (NQS), eixo de transporte norte-sul importantíssimo para o trânsito da cidade e que inclusive serve como infraestrutura viária do transmilênio, o principal corredor de transporte público da cidade. Nova lorque (Figura 4.23) e São Francisco (Figura 4.25) são as cidades que apresentam as menores concentrações de segmentos vermelhos, porém estão localizados pontualmente em entroncamento de vias arteriais; em Nova lorque, na entrada da ponte Williamsburg e em São Francisco, no entroncamento das rodovias I-80 e US-101. 


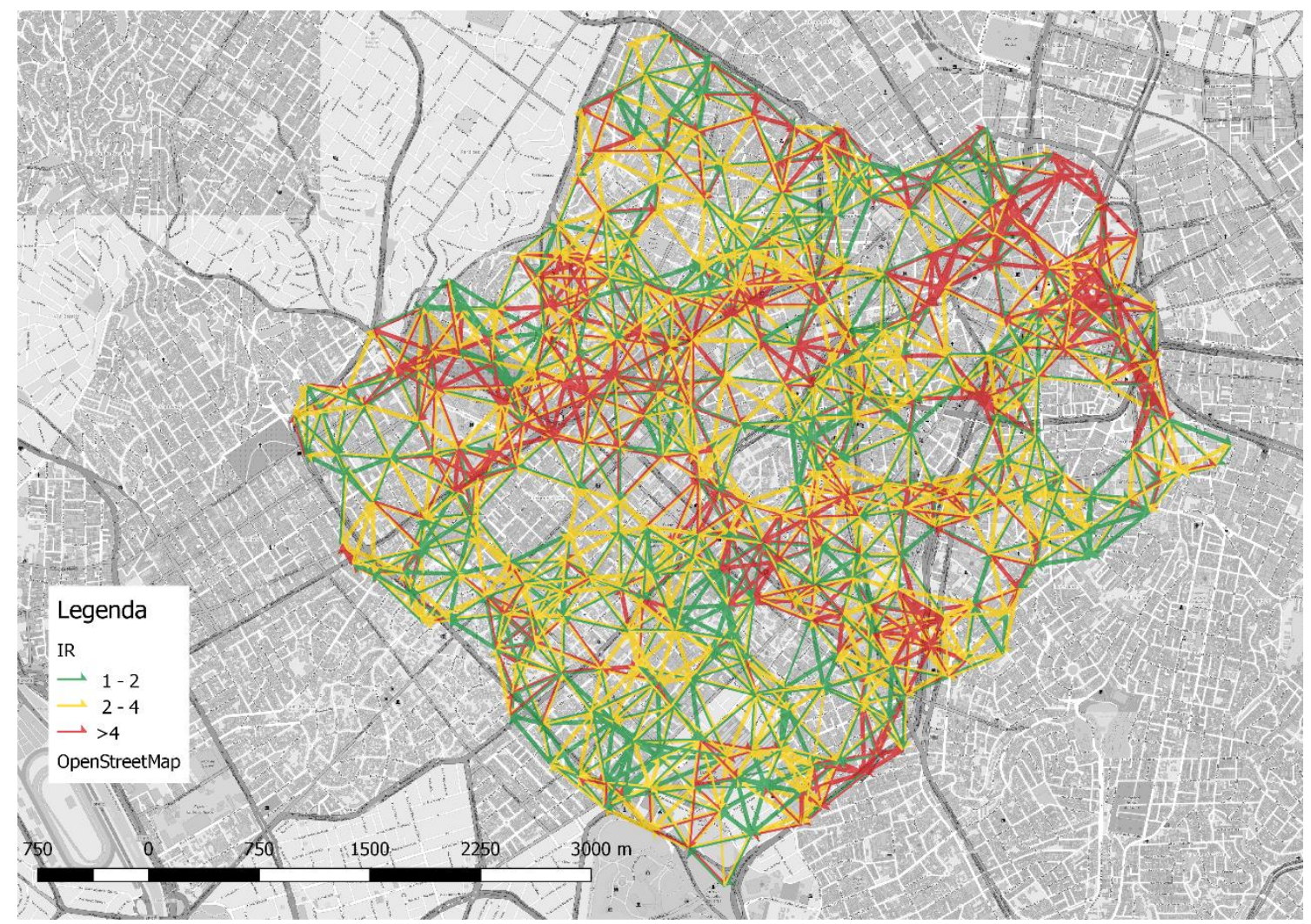

Figura 4.20: Mapa com os IRs para veículos motorizados em São Paulo.

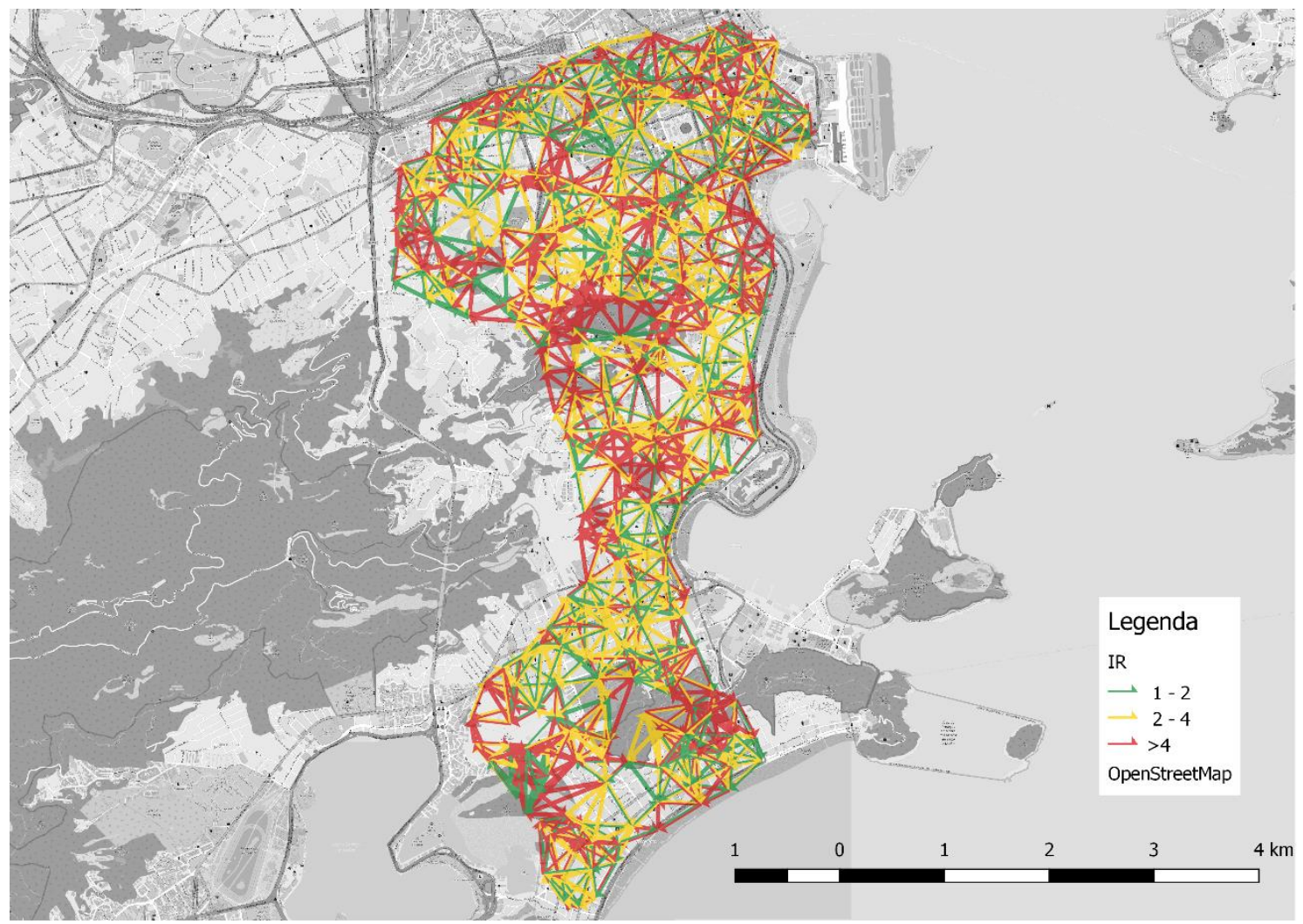

Figura 4.21: Mapa com os IRs para veículos motorizados no Rio de Janeiro. 


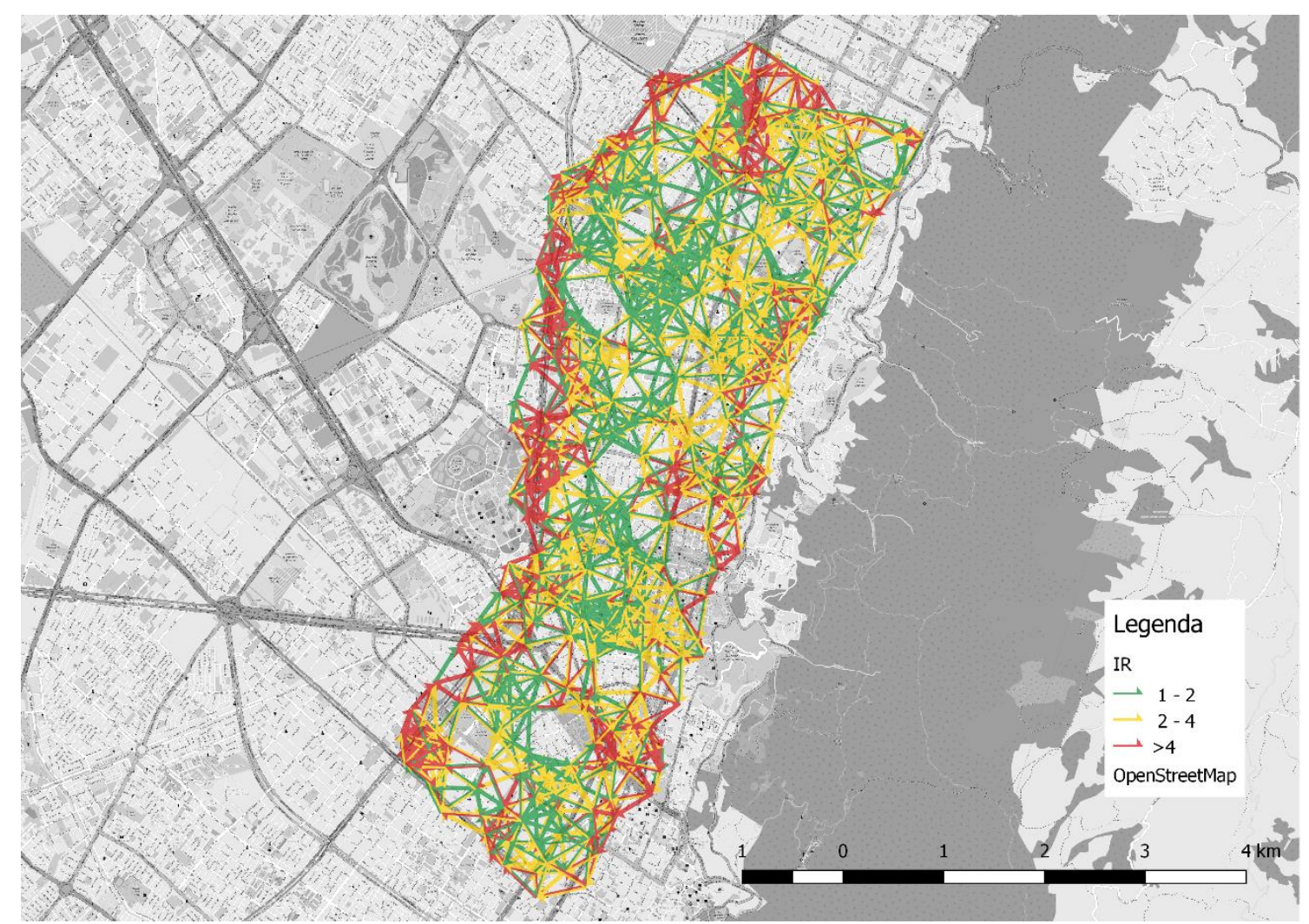

Figura 4.22: Mapa com os IRs para veículos motorizados em Bogotá.

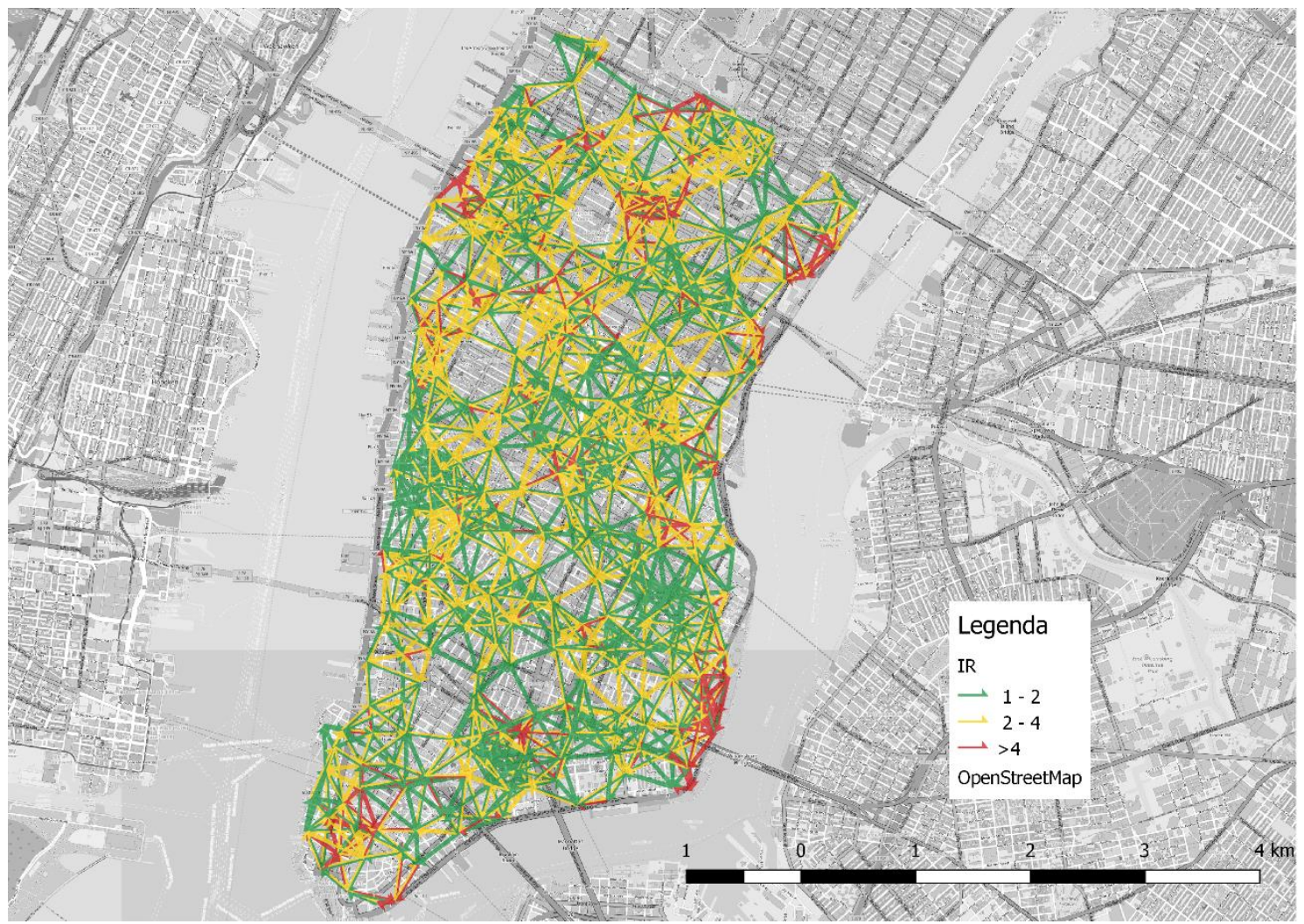

Figura 4.23: Mapa com os IRs para veículos motorizados em Nova lorque. 


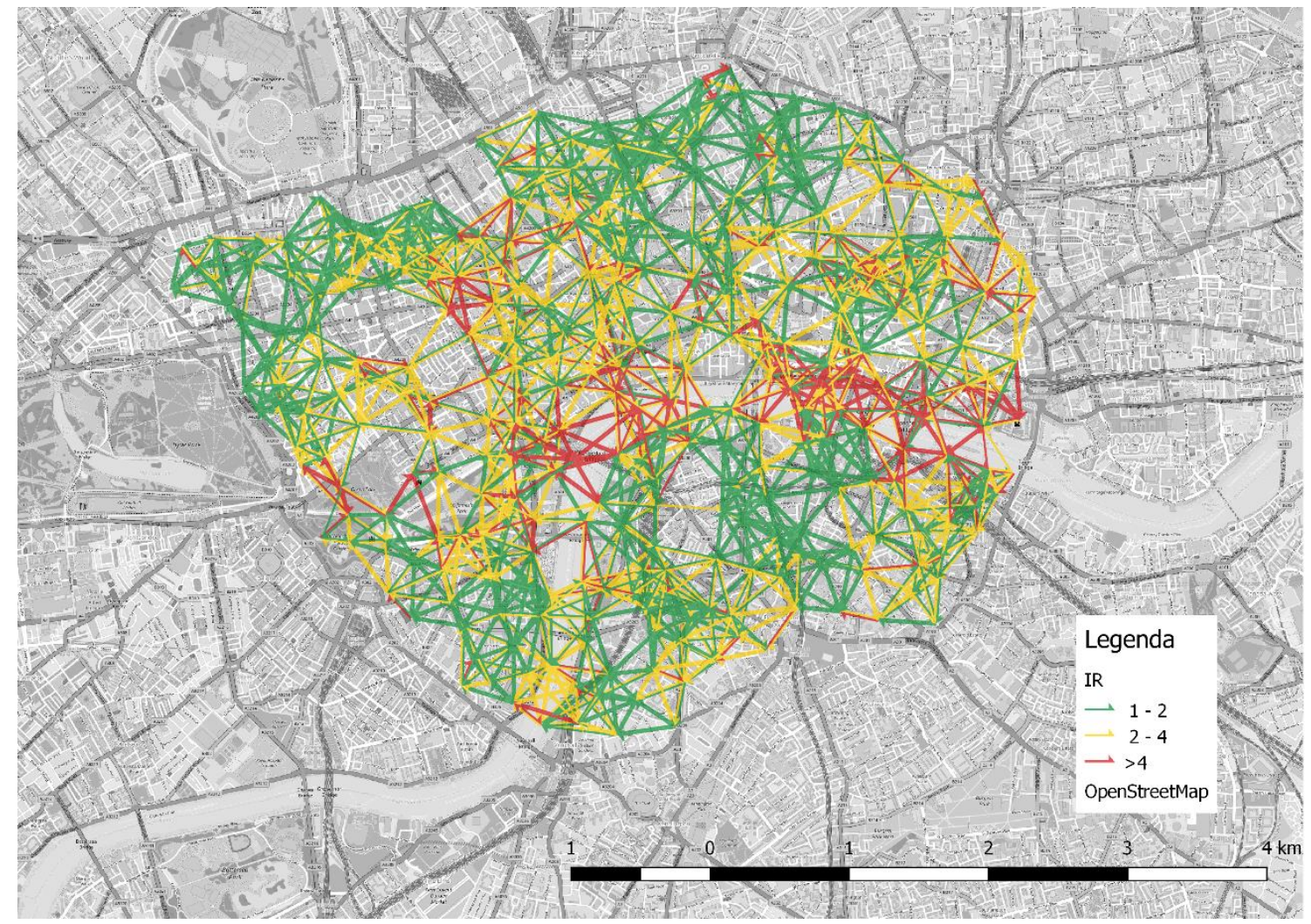

Figura 4.24: Mapa com os IRs para veículos motorizados em Londres.

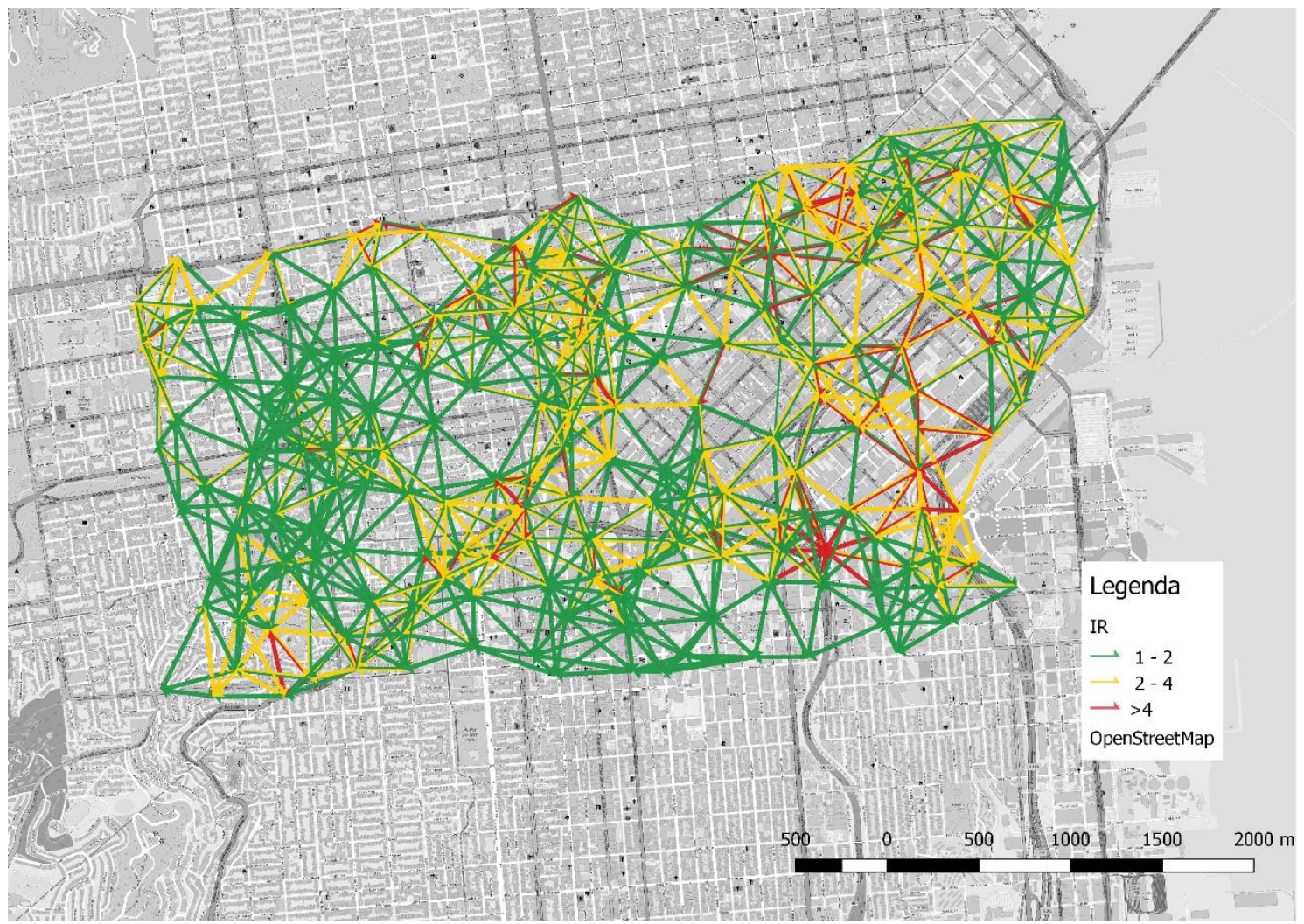

Figura 4.25: Mapa com os IRs para veículos motorizados em São Francisco. 


\subsubsection{Velocidades de Tráfego}

Para a obtenção das velocidades, foram estipulados os horários $8 \mathrm{~h}$ e $18 \mathrm{~h}$ como horários de pico de tráfego e 1h e 13h como horários de nível de ocupação intermediária do sistema viário das áreas analisadas. Todos os horários são locais segundo os fusos onde se localizam as cidades. Os resultados das velocidades médias de circulação nas áreas analisadas encontram-se na Tabela 4.6 e na Figura 4.26 .

Pela Tabela 4.6 e a Figura 4.26, percebe-se que a variação de velocidade média esperada ao longo do dia é muito parecida em São Paulo, Rio de Janeiro, Bogotá e Londres, em que se observa uma redução de aproximadamente $23 \%$ da velocidade mais alta (a 1h) para a velocidade mais baixa (as 13h). Não era esperado que a previsão de velocidades indicasse o horário das 13h como o mais problemático (velocidade média de circulação mais baixa ao longo do dia), o que ocorre em todas as cidades menos São Francisco, a única que apresenta a manhã (8h) como momento do dia mais problemático, porém em todas as cidades a velocidade média de circulação estimada para as $13 \mathrm{~h}$ está muito próxima da velocidade média de circulação estimada para as $18 \mathrm{~h}$, apresentando variação percentual menor que $2 \%$ entre os dois horários.

Ainda, os resultados (Tabela 4.6 e a Figura 4.26) indicam que São Paulo e São Francisco são as cidades em que se espera trafegar com maiores velocidades médias, já Nova lorque é a cidade que espera-se trafegar com a menor velocidade média. Por exemplo, em Nova lorque a velocidade de circulação média estimada para as $13 \mathrm{~h}$ é $27 \%$ menor que a estimada para São Paulo no mesmo horário.

Tabela 4.6: Velocidades Médias $(\mathrm{km} / \mathrm{h})$ de circulação.

\begin{tabular}{ccccc}
\hline & $1 \mathrm{~h}$ & $8 \mathrm{~h}$ & $13 \mathrm{~h}$ & $18 \mathrm{~h}$ \\
\hline São Paulo & 19,33 & 16,57 & 14,9 & 15,07 \\
Rio de Janeiro & 17,20 & 14,71 & 13,64 & 13,76 \\
Bogotá & 17,42 & 14,04 & 12,75 & 12,75 \\
Nova lorque & 15,83 & 12,32 & 10,81 & 11,16 \\
Londres & 15,01 & 13,00 & 11,97 & 12,33 \\
São Francisco & 19,83 & 15,6 & 15,93 & 16,02 \\
\hline
\end{tabular}




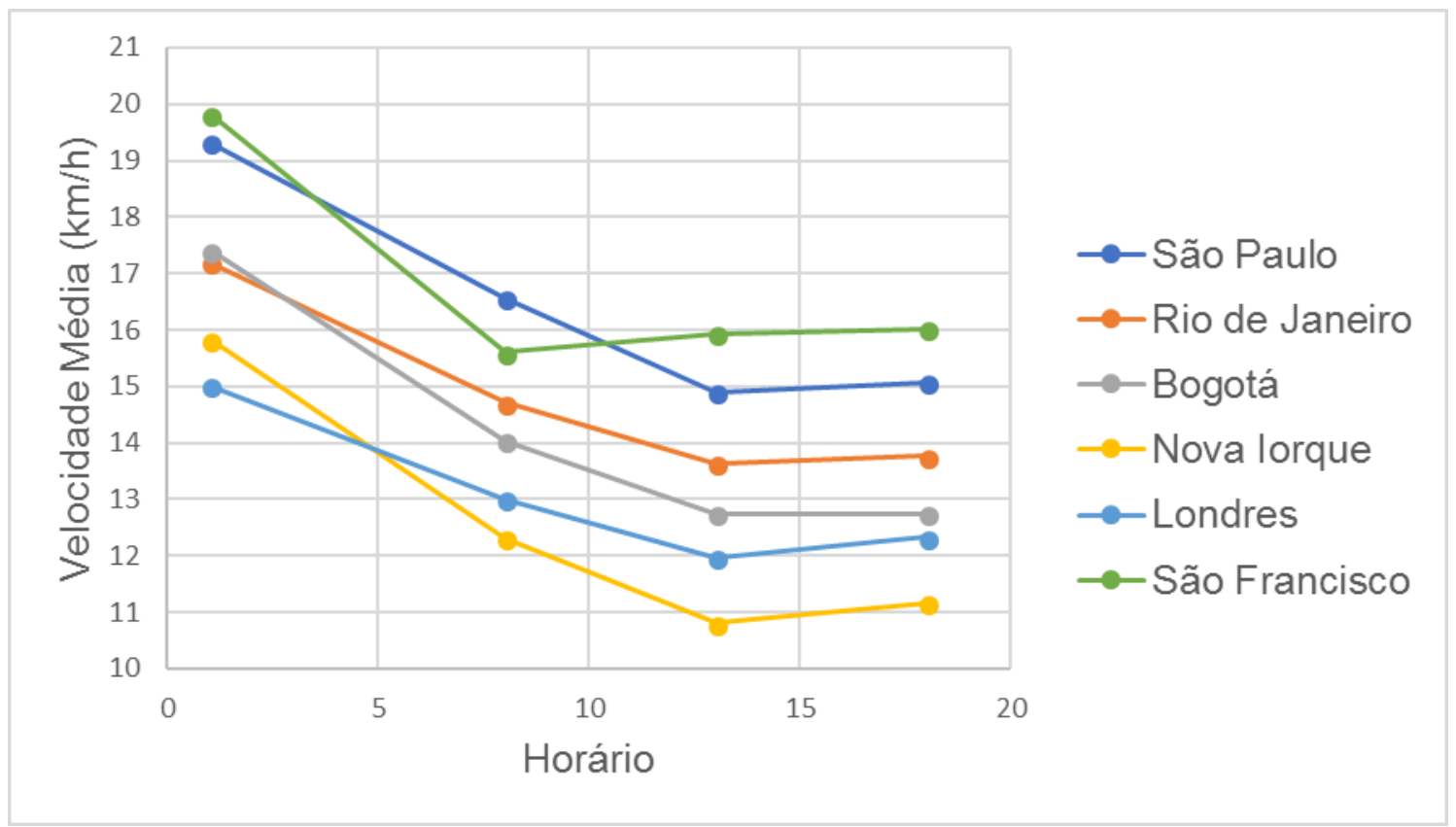

Figura 4.26: Velocidade Média de Circulação x Horário.

Também foram calculadas as correlações das velocidades médias de circulação obtidas com as métricas que caracterizam a malha viárias das cidades (Tabela 4.2); os resultados para as correlações estão na Tabela 4.7. Do ponto de vista da eficiência dos tempos de viagem, os valores absolutos de correlação são baixos, ou seja, pode-se inferir que há pouca influência destas características da rede viária na velocidade de tráfego. Observa-se (Tabela 4.7) que a extensão média do segmento de via apresenta correlação positiva com as velocidades, ou seja, maiores extensões de segmento de via estão associadas a maiores velocidades. Por outro lado, observase correlação negativa entre a densidade de interseções e as velocidades, ou seja, mais interseções estão associadas a menores velocidades. Ambas observações são complementares, pois sabe-se que interseções de vias representam locais de conflito de tráfego em que os motoristas reduzem ou param totalmente os veículos, reduzindo as velocidades médias de deslocamento. Sendo assim, é esperado que uma rede com menos interseções seja uma rede cujos segmentos de via são mais longos e que, portanto, seja mais propícia para maiores velocidades de tráfego.

Com os dados obtidos, também é possível a elaboração de mapas que auxiliam na identificação de gargalos do trânsito. As Figuras 4.27 a 4.50 apresentam os mapas e as Tabelas 4.8 a 4.11 , a porcentagem de quilômetros de vias sujeitas a cada faixa de velocidade em cada horário. 
Em São Paulo (Figuras 4.27 a 4.30), percebe-se maior concentração de vias com velocidade de tráfego inferior a $10 \mathrm{~km} / \mathrm{h}$ (cor vermelha) no centro da cidade, área entre a Catedral da Sé e o Mercado Municipal, as 13h (Figura 4.29). Em geral, observa-se a predominância de vias com velocidade de tráfego entre 10 e $20 \mathrm{~km} / \mathrm{h}$ (cor amarela) nos quatro horários, o que sugere que a maioria das vias têm velocidade de tráfego próxima a velocidade média de circulação da área. Esta percepção pode ser confirmada com as informações nas Tabelas 4.9 a 4.11, em que se observa que mais de $50 \%$ de extensão de vias apresentam velocidade de tráfego entre 10 e 20 $\mathrm{km} / \mathrm{h}$ nos horários das $8 \mathrm{~h}, 13 \mathrm{~h}$ e $18 \mathrm{~h}$.

Rio de Janeiro (Figura 4.31 a 4.34), Bogotá (Figura 4.35 a 4.38) e São Francisco (Figura 4.47 a 4.50) apresentam comportamento similar ao de São Paulo quanto a porcentagem de vias com velocidade de tráfego entre 10 e $20 \mathrm{~km} / \mathrm{h}$. O Rio de Janeiro apresenta, dois focos de vias com velocidades abaixo de $10 \mathrm{~km} / \mathrm{h}$ no horário das $13 \mathrm{~h}$ (Figura 4.33), um fica no bairro central da cidade nos arredores da Central do Brasil e o outro no bairro de Copacabana, zona Sul da cidade. Bogotá também apresenta dois focos de vias coloridas de vermelho as 13h (Figura 4.37), um é na região do centro histórico da cidade, nos arredores no Museu do Ouro, e o outro na zona Norte, entre as Ruas 63 e 67. São Francisco apresenta apenas um foco de concentração de vias com velocidade de tráfego inferior a $10 \mathrm{~km} / \mathrm{h}$, a Avenida Octavia e seus arredores (Figura 4.49), se destacando como o maior gargalo de tráfego da área estudada; diferentemente das outras cidades, São Francisco não apresenta muitas vias esparsas (fora do único gargalo de tráfego) coloridas de vermelho, o que pode ser confirmado pelos valores das Tabelas 4.8 a 4.11, em que São Francisco é a única cidade que mantem menos de $10 \%$ de quilometragem de vias com tráfego menor que $10 \mathrm{~km} / \mathrm{h}$ nos quatro horários.

Nova lorque (Figuras 4.39 a 4.42) e Londres (Figuras 4.43 a 4.46) são as cidades com piores resultados de velocidades estimadas, ou seja, estimam-se as velocidades mais baixas de tráfego dentre as seis cidades. Em Londres não são observadas concentrações de trânsito, ou gargalos, as vias com coloração vermelha estão distribuídas ao longo de toda a área analisada. Em Nova lorque observa-se a formação e expansão de uma "mancha vermelha" ao longo do dia; as 8h (Figura 4.40), as vias que apresentam velocidade de tráfego inferior a $10 \mathrm{~km} / \mathrm{h}$ estão principalmente

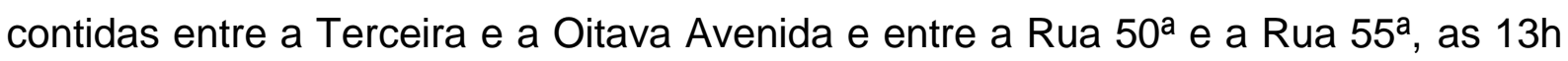


(Figura 4.41), este perímetro se expande e passa a ser contido entre a Terceira e a

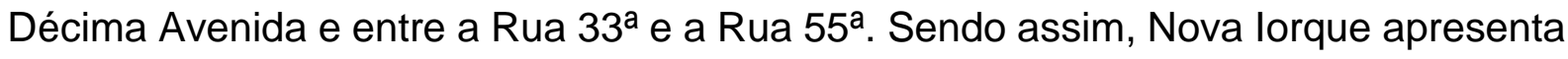
a maior sensibilidade à ocupação viária dentre as seis cidades estudadas, em outras palavras, Nova lorque é a cidade que apresenta a maior queda no valor da velocidade de circulação média ao longo do dia e apresenta o maior aumento na porcentagem de vias com velocidade de tráfego inferior a $10 \mathrm{~km} / \mathrm{h}$, atingindo a marca de $34,7 \%$ de extensão de vias (Tabela 4.10).

Tabela 4.7: Correlação entre métricas da rede viária e velocidades médias de circulação.

\begin{tabular}{lcccc}
\hline & $\begin{array}{c}\text { Densidade } \\
\text { de vias } \\
\left(\mathrm{m} / \mathrm{km}^{2}\right)\end{array}$ & $\begin{array}{c}\text { Extensão } \\
\text { média do } \\
\text { segmento de } \\
\text { via }(\mathrm{m})\end{array}$ & $\begin{array}{c}\text { Densidade } \\
\text { de } \\
\text { interseções } \\
\left(\mathrm{km}^{-2}\right)\end{array}$ & $\begin{array}{c}\text { Proporção de } \\
\text { extensão de } \\
\text { vias de mão } \\
\text { única }(\mathrm{m} / \mathrm{m})\end{array}$ \\
\hline $\begin{array}{c}\text { Velocidade } \\
\text { Média 1h }\end{array}$ & 0.026425 & 0.509138 & -0.390408 & 0.054961 \\
$\begin{array}{c}\text { Velocidade } \\
\text { Média } 8 \mathrm{~h}\end{array}$ & -0.202579 & 0.386595 & -0.352454 & -0.007843 \\
$\begin{array}{c}\text { Velocidade } \\
\text { Média 13h }\end{array}$ & -0.215983 & 0.382535 & -0.361903 & -0.267854 \\
$\begin{array}{c}\text { Velocidade } \\
\text { Média 18h }\end{array}$ & -0.246044 & 0.382913 & -0.37691 & -0.290751 \\
\hline
\end{tabular}

Tabela 4.8: Porcentagem de quilometragem de vias com tráfego em determinadas faixas de velocidade a $1 \mathrm{~h}$.

\begin{tabular}{cccc}
\hline & $0-10 \mathrm{~km} / \mathrm{h}$ & $10-20 \mathrm{~km} / \mathrm{h}$ & maior que $20 \mathrm{~km} / \mathrm{h}$ \\
\hline São Paulo & $3,1 \%$ & $42,4 \%$ & $54,5 \%$ \\
Rio de Janeiro & $7,6 \%$ & $46,7 \%$ & $45,7 \%$ \\
Bogotá & $9,2 \%$ & $39,6 \%$ & $51,1 \%$ \\
Nova lorque & $6,2 \%$ & $65,8 \%$ & $28,0 \%$ \\
Londres & $15,9 \%$ & $57,7 \%$ & $26,4 \%$ \\
São Francisco & $3,7 \%$ & $50,9 \%$ & $45,5 \%$ \\
\hline
\end{tabular}


Tabela 4.9: Porcentagem de quilometragem de vias com tráfego em determinadas faixas de velocidade as $8 \mathrm{~h}$.

\begin{tabular}{cccc}
\hline & $0-10 \mathrm{~km} / \mathrm{h}$ & $10-20 \mathrm{~km} / \mathrm{h}$ & maior que $20 \mathrm{~km} / \mathrm{h}$ \\
\hline São Paulo & $5,3 \%$ & $59,3 \%$ & $35,4 \%$ \\
Rio de Janeiro & $11,5 \%$ & $58,3 \%$ & $30,2 \%$ \\
Bogotá & $13,9 \%$ & $58,7 \%$ & $26,4 \%$ \\
Nova lorque & $19,5 \%$ & $69,9 \%$ & $10,6 \%$ \\
Londres & $22,5 \%$ & $68,3 \%$ & $9,1 \%$ \\
São Francisco & $9,3 \%$ & $73,5 \%$ & $17,2 \%$ \\
\hline
\end{tabular}

Tabela 4.10: Porcentagem de quilometragem de vias com tráfego em determinadas faixas de velocidade as $13 \mathrm{~h}$.

\begin{tabular}{cccc}
\hline & $0-10 \mathrm{~km} / \mathrm{h}$ & $10-20 \mathrm{~km} / \mathrm{h}$ & maior que $20 \mathrm{~km} / \mathrm{h}$ \\
\hline São Paulo & $9,3 \%$ & $63,7 \%$ & $27,1 \%$ \\
Rio de Janeiro & $15,9 \%$ & $59,9 \%$ & $24,2 \%$ \\
Bogotá & $19,5 \%$ & $60,9 \%$ & $19,5 \%$ \\
Nova lorque & $34,7 \%$ & $56,3 \%$ & $9,0 \%$ \\
Londres & $31,0 \%$ & $62,2 \%$ & $6,3 \%$ \\
São Francisco & $8,1 \%$ & $72,5 \%$ & $19,3 \%$ \\
\hline
\end{tabular}

Tabela 4.11: Porcentagem de quilometragem de vias com tráfego em determinadas faixas de velocidade as $18 \mathrm{~h}$.

\begin{tabular}{cccc}
\hline & $0-10 \mathrm{~km} / \mathrm{h}$ & $10-20 \mathrm{~km} / \mathrm{h}$ & maior que $20 \mathrm{~km} / \mathrm{h}$ \\
\hline São Paulo & $8,3 \%$ & $64,7 \%$ & $27,0 \%$ \\
Rio de Janeiro & $15,5 \%$ & $59,4 \%$ & $25,1 \%$ \\
Bogotá & $18,5 \%$ & $64,0 \%$ & $17,4 \%$ \\
Nova lorque & $29,4 \%$ & $63,4 \%$ & $7,2 \%$ \\
Londres & $27,0 \%$ & $66,9 \%$ & $6,1 \%$ \\
São Francisco & $8,3 \%$ & $72,2 \%$ & $19,5 \%$ \\
\hline
\end{tabular}




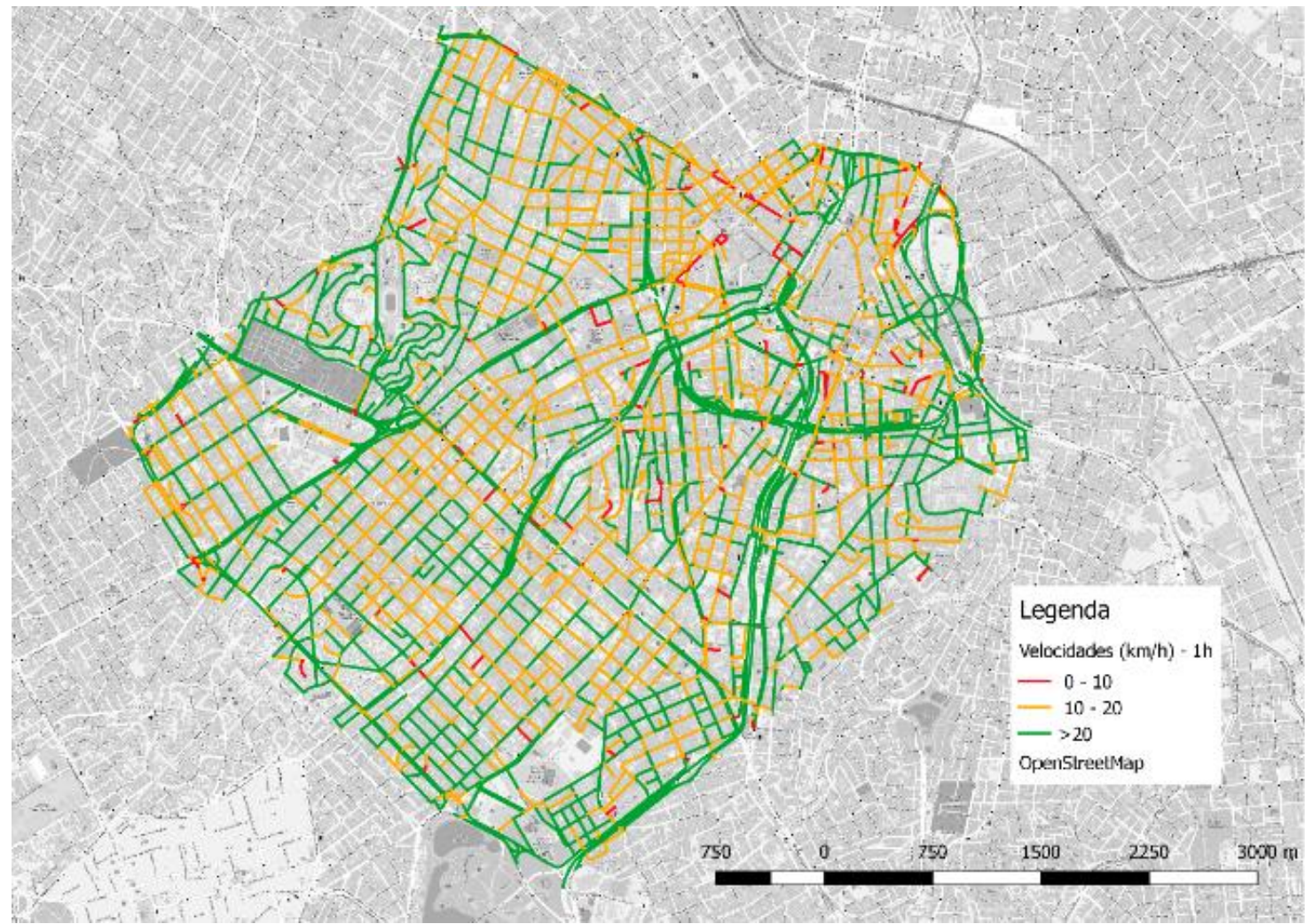

Figura 4.27: Velocidades de tráfego em São Paulo a 1h.

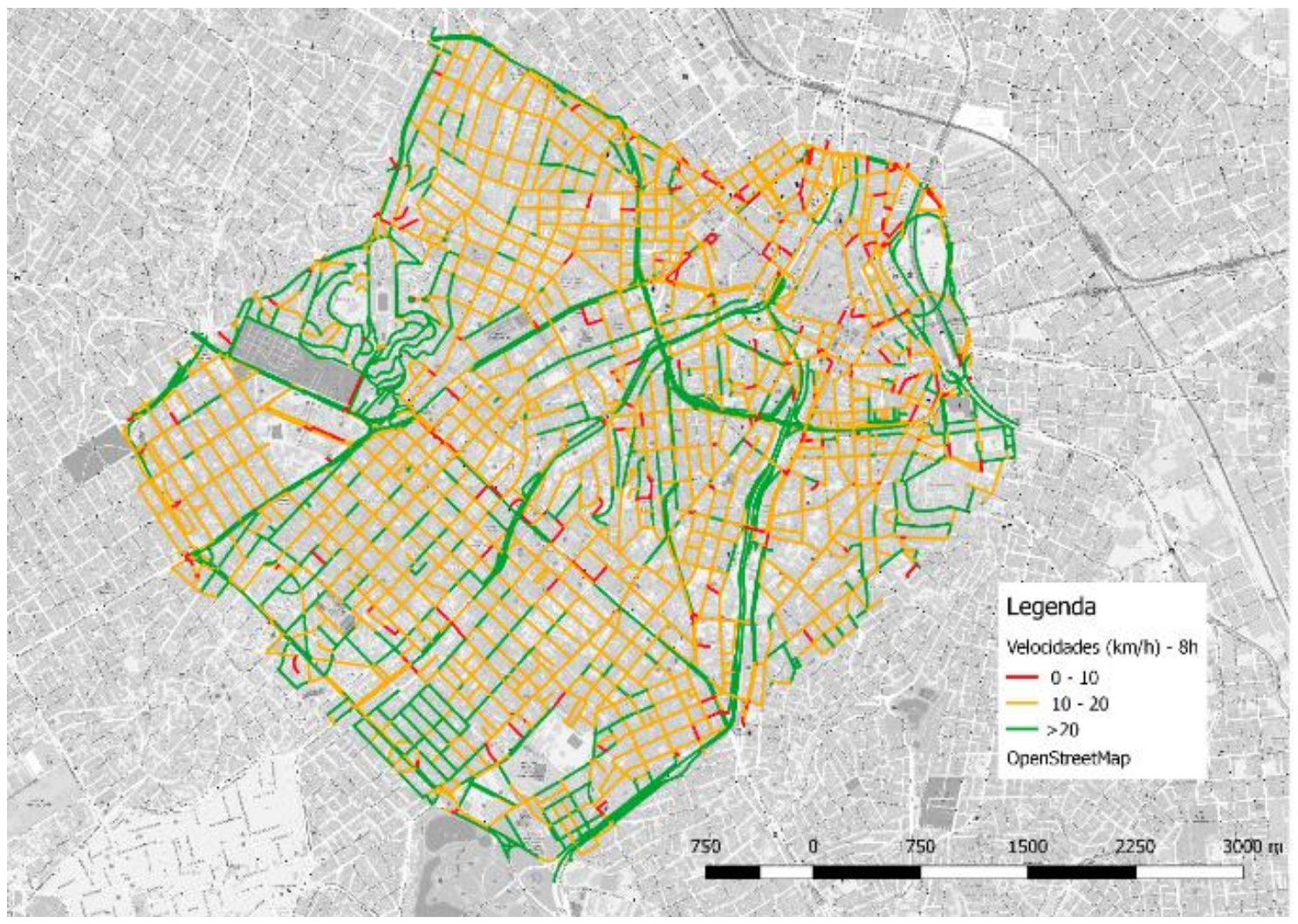

Figura 4.28: Velocidades de tráfego em São Paulo as 8h. 


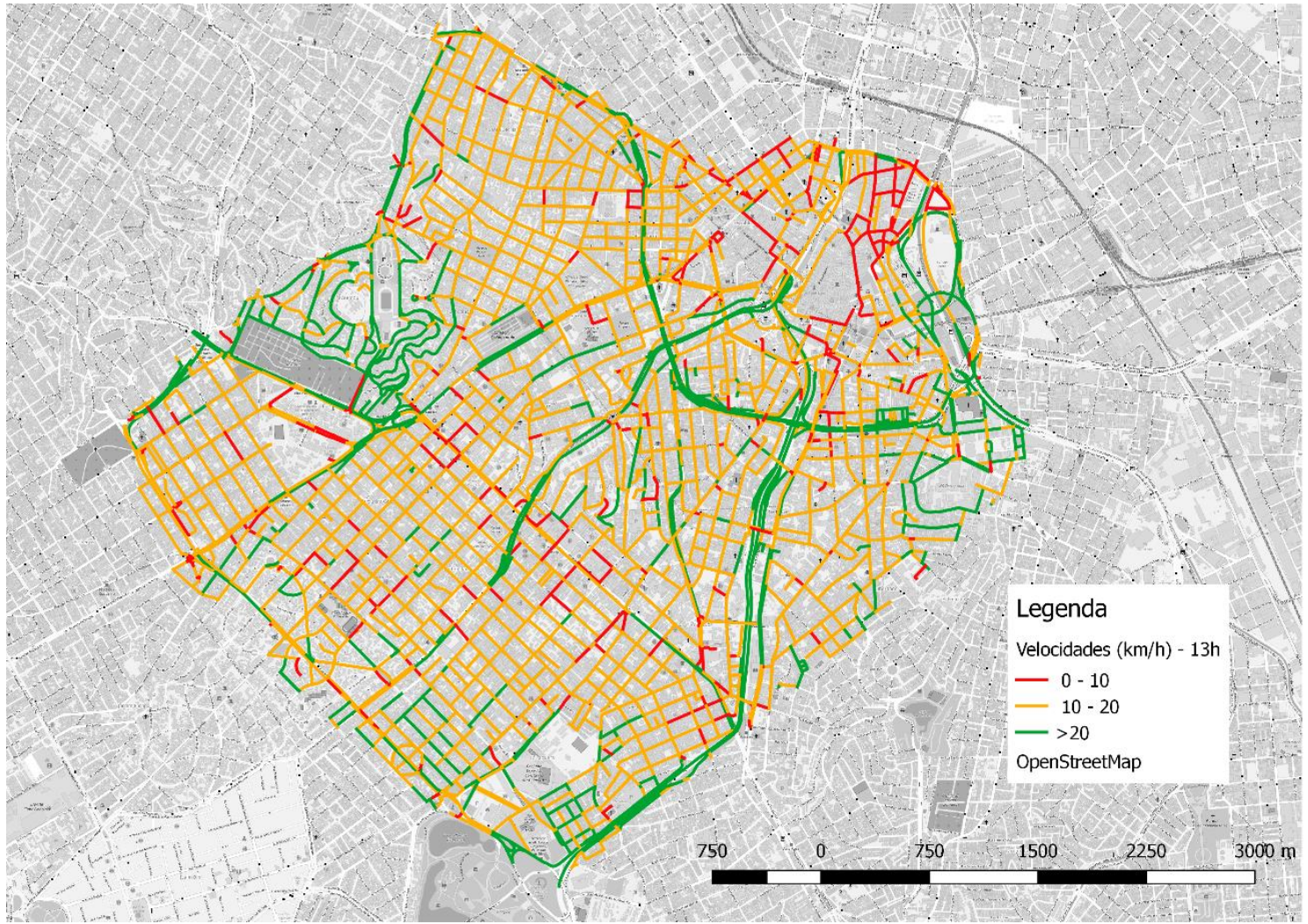

Figura 4.29: Velocidades de tráfego em São Paulo as 13h.

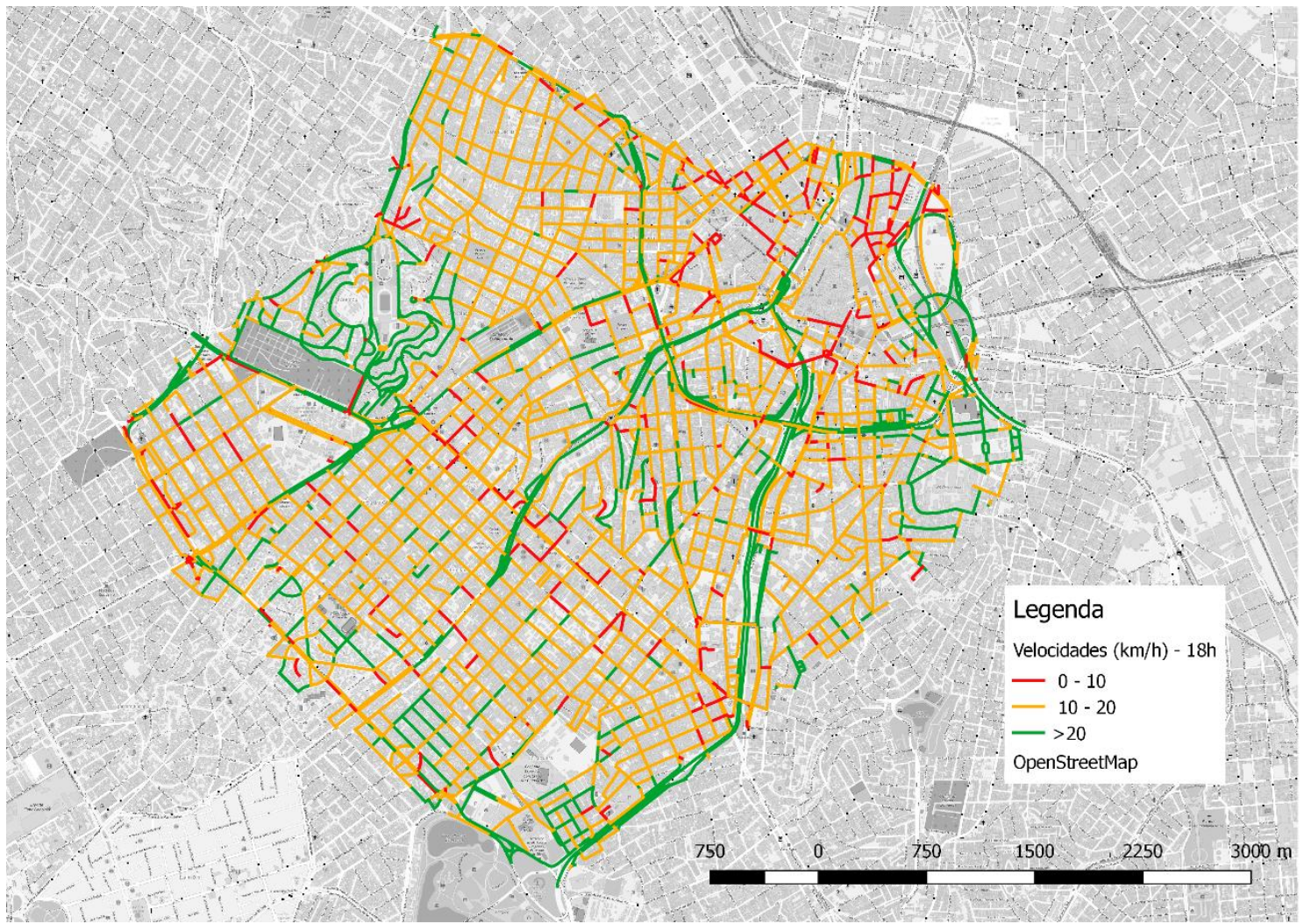

Figura 4.30: Velocidades de tráfego em São Paulo as 18h. 


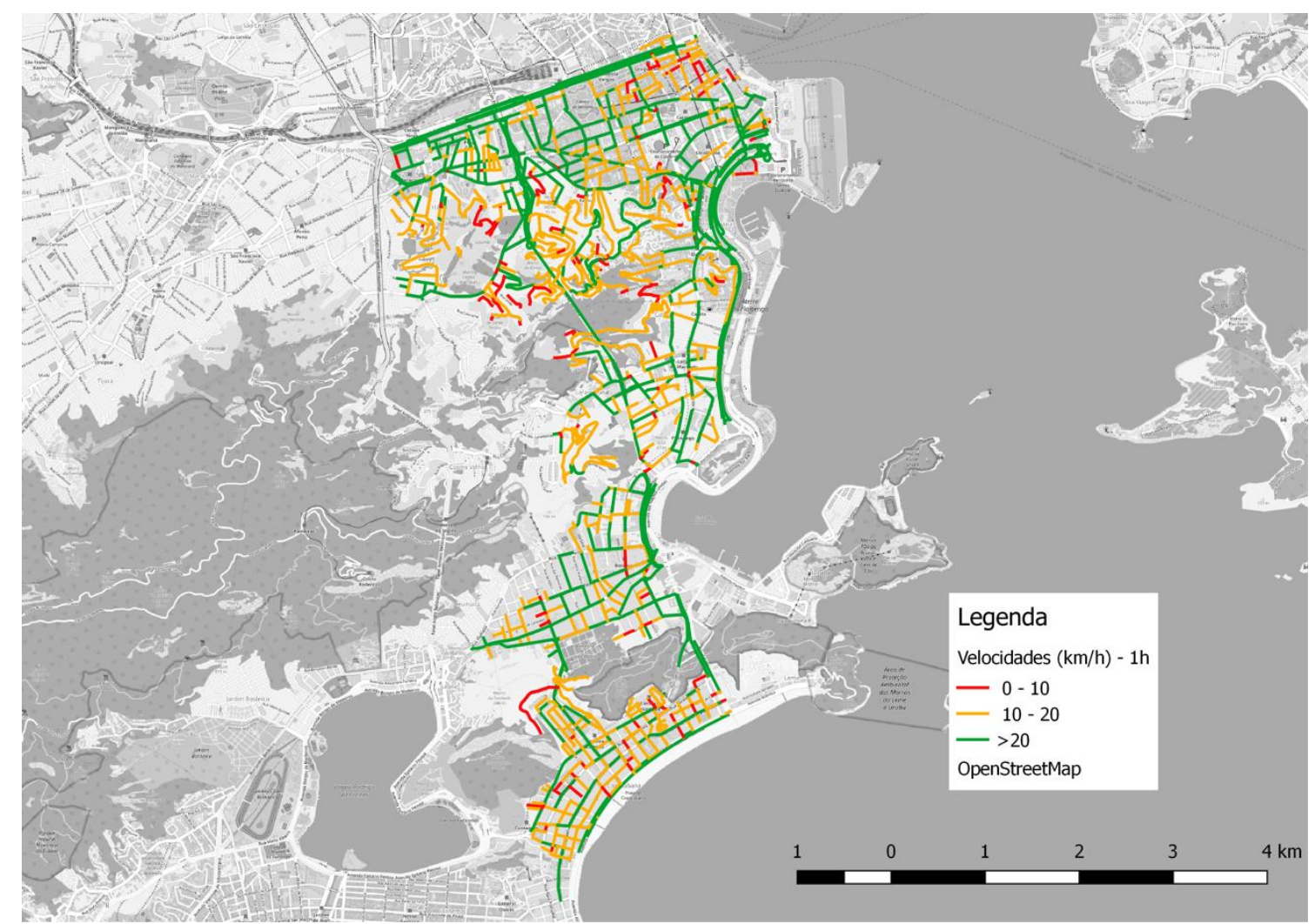

Figura 4.31: Velocidades de tráfego no Rio de Janeiro a 1h.

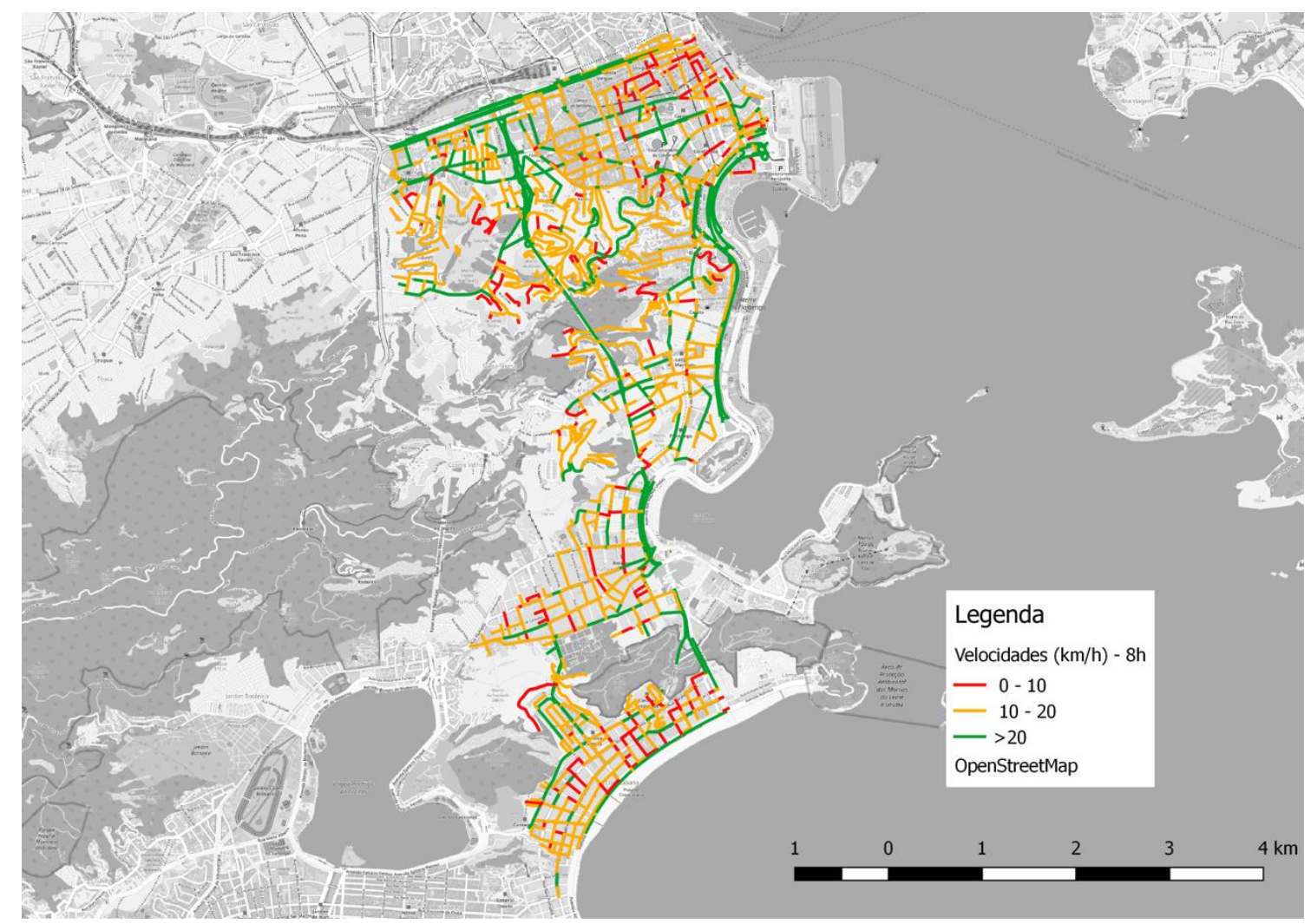

Figura 4.32: Velocidades de tráfego no Rio de Janeiro as 8h. 


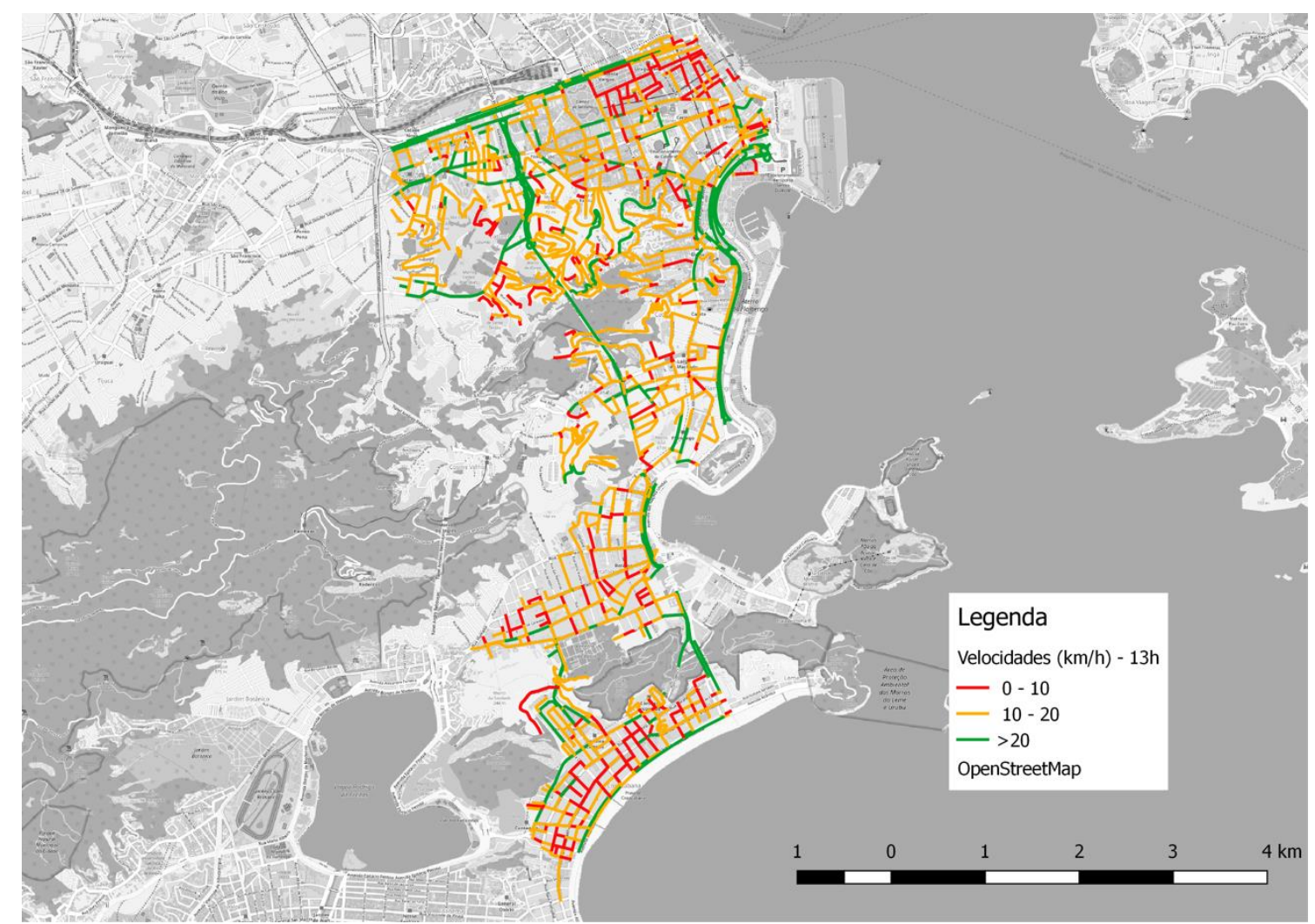

Figura 4.33: Velocidades de tráfego no Rio de Janeiro as $13 \mathrm{~h}$.

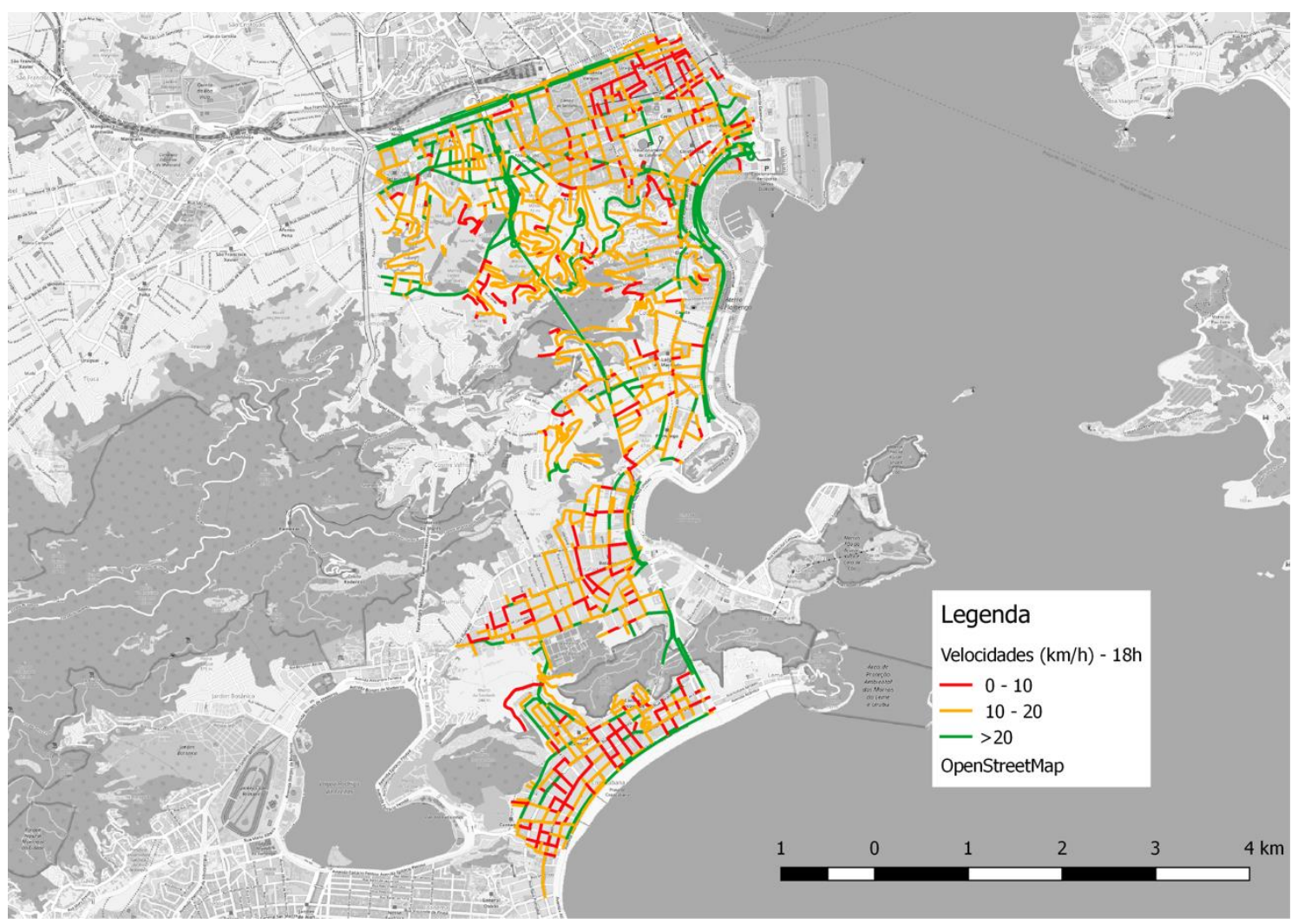

Figura 4.34: Velocidades de tráfego no Rio de Janeiro as $18 \mathrm{~h}$. 


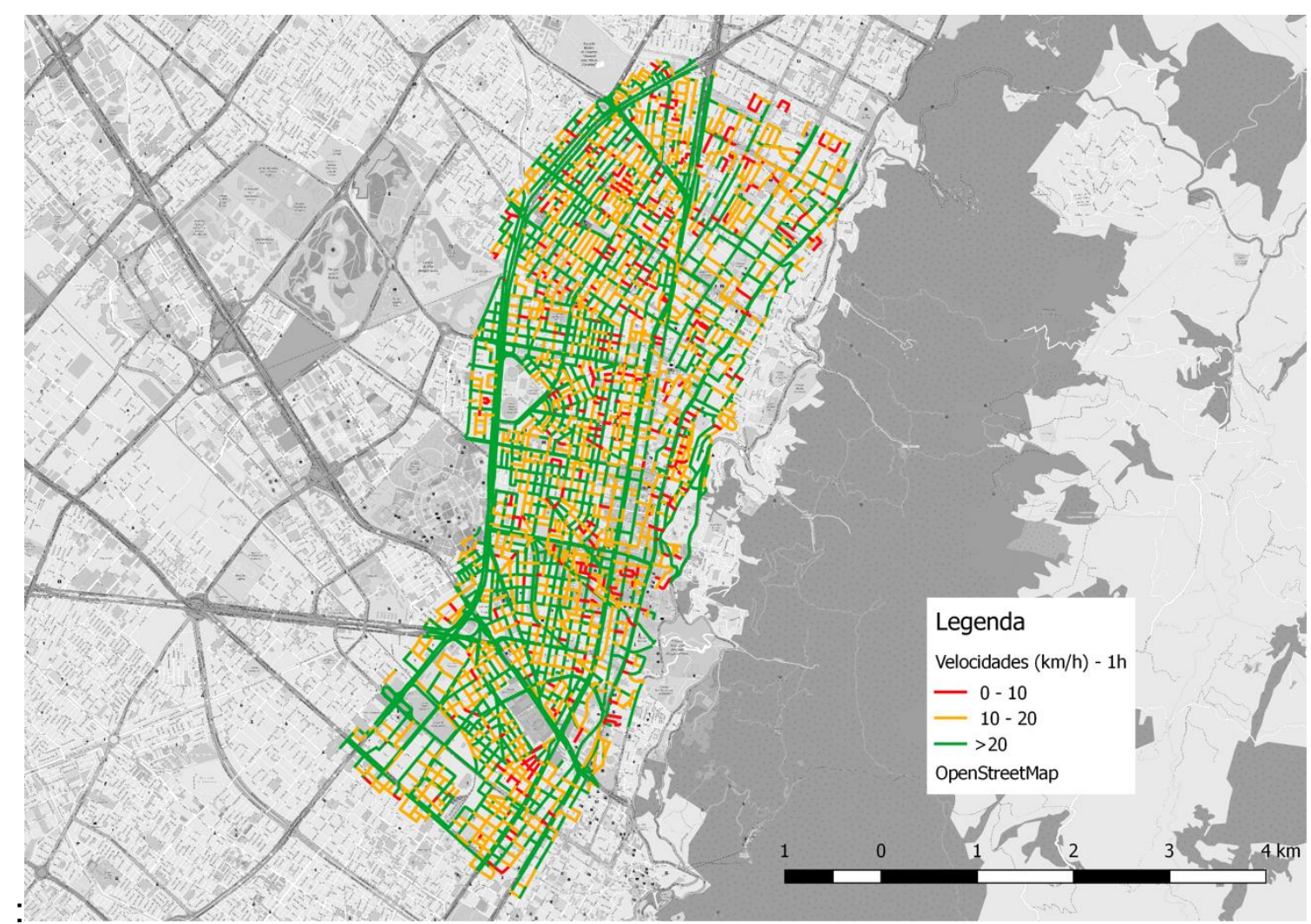

Figura 4.35: Velocidades de tráfego em Bogotá a 1h.

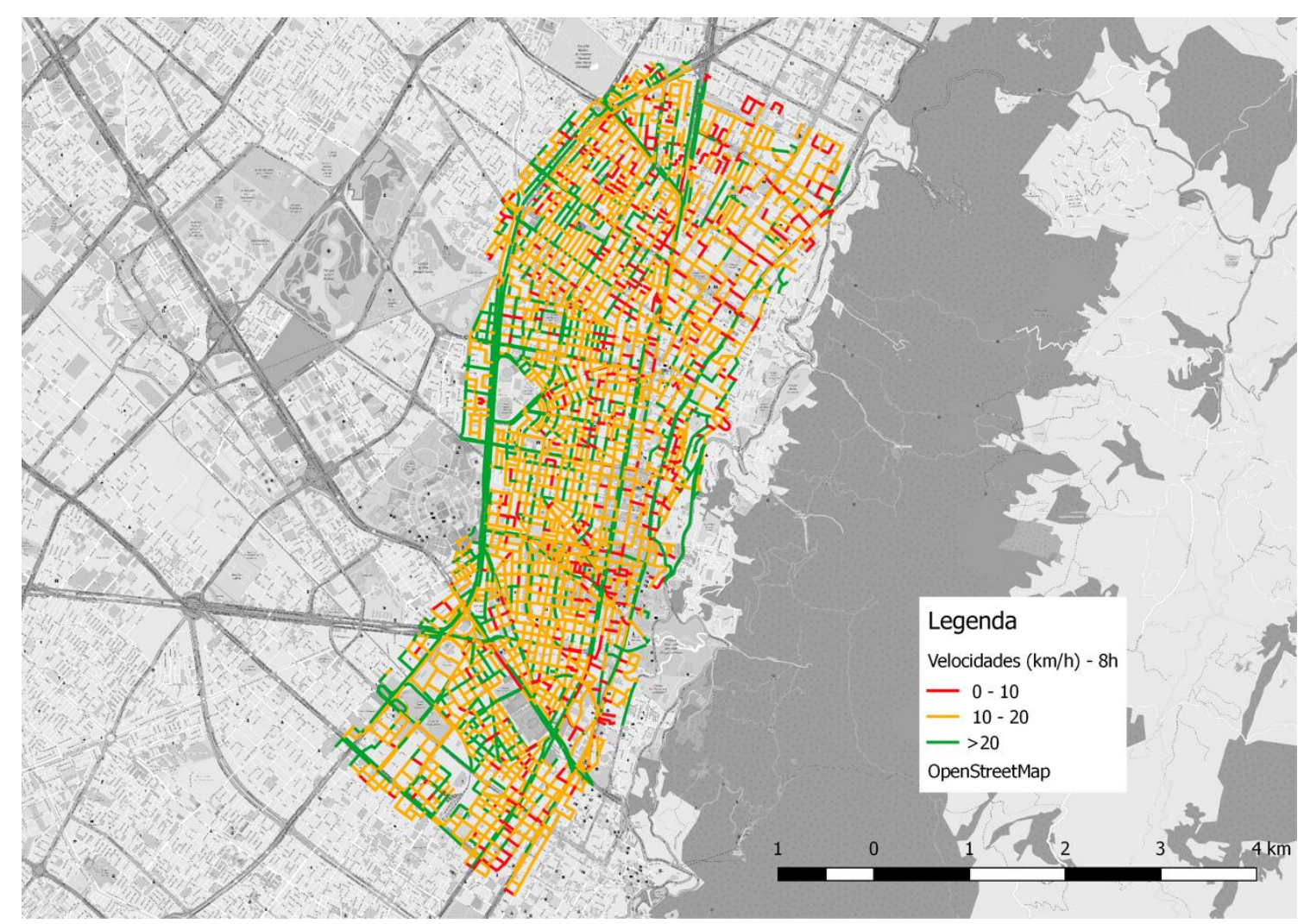

Figura 4.36: Velocidades de tráfego em Bogotá as 8h. 


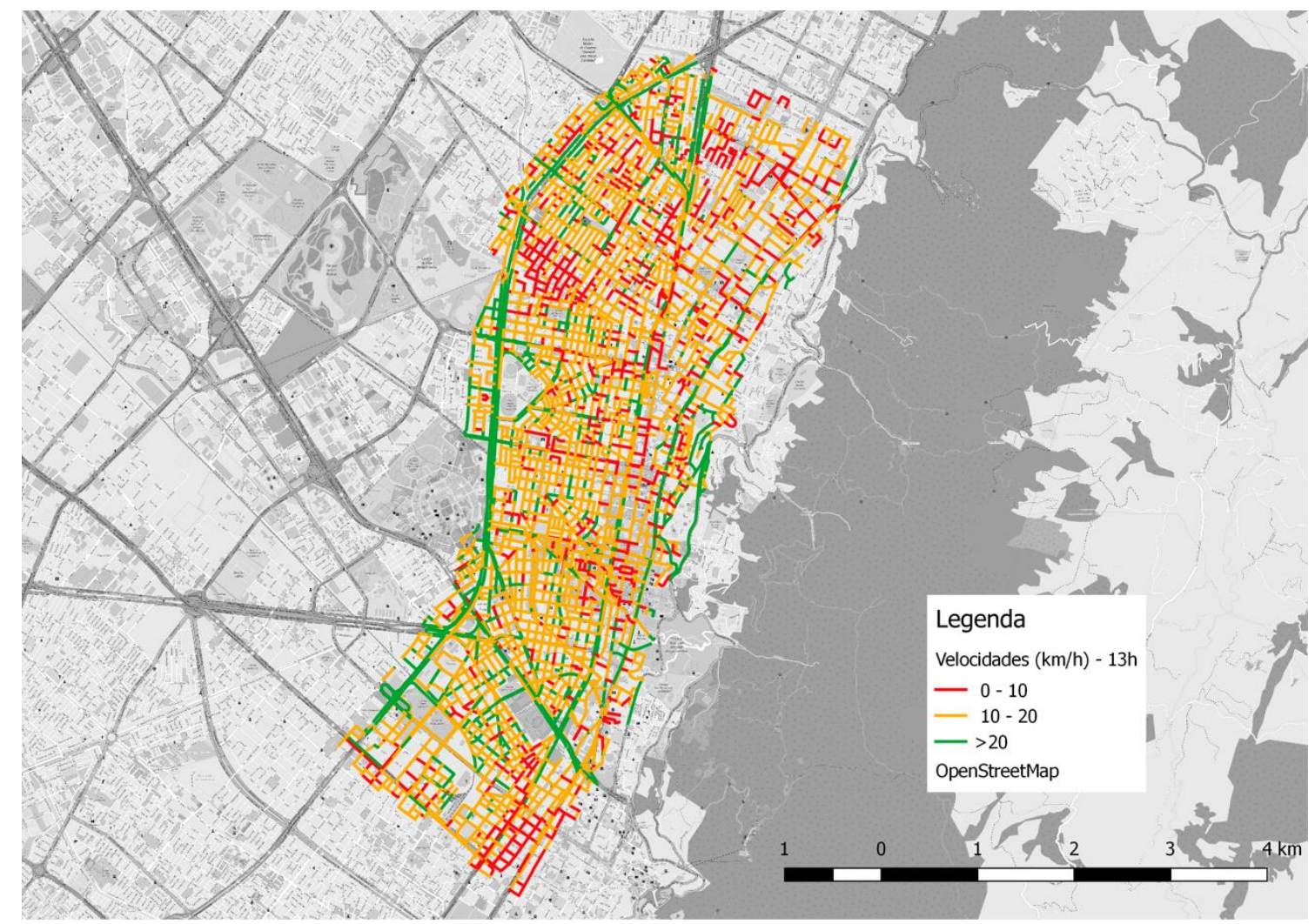

Figura 4.37: Velocidades de tráfego em Bogotá as 13h.

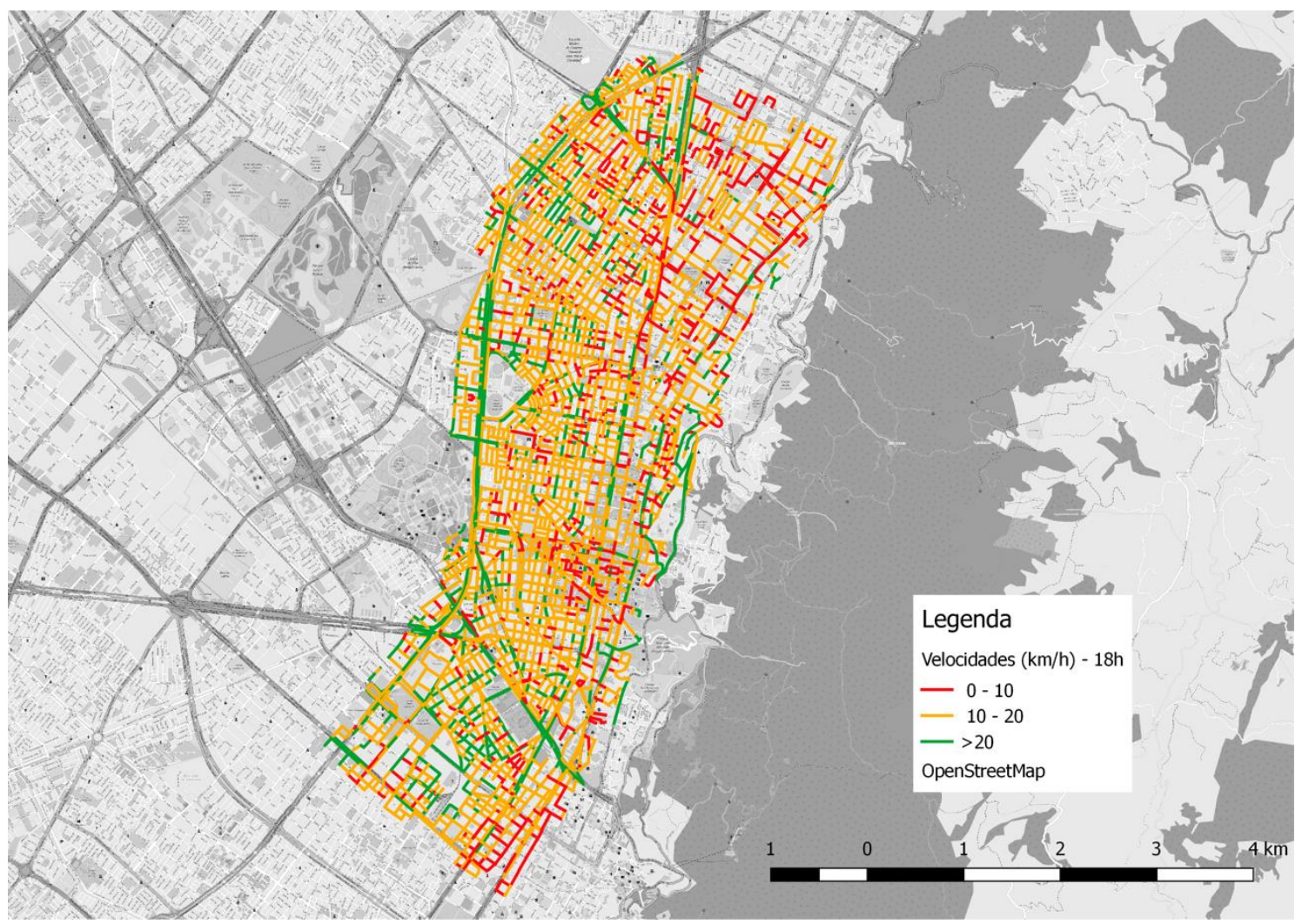

Figura 4.38: Velocidades de tráfego em Bogotá as 18h. 


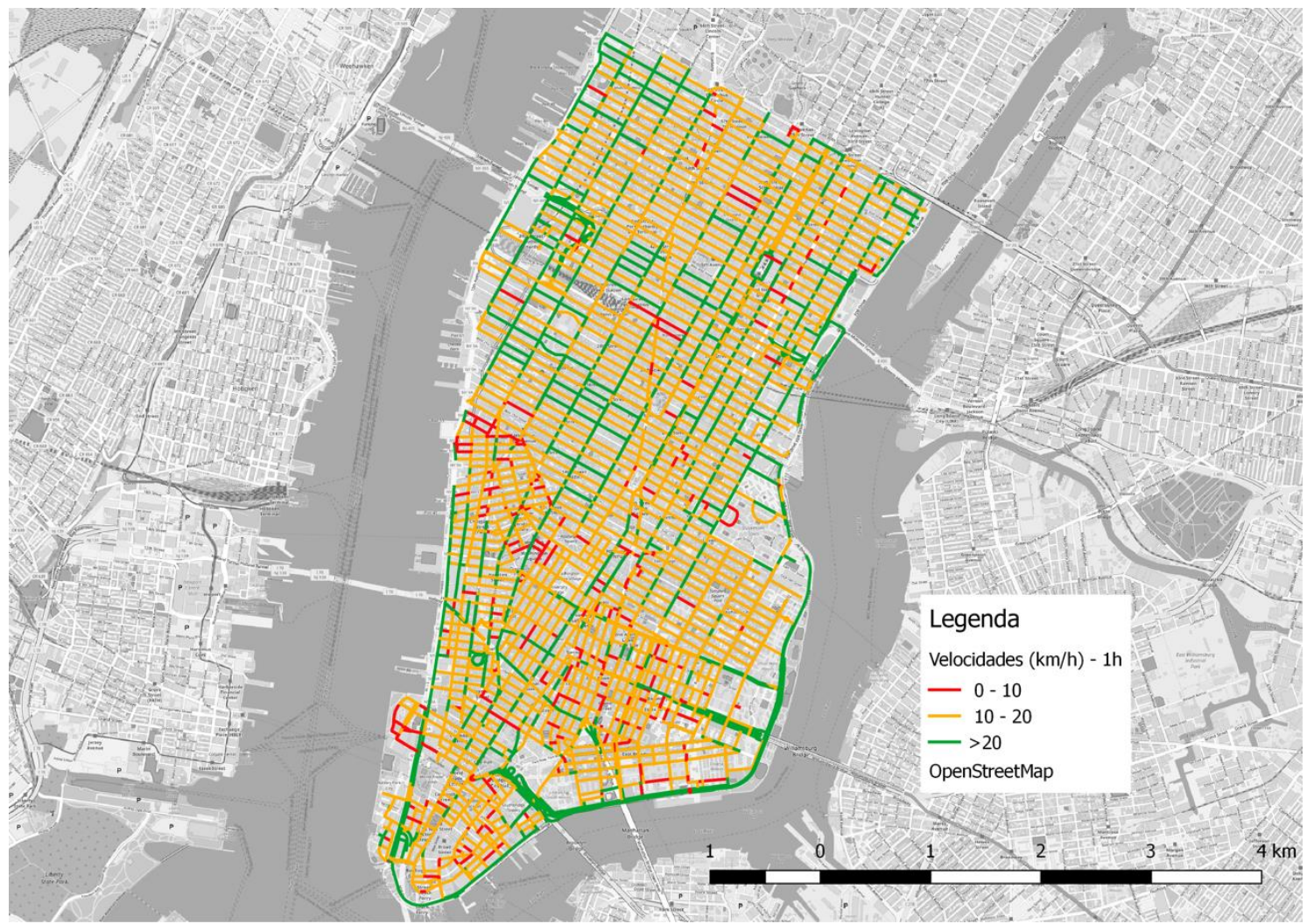

Figura 4.39: Velocidades de tráfego em Nova lorque a $1 \mathrm{~h}$.

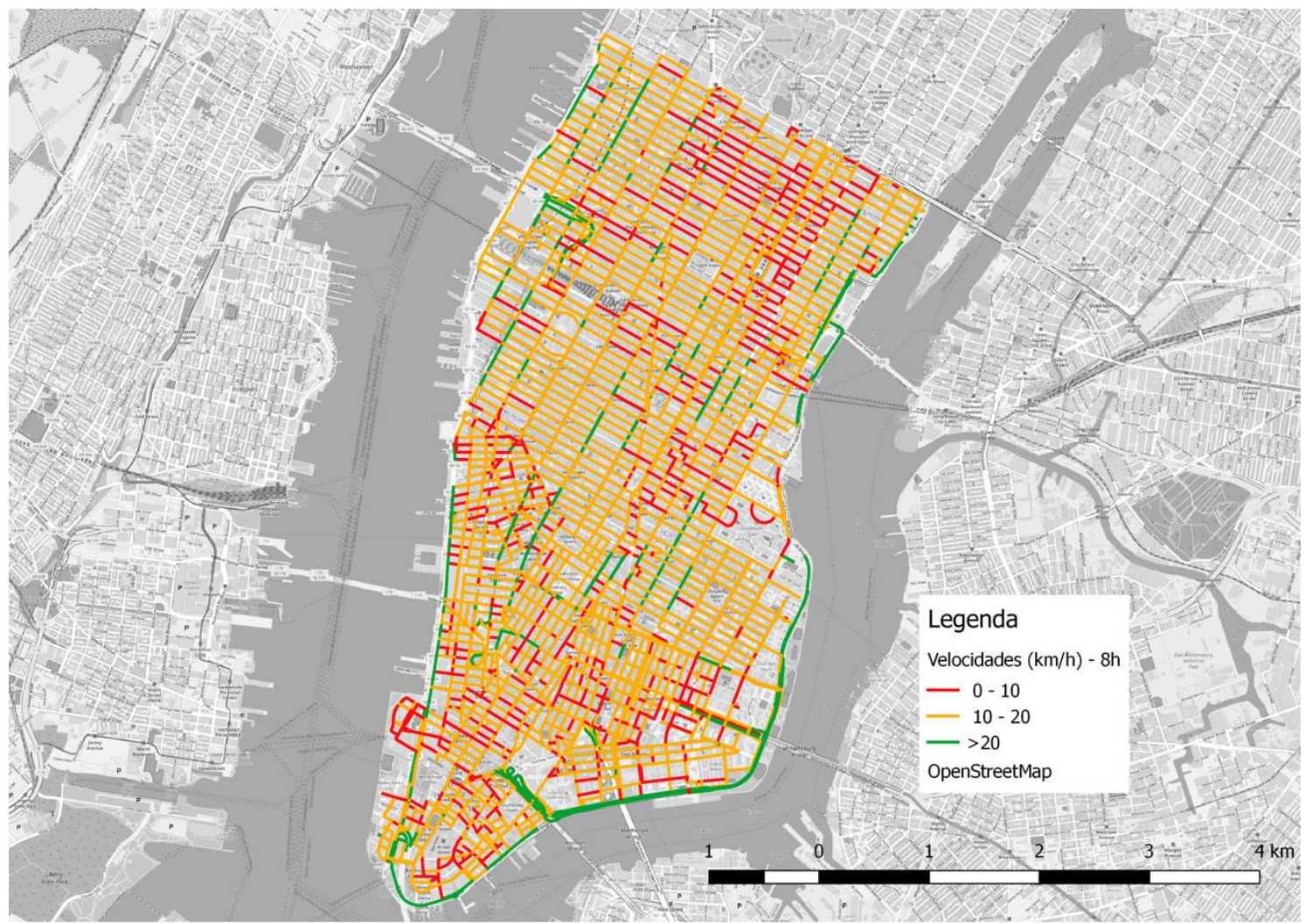

Figura 4.40: Velocidades de tráfego em Nova lorque as 8h. 


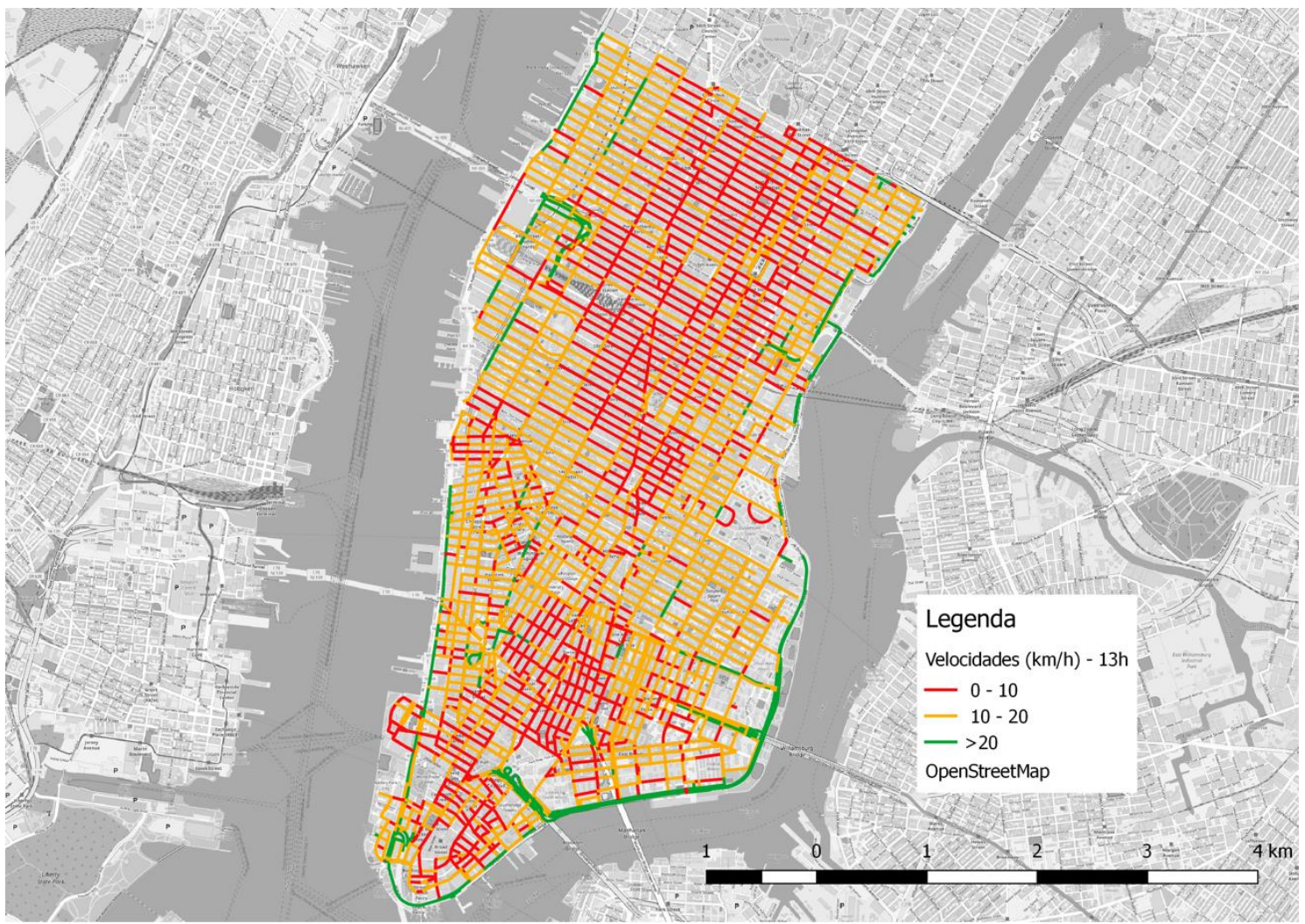

Figura 4.41: Velocidades de tráfego em Nova lorque as 13h.

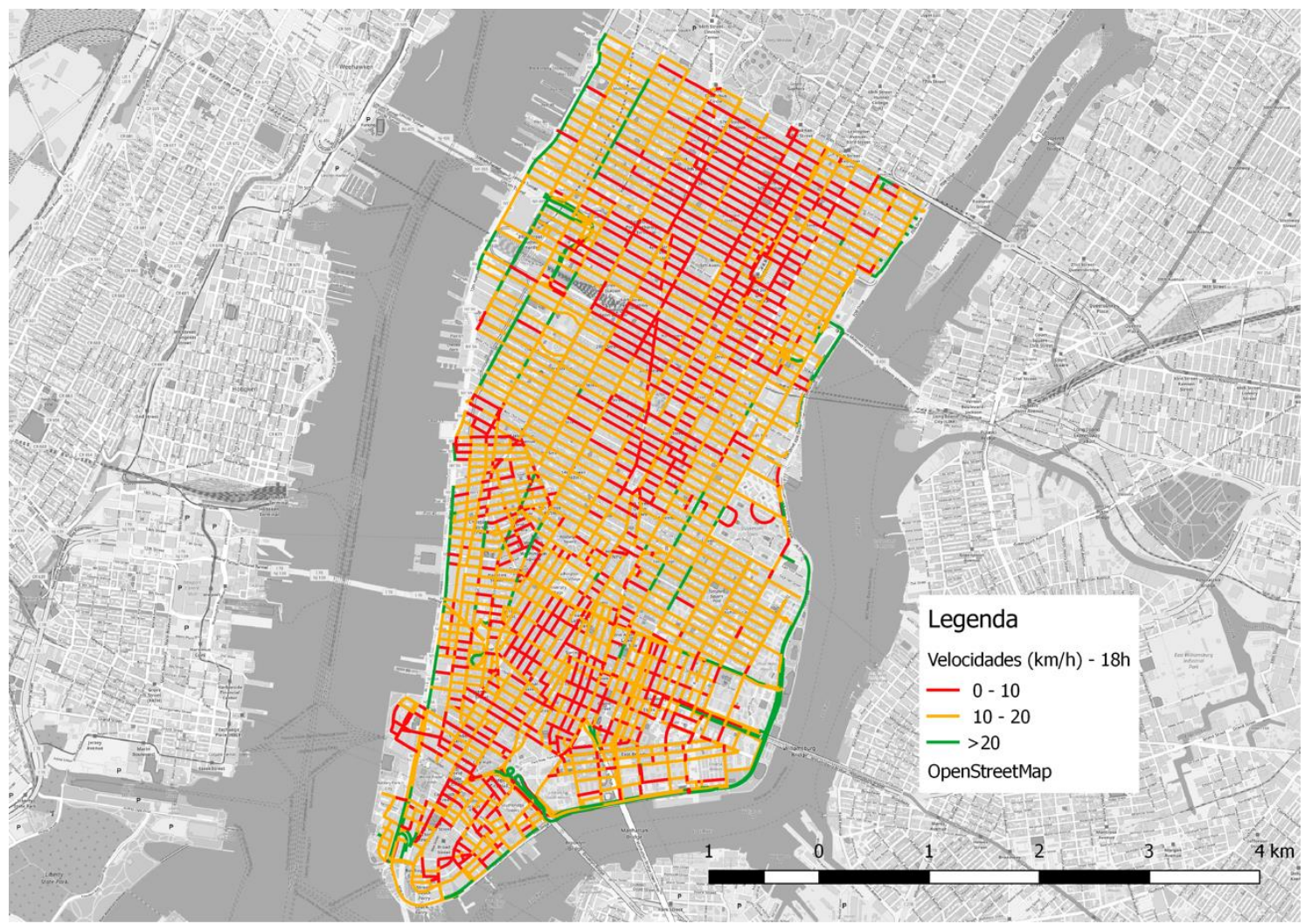

Figura 4.42: Velocidades de tráfego em Nova lorque as $18 \mathrm{~h}$. 


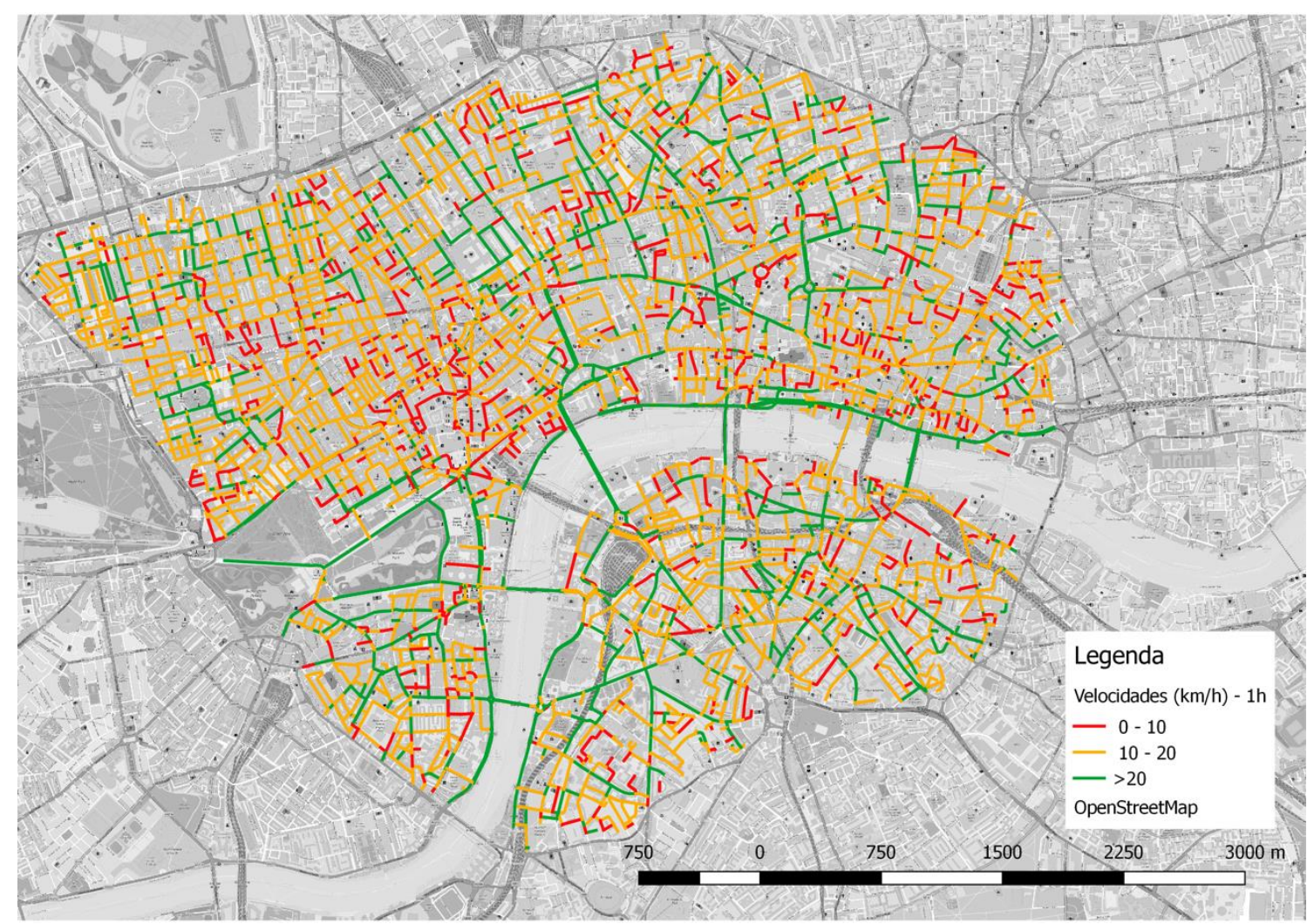

Figura 4.43: Velocidades de tráfego em Londres a $1 \mathrm{~h}$.

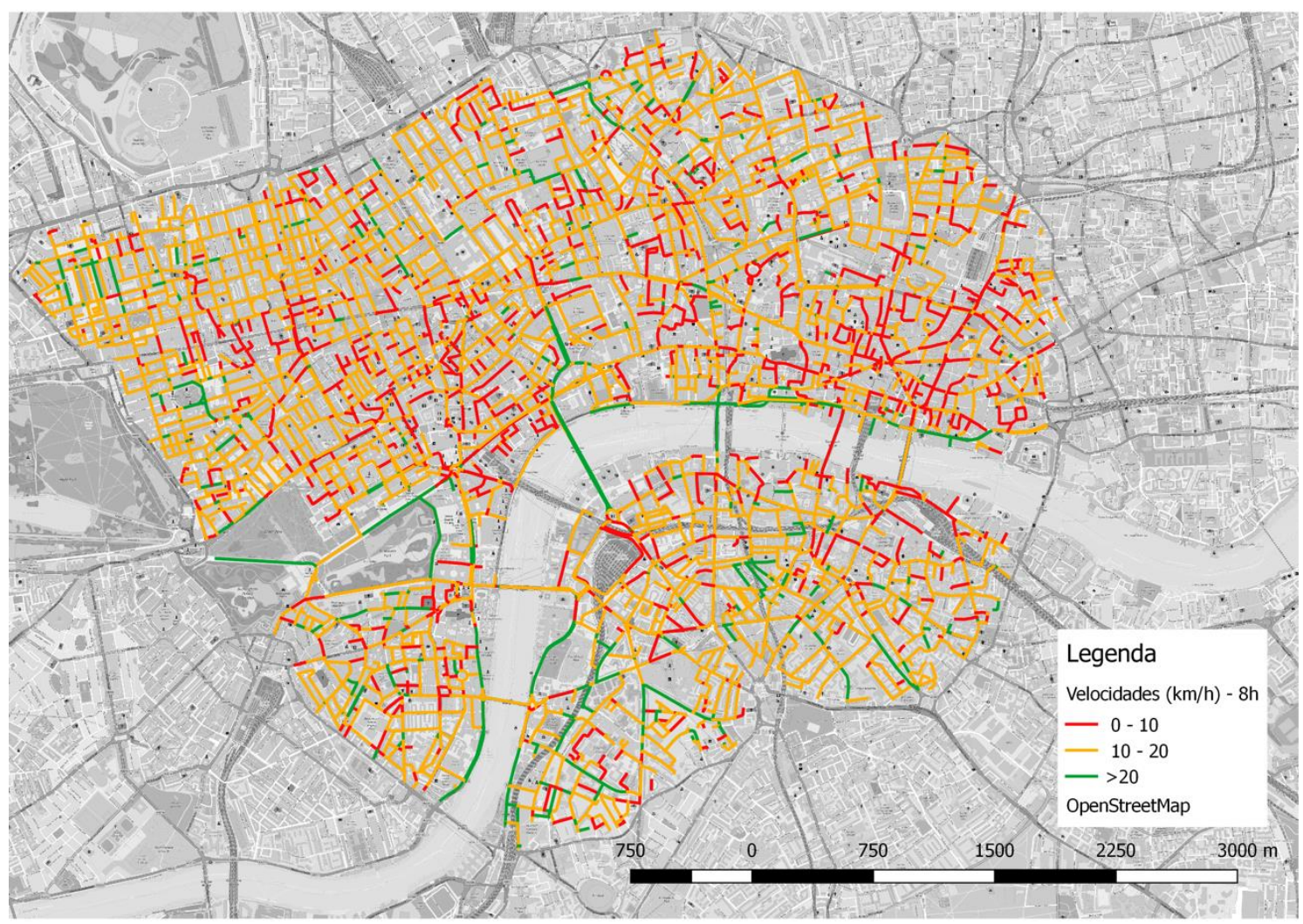

Figura 4.44: Velocidades de tráfego em Londres as $8 \mathrm{~h}$. 


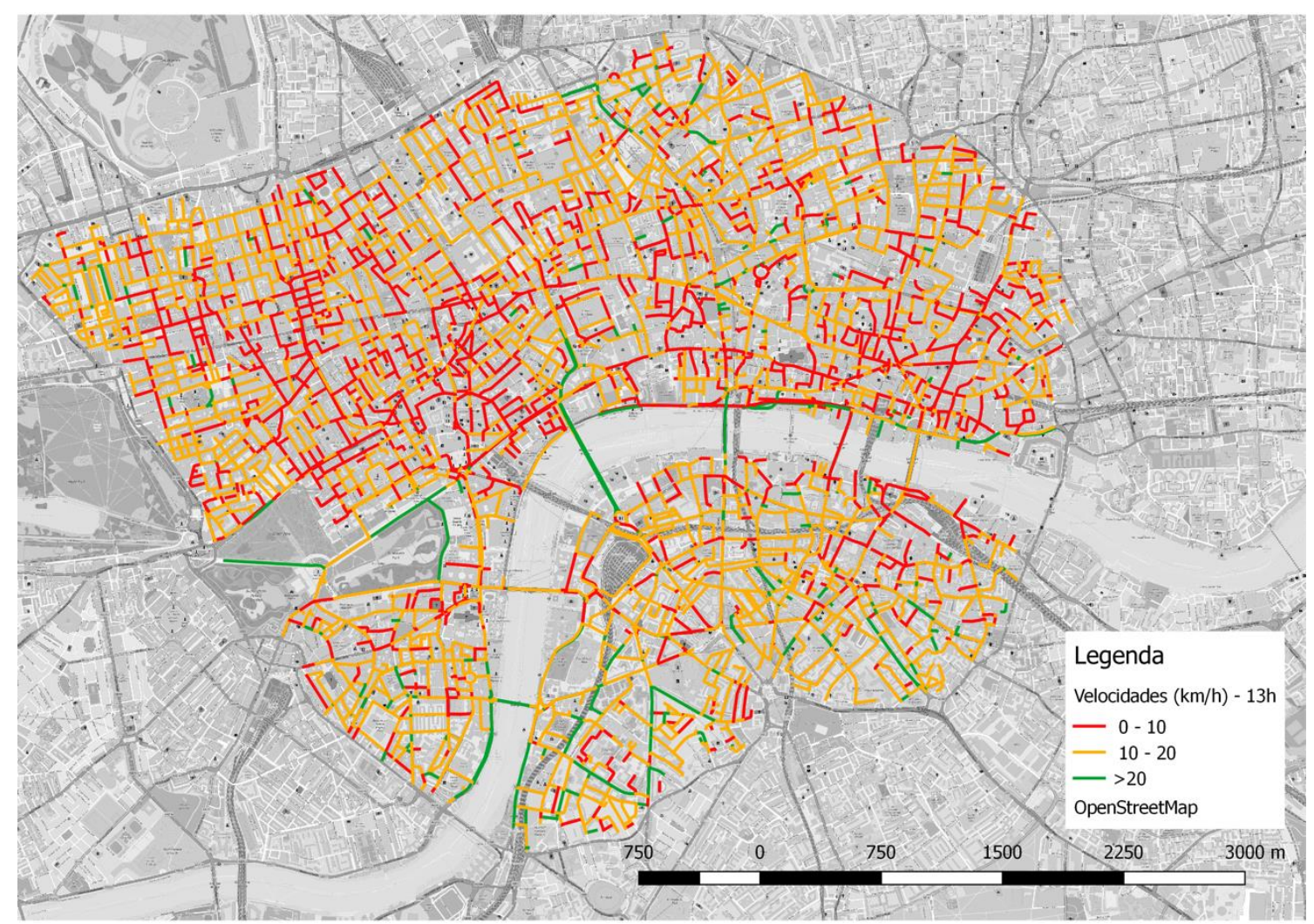

Figura 4.45: Velocidades de tráfego em Londres as 13h.

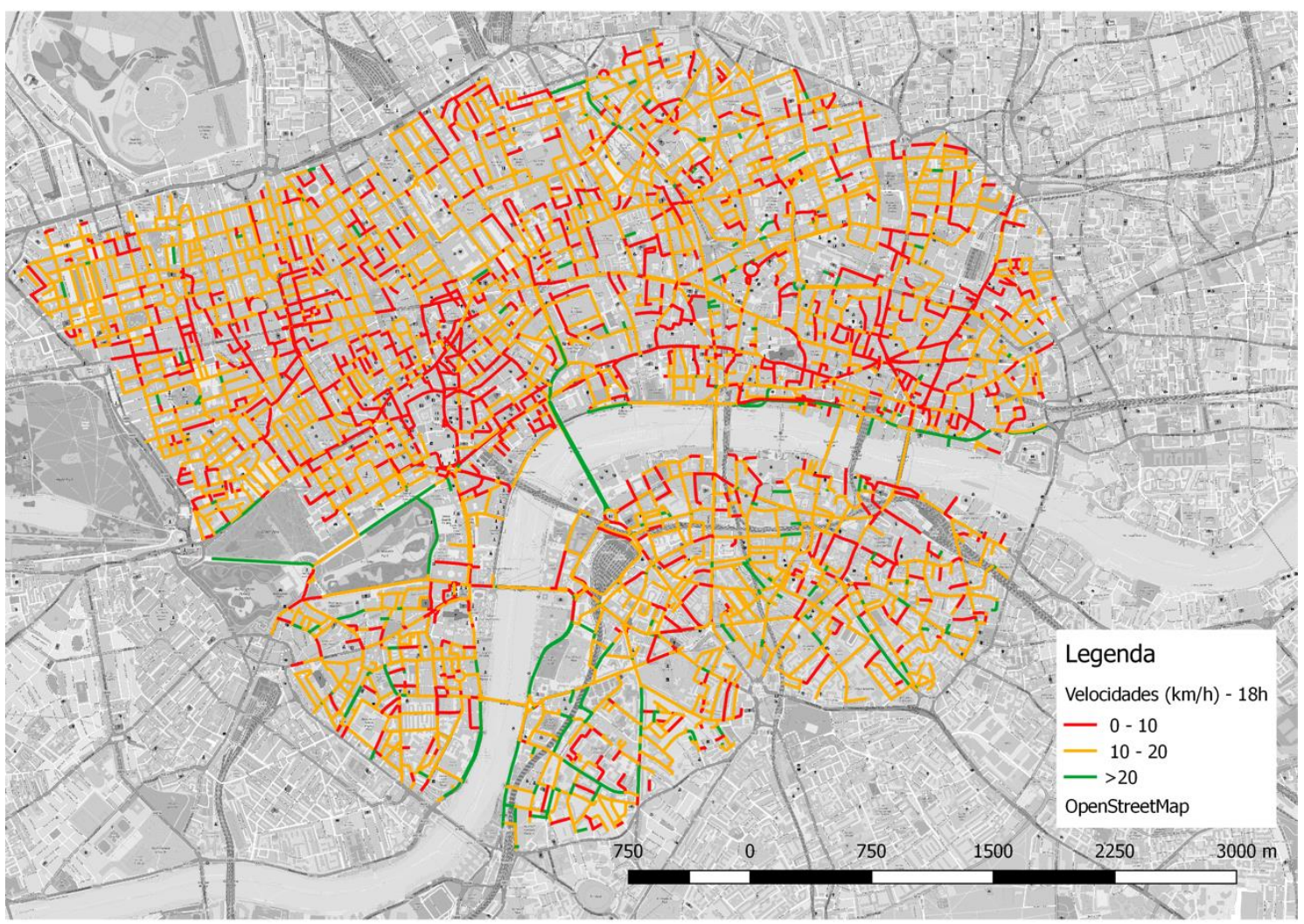

Figura 4.46: Velocidades de tráfego em Londres as $18 \mathrm{~h}$. 


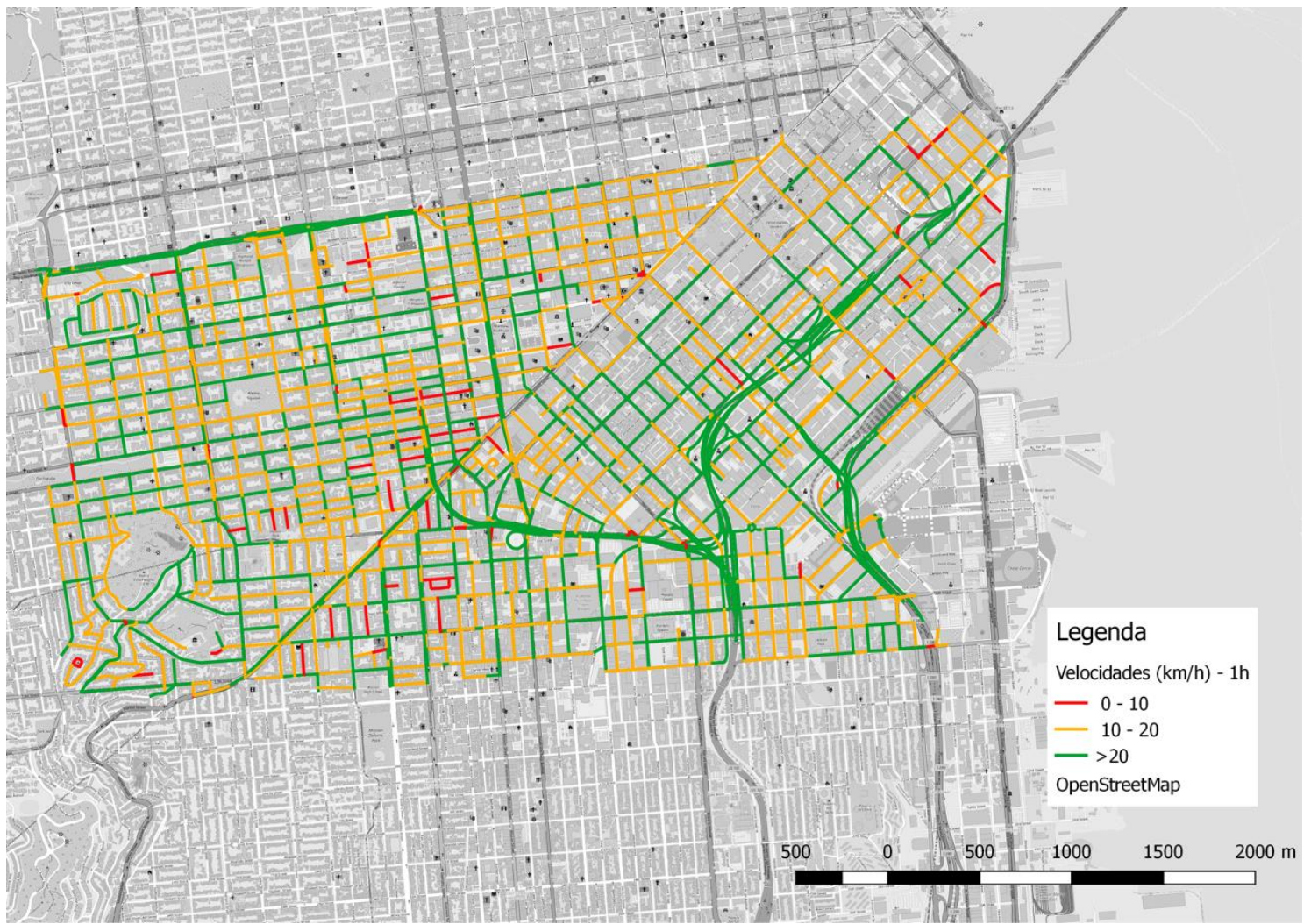

Figura 4.47: Velocidades de tráfego em São Francisco a 1h.

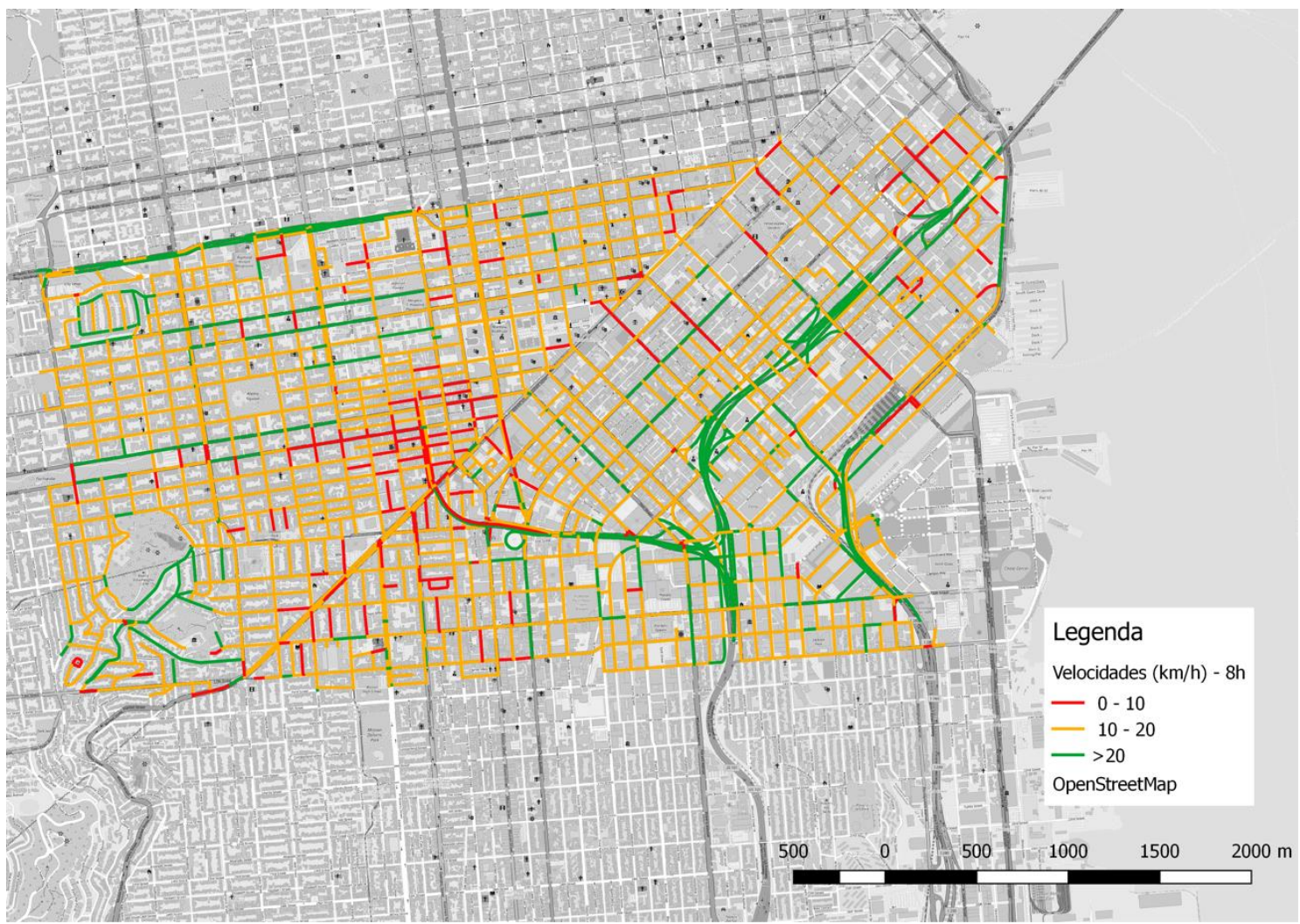

Figura 4.48: Velocidades de tráfego em São Francisco as 8h. 


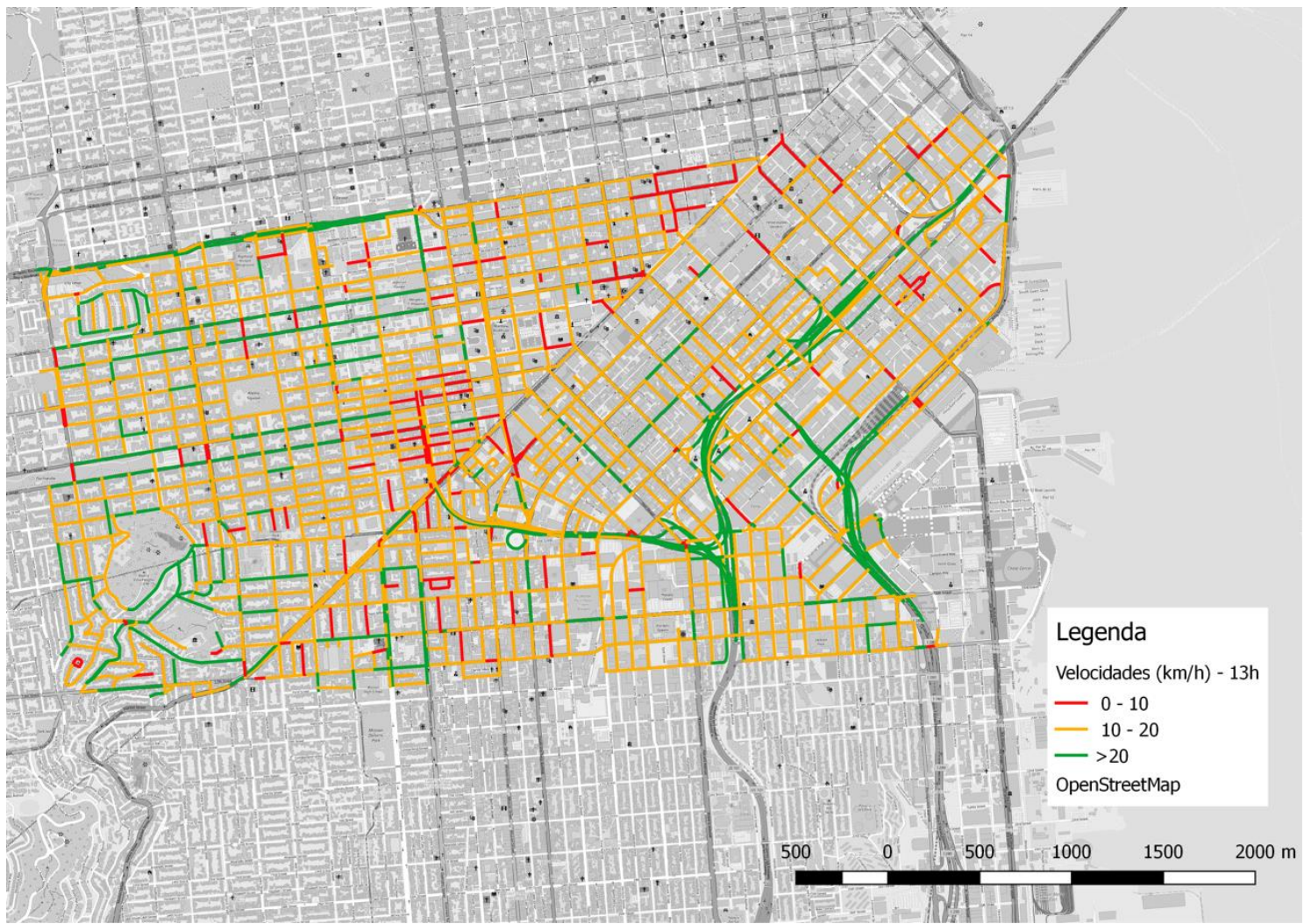

Figura 4.49: Velocidades de tráfego em São Francisco as 13h.

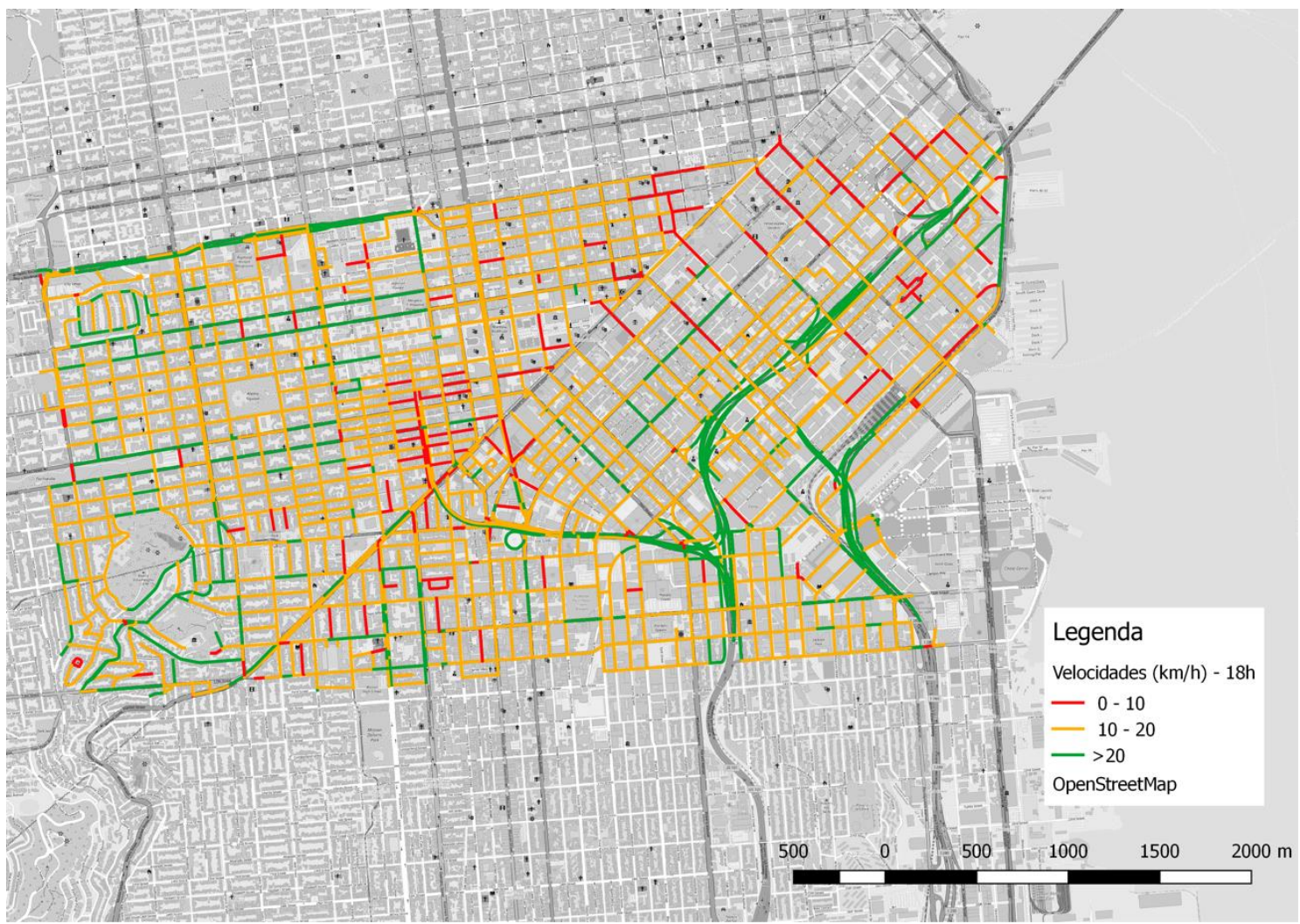

Figura 4.50: Velocidades de tráfego em São Francisco as 18h. 


\subsubsection{Modos Não Motorizados}

Também foram calculados os IRs para os modos bicicleta e a pé. Como discutido no capítulo 3, não foram feitas solicitações à API do Google Maps de todas as rotas possíveis (todas as combinações origem e destino possíveis entre os pontos aleatórios). Só foram feitas solicitações para os pares de pontos cuja distância linear entre si fosse menor que $1 \mathrm{~km}$ para caminhada e $3 \mathrm{~km}$ para bicicleta.

Os resultados obtidos para o modo bicicleta estão nos gráficos das Figuras 4.51 a 4.55. Está parte da análise não foi conduzida em Bogotá, pois o Google Maps ainda não possui a ferramenta de cálculo de caminhos para bicicletas na cidade.

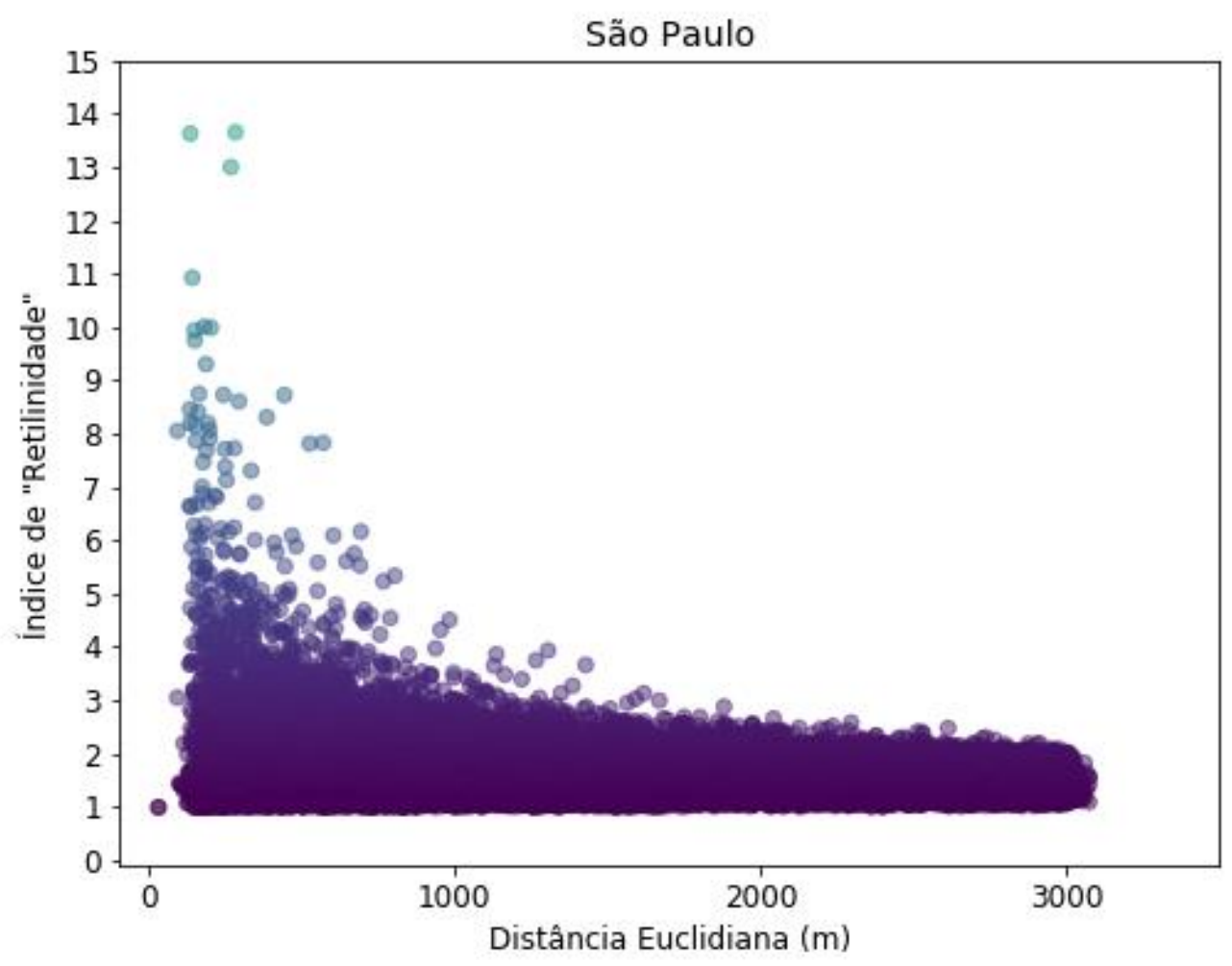

Figura 4.51: Distribuição IRbicicleta x Distância Euclidiana de São Paulo. 


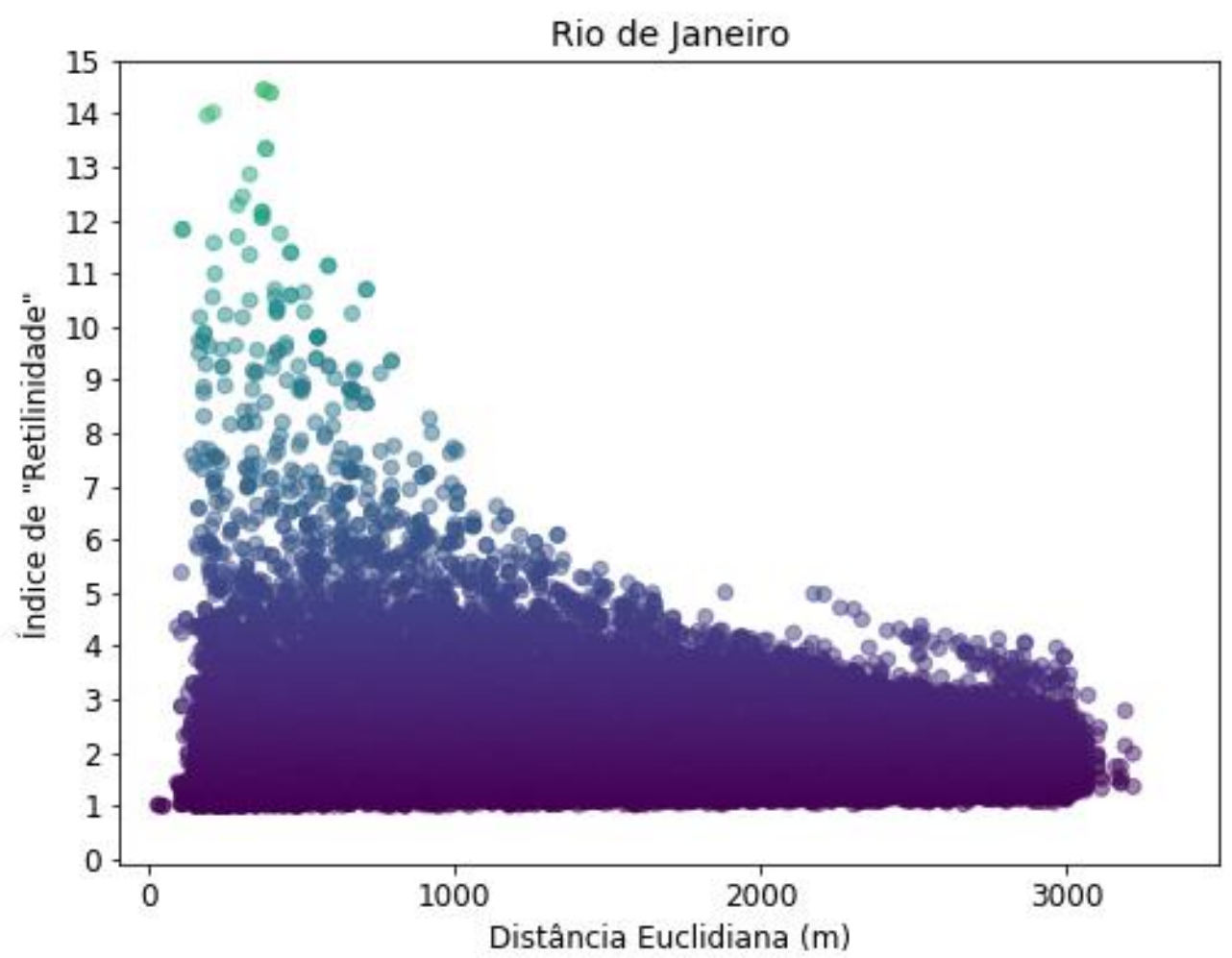

Figura 4.52: Distribuição IRbicicleta X Distância Euclidiana do Rio de Janeiro.

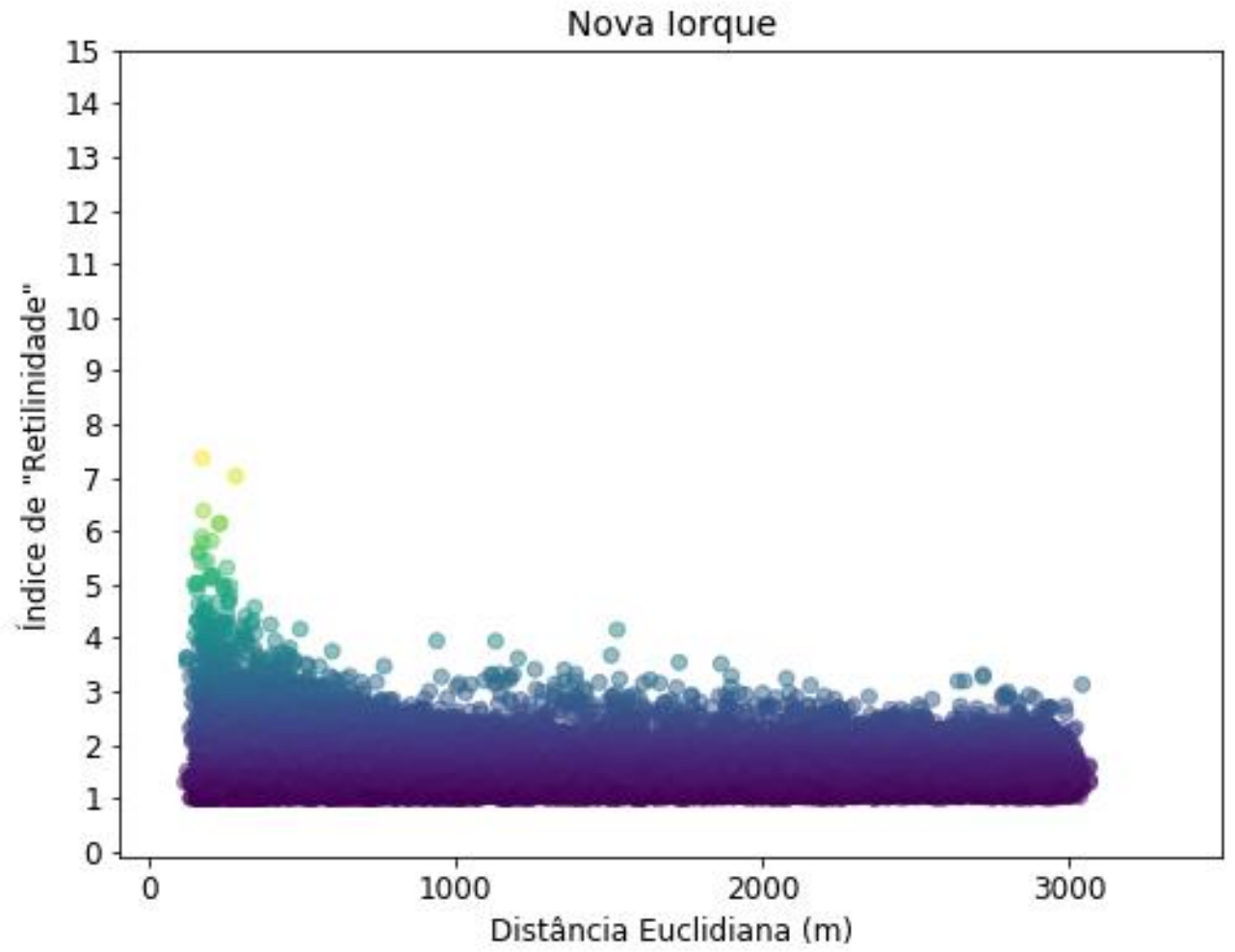

Figura 4.53: Distribuição IRbicicleta $\times$ Distância Euclidiana de Nova lorque. 


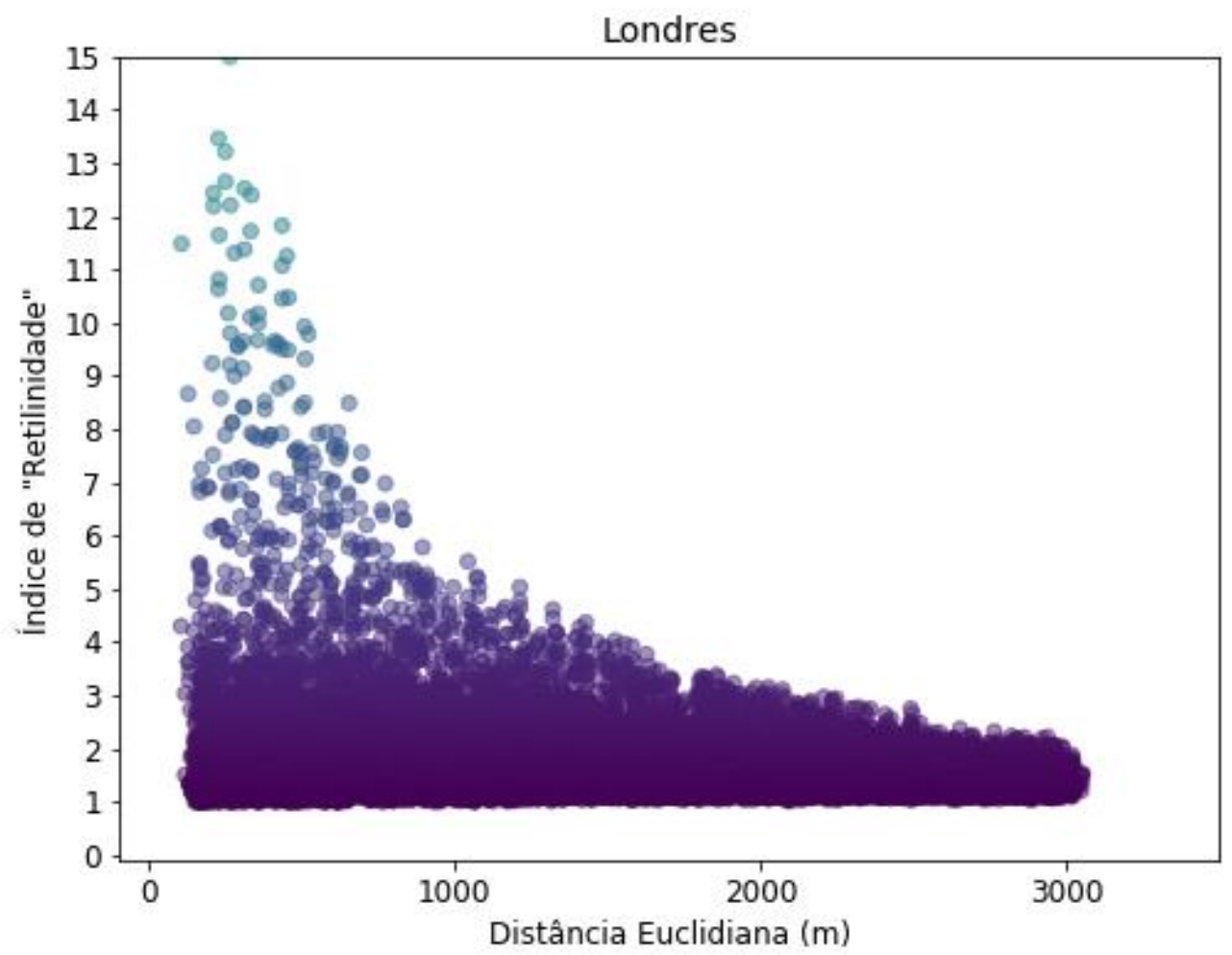

Figura 4.54: Distribuição IR bicicleta x Distância Euclidiana de Londres.

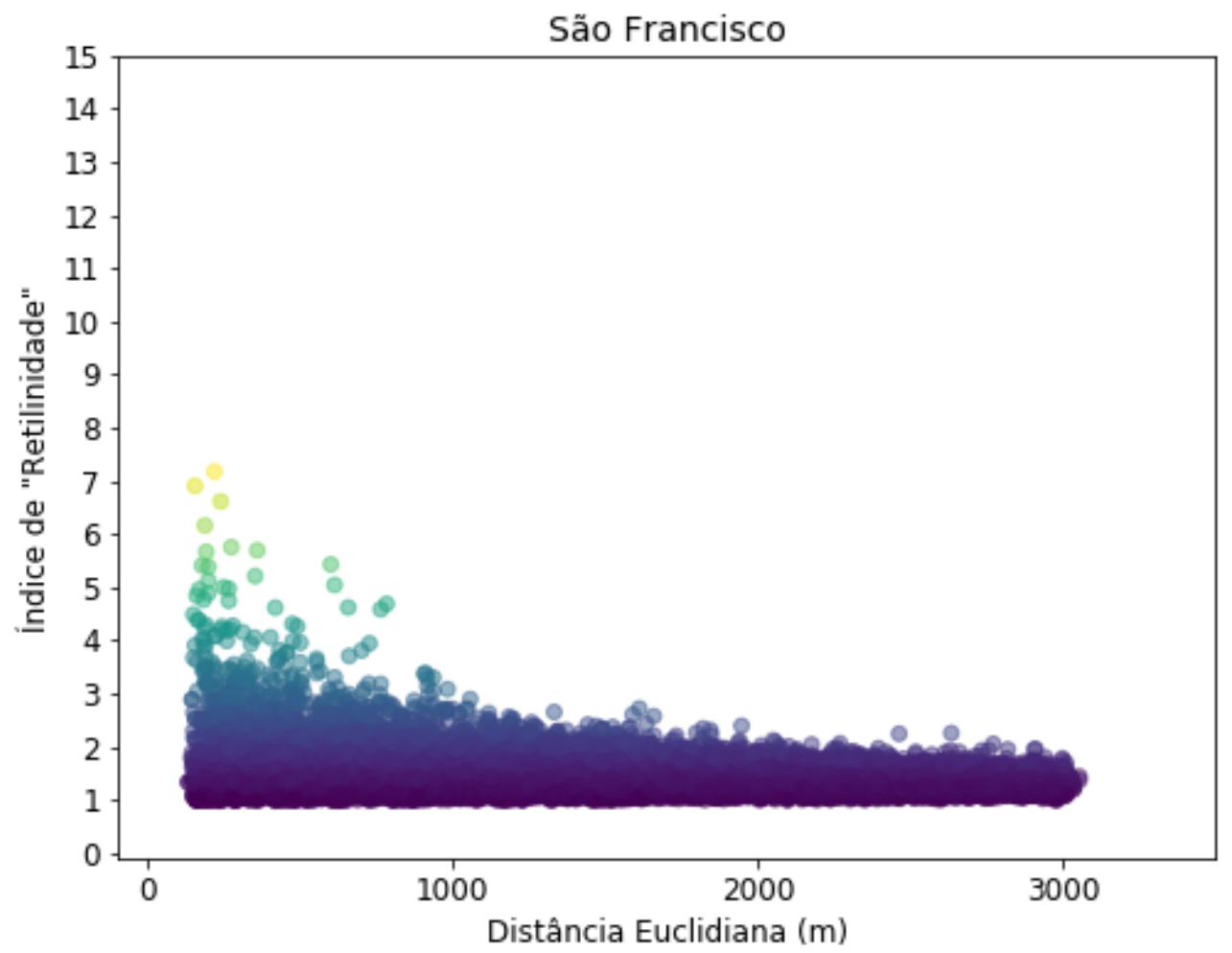

Figura 4.55: Distribuição IR bicicleta X Distância Euclidiana de São Francisco. 
Observa-se que, assim como para modos motorizados, o IR é sensível a distância euclidiana; maiores amplitudes de IR são esperadas para menores distância euclidianas. Porém, percebe-se que as distribuições geradas são diferentes para cada cidade, por exemplo São Paulo, Rio de Janeiro e Londres apresentam maiores valores de IR para menores valores de distância euclidiana que Nova lorque e São Francisco.

A fim de manter a coerência da análise e permitir a comparação dos resultados entre modos motorizados e não motorizados, os resultados são separados pelos mesmos intervalos de distâncias euclidianas: $100 \mathrm{~m}$ a $500 \mathrm{~m}, 500 \mathrm{~m}$ a $1 \mathrm{~km}, 1 \mathrm{~km}$ a $2 \mathrm{~km}$, $2 \mathrm{~km}$ a $3 \mathrm{~km}$ e maior que $3 \mathrm{~km}$. Note que nesta analise são cinco faixas de distância ao invés de seis, devido ao critério de limitar as análises para bicicleta a uma distância euclidiana entre pontos consecutivos até $3 \mathrm{~km}$.

A Tabela 4.12 apresenta os valores de IRM e a Figura 4.56 apresenta os boxplots resultantes para cada faixa de distância. Observa-se pelos boxplots da Figura 4.56 que a amplitude e os valores de IR para bicicleta em geral são menores do que para veículos motorizados (Figura 4.19), porém comparando os valores entre as cidades, as que apresentam os maiores valores de IR para bicicleta são as mesmas que apresentam os maiores valores de IR para veículos motorizados. Tanto pela Tabela 4.12,quanto pelos boxplots, percebe-se que o Rio de Janeiro é a cidade em se espera maiores distâncias percorridas em uma operação de entregas realizada de bicicleta, pois os valores de IRM obtidos são maiores que das outras cidades para todas as faixas de distância, o contrário pode ser dito para São Francisco que apresenta os menores valores de IRM.

Tabela 4.12: Índices de "Retilinidade" Médios para bicicleta.

\begin{tabular}{cccccc}
\hline & $0.1-0.5 \mathrm{~km}$ & $0.5-1 \mathrm{~km}$ & $1-2 \mathrm{~km}$ & $2-3 \mathrm{~km}$ & $>3 \mathrm{~km}$ \\
\hline São Paulo & 2,06 & 1,70 & 1,51 & 1,43 & 1,40 \\
Rio de Janeiro & 2,66 & 2,29 & 1,95 & 1,83 & 1,84 \\
Nova lorque & 1,83 & 1,56 & 1,45 & 1,40 & 1,42 \\
Londres & 2,14 & 1,74 & 1,54 & 1,43 & 1,39 \\
São Francisco & 1,75 & 1,54 & 1,42 & 1,35 & 1,32 \\
\hline
\end{tabular}




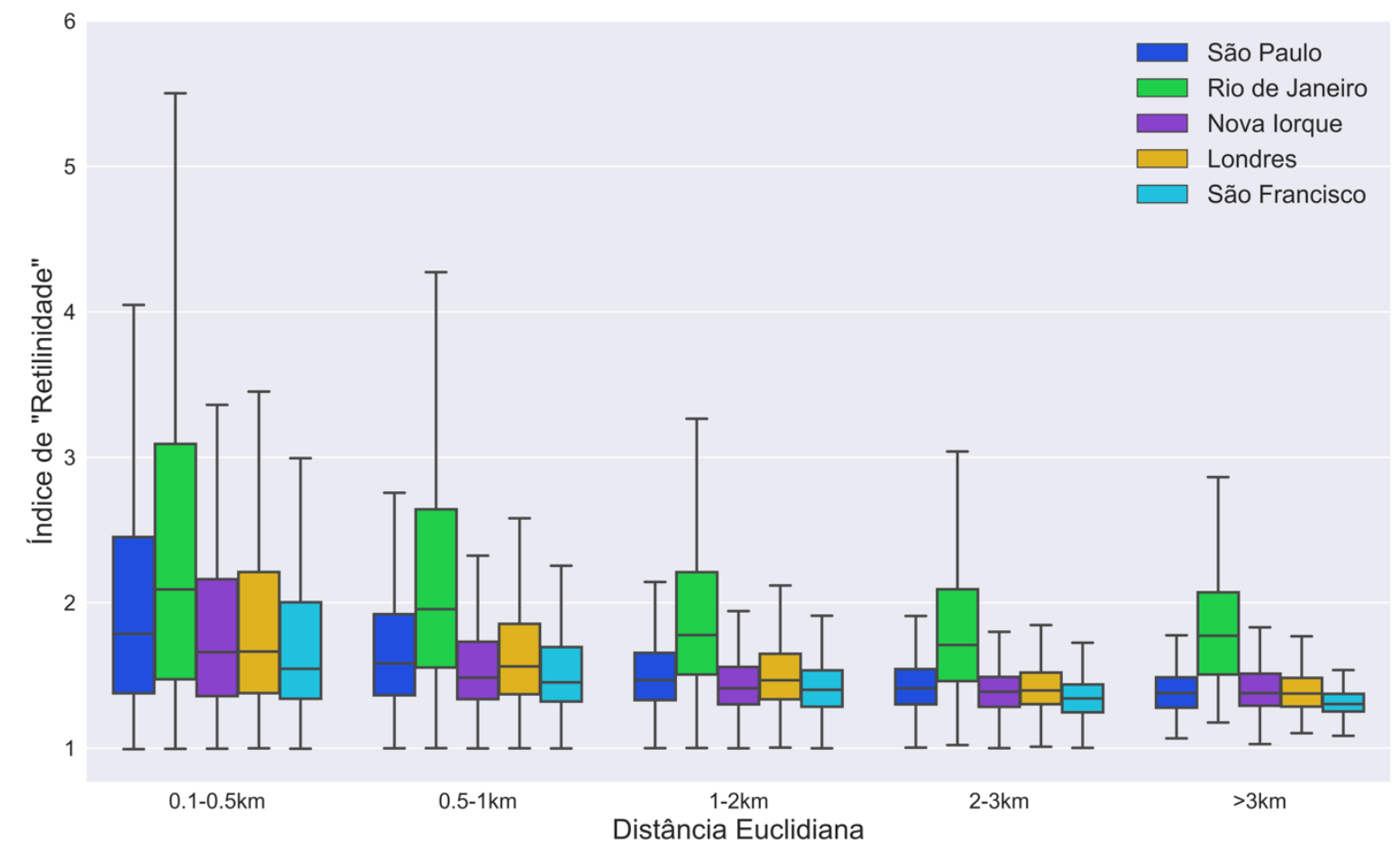

Figura 4.56: Boxplots dos IRs para bicicleta por cidade e faixa de distância euclidiana.

A Tabela 4.13 apresenta os valores de correlação entre os IRMs obtidos para o modo bicicleta (Tabela 4.12) e as métricas que caracterizam a malha viária das cidades (Tabela 4.2). Assim como foi visto na correlação com IRMmotorizados (Tabela 4.7), observa-se que as densidades de vias e interseções apresentam correlação negativa com todos os IRMs, o que significa que quanto maior as densidades, menor o valor de IRM esperado para o modo bicicleta. A baixa correlação entre IRMbicicleta é um aspecto interessante que ajuda a explicar o porquê dos valores de IR obtidos para o modo bicicleta serem consideravelmente mais baixos que os valores de IR obtidos para veículos motorizados (37\% menor no caso do Rio de Janeiro para distâncias entre 100 e 500m, caso em que se observa a maior redução), pois significa que a mão de direção das vias não afeta tanto a eficiência da circulação de bicicletas quanto afeta a circulação de veículos motorizados. Apesar de seguirem mãos de direção como os carros, a correlação é menor, porque ciclistas tem mais flexibilidade quanto às regras de trânsito, por exemplo, podem desmontar da bicicleta e atravessar ruas como pedestres, algo que é capturado pelas distâncias reais fornecidas pela API do Google Maps. 
Tabela 4.13: Correlação entre métricas da rede viária e IR para veículos bicicleta.

\begin{tabular}{llcccc}
\hline & $\begin{array}{c}\text { Densidade } \\
\text { de vias } \\
\left(\mathrm{m} / \mathrm{km}^{2}\right)\end{array}$ & $\begin{array}{c}\text { Extensão } \\
\text { média do } \\
\text { segmento de } \\
\text { via }(\mathrm{m})\end{array}$ & $\begin{array}{c}\text { Densidade } \\
\text { de } \\
\text { interseções } \\
\left(\mathrm{km}^{-2}\right)\end{array}$ & $\begin{array}{c}\text { Proporção de } \\
\text { extensão de } \\
\text { vias de mão } \\
\text { única }(\mathrm{m} / \mathrm{m})\end{array}$ \\
\hline IRbicicleta & $0.1-0.5 \mathrm{~km}$ & -0.952919 & 0.078889 & -0.242826 & 0.086778 \\
IRbicicleta & $0.5-1 \mathrm{~km}$ & -0.981081 & 0.224006 & -0.386427 & 0.112144 \\
IRbicicleta & $1-2 \mathrm{~km}$ & -0.974523 & 0.270902 & -0.430938 & 0.143797 \\
IRbicicleta & $2-3 \mathrm{~km}$ & -0.955959 & 0.34792 & -0.501267 & 0.220327 \\
IRbicicleta & $>3 \mathrm{~km}$ & -0.918212 & 0.406356 & -0.551566 & 0.300225 \\
\hline
\end{tabular}

As Figuras 4.57 a 4.62, a Tabela 4.14 e a Figura 4.63 são análogas as já apresentadas para modos motorizados e bicicleta, porém são referentes a trajetos feitos a pé.

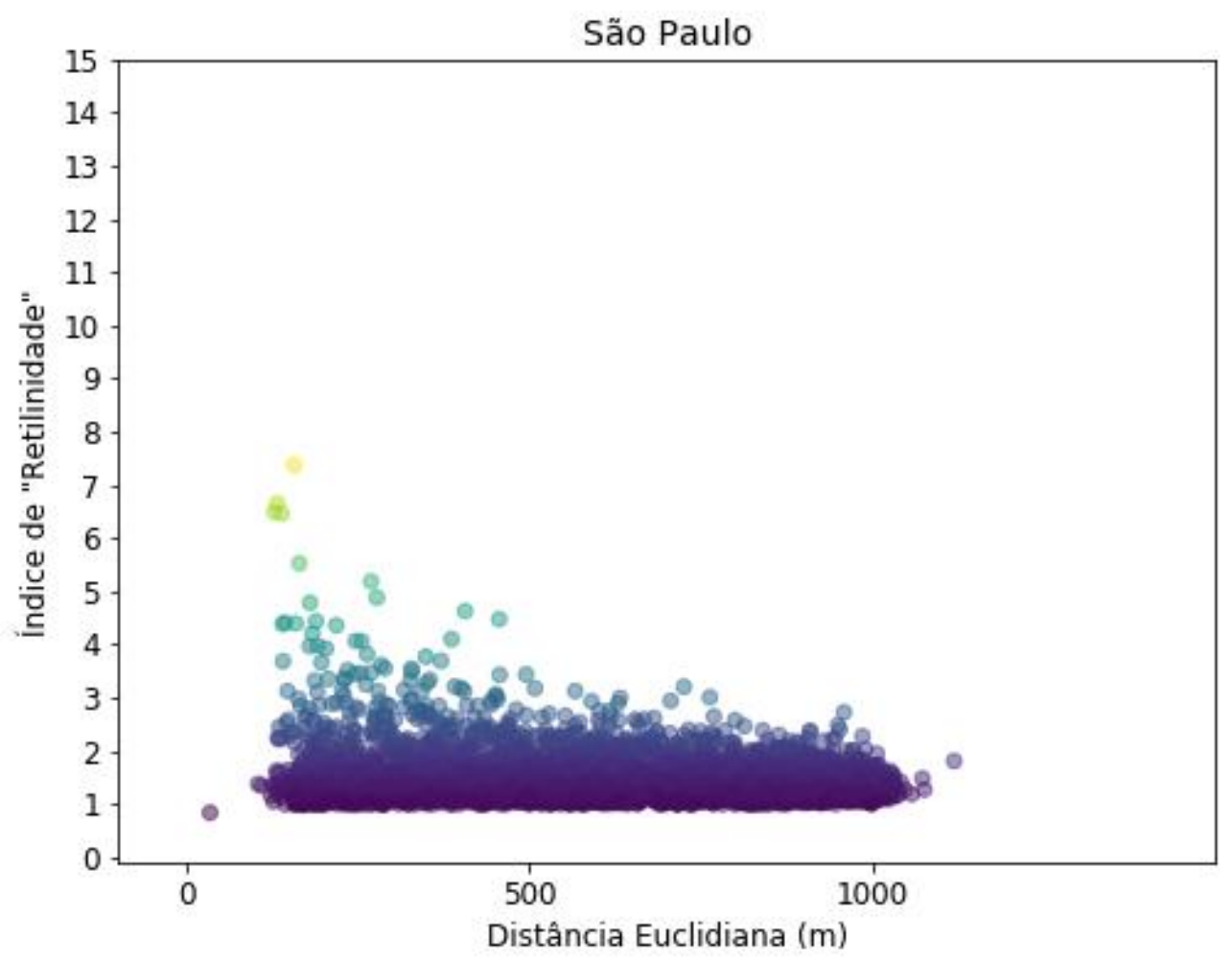

Figura 4.57: Distribuição IRa pé X Distância Euclidiana de São Paulo. 


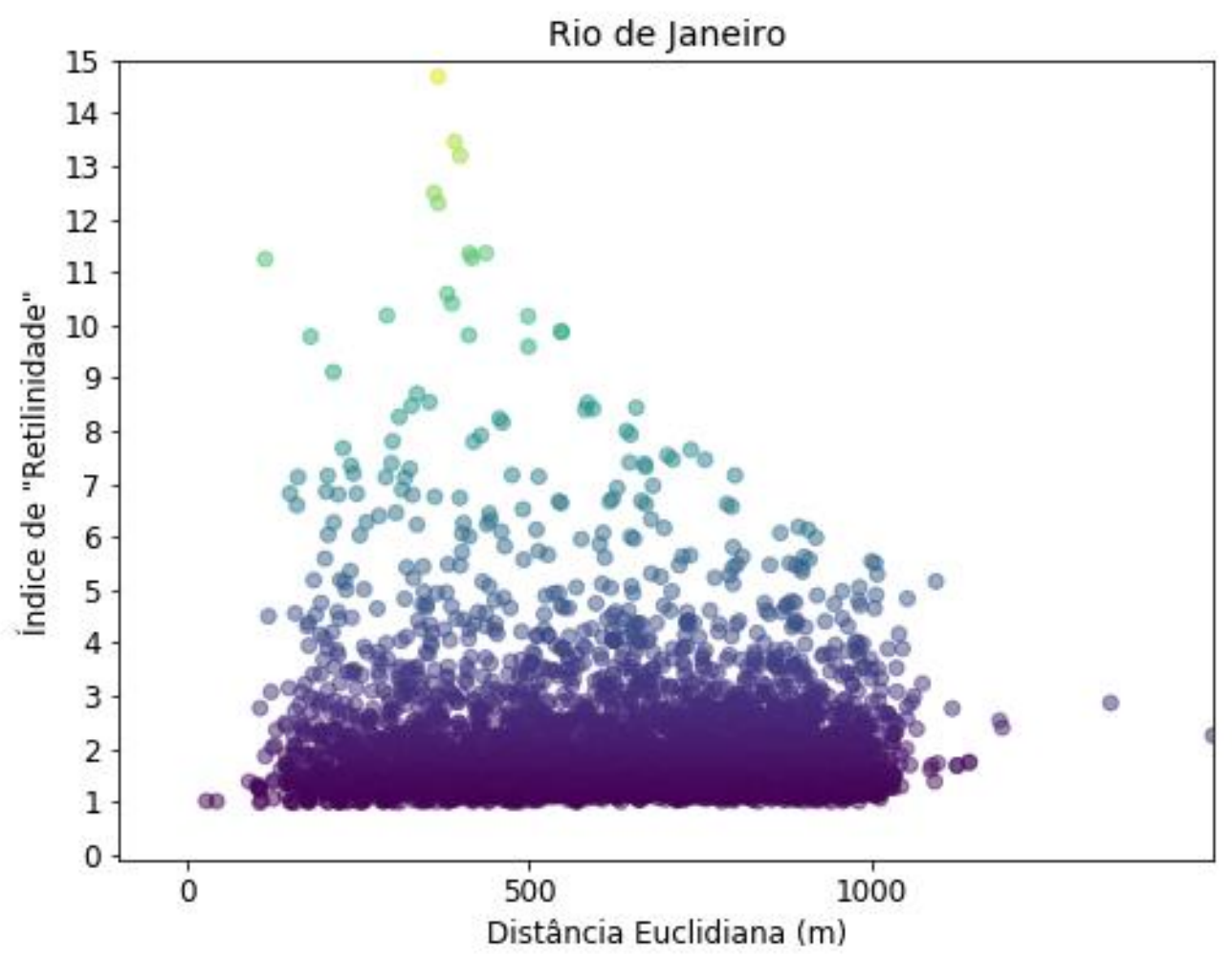

Figura 4.58: Distribuição IRa péx Distância Euclidiana do Rio de Janeiro.

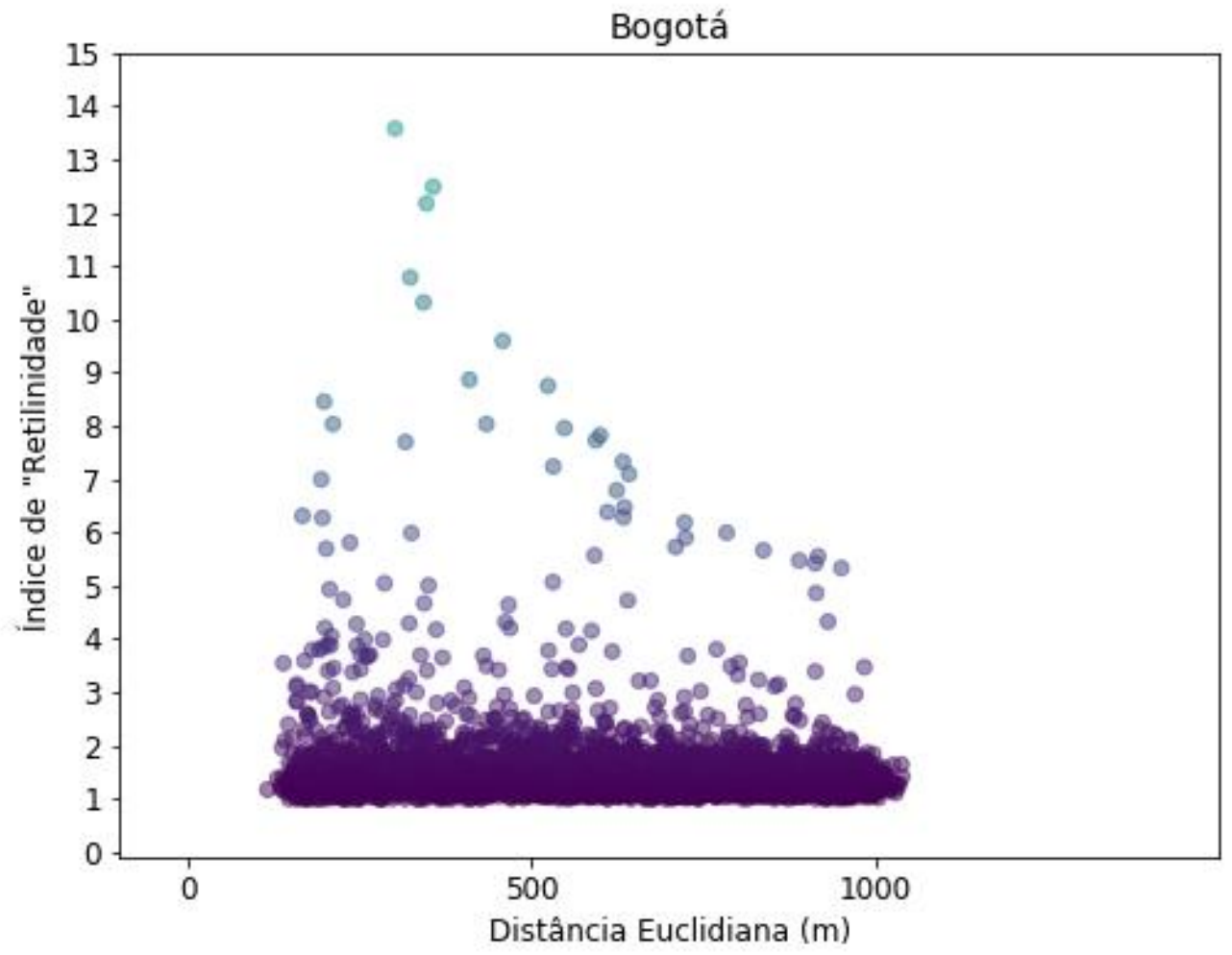

Figura 4.59: Distribuição IRa péx Distância Euclidiana de Bogotá. 


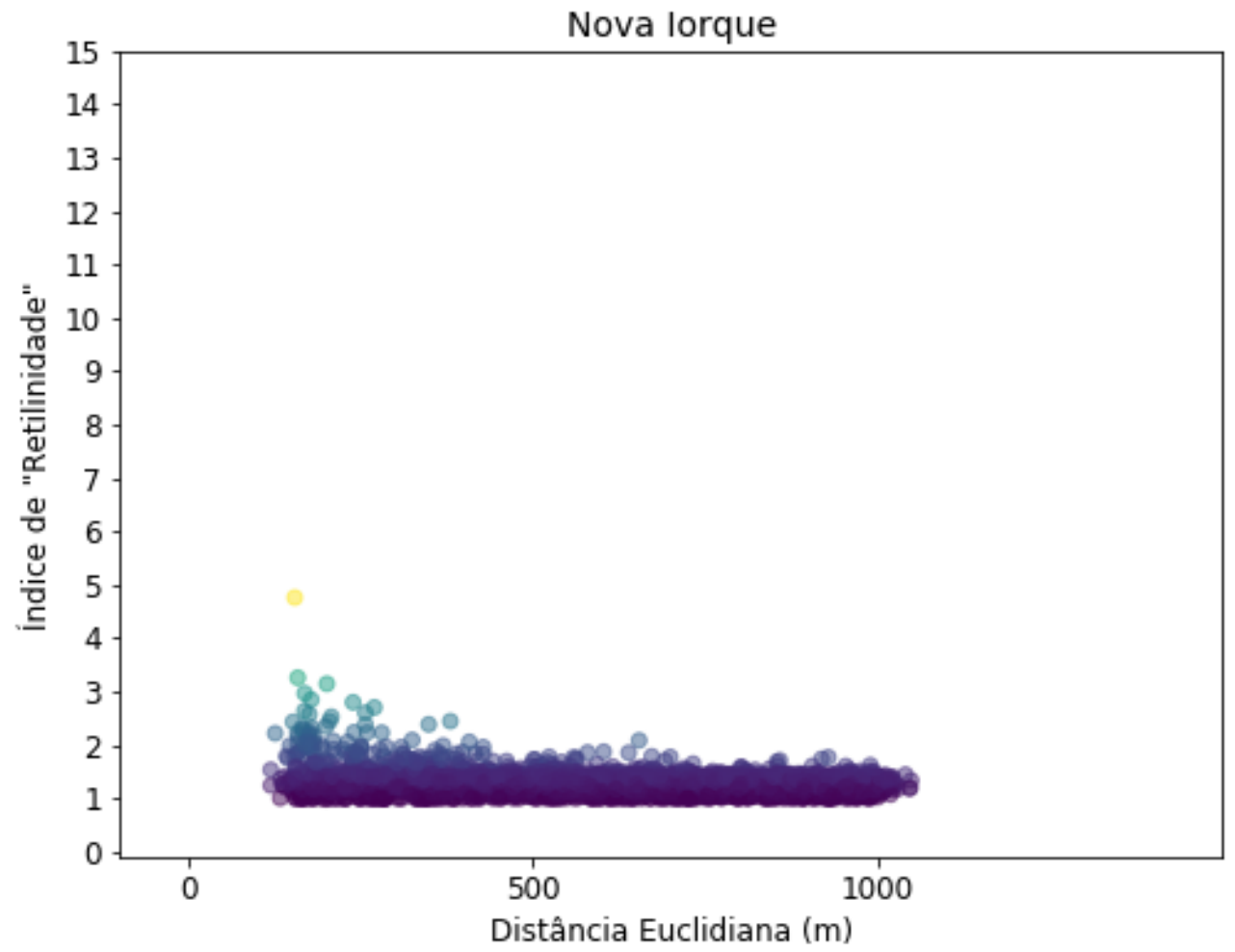

Figura 4.60: Distribuição IRa pé X Distância Euclidiana de Nova lorque.

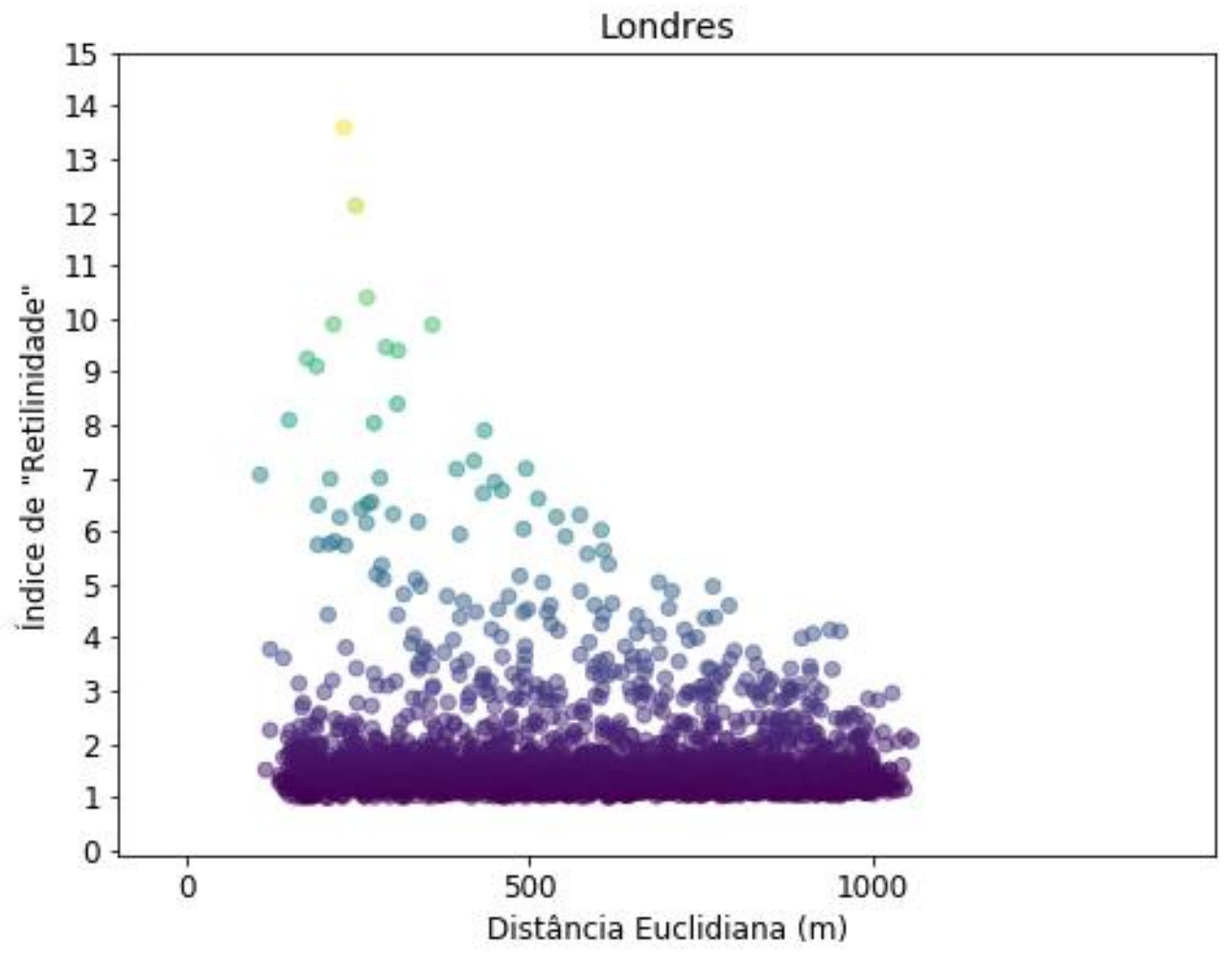

Figura 4.61: Distribuição IRa pé X Distância Euclidiana de Londres. 


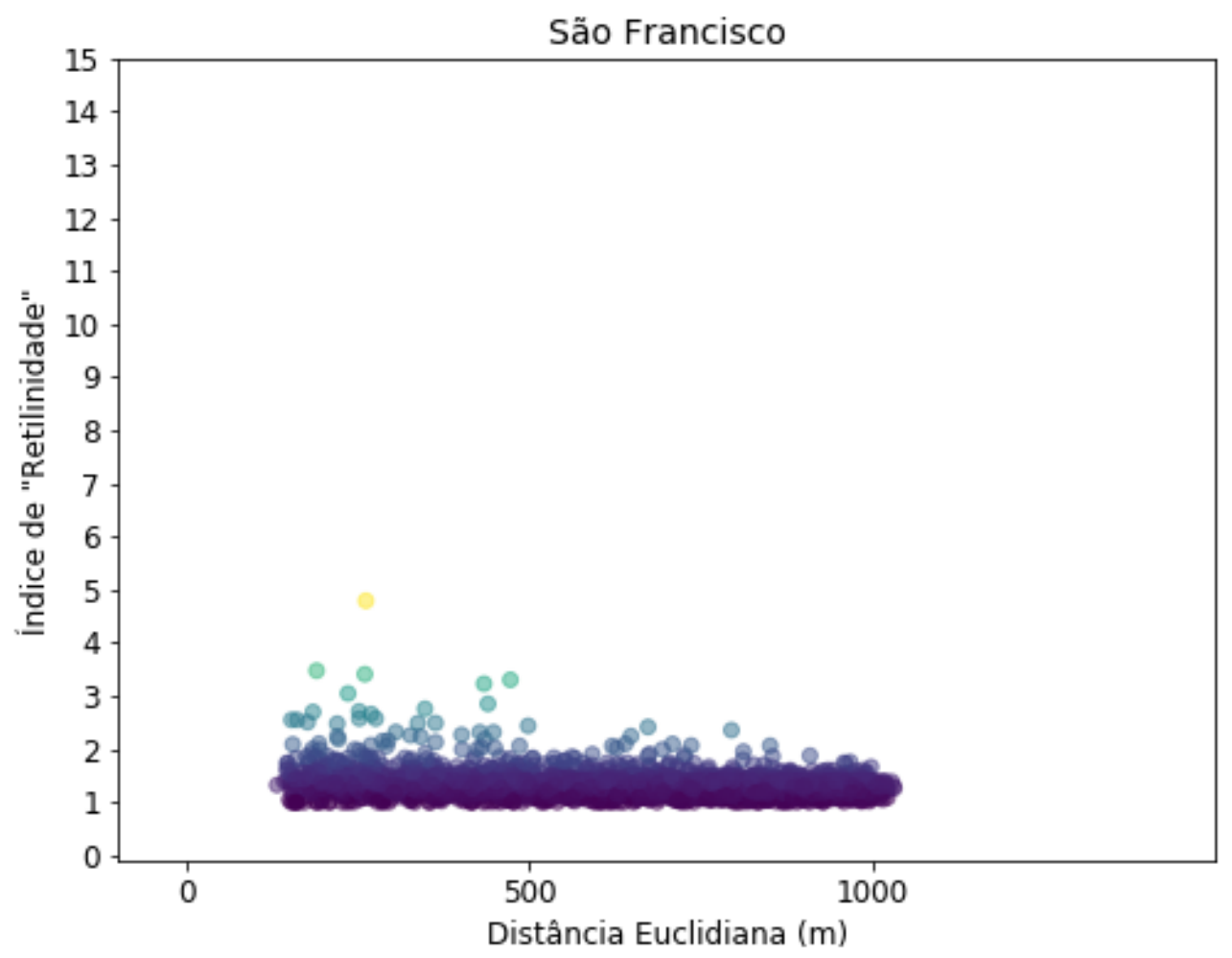

Figura 4.62: Distribuição IRa péx Distância Euclidiana de São Francisco.

Tabela 4.14: Índices de "Retilinidade" Médios para caminhada.

\begin{tabular}{cccc}
\hline & $0.1-0.5 \mathrm{~km}$ & $0.5-1 \mathrm{~km}$ & $>1 \mathrm{~km}$ \\
\hline São Paulo & 1,56 & 1,38 & 1,34 \\
Rio de Janeiro & 2,17 & 1,88 & 2,13 \\
Bogotá & 1,60 & 1,39 & 1,34 \\
Nova lorque & 1,34 & 1,27 & 1,26 \\
Londres & 1,66 & 1,41 & 1,42 \\
São Francisco & 1,39 & 1,30 & 1,28 \\
\hline
\end{tabular}

Analisando as Figuras 4.57 a 4.62 e a Tabela 4.14 referentes ao modo a pé, observa-se que os IRs não tendem a diminuir com o aumento da distância euclidiana, como havia sido observado para os outros modos. Para caminhadas, percebe-se que os valores são mais baixos (entre 1 e 2), se aproximando do valor esperado de $\sqrt{2} \cong 1,42$ para uma rede quadriculada (razão entre soma de dois lados e a diagonal de um quadrado), também conhecida como Manhattan.

A única cidade analisada que apresenta IRM para caminhada fora da faixa entre 1 e 2 esperada é o Rio de Janeiro. Este fato pode ser explicado pelo relevo e a topografia do local, que gera segmentos de vias sinuosos 


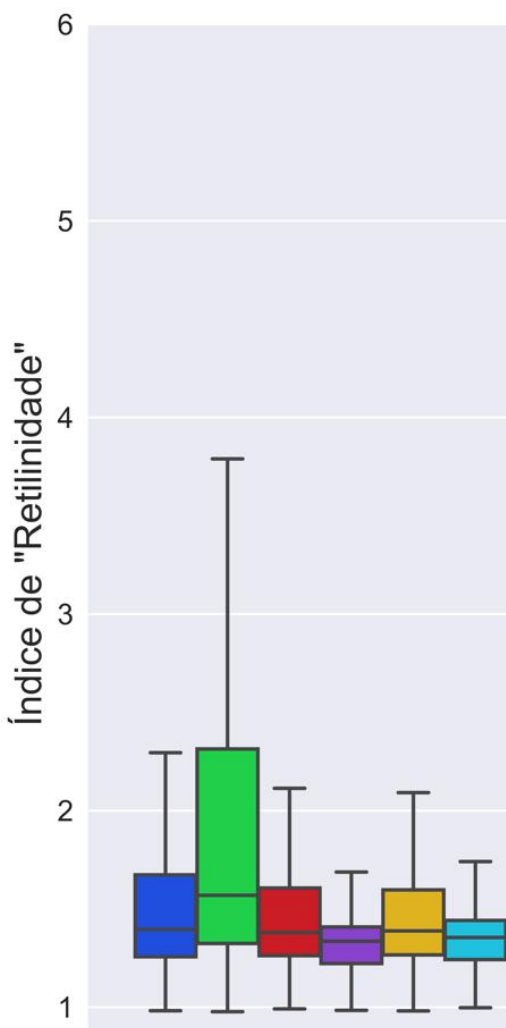

$0.1-0.5 \mathrm{~km}$
$0.5-1 \mathrm{~km}$

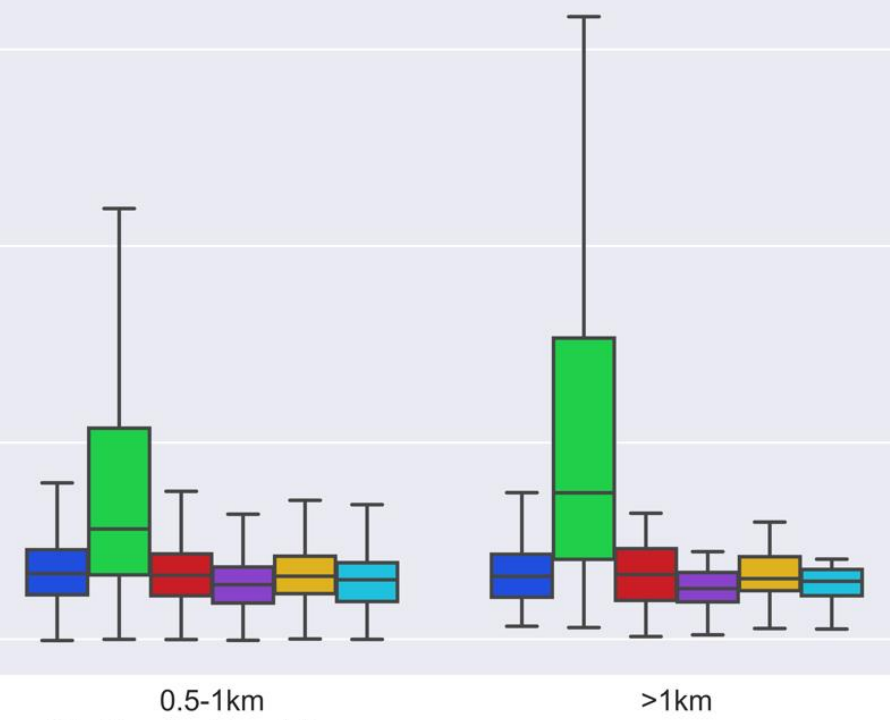

Distância Euclidiana
$>1 \mathrm{~km}$

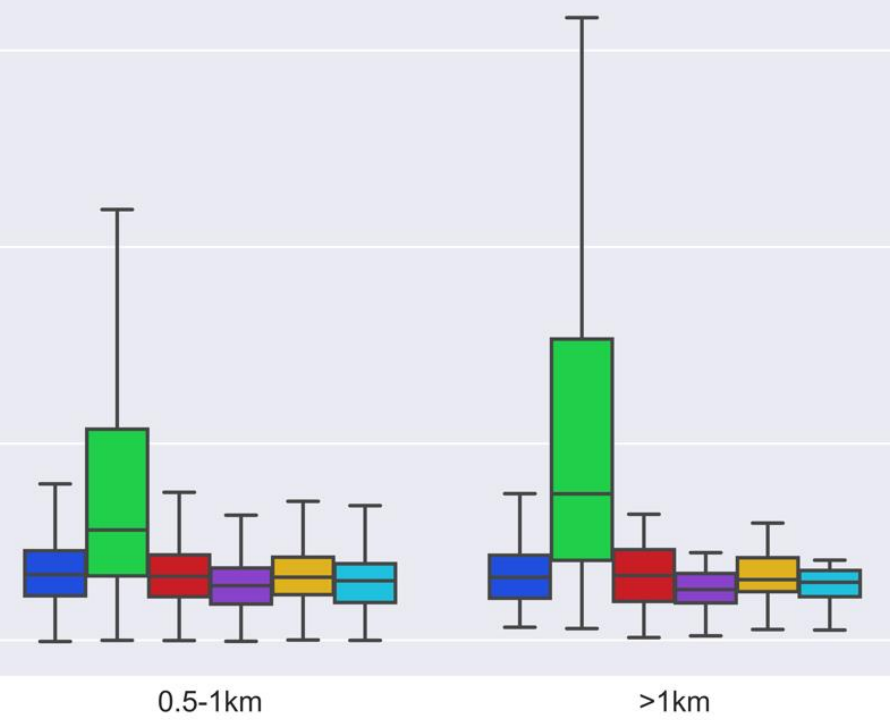

São Paulo

Rio de Janeiro

Bogotá

Nova lorque

Londres

São Francisco

Figura 4.63: Boxplots dos IRs para caminhada por cidade e faixa de distância euclidiana.

. Novamente, são calculadas as correlações entre os IRMs obtidos (Tabela 4.14) e as métricas da Tabela 4.2; os resultados estão presentes na Tabela 4.15. Assim como nas correlações calculadas com IRMmotorizado e IRMbicicleta, observa-se que a "densidade de vias" apresenta correlação negativa com todos os IRMs para caminhada, reforçando o aspecto intuitivo de que quanto mais densa a malha (maior quilometragem de vias disponíveis), mais eficiente ela será. A baixa correlação entre IRMa pé e proporção de vias mão única é esperada, pois significa que a mão de direção das vias não afeta a eficiência da circulação a pé.

Como proposto, a Tabela 4.16 e a Tabela 4.17 trazem os valores comparativos de IRM entre o modo motorizado e os modos não motorizados. A Tabela 4.16 apresenta os valores para IRMmotorizado sobre IRMbicicleta e a Tabela 4.17 apresenta os valores para IRMmotorizado sobre IRMa pé. 
Tabela 4.15: Correlação entre métricas da rede viária e IR para caminhada.

\begin{tabular}{|c|c|c|c|c|c|}
\hline & & $\begin{array}{l}\text { Densidade } \\
\text { de vias } \\
\left(\mathrm{m} / \mathrm{km}^{2}\right)\end{array}$ & $\begin{array}{c}\text { Extensão média } \\
\text { do segmento de } \\
\text { via }(\mathrm{m})\end{array}$ & $\begin{array}{l}\text { Densidade } \\
\text { de } \\
\text { interseções } \\
\left(\mathrm{km}^{-2}\right)\end{array}$ & $\begin{array}{l}\text { Proporção } \\
\text { de extensão } \\
\text { de vias de } \\
\text { mão única } \\
(\mathrm{m} / \mathrm{m})\end{array}$ \\
\hline . nup & $1-0.5 \mathrm{~km}$ & -0.659015 & 0.116748 & 355 & -0.012647 \\
\hline IRa pé & $0.5-1 \mathrm{~km}$ & -0.714287 & 0.28649 & -0.396569 & 0.056086 \\
\hline IRa pé & $>1 \mathrm{~km}$ & -0.758668 & 0.336455 & -0.458038 & 0.045753 \\
\hline
\end{tabular}

Tabela 4.16: Razão entre IRM dos modos motorizado e bicicleta.

\begin{tabular}{cccccc}
\hline & $0.1-0.5 \mathrm{~km}$ & $0.5-1 \mathrm{~km}$ & $1-2 \mathrm{~km}$ & $2-3 \mathrm{~km}$ & $>3 \mathrm{~km}$ \\
\hline São Paulo & 1,61 & 1,31 & 1,22 & 1,18 & 1,15 \\
Rio de Janeiro & 1,59 & 1,26 & 1,12 & 1,06 & 1,00 \\
Nova lorque & 1,39 & 1,15 & 1,07 & 1,09 & 1,09 \\
Londres & 1,18 & 1,10 & 1,06 & 1,06 & 1,04 \\
São Francisco & 1,26 & 1,11 & 1,04 & 1,04 & 1,08 \\
\hline
\end{tabular}

Tabela 4.17: Razão entre IRM dos modos motorizado e caminhada.

\begin{tabular}{cccc}
\hline & $0.1-0.5 \mathrm{~km}$ & $0.5-1 \mathrm{~km}$ & $>1 \mathrm{~km}$ \\
\hline São Paulo & 2,12 & 1,61 & 1,37 \\
Rio de Janeiro & 1,95 & 1,54 & 1,03 \\
Bogotá & 1,92 & 1,51 & 1,29 \\
Nova lorque & 1,90 & 1,42 & 1,23 \\
Londres & 1,52 & 1,36 & 1,15 \\
São Francisco & 1,59 & 1,32 & 1,15 \\
\hline
\end{tabular}

Quanto maiores os valores nas Tabelas 4.16 e 4.17, maior a redução potencial de distâncias percorridas ao se adotar um modo não motorizado em detrimento do motorizado. Quanto mais próximo da unidade for o valor, menor o ganho esperado em eficiência do ponto de vista das distâncias percorridas. Por exemplo, para pontos de entrega que estão a menos de $500 \mathrm{~m}$ entre si, em São Paulo pode-se esperar distâncias totais percorridas 2,12 vezes maiores em uma operação de entrega motorizada do que em entregas feitas a pé.

Seguindo o procedimento proposto no Capítulo 3, a análise também contempla a topografia local. As Figuras 4.64 a 4.69 apresentam os mapas temáticos referentes a topografia de cada área analisada e a Tabela 4.18 apresenta os valores de porcentagem de vias em cada intervalo de declividade. 
Tabela 4.18: Porcentagem de quilometragem de vias em determinadas faixas de declividade.

\begin{tabular}{cccc}
\hline & $0-2 \%$ & $2 \%-5 \%$ & $>5 \%$ \\
\hline São Paulo & $39 \%$ & $36 \%$ & $25 \%$ \\
Rio de Janeiro & $39 \%$ & $29 \%$ & $32 \%$ \\
Bogotá & $77 \%$ & $18 \%$ & $5 \%$ \\
Nova lorque & $93 \%$ & $7 \%$ & $<1 \%$ \\
Londres & $80 \%$ & $16 \%$ & $4 \%$ \\
São Francisco & $58 \%$ & $21 \%$ & $21 \%$ \\
\hline
\end{tabular}

Pela análise das declividades, percebe-se que algumas cidades têm topografia mais favorável ao uso de modos de transporte não motorizados do que outras. É o caso, por exemplo, de Nova lorque (Figura 4.67) que possui menos de $1 \%$ de comprimento de vias com declividade superior a 5\% e 93\% com declividade inferior a $2 \%$, ideal para caminhar e pedalar. Rio de Janeiro (Figura 4.65), São Paulo (Figura 4.64) e São Francisco (Figura 4.69) são as cidades com topografia mais desfavorável, ainda assim pode-se considerar o uso de modos não motorizados nas áreas mais planas.

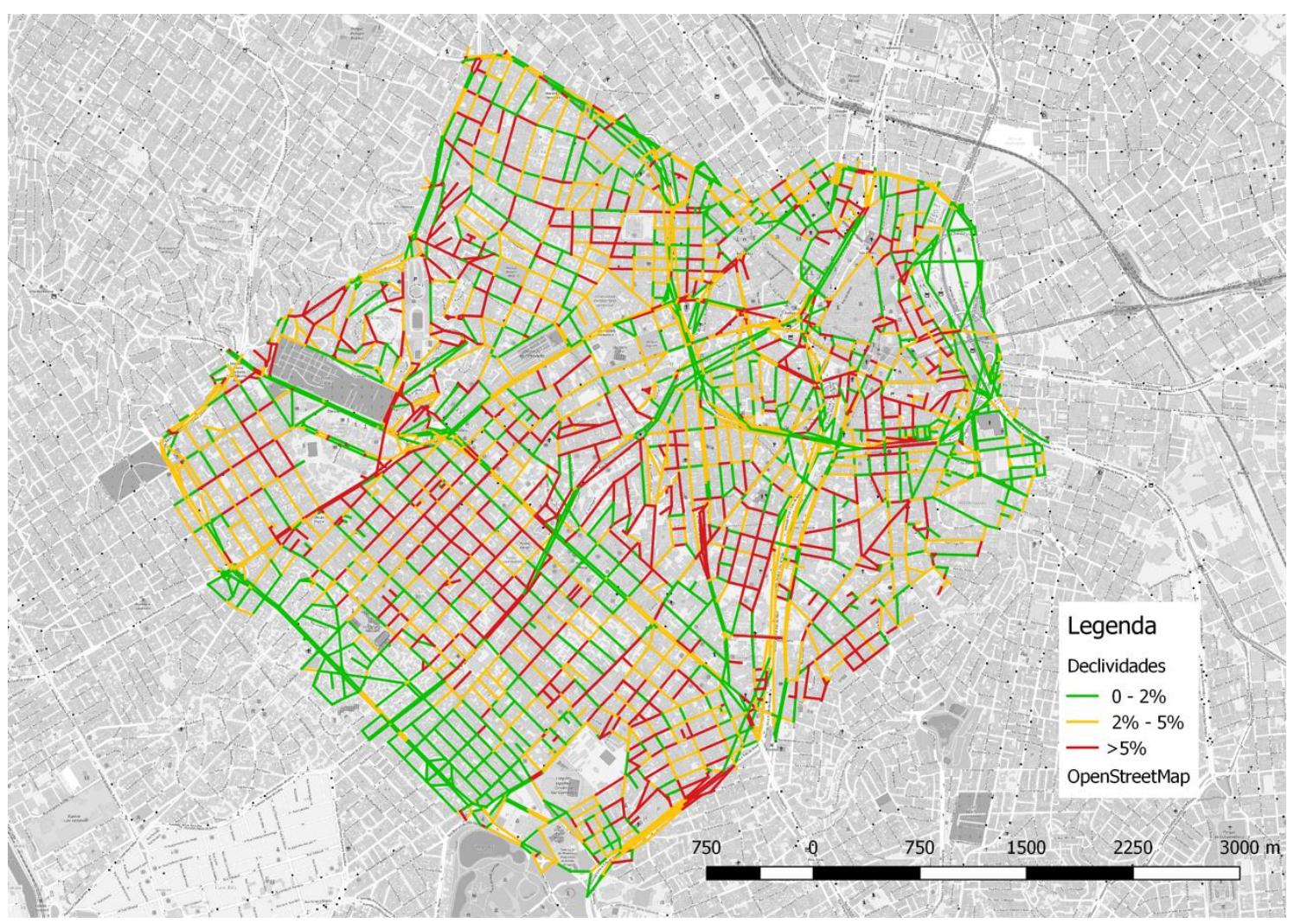

Figura 4.64: Declividades das vias em São Paulo. 


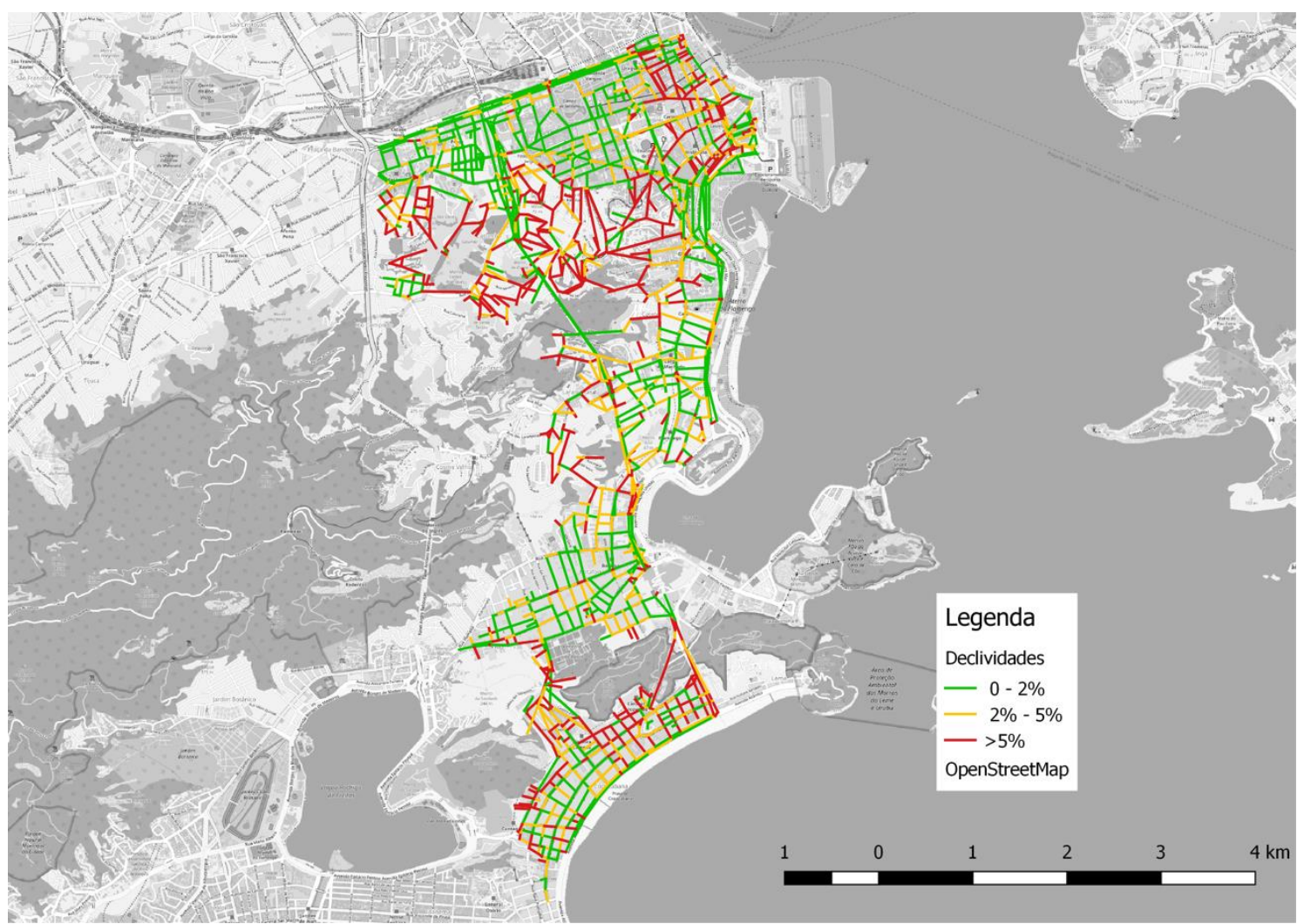

Figura 4.65: Declividades das vias no Rio de Janeiro.

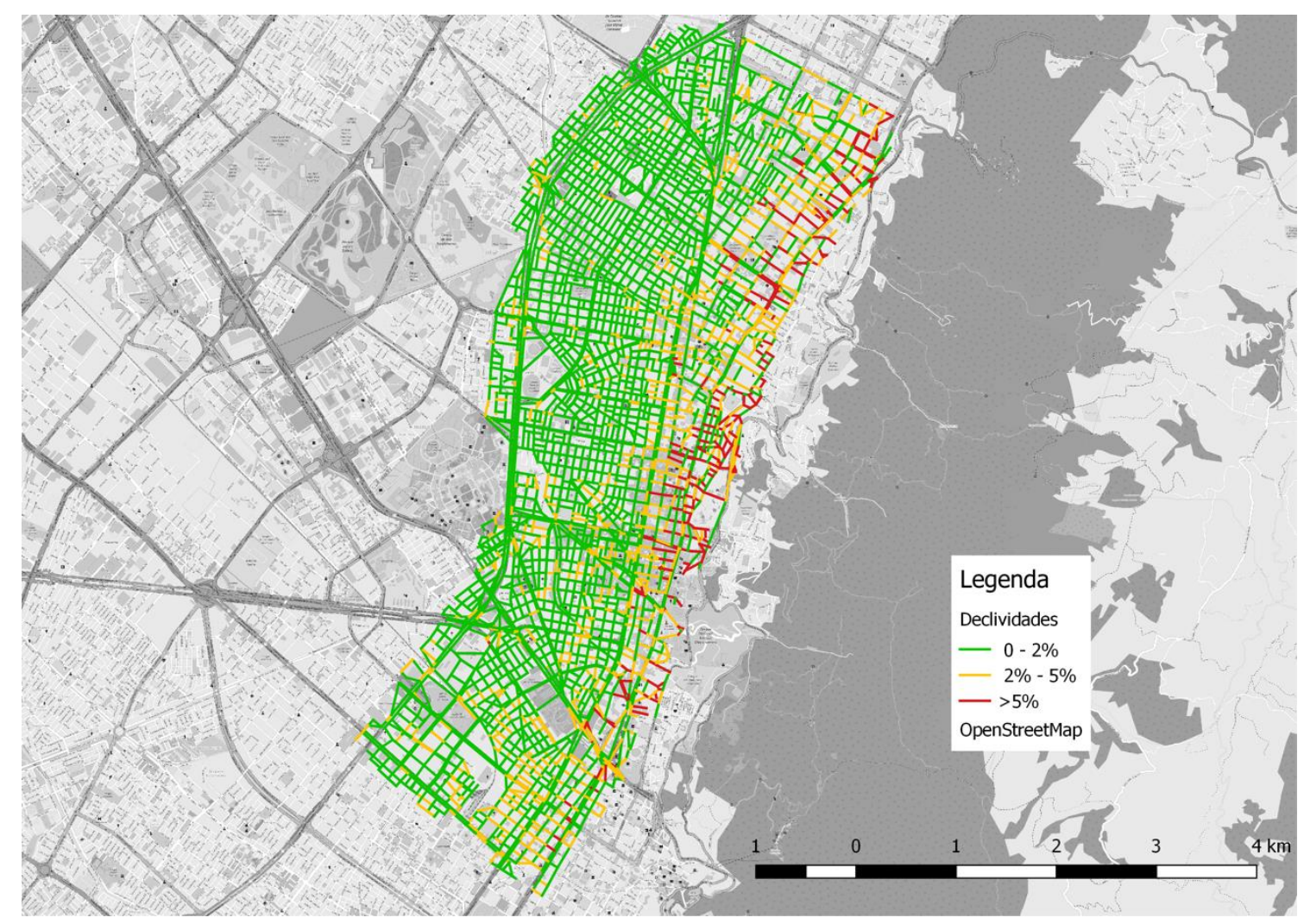

Figura 4.66: Declividades das vias em Bogotá. 


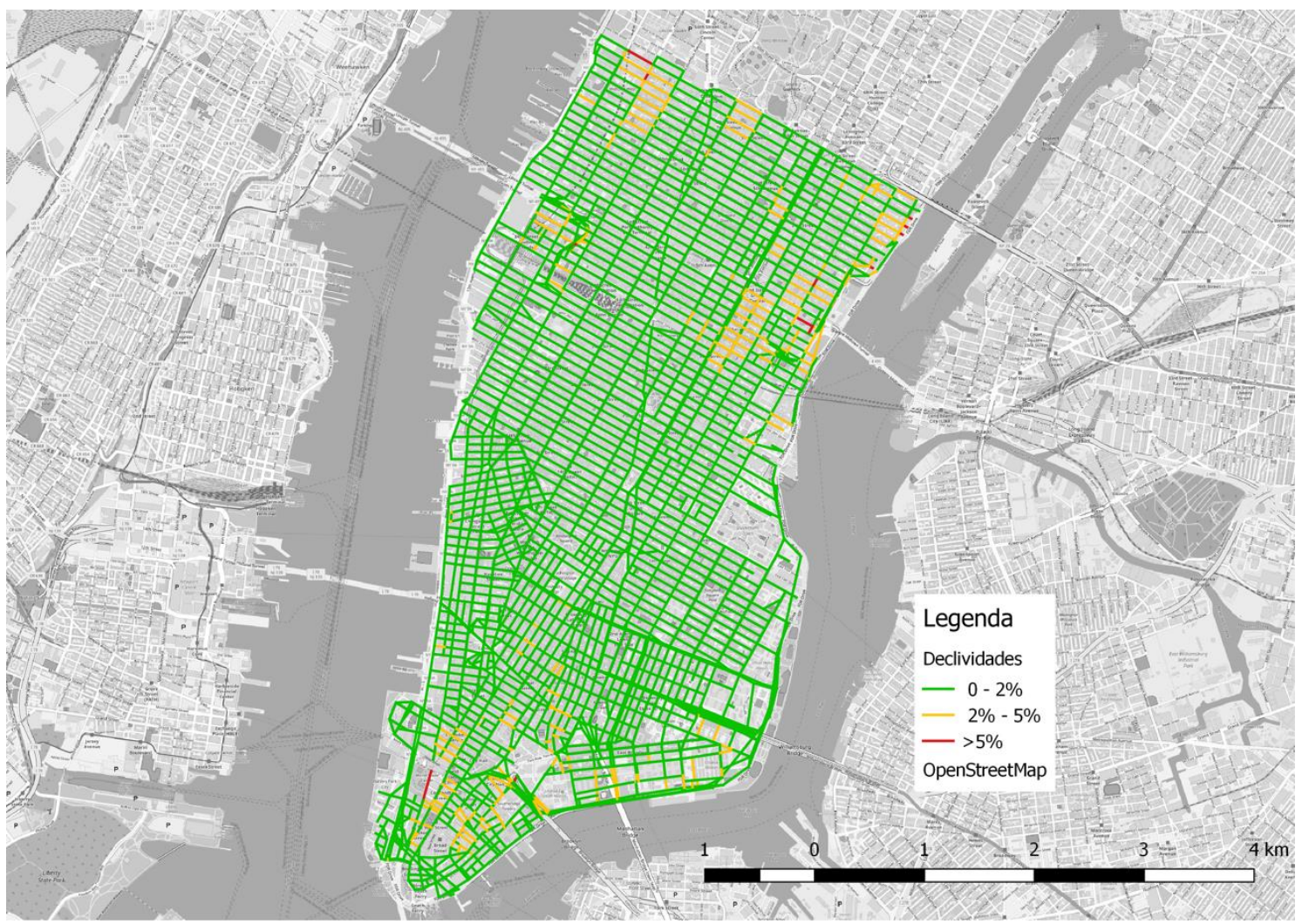

Figura 4.67: Declividades das vias em Nova lorque.

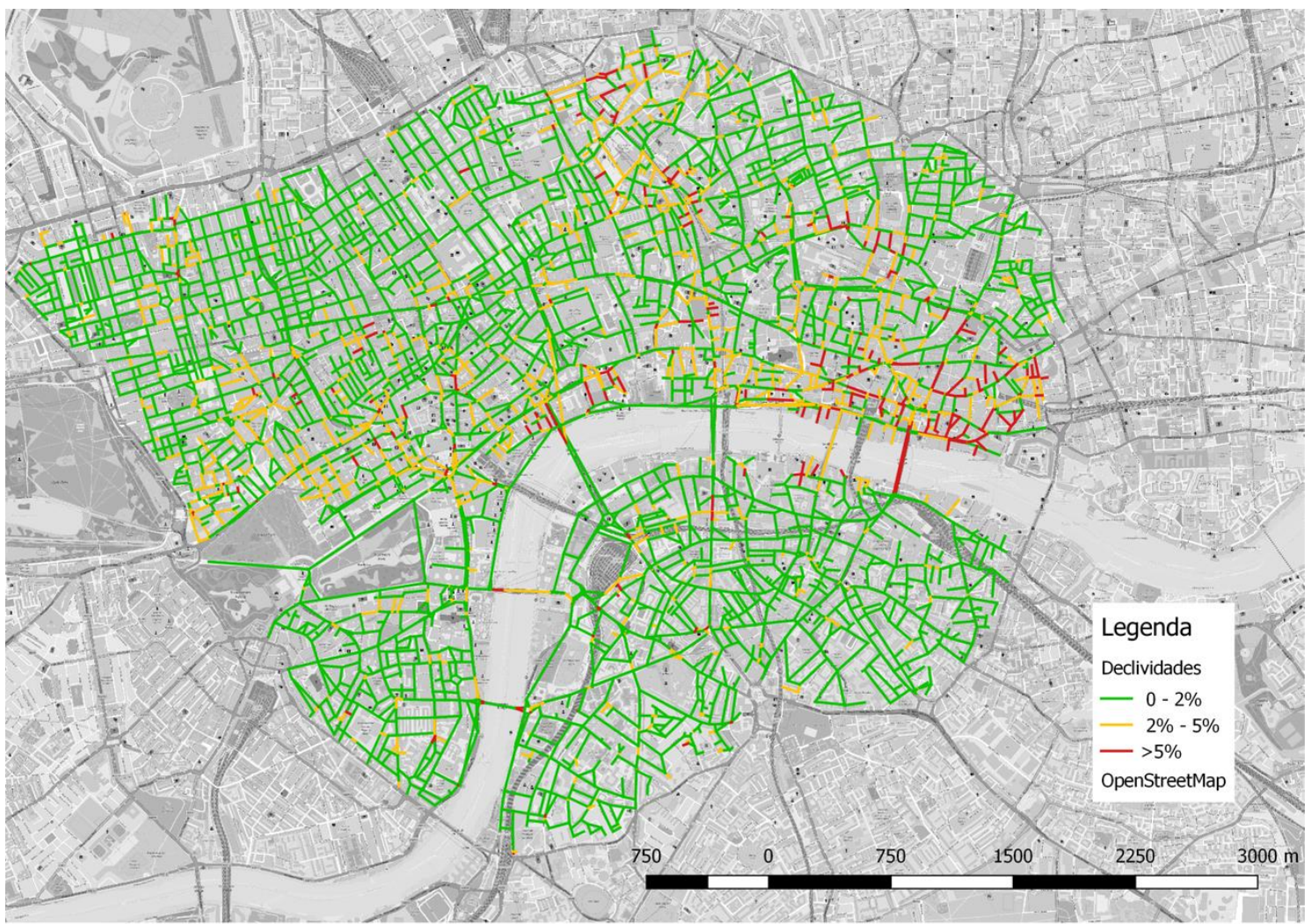

Figura 4.68: Declividades das vias em Londres. 


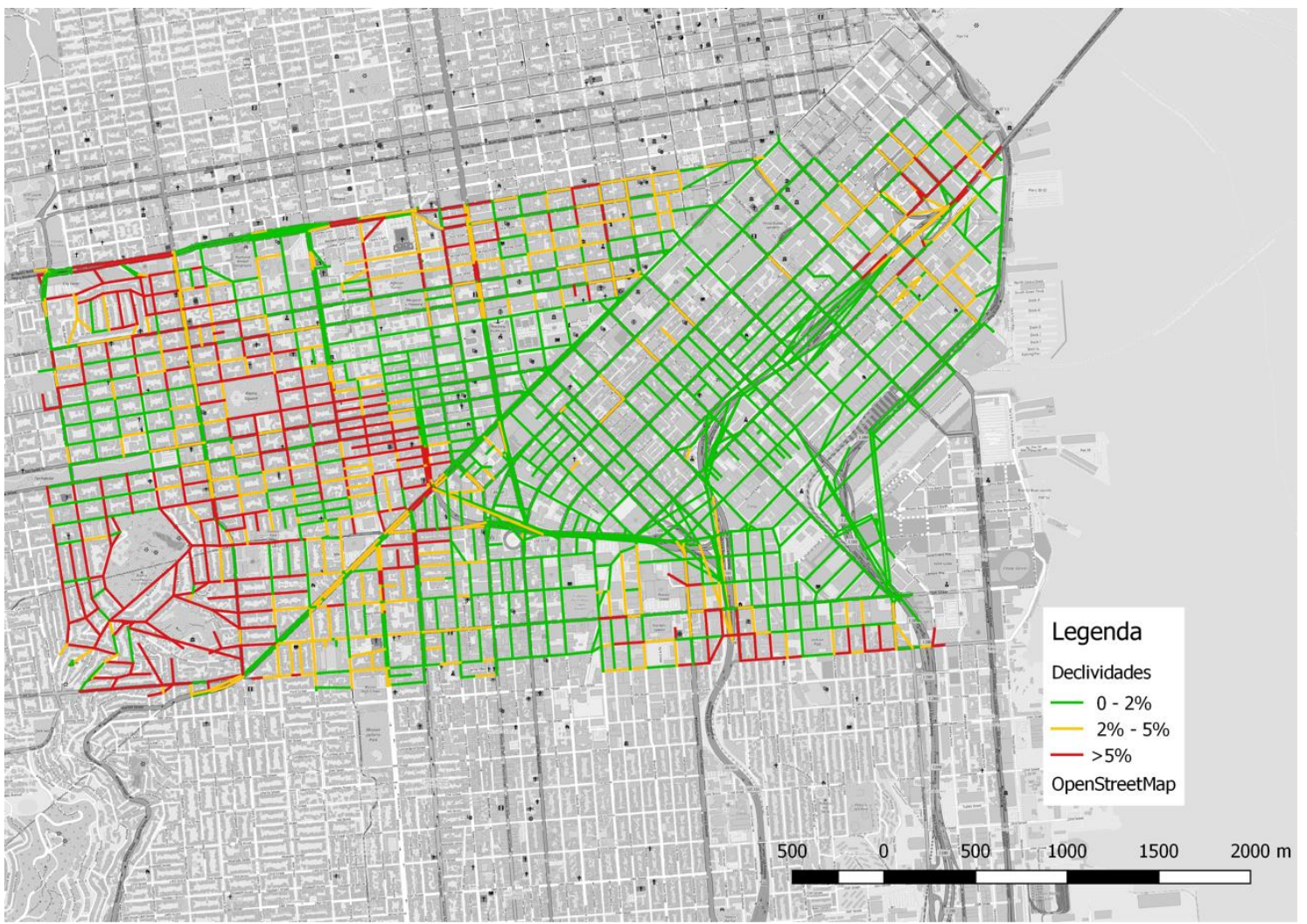

Figura 4.69: Declividades das vias em São Francisco.

\subsection{Acesso à Área de Entrega}

As análises da etapa de line-haul foram realizadas apenas para uma região central do município de São Paulo, pois são conhecidos os locais que costumam agregar instalações logísticas na região metropolitana. Foram selecionados quatro potenciais locais de centro de distribuição (CD) as margens das rodovias Dutra, Anhanguera, Castelo Branco e Raposo Tavares. Os resultados para o acesso e regresso a área de entrega apresentados a seguir contemplam estes potenciais locais de centro de distribuição e os pontos aleatórios (potenciais locais de entrega) gerados na região estudada.

A Tabela 4.19 e a Tabela 4.20 trazem as características dos trajetos de acesso e regresso a região analisada. A coluna "id Ponto" mostra a identificação do ponto localizado dentro da região que representa a origem ou destino do trajeto de acordo com o critério associado. Por exemplo, o acesso à região, a partir do CD localizado na Rodovia Raposo Tavares tem menor distância com destino no ponto 145 e tem menor tempo com destino no ponto 121. Percebe-se que, em alguns casos, coincide de um trajeto ser o melhor nos dois critérios, como o caso da Dutra cujos trajetos de 
acesso têm menor tempo e menor distância para o ponto 97 contido na Região A. As demais colunas contêm outras informações relevantes sobre os trajetos e indicam que as características de trajetos equivalentes para critérios diferentes não variam significativamente. O caso mais crítico de variação de distância é o trajeto Anhanguera-ponto 81 que aumenta cerca de $4 \mathrm{~km}$ no caminho do trajeto mais curto para o menos demorado e aumenta certa de 7 minutos do trajeto menos demorado para o mais curto

Tabela 4.19: Características dos trajetos de acesso à Região $\mathrm{A}$ partir dos potenciais locais de centro de distribuição.

\begin{tabular}{cccccc}
\hline Critério & $\begin{array}{c}\text { Local do CD } \\
\text { (origem) }\end{array}$ & $\begin{array}{c}\text { id Ponto } \\
\text { (destino) }\end{array}$ & $\begin{array}{c}\text { Distância } \\
(\mathrm{km})\end{array}$ & $\begin{array}{c}\text { Tempo } \\
(\mathrm{min})\end{array}$ & $\begin{array}{c}\text { Índice de } \\
\text { "Retilinidade" }\end{array}$ \\
\hline \multirow{3}{*}{ Menor } & Dutra & 97 & 28,29 & 40,2 & 1,23 \\
Distância & Anhanguera & 81 & 15,11 & 28,1 & 1,28 \\
& Castelo Branco & 37 & 18,94 & 27,1 & 1,16 \\
& Raposo Tavares & 145 & 12,77 & 21,7 & 1,10 \\
\hline \multirow{3}{*}{ Menor } & Dutra & 97 & 28,29 & 40,2 & 1,23 \\
Tempo & Anhanguera & 109 & 19,56 & 21,3 & 1,39 \\
& Castelo Branco & 109 & 20,53 & 23,1 & 1,14 \\
& Raposo Tavares & 121 & 12,90 & 21,6 & 1,09 \\
\hline
\end{tabular}

Tabela 4.20: Características dos trajetos de regresso aos potenciais locais de centro de distribuição a partir da Região A.

\begin{tabular}{cccccc}
\hline Critério & $\begin{array}{c}\text { Local do CD } \\
\text { (destino) }\end{array}$ & $\begin{array}{c}\text { id Ponto } \\
\text { (origem) }\end{array}$ & $\begin{array}{c}\text { Distância } \\
(\mathrm{km})\end{array}$ & $\begin{array}{c}\text { Tempo } \\
(\mathrm{min})\end{array}$ & $\begin{array}{c}\text { Índice de } \\
\text { "Retilinidade" }\end{array}$ \\
\hline \multirow{3}{*}{ Menor } & Dutra & 172 & 26,13 & 30,1 & 1,14 \\
Distância & Anhanguera & 206 & 17,88 & 20,7 & 1,51 \\
& Castelo Branco & 206 & 18,48 & 22,5 & 1,14 \\
& Raposo Tavares & 127 & 12,53 & 20,5 & 1,07 \\
\hline \multirow{3}{*}{ Menor } & Dutra & 99 & 26,38 & 29,5 & 1,17 \\
Tempo & Anhanguera & 201 & 18,85 & 20,0 & 1,52 \\
& Castelo Branco & 201 & 19,45 & 21,8 & 1,16 \\
& Raposo Tavares & 201 & 12,91 & 20,0 & 1,07 \\
\hline
\end{tabular}


A Figura 4.70 e a Figura 4.71 mostram o traçado dos trajetos especificados na Tabela 4.19 e Tabela 4.20. Comparando o traçado entre CD e região (e vice-versa) para o critério de menor tempo e menor distância, é possível observar que seguem pelas mesmas vias por grande parte do percurso com variações apenas nas proximidades da região estudada, o que justifica a pequena diferença encontrada dos tempos e distâncias de viagem.

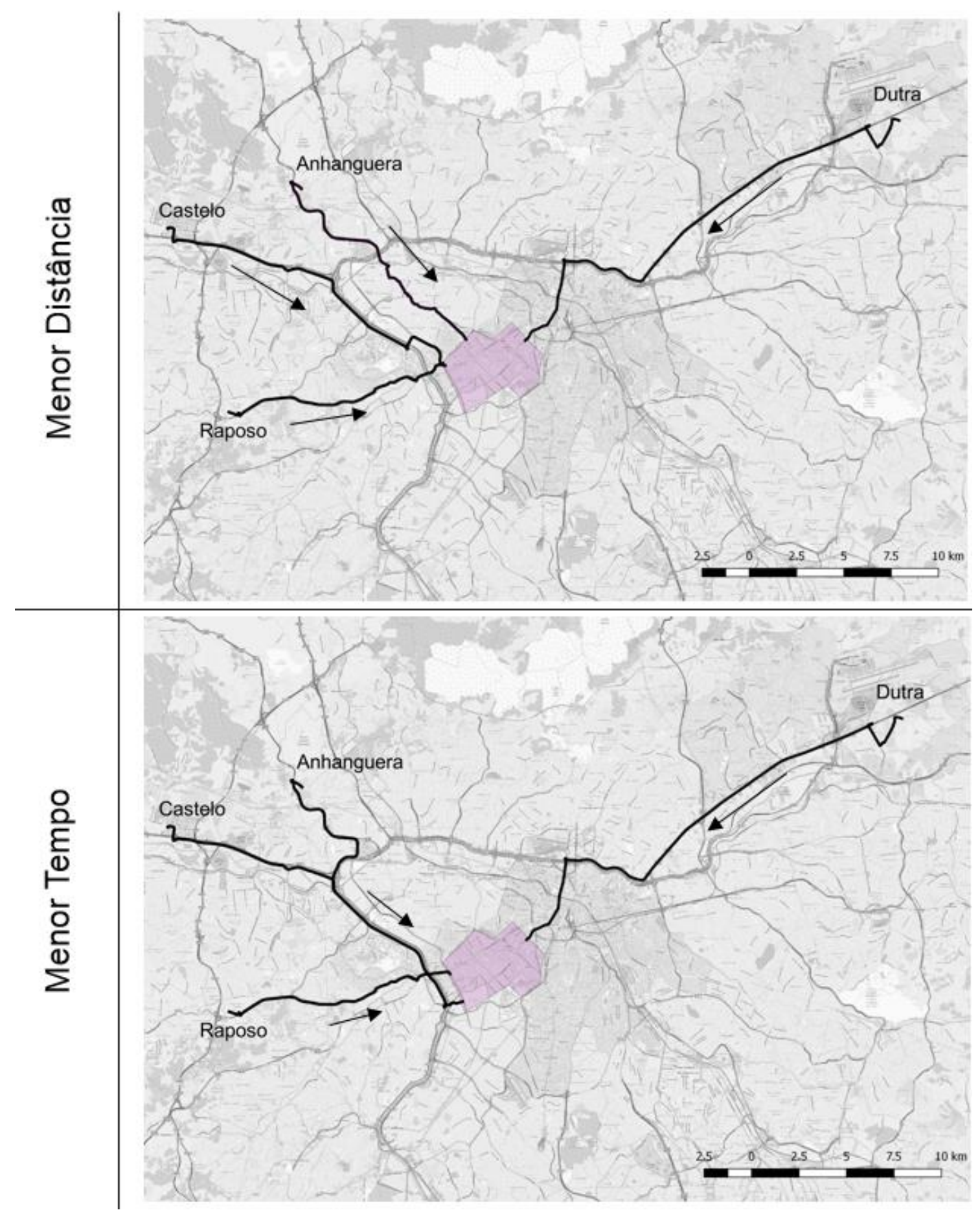

Figura 4.70: Traçados dos trajetos com origem nos potenciais locais de CD e destino na região central. 


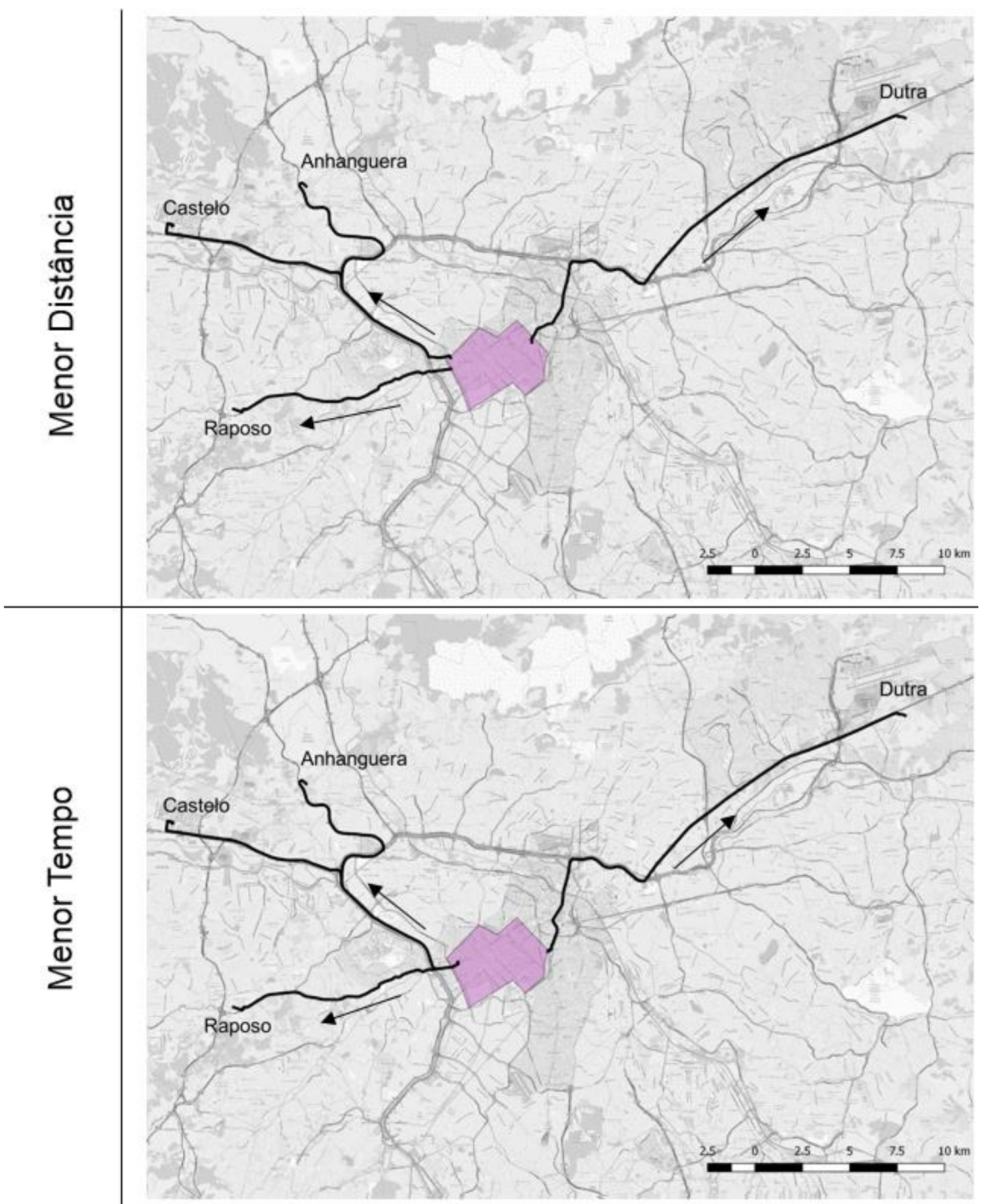

Figura 4.71: Traçados dos trajetos com origem na região central e destino nos potenciais locais de CD.

$\mathrm{Na}$ sequência, foram elaborados os perfis de velocidade ao longo do dia para os pares origem e destino especificados na Tabela 4.19 e na Tabela 4.20. A Figura 4.72 apresenta os perfis de velocidade para os trajetos com origem nos centros de distribuição e destino na região estudada para os critérios de menor distância e menor tempo. A Figura 4.73 apresenta os perfis para os trajetos com origem na região estudada e destinos nos potenciais locais de centro de distribuição. 


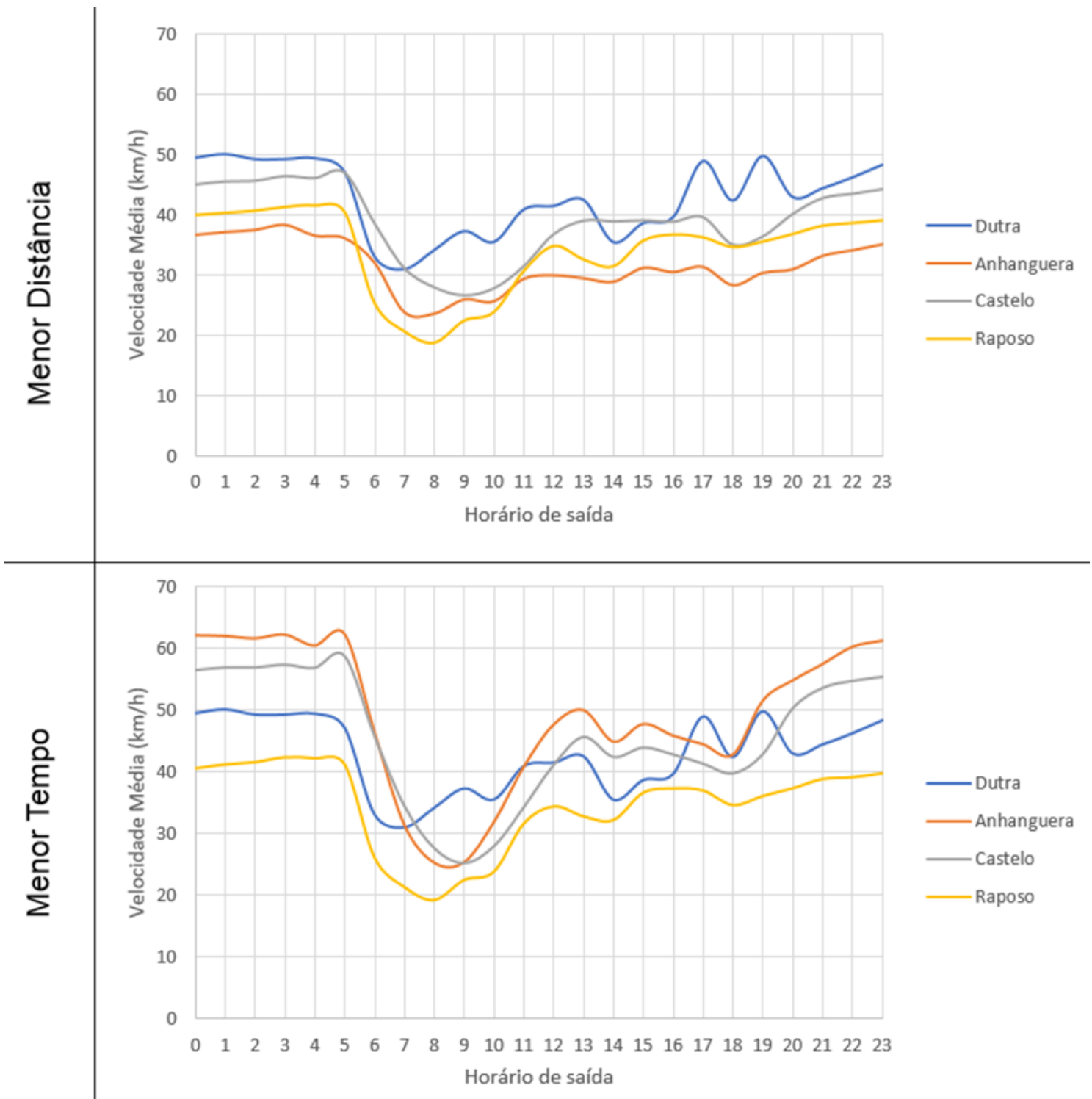

Figura 4.72: Perfis de velocidade para os trajetos com sentido centro. 


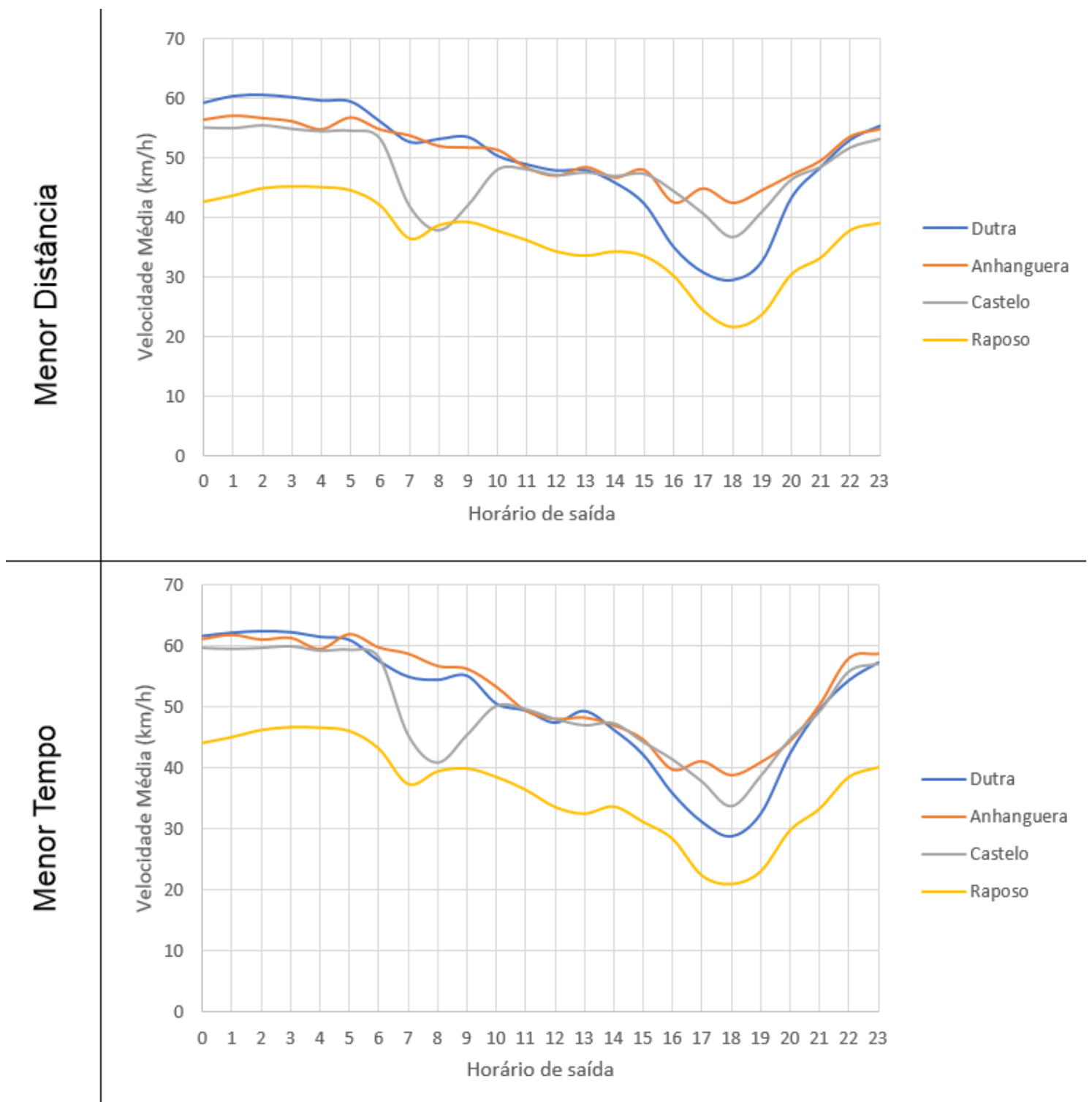

Figura 4.73: Perfis de velocidade para os trajetos com sentido aos potenciais locais de centro de distribuição.

Os perfis de velocidade apresentam resultados esperados, pois os vales de menor velocidade correspondem ao horário de pico da manhã para os trajetos com sentido centro e pico da tarde para os trajetos sentido interior.

Os resultados também evidenciam que apenas a distância entre o local do CD e o distrito de entrega não é suficiente para caracterizar a dificuldade de acesso. Por exemplo, a Rodovia Tavares apresenta velocidades consistentemente inferiores às demais rodovias, principalmente no retorno, sendo essa diferença de quase $50 \%$ se considerada a Rodovia Anhanguera, independentemente do horário. 


\subsection{Comentários Gerais}

Os resultados apresentados nas seções 4.1 e 4.2 são coerentes com o que foi proposto no Capítulo 3. Na seção 4.2, pretendia-se analisar a parte de circulação local da distribuição de última milha em cidades através de valores de IR obtidos em cada cidade, tanto para veículos motorizados quanto não-motorizados, e as velocidades de tráfego estimadas nas seis cidades em quatro horários do dia diferentes $(1 \mathrm{~h}, 8 \mathrm{~h}, 13 \mathrm{~h}$ e 18h). Foram apresentados os valores de Índice de "Retilinidade" Médio para as seis cidades de acordo com faixas de distância euclidiana; pode-se concluir que para distâncias euclidianas maiores são esperados menores IRs, pois esse comportamento foi observado em todas as cidades. Além disso, através dos IRMs é possível estimar as distâncias percorridas em uma operação de entrega no local baseado na distância linear entre os locais de entrega, levando a dedução que, das cidades estudadas, o Rio de Janeiro é a cidade em que esperasse maiores distâncias de percurso em uma operação de entrega e São Francisco a que se espera as menores distâncias de percurso. A comparação entre os IRMs obtidos para modos motorizados e não motorizados indicam que os modos não motorizados exigem distâncias de percurso menores que os veículos motorizados, tornando o seu uso interessante principalmente em operações de distribuição cujos locais de entrega são próximos entre si. Os IRs também se mostraram úteis na identificação de barreiras urbanas para a circulação quando representados em um mapa (Figuras 4.20 a 4.25).

Ainda na seção 4.2, foram estimadas as velocidades de tráfego dentro das áreas de estudo. Os resultados apontam que as cidades apresentam comportamento diferente quanto a variação das velocidades ao longo do dia. Nova lorque se mostrou a cidade que apresenta a maior amplitude de velocidades de tráfego ao longo do dia e a pior velocidade média de circulação. Um fator interessante da análise é que as velocidades de tráfego estimadas para as 13h são muito próximas das velocidades de tráfego estimadas para as $18 \mathrm{~h}$ em todas as cidades, um resultado contra intuitivo, pois é comum atribuir o horário de pico da ocupação viária no fim da tarde.

Foram calculados também as correlações entre os IRMs e velocidades médias de circulação obtidos e as métricas descritivas das malhas viárias contidas nas áreas de estudo. Os resultados indicam que malhas viárias mais densas, ou seja, maior 
disponibilidade de metragem de vias por quilômetro quadrado, são mais eficientes em conectar origens e destinos do ponto de vista das distâncias percorridas, em outras palavras, caminhos alocados em malhas viárias mais densas tem distância mais próxima da distância linear entre origem e destino. Além disso, as correlações deixaram claro o que já era esperado em relação as restrições de trânsito e os modos não motorizados, que é que as distâncias de percurso em caminhos realizados por modos não motorizados não são influenciadas pelas regras de trânsito.

Na seção 4.3 são apresentados os resultados obtidos para o acesso/regresso dos CDs ao distrito de entrega. Os resultados apontam que esta parte do caminho da distribuição de última milha nas cidades apresenta valores de IR baixos, próximos da unidade, diferente dos caminhos discutidos na seção 4.2, que compõem a parte de circulação local da distribuição. Este resultado indica que no acesso/regresso ao distrito de entrega os tempos de viagem prolongados devido a ocupação viária afetam mais a eficiência da distribuição do que as distâncias percorridas. Ainda, através dos perfis de velocidade gerados, conclui-se que há variação considerável nas velocidades de tráfego ao longo do dia e que a localização do CD é um fator determinante, não pela distância que está do distrito de entrega, e sim devido as vias de acesso disponíveis que podem estar mais sujeitas a velocidades baixas que outras, que é o caso da Rodovia Anhanguera em São Paulo. 


\section{CONSIDERAÇÕES FINAIS}

Este trabalho teve por finalidade propor um método de avaliação e comparação de áreas urbanas quanto a complexidade para a realização da chamada distribuição urbana de carga de última milha. Primeiramente, foi realizada uma abrangente pesquisa bibliográfica em que se buscou por métricas de caracterização de áreas urbanas da literatura que pudessem ser utilizadas ou adaptadas para o problema da distribuição de última milha nas cidades. Muitas métricas encontradas têm o propósito de aplicações geográficas gerais, que pouco contribuem para a compreensão da complexidade da realização de entregas em áreas urbanas. Outras métricas encontradas têm aplicação restrita ou não universal, pois requerem coleta de dados em campo ou utilização de dados de acesso restrito, como imagens de satélites. Como a premissa do método proposto é que ele seja automatizado e que possa ser aplicado em qualquer área urbana de qualquer lugar do mundo, excluiu-se a possibilidade de uso de qualquer métrica que não atingisse estes requisitos. Das métricas encontradas na literatura, a mais promissora devido a sua possibilidade de aplicação e facilidade de obtenção de dados é o Índice de "Retilinidade", utilizado por Ballou (2002) e Crucitti et al. (2006) para análise de redes viárias, por Levinson e El-Geneidy (2009), Levinson (2012), Parthasarathi et al. (2013) e Huand e Levinson (2015) para análise de transporte urbano de passageiros e por Merchan et al. (2015) para análise voltada ao transporte de carga urbano.

Na sequência, foi proposto e desenvolvido um método para avaliação da complexidade da distribuição urbana de carga. São identificadas duas partes da distribuição urbana de carga para a avaliação: o acesso/regresso ao distrito de entrega (line-haul) e a circulação local. O usuário tem a liberdade de delimitar a área de interesse em que se deseja fazer a avaliação da circulação local e de apontar os possíveis locais de centro de distribuição para a avaliação do line-haul. Foi apresentado o procedimento para a obtenção de Índices de "Retilinidade" e velocidades de tráfego em ambas as partes da distribuição urbana de carga. Adicionalmente, para contemplar o uso de modos de transporte não motorizados na circulação local, apresenta-se o procedimento para a obtenção de Índices de "Retilinidade" para os modos bicicleta e a pé e de declividades das vias dá área de estudo. 
O método foi aplicado para a avaliação da circulação local em seis áreas urbanas de seis cidades diferentes (São Paulo, Rio de Janeiro, Bogotá, Nova lorque, Londres e São Francisco). Para cada cidade foram calculados e apresentados:

(i) Métricas das redes viárias nas áreas de estudo: densidade de vias, extensão média do seguimento de via, densidade de interseções e proporção de extensão vias de mão única;

(ii) Representação gráfica das redes viárias destacando as vias de mão única;

(iii) Gráfico com a distribuição de Índice de "Retilinidade" em função da distância euclidiana para veículos motorizados;

(iv) Boxplots dos Índices de "Retilinidade" para diferentes faixas de distância euclidiana;

(v) Índices de "Retilinidade" Médios para veículos motorizados;

(vi) Mapa para a visualização espacial dos IRs obtidos e identificação de barreiras urbanas;

(vii) Velocidades média de circulação estimadas em quatro horários diferentes do dia (1h, 8h, 13h e 18h);

(viii) Mapas com a velocidade de tráfego estimada por segmento de via em quatro horários diferentes do dia (1h, 8h, 13h e 18h);

(ix) Porcentagem de extensão de vias em que se estima velocidade de tráfego menor que $10 \mathrm{~km} / \mathrm{h}$, entre 10 e $20 \mathrm{~km} / \mathrm{h}$ e maior que $20 \mathrm{~km} / \mathrm{h}$ em quatro horários diferentes do dia (1h, 8h, 13h e 18h);

(x) Gráfico com a distribuição de Índice de "Retilinidade" em função da distância euclidiana para o modo bicicleta;

(xi) Boxplots dos Índices de "Retilinidade" para o modo bicicleta para diferentes faixas de distância euclidiana;

(xii) Índices de "Retilinidade" Médios para bicicletas;

(xiii) Gráfico com a distribuição de Índice de "Retilinidade" em função da distância euclidiana para o modo a pé;

(xiv) Boxplots dos Índices de "Retilinidade" para o modo a pé para diferentes faixas de distância euclidiana;

(xv) Índices de "Retilinidade" Médios para o modo a pé; 
(xvi) Razão entre IRM para veículos motorizados e não motorizados;

(xvii) Porcentagem de extensão de vias com declividade entre 0 e $2 \%$, entre 2 e $5 \%$ e maior que $5 \%$;

(xviii) Mapa com a declividade dos segmentos de via;

Foram também apresentados resultados para avaliação do acesso/regresso de quatro possíveis locais de $C D$ às margens de quatro rodovias diferentes destinadas a um distrito de entrega na cidade de São Paulo. São apresentados:

(i) Índices de "Retilinidade" para os trajetos de acesso ao distrito de entrega e regresso ao $C D$;

(ii) Mapas com os traçados dos trajetos;

(iii) Perfis de velocidade ao longo do dia para os trajetos;

Como o objetivo deste trabalho era criar um atlas de métricas urbanas associadas ao desempenho da distribuição de última milha nas cidades, afim de possibilitar a avaliação e a comparação de áreas urbanas quanto à dificuldade imposta à circulação de veículos que realizam a distribuição de última milha, pode-se dizer que os resultados obtidos atingem a este objetivo. Através de métricas, mapas e gráficos foi possível avaliar e comparar as seis cidades escolhidas.

Adicionalmente, também foram apresentadas neste trabalho as correlações entre as métricas estruturais das malhas viárias e as métricas associadas ao desempenho da distribuição de última milha (IRMs e velocidades). Como este trabalho apresentou resultados para apenas seis áreas urbanas, não foi possível criar um modelo descritivo relacionando as métricas. Tal ferramenta seria útil para, por exemplo, estimar IRM em função das métricas estruturais da malha viária, que são de obtenção imediata. Sendo assim, a obtenção de mais dados para explorar o uso de modelos matemáticos para estimar métricas associadas ao desempenho da distribuição de última milha em função de métricas estruturais da malha viária é uma das recomendações para trabalhos futuros.

Outra recomendação para trabalhos futuros é incorporar os dados levantados pelo método apresentado neste trabalho em modelos de otimização ou heurísticas, a fim de melhorar o desempenho das operações de distribuição urbana de carga. Um exemplo deste tipo de aplicação seria utilizar os dados das malhas viárias obtidos em 
um modelo de otimização para definição de distritos de entrega, a fim de excluir a possibilidade de distritos de entrega cortados por barreiras de circulação aos veículos, como rios ou avenidas expressas. 


\section{REFERÊNCIAS}

Ballou, R. H., Rahardja, H., e Sakai, N. (2002). Selected country circuity factors for road travel distance estimation. Transportation Research Part A: Policy and Practice, v. 36, n. 9 , p. 843-848.

Boeing, G. 2017. "OSMnx: New Methods for Acquiring, Constructing, Analyzing, and Visualizing Complex Street Networks." Computers, Environment and Urban Systems 65, 126-139. doi:10.1016/j.compenvurbsys.2017.05.004.

Braekers, K., Ramaekers, K., e Van Nieuwenhuyse, I. (2016). The vehicle routing problem: State of the art classification and review. Computers \& Industrial Engineering, v. 99, p. 300-313.

Companhia de Engenharia de Tráfego. (2018) Locais com restrição ao caminhão. Disponível em <http://www.cetsp.com.br/consultas/caminhoes/locais-comrestricao-ao-caminhao/zona-de-maxima-restricao-de-circulacao-zmrc.aspx>. Acesso em 6 de junho de 2018.

Crucitti, P., Latora, V., e Porta, S. (2006). Centrality measures in spatial networks of urban streets. Physical Review E, v. 73, n. 3, p. 036125.

Cunha, C. B. (2006). Contribuição à Modelagem de Problemas em Logística e Transpirtes. Tese de Livre Docência. Departamento de Engenharia de Transportes da Escola Politécnica da USP, São Paulo, SP, Brasil.

Dablanc, L., e Rakotonarivo, D. (2010). The impacts of logistics sprawl: How does the location of parcel transport terminals affect the energy efficiency of goods' movements in Paris and what can we do about it?. Procedia-Social and Behavioral Sciences, v. 2, n. 3, p. 6087-6096.

Dablanc, L., Ogilvie, S., e Goodchild, A. (2014). Logistics sprawl: differential warehousing development patterns in Los Angeles, California, and Seattle, Washington. Transportation Research Record: Journal of the Transportation Research Board, v. 2410, p. 105-112

Daganzo, C. F. (1984). The distance traveled to visit N points with a maximum of C stops per vehicle: An analytic model and an application. Transportation Science, v. 18, n. 4 , p. 331-350.

Dill, J. (2004). Measuring network connectivity for bicycling and walking. In 83rd Annual Meeting of the Transportation Research Board, Washington, DC, p. 11-15.

FourSquare. (2018). Disponível em: <https://pt.foursquare.com/about>. Acesso em 4 de julho de 2018.

Freiria, S., Ribeiro, B., e Tavares, A. O. (2015). Understanding road network dynamics: Link-based topological patterns. Journal of transport geography, v. 46, p. 55-66.

GeoSampa (2017). Mapa Digital da Cidade de São Paulo. Disponível em: <http://geosampa.prefeitura.sp.gov.br/>. Acesso em 6 de julho de 2017. 
Google Maps Directions API (2017) Google Maps APIs, documento de referência para desenvolvedores.Disponível em < https://developers.google.com/maps/documentation/directions/start?hl=pt-br $\quad>$. Acesso em 3 de julho de 2017.

GraphHopper Route Optimization API (2016) GraphHopper Directions API, documento de referência para desenvolvedores. Disponível em: <https://graphhopper.com/api/1/docs/>. Acesso em 8 de julho de 2016.

Gruber, J., e Kihm, A. (2016). Reject or embrace? Messengers and electric cargo bikes. Transportation Research Procedia,v. 12, p. 900-910.

Guia Kekanto. (2016). Disponível em: https://kekanto.com.br/. Acesso 8 de julho de 2016.

Hagberg, A., Schult, D. e Swart, P. (2008). Exploring network structure, dynamics, and function using NetworkX. 7th Python in Science Conference (SciPy2008), Pasadena, CA, Estados Unidos), p. 11-15.

Holguín-Veras, J.; J. A. Leal e B. B. Seruya (2017). Urban freight policymaking: The role of qualitative and quantitative research. Transport Policy, v. 56, p. 75-85.

Huang, J., \& Levinson, D. M. (2015). Circuity in urban transit networks. Journal of Transport Geography, v. 48, p. 145-153.

Jiang, B., e Claramunt, C. (2004). Topological analysis of urban street networks. Environment and Planning B: Planning and design, v. 31, n.1, p. 151-162.

Katsavounidis, I., C. C. J. Kuo e Z. Zhang (1994) A new initialization technique for generalized Lloyd iteration. IEEE Signal processing letters, v. 1, n. 10, p. 144-146.

Latora, V., e Marchiori, M. (2001). Efficient behavior of small-world networks. Physical review letters, v. 87, n. 19, p. 198701.

Levinson, D., e El-Geneidy, A. (2009). The minimum circuity frontier and the journey to work. Regional science and urban economics, v. 39, n. 6, p. 732-738.

Levinson, D. (2012). Network structure and city size. PloS one, v. 7, n. 1, p. e29721.

Lindholm, M. E. e M. Blinge (2014). Assessing knowledge and awareness of the sustainable urban freight transport among Swedish local authority policy planners. Transport policy, v. 32, p. 124-131.

Lindner, J. (2011). Last Mile Logistics Capability: a Multidimensional System Requirements Analysis for a General Modelling and Evaluation Approach. Dipl. Technical University of Munich, Alemanha.

Louf, R. e M. Barthelemy (2014). A typology of street patterns. Journal of The Royal Society Interface, v. 11, n. 101, p. 20140924.

MacQueen, J. (1967) Some methods for classification and analysis of multivariate observations. Anais do the fifth Berkeley symposium on mathematical statistics and probability , v. 1,n. 14, p. 281-297.

Marujo, L. G., Goes, G. V., D'Agosto, M. A., Ferreira, A. F., Winkenbach, M., e 
Bandeira, R. A. (2018). Assessing the sustainability of mobile depots: The case of urban freight distribution in Rio de Janeiro. Transportation Research Part D: Transport and Environment, v. 62, p. 256-267.

Merchán, D., Blanco, E., e Bateman, A. (2015). Urban metrics for urban logistics: building an atlas for urban freight policy makers. 14th International Conference on Computers in Urban Planning and Urban Management, Cambridge, MA, Estados Unidos.

Mohajeri, N. e A. Gudmundsson (2014). The evolution and complexity of urban street networks. Geographical Analysis, v. 46, n. 4, p. 345-367.

Nations, U. (2014) World urbanization prospects.

Novaes, A. G., de Cursi, J. E. S., e Graciolli, O. D. (2000). A continuous approach to the design of physical distribution systems. Computers \& Operations Research, v. 27, n. 9 , p. $877-893$.

Oliveira, L. K., dos Santos, O. R., de Albuquerque Nóbrega, R. A., Dablanc, L., e de Oliveira, R. L. M. (2017). Análise do espraiamento logístico: um estudo para a região metropolitana de Belo Horizonte. TRANSPORTES, v. 25, n. 4, p. 42-56.

Oliveira, L. K., Barraza, B., Bertoncini, B., Isler, C., Pires, D., Madalon, E., Lima, J., Vieira, J. G., Meira, L., Bracarense, L., Bandeira, R., Oliveira, R., Ferreira, S. (2018). An Overview of Problems and Solutions for Urban Freight Transport in Brazilian Cities. Sustainability, v.10, n. 4, p. 1-14.

OpenStreetMap. (2017). Disponível em: <https://www.openstreetmap.org/>. Acesso em 22 de setembro de 2017.

Partyka, J. e Hall, R. (2012). Computing-Vehicle routing: On the road to innovationBiennial survey of vehicle routing software reveals fierce competition produces creative solutions. OR/MS Today, v. 39, n. 1, p. 38.

Parthasarathi, P., e Levinson, D. (2010). Post-construction evaluation of traffic forecast accuracy. Transport Policy, v. 17, n. 6, p. 428-443.

Parthasarathi, P., Levinson, D., \& Hochmair, H. (2013). Network structure and travel time perception. PloS one, v. 8, n. 10, p. e77718.

Porta, S., Crucitti, P., e Latora, V. (2006). The network analysis of urban streets: a dual approach. Physica A: Statistical Mechanics and its Applications, v. 369, n. 2, p. 853-866.

Porta, S., Romice, O., Maxwell, J. A., Russell, P., e Baird, D. (2014). Alterations in scale: Patterns of change in main street networks across time and space. Urban Studies, v. 51, n.16, p. 3383-3400.

QGIS 2.18 (2017). QGIS, um Sistema e informação geográfica livre e aberto. Disponível em: < http://www.qgis.org/pt_BR/site/>. Acesso em 3 de julho de 2017.

Robusto, C. C. (1957) The cosine-haversine formula. The American Mathematical Monthly, v. 64, n. 1, p. 38-40. 
Redmond, S. e C. Heneghan. (2007). A method for initialising the K-means clustering algorithm using kd-trees. Pattern Recognition Letters, v. 28, n. 8, p. 965-973.

Strano, E., Nicosia, V., Latora, V., Porta, S., e Barthélemy, M. (2012). Elementary processes governing the evolution of road networks. Scientific reports, 2.

Taubenböck, H., T. Esch, A. Felbier, M. Wiesner, A. Roth, e S. Dech (2012) Monitoring urbanization in mega cities from space. Remote sensing of Environment, v. 117, p. $162-176$.

Yuen, K. F., Wang, X., Ng, L. T. W., Wong, Y. D. (2018). An investigation of customers' intention to use self-collection services for last-mile delivery. Transport Policy, $v$. 66 , p. 1-8.

Zambuzi, N. (2015). Metodologia para a avaliação de medidas voltadas à distribuição urbana de cargas através do uso da microssimulação de tráfego. Tese de doutorado. Departamento de Engenharia de Transportes da Escola Politécnica da USP, São Paulo, SP, Brasil.

Zhang, X., Miller-Hooks, E., e Denny, K. (2015). Assessing the role of network topology in transportation network resilience. Journal of Transport Geography, v. 46, p. 3545. 


\section{ANEXO A: RESUMO DAS MÉTRICAS ENCONTRADAS NA LITERATURA}

Tabela A.1: Métricas encontradas na literatura.

\begin{tabular}{|c|c|c|c|}
\hline Métrica & Descrição & Unidade & Citada por: \\
\hline Área de caminhada efetiva & $\begin{array}{l}\text { razão entre a área que pode ser } \\
\text { alcançada caminhando } 0,25 \mathrm{mi} \text { e } \\
\text { círculo de raio } 0,25 \mathrm{mi}\end{array}$ & - & Dill (2004) \\
\hline Área do quarteirão & $\begin{array}{l}\text { área dos polígonos delimitados por } \\
\text { vias }\end{array}$ & $\mathrm{m}^{2}$ & $\begin{array}{l}\text { Dill (2004) } \\
\text { Strano et al. (2012) } \\
\text { Louf e Barthelemy (2014) } \\
\end{array}$ \\
\hline Área Urbana & área da mancha urbana & $\mathrm{km}^{2}$ & Taubenböck et al. (2012) \\
\hline $\begin{array}{l}\text { "Circuicidade" } \\
\text { Índice de "retilinidade" }\end{array}$ & $\begin{array}{l}\text { razão entre a distância em linha } \\
\text { reta e a distância em rede entre } \\
\text { dois nós }\end{array}$ & - & $\begin{array}{l}\text { Ballou (2002) } \\
\text { Dill (2004) } \\
\text { Crucitti et al. (2006) } \\
\text { Levinson e El-Geneidy (2009) } \\
\text { Levinson (2012) } \\
\text { Parthasarathi et al. (2013) } \\
\text { Huang e Levinson (2015) } \\
\text { Merchan et al. (2015) }\end{array}$ \\
\hline Centralidade de informação & $\begin{array}{l}\text { diferença de eficiência global da } \\
\text { rede no caso do desligamento de } \\
\text { um nó }\end{array}$ & - & Crucitti et al. (2006) \\
\hline Centralidade de intermediação & $\begin{array}{l}\text { mede a participação de um nó nos } \\
\text { caminhos que ligam os demais nós } \\
\text { da rede }\end{array}$ & - & $\begin{array}{l}\text { Crucitti et al. (2006) } \\
\text { Strano et al. (2012) } \\
\text { Freiria et al. (2015) }\end{array}$ \\
\hline Centralidade de proximidade & $\begin{array}{l}\text { proximidade de um nó em relação } \\
\text { aos demais }\end{array}$ & - & Crucitti et al. (2006) \\
\hline
\end{tabular}




\begin{tabular}{|c|c|c|c|}
\hline \multicolumn{4}{|c|}{ Continuação } \\
\hline Métrica & Descrição & Unidade & Citada por: \\
\hline Ciclicidade & $\begin{array}{l}\text { proporção de caminhos que } \\
\text { retornam a um nó já visitado em um } \\
\text { conjunto de caminhos aleatórios }\end{array}$ & - & Zhang et al. (2015) \\
\hline "Circuicidade" média & $\begin{array}{l}\text { razão entre a soma das distâncias } \\
\text { em rede e soma das distâncias } \\
\text { euclidianas }\end{array}$ & - & Parthasarathi e Levinson (2010) \\
\hline $\begin{array}{l}\text { Coeficiente de aglomeração } \\
\text { Índice de "clusterização" }\end{array}$ & $\begin{array}{l}\text { medida que expressa quantos nós } \\
\text { vizinhos do nó i estão ligados entre } \\
\text { si }\end{array}$ & - & $\begin{array}{l}\text { Jiang e Claramunt (2004) } \\
\text { Porta et al. (2006) } \\
\text { Freiria et al. (2015) } \\
\end{array}$ \\
\hline Completude & $\begin{array}{l}\text { porcentagem da rede existente em } \\
\text { relação a rede completa que teria } \\
\text { todos os nós ligados entre si }\end{array}$ & - & Parthasarathi e Levinson (2010) \\
\hline $\begin{array}{l}\text { Comprimento dos segmentos de via } \\
\text { Comprimento médio dos quarteirões }\end{array}$ & $\begin{array}{l}\text { comprimento dos segmentos de via } \\
\text { entre interseções }\end{array}$ & $\mathrm{m}$ & $\begin{array}{l}\text { Dill (2004) } \\
\text { Mohajeri e Gudmundsson (2014) }\end{array}$ \\
\hline $\begin{array}{l}\text { Comprimento médio de caminho } \\
\text { Comprimento de caminho característico }\end{array}$ & $\begin{array}{l}\text { número médio de arcos entre os } \\
\text { nós da rede }\end{array}$ & - & $\begin{array}{l}\text { Jiang e Claramunt (2004) } \\
\text { Porta et al. (2006) }\end{array}$ \\
\hline Comprimento total de vias & $\begin{array}{l}\text { soma do comprimento de todas as } \\
\text { vias da rede }\end{array}$ & $\mathrm{m}$ & $\begin{array}{l}\text { Levinson e El-Geneidy (2009) } \\
\text { Strano et al. (2012) }\end{array}$ \\
\hline $\begin{array}{l}\text { Conectividade } \\
\text { Grau médio } \\
\text { Índice Beta }\end{array}$ & $\begin{array}{l}\text { número médio de arcos ligados aos } \\
\text { nós da rede }\end{array}$ & - & $\begin{array}{l}\text { Jiang e Claramunt (2004) } \\
\text { Porta et al. (2006) } \\
\text { Levinson (2012) } \\
\text { Zhang et al. (2015) }\end{array}$ \\
\hline Correlação de grau & $\begin{array}{l}\text { correlação entre o grau de um nó e } \\
\text { o grau dos seus vizinhos }\end{array}$ & - & Porta et al. (2006) \\
\hline
\end{tabular}




\begin{tabular}{|c|c|c|c|}
\hline \\
\hline Métrica & Descrição & Unidade & Citada por: \\
\hline Densidade de interseções & $\begin{array}{l}\text { número de interseções em } \\
\text { determinada unidade de área }\end{array}$ & un. $/ \mathrm{km}^{2}$ & $\begin{array}{l}\text { Dill (2004) } \\
\text { Levinson e El-Geneidy (2009) } \\
\text { Parthasarathi et al. (2013) }\end{array}$ \\
\hline Densidade de quarteirões & $\begin{array}{l}\text { número de quarteirões por unidade } \\
\text { de área }\end{array}$ & un. $/ \mathrm{km}^{2}$ & Dill (2004) \\
\hline Densidade de vias & $\begin{array}{l}\text { comprimento das vias existentes } \\
\text { por unidade de área }\end{array}$ & $\mathrm{m} / \mathrm{km}^{2}$ & $\begin{array}{l}\text { Dill (2004) } \\
\text { Parthasarathi e Levinson (2010) } \\
\text { Parthasarathi et al. (2013) }\end{array}$ \\
\hline Descontinuidade relativa & $\begin{array}{l}\text { parâmetro que captura as } \\
\text { diferenças de classes de vias } \\
\text { presentes na malha }\end{array}$ & - & Parthasarathi et al. (2013) \\
\hline Diâmetro & $\begin{array}{l}\text { maior caminho entre dois nós da } \\
\text { rede }\end{array}$ & - & Zhang et al. (2015) \\
\hline Distribuição de grau & $\begin{array}{l}\text { probabilidade de se encontrar na } \\
\text { rede um nó com determinado grau }\end{array}$ & - & Porta et al. (2006) \\
\hline Eficiência global & $\begin{array}{l}\text { medida de quão bem os nós de } \\
\text { uma rede se comunicam entre si }\end{array}$ & - & $\begin{array}{l}\text { Latora e Marchiori (2001) } \\
\text { Porta et al. (2006) }\end{array}$ \\
\hline Eficiência local & $\begin{array}{l}\text { mesmo que eficiência global, mas } \\
\text { para um subgrafo delimitado da } \\
\text { rede }\end{array}$ & - & $\begin{array}{l}\text { Latora e Marchiori (2001) } \\
\text { Porta et al. (2006) }\end{array}$ \\
\hline Fator de forma do quarteirão & $\begin{array}{l}\text { razão entre a área do quarteirão e } \\
\text { do círculo que o circunscreve }\end{array}$ & - & $\begin{array}{l}\text { Strano et al. (2012) } \\
\text { Louf e Barthelemy (2014) }\end{array}$ \\
\hline Fragmentação & proporção de nós isolados da rede & - & Freiria et al. (2015) \\
\hline Índice alpha & $\begin{array}{l}\text { medida que avalia o número de } \\
\text { ciclos existentes em comparação } \\
\text { ao número máximo de ciclos }\end{array}$ & - & Freiria et al. (2015) \\
\hline
\end{tabular}


Continuação

\begin{tabular}{|c|c|c|c|}
\hline Métrica & Descrição & Unidade & Citada por: \\
\hline Número de arcos & quantos arcos a rede possui & & $\begin{array}{l}\text { Porta et al. (2006) } \\
\text { Strano et al. (2012) }\end{array}$ \\
\hline Número de nós & quantos nós a rede possui & - & $\begin{array}{l}\text { Porta et al. (2006) } \\
\text { Strano et al. (2012) }\end{array}$ \\
\hline Orientação das vias & azimutes dos segmentos de via & graus & Mohajeri e Gudmundsson (2014) \\
\hline P2A & $\begin{array}{l}\text { razão entre o quadrado do } \\
\text { perímetro do polígono que contorna } \\
\text { a malha e a sua área }\end{array}$ & - & Parthasarathi et al. (2013) \\
\hline Padrão de grade & $\begin{array}{l}\text { binário que identifica se a malha } \\
\text { apresenta padrão de grade, ou não }\end{array}$ & - & Dill (2004) \\
\hline Perímetro dos quarteirões & $\begin{array}{l}\text { perímetro dos polígonos } \\
\text { delimitados por vias }\end{array}$ & $\mathrm{m}$ & Dill (2004) \\
\hline Pontos de corte & $\begin{array}{l}\text { nós que se removidos promovem a } \\
\text { fragmentação da rede }\end{array}$ & - & Freiria et al. (2015) \\
\hline Potência de Bonacich & $\begin{array}{l}\text { medida que avalia a conectividade } \\
\text { de acordo com o número de } \\
\text { ligações de um nó e seus vizinhos }\end{array}$ & - & Freiria et al. (2015) \\
\hline Proporção de nós conectados & $\begin{array}{l}\text { número de interseções de vias } \\
\text { sobre número total de nós }\end{array}$ & - & Dill (2004) \\
\hline Proporção de vias expressas & $\begin{array}{l}\text { razão entre comprimento de vias } \\
\text { expressas e total de vias do local }\end{array}$ & - & Parthasarathi et al. (2013) \\
\hline Razão entre segmentos de vias e nós & $\begin{array}{l}\text { número total de arcos sobre } \\
\text { número total de nós }\end{array}$ & - & Dill (2004) \\
\hline "Treeness" & $\begin{array}{l}\text { número de subredes em forma de } \\
\text { árvore }\end{array}$ & - & $\begin{array}{l}\text { Parthasarathi e Levinson (2010) } \\
\text { Parthasarathi et al. (2013) }\end{array}$ \\
\hline
\end{tabular}




\section{ANEXO B: ÍNDICE DE "RETILINIDADE" - ESTUDO DE CASO EM TRÊS BAIRROS DE SÃO PAULO}

A primeira análise preliminar realizada no processo deste trabalho utiliza o índice de "retilinidade". Foram selecionadas três regiões da cidade de São Paulo com características distintas. Dentro de cada região foram selecionados 10 potenciais pontos de entrega (restaurantes e bares), provenientes da base de estabelecimentos de um guia colaborativo de serviços, chamado Kekanto. Para cada região foram calculados 90 índices de "retilinidade", correspondentes a todas ligações entre os pontos, ou seja, todas as combinações origem e destino possíveis com 10 pontos.

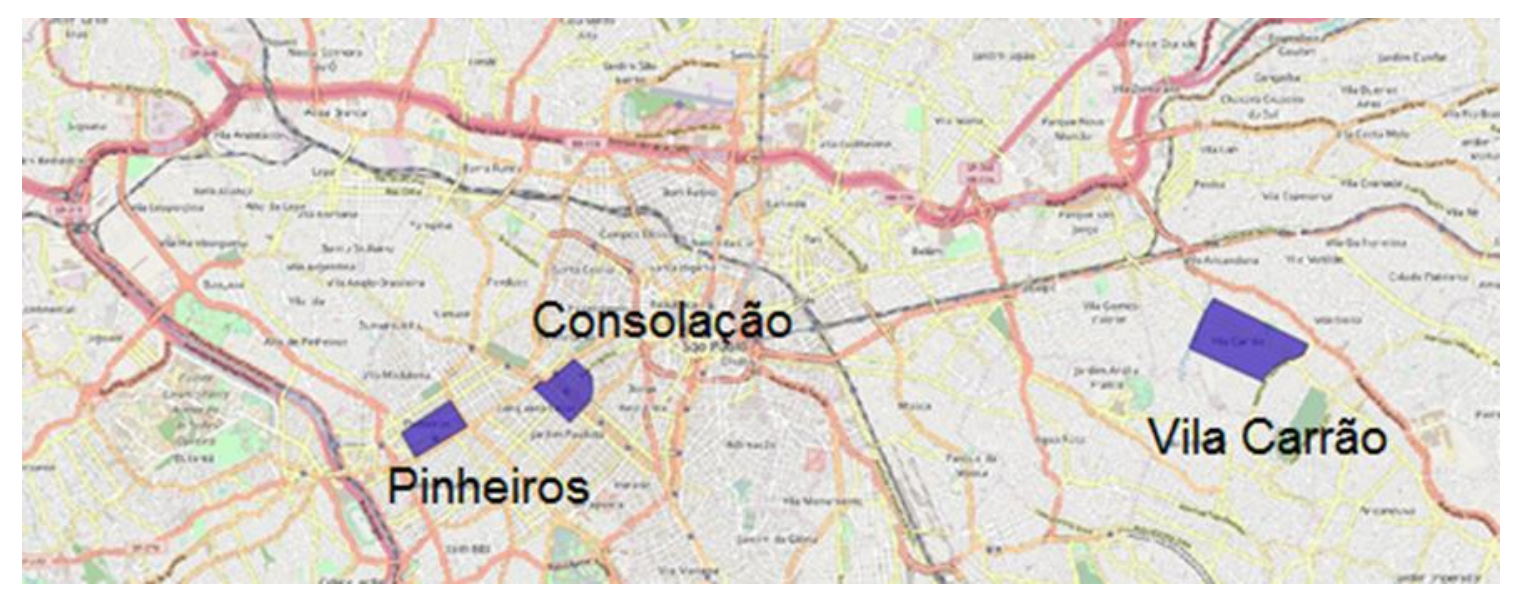

Figura B.1: Localização das regiões estudadas.

A Figura B.1 mostra a localização das três regiões escolhidas na cidade de São Paulo. O primeiro conjunto de pontos está na região da Avenida Paulista, no bairro da Consolação, um bairro de uso residencial e comercial, onde a densidade demográfica é alta, os estabelecimentos comerciais uniformemente distribuídos e o viário apresenta muitas restrições de mão de direção e de conversão. A segunda região está dentro do bairro de Pinheiros, assim como a Consolação, a densidade populacional também é alta e o viário também conta com muitas restrições de mão de direção, porém existe uma maior concentração de estabelecimentos comerciais em uma via principal. O terceiro grupo de pontos foi retirado do bairro Vila Carrão; uma região mais periférica da cidade, onde a densidade é mais baixa e são poucas as restrições de mão de direção. 


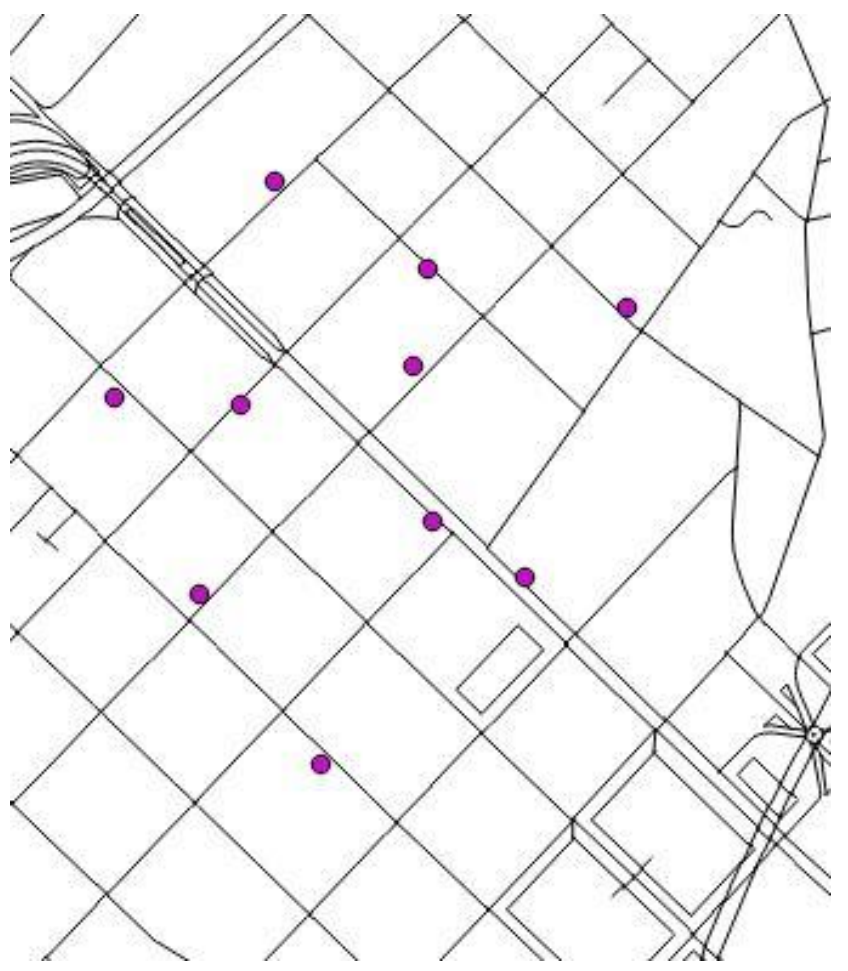

Figura B.2: Potenciais pontos de entrega na região da Paulista/Consolação.

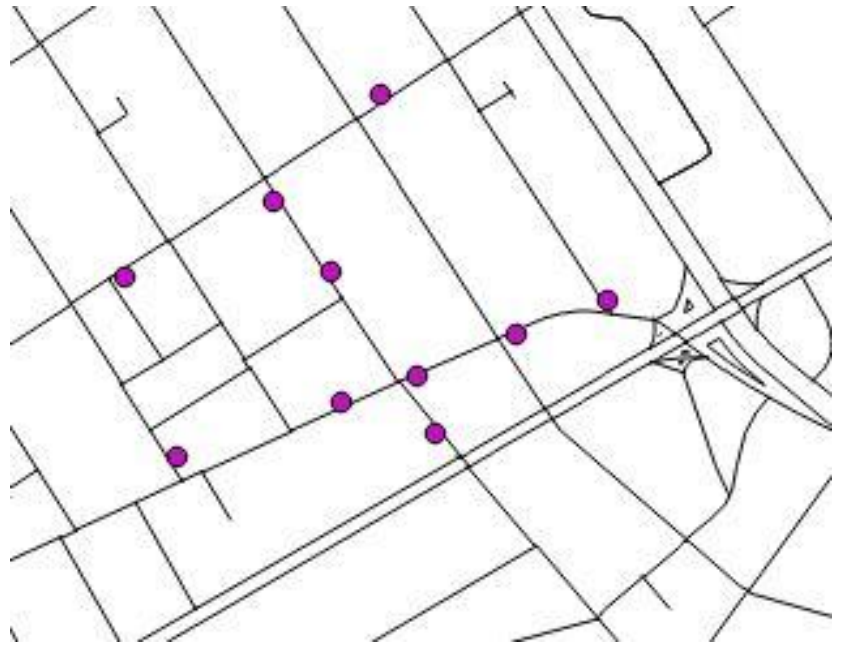

Figura B.3: Potenciais pontos de entrega em Pinheiros. 


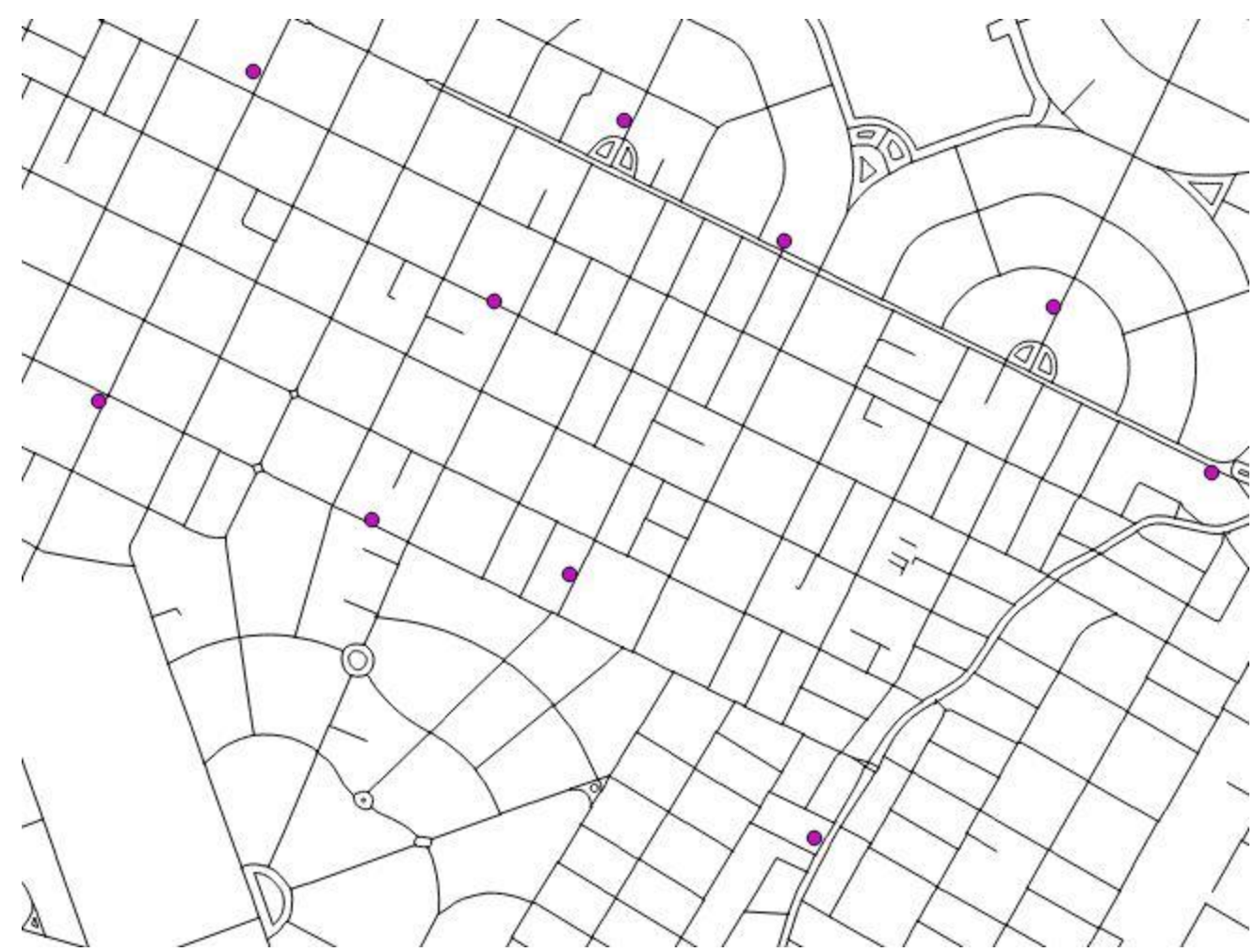

Figura B.4: Potenciais pontos de entrega na Vila Carrão.

A Figura B.2, a Figura B.3 e a Figura B.4 apresentam a localização dos potenciais pontos de entrega, representados graficamente em rosa, no meio viário das regiões estudadas. Nota-se que as três localidades possuem malha viária predominantemente em grade. Além disso, percebe-se que em Pinheiros os pontos estão mais concentrados ao longo de uma via principal em comparação as outras duas regiões onde estão mais uniformemente distribuídos.

Os valores resultantes da aplicação do método estão apresentados a seguir na Tabela B.1 e nas Figuras Figura B.5 e Figura B.6.

Tabela B.1: Médias dos valores obtidos por região estudada.

\begin{tabular}{lccc}
\hline Região & $\begin{array}{c}\text { Média Distâncias } \\
\text { Euclidianas }(\mathrm{m})\end{array}$ & $\begin{array}{c}\text { Média Distâncias } \\
\text { Reais }(\mathrm{m})\end{array}$ & $\begin{array}{c}\text { Indice de "Retilinidade" } \\
\text { Médio (IRM) }\end{array}$ \\
\hline Consolação & 244 & 1122 & 4,60 \\
Pinheiros & 224 & 722 & 3,22 \\
Vila Carrão & 620 & 820 & 1,32 \\
\hline
\end{tabular}




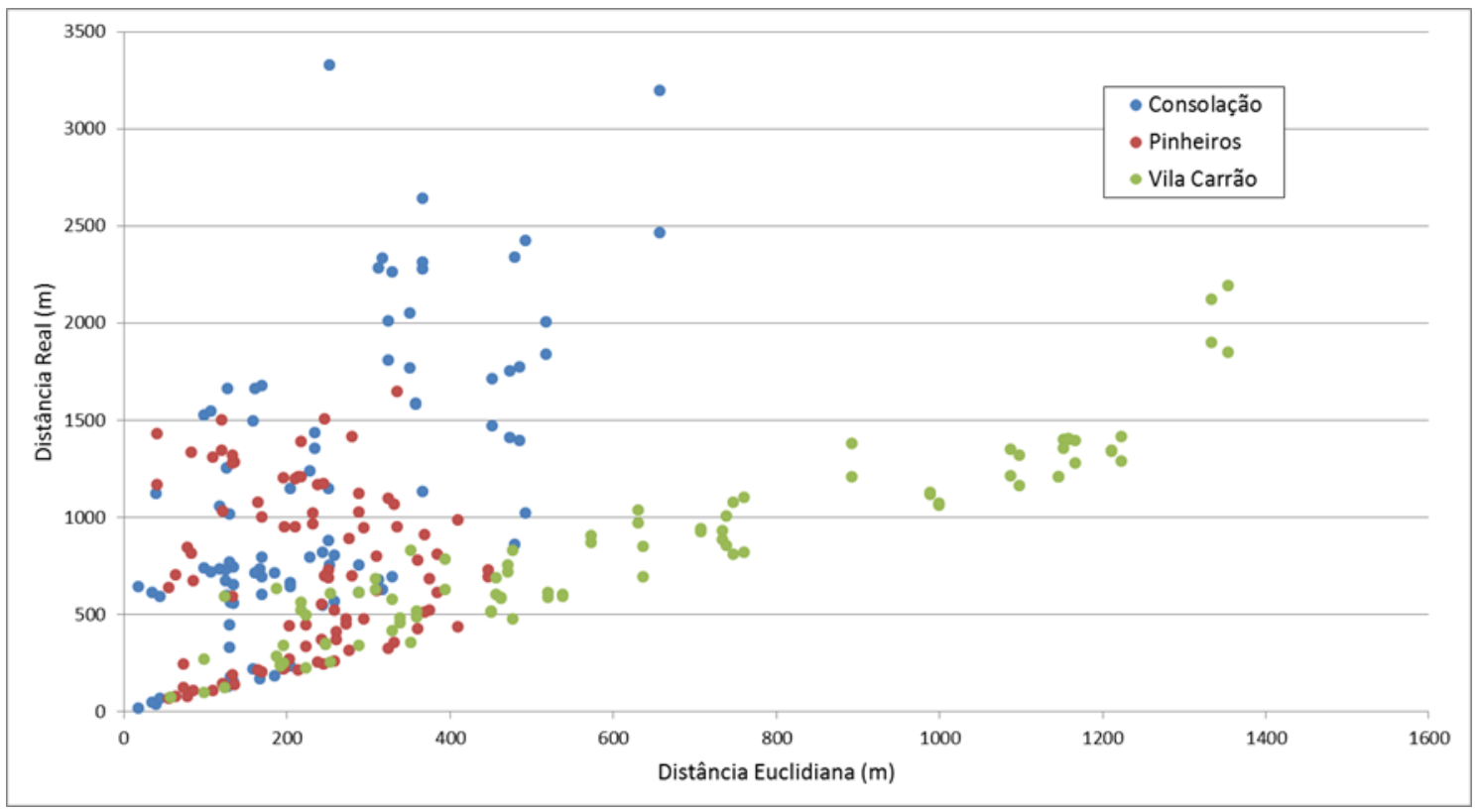

Figura B.5: Comparação das distâncias reais com as distâncias euclidianas.

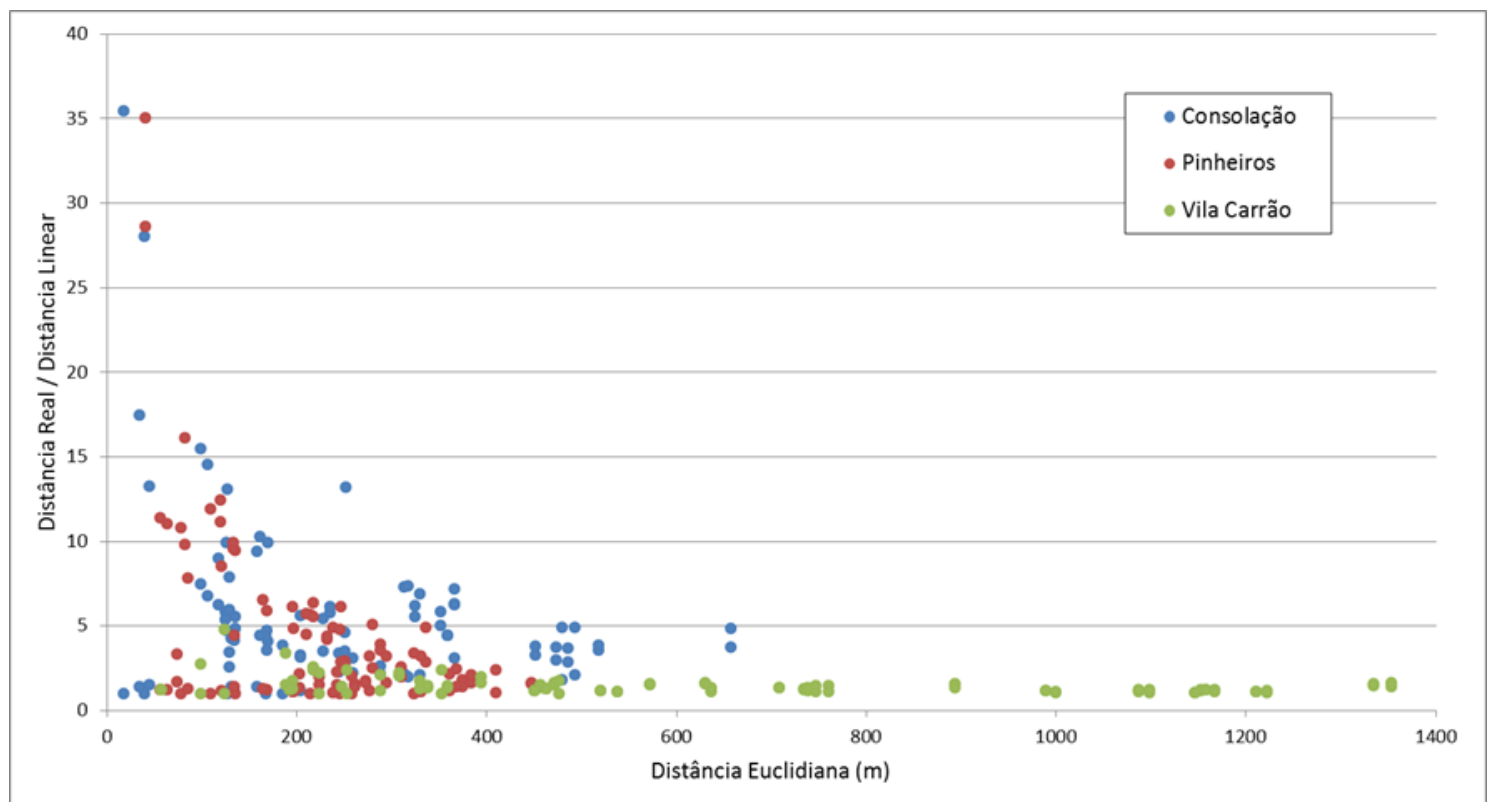

Figura B.6: Comparação do índice de "retilinidade" com as distâncias euclidianas.

$\mathrm{Na}$ Tabela B.1 é possível identificar através das médias dos resultados que no geral os valores das razões entre distâncias reais e distâncias euclidianas são consideravelmente maiores para Consolação e Pinheiros. Este fato pode ser explicado devido à forte presença de vias de mão única e restrições de conversões na malha viária dessas duas regiões. A diferença entre os valores da Consolação e de Pinheiros pode ser atribuída ao fato da maior concentração dos estabelecimentos comerciais na região de Pinheiros em uma via principal.

Na Vila Carrão, as vias locais são de mão dupla, portanto é de se esperar que as distâncias reais se aproximem da distância Manhattan. Sendo assim, o valor 1,32 
para média do índice de "retilinidade" se aproxima muito do esperado $\sqrt{2} \cong 1,41$, que corresponde ao coeficiente da diagonal em linha reta de uma malha retangular, também conhecida como Manhattan.

As Figura B.5 e a Figura B.6 ilustram os resultados para cada par de pontos estudados em forma gráfica. Como os valores de distância real mudam ao se alterar a origem com o destino e os de distância euclidiana não, cada distância euclidiana apresenta dois valores correspondentes de distância real na Figura B.5 e de distância real sobre distância euclidiana na Figura B.6.

Percebe-se haver uma tendência de quanto maior a distância euclidiana entre dois pontos, menor a diferença para a distância real, ou seja, menor o índice calculado. Este é outro motivo para os valores da Vila Carrão serem menores que os da Consolação e Pinheiros. Como a Vila Carrão é um bairro menos denso, as distâncias entre seus estabelecimentos comerciais são naturalmente maiores do que de locais com maiores densidades. Supõe-se que isso ocorra pelo fato de que quanto maior a distância a ser percorrida entre dois pontos, menos significativos se tornam os detalhes como mãos de direção e restrições de conversões da malha viária, possibilitando uma rota mais direta.

Outro ponto para ser considerado são os altos valores dos índices que aparecem para distâncias euclidianas abaixo de 100 metros. Esses valores são devidos a pares de pontos localizados, por exemplo, em uma mesma via de mão única.

Os resultados obtidos neste experimento são promissores e indicam que o índice de "retilinidade" consegue capturar as características e peculiaridades dos locais em que é aplicado. 


\section{ANEXO C: AGRUPAMENTO DE PONTOS DE ENTREGA UTILIZANDO O ALGORITMO K-MEANS}

Esta proposta tem base em um algoritmo de clusterização espacial $k$-means modificado. O algoritmo k-means tradicional (MacQueen, 1967) separa n observações em $k$ grupos, sendo que o objetivo é minimizar a soma das distâncias das observações para o centroide do grupo. Primeiro, $k$ centroides aleatórios são selecionados e as observações são alocadas em clusters correspondentes ao centroide que estão mais próximas de acordo com o critério de distância desejado, em seguida são redefinidos os centroides de acordo com o cluster formado e novamente os pontos são redistribuídos de acordo com a proximidade destes novos centroides. O processo é iterativo e é repetido até a escolha dos centroides não se modificar mais e assim o algoritmo é encerrado retornando $k$ centroides e a partição das $n$ observações.

Nesta análise, busca-se utilizar o algoritmo $k$-means para investigar a influência da rede viária no agrupamento de locais de entrega. Para esta aplicação, utilizam-se pontos definidos por coordenadas geográficas (latitude e longitude) como observações a serem divididas em $k$ grupos. Esses pontos representam potenciais pontos de entrega, assim como no método anterior, e são agrupados pelo k-means modificado seguindo dois critérios. O primeiro é de acordo com as distâncias euclidianas e o segundo é de acordo com as distâncias reais. O objetivo é comparar os resultados gerados por cada critério de distância e verificar como a rede viária influencia os grupos formados.

Por uma questão conceitual, os centroides dos clusters não são calculados pela média das observações do grupo, como no k-means tradicional. No caso estudado, os centroides são obrigatoriamente pontos da base e são atribuídos de acordo com a proximidade com os outros pontos que estão no mesmo cluster. Como o objetivo é escolher o ponto mais central do cluster, atribui-se como centroide o ponto cuja somatória das distâncias para todos os outros pontos do grupo seja menor. Esta maneira de atribuir os centroides que confere a característica modificada do algoritmo utilizado.

Por ser um método de otimização local, o k-means é sensível à escolha inicial dos centroides. Portanto, para os fins deste estudo, foi necessário escolher um 
método de inicialização não aleatório a fim de otimizar os resultados obtidos e garantir a convergência do algoritmo. O método de inicialização escolhido é conhecido como algoritmo KKZ (Katsavounidis et al., 1994) que, dado um conjunto de pontos, tem como objetivo retornar os $k$ pontos mais distantes entre si. Apesar de Redmond e Heneghan (2007) destacarem que esse método falha em encontrar uma solução inicial próxima da final, exigindo mais iterações do programa, ele foi escolhido devido aos resultados satisfatórios e facilidade de implementação. O primeiro centroide é escolhido como sendo o ponto mais distante de todos os outros, o segundo é o ponto mais distante do primeiro e os demais são escolhidos como o ponto mais distante do centroide mais próximo.

A primeira parte do processo consiste em definir a matriz de distâncias $n \times n$ entre os pares de pontos do conjunto estudado. No caso a aplicação para distâncias euclidianas, são calculadas através da fórmula de Haversine (Robusto, 1957), assim como no método anterior. Para as distâncias reais, é utilizada a biblioteca GraphHopper. O GraphHopper é uma biblioteca e um servidor baseado em OpenStreetMap que planeja rotas ponto a ponto para diversos modais de transporte. Para este estudo foi utilizada a opção de cálculo de rota para o modo carro. É formada uma matriz de distâncias simétrica, na qual para cada par de pontos $i-j$ é utilizada a menor das distâncias entre $i-j$ e $j-i$.

O próximo passo é determinar o número desejado de clusters a serem formados $(k)$. A partir disso, o algoritmo já possui todas as informações necessárias para ser inicializado. Primeiro são escolhidos os $k$ centroides iniciais de acordo com as informações de valores fornecidas pela matriz de distâncias e seguindo os critérios do método de inicialização escolhido já discutido anteriormente. Na sequência, iniciase o $k$-means modificado. $O$ resultado final é uma lista de $k$ centroides e uma lista com $n$ valores variando de 0 a $k-1$ que fazem referência a qual cluster aquele ponto faz parte.

O objetivo de agrupar os potenciais pontos de entrega de acordo com as distâncias euclidianas e reais é verificar a diferença de composição entre os grupos formados pelos dois critérios. Quanto maior a diferença entre os resultados, maior a dificuldade de circulação na malha viária, e por consequência, maior a influência da rede viária na distribuição de última milha. 
Para a aplicação do $k$-means, foi escolhida uma região central da cidade de São Paulo cruzada por vias importantes, como a Av. Paulista e a Av. Nove de Julho. Utilizando a base de estabelecimentos Kekanto, foi aplicado um filtro de tipo de restaurante para diminuir a quantidade de dados e manter a coerência quanto a possíveis pontos de entrega. Selecionando apenas os restaurantes categorizados como italianos, o grupo de pontos estudado ficou com 94 pontos distribuídos nos bairros Jardim Paulista, Paraíso, Consolação e Bela Vista.

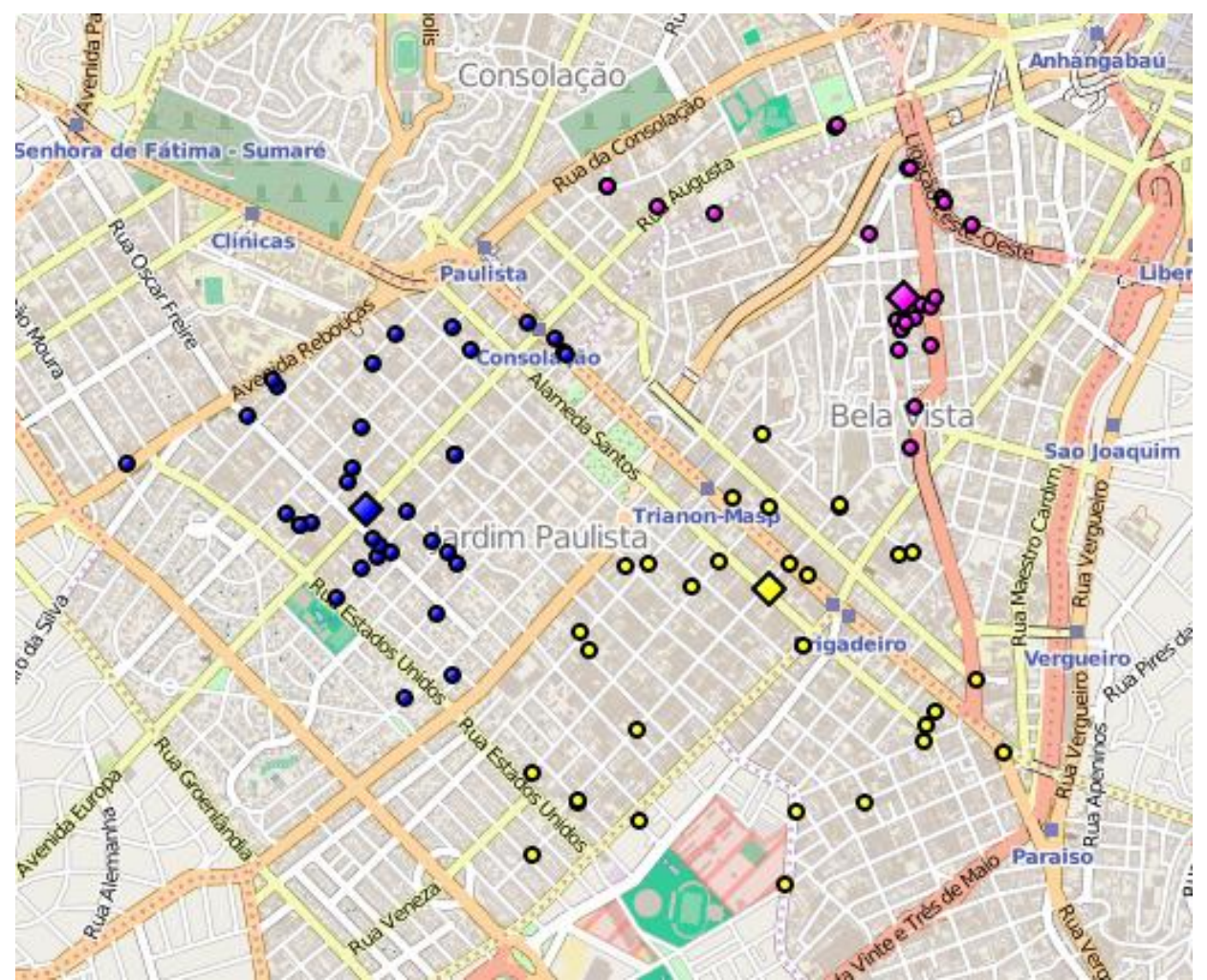

Figura C.1: Resultado do agrupamento para k = 3 com distâncias euclidianas. 


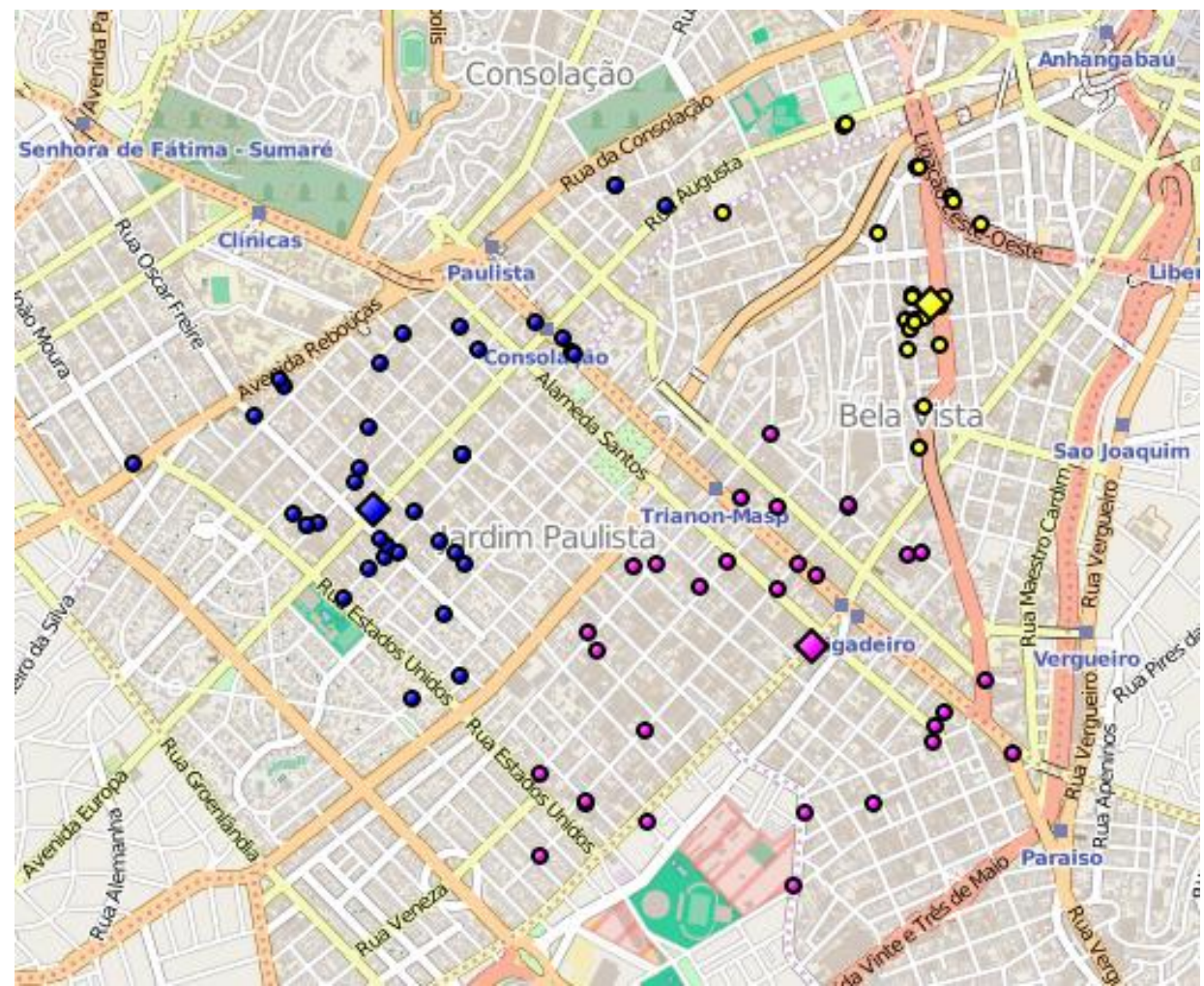

Figura C.2: Resultado do agrupamento para $\mathrm{k}=3$ com distâncias reais.

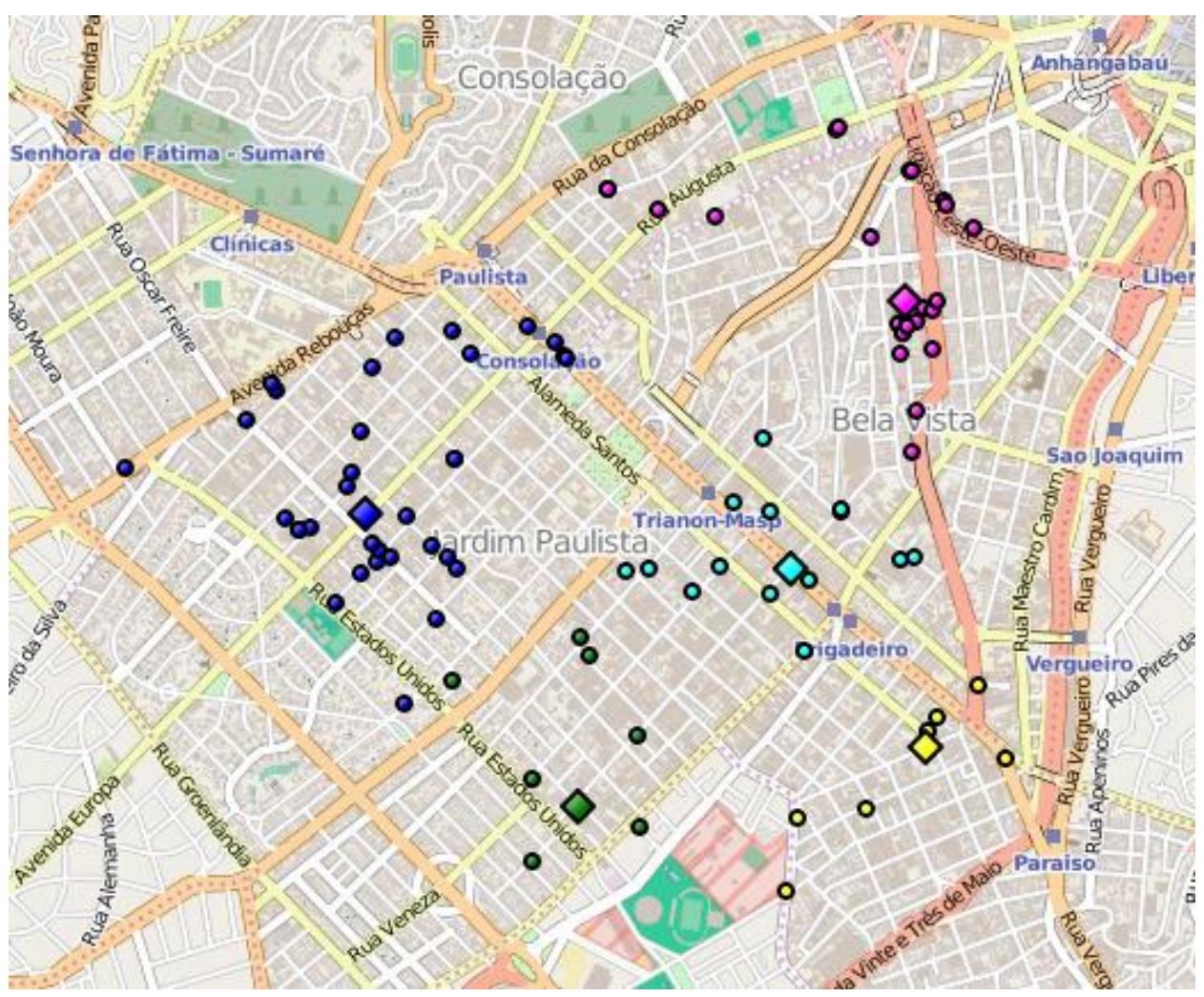

Figura C.3: Resultado do agrupamento para $\mathrm{k}=5$ com distâncias euclidianas. 


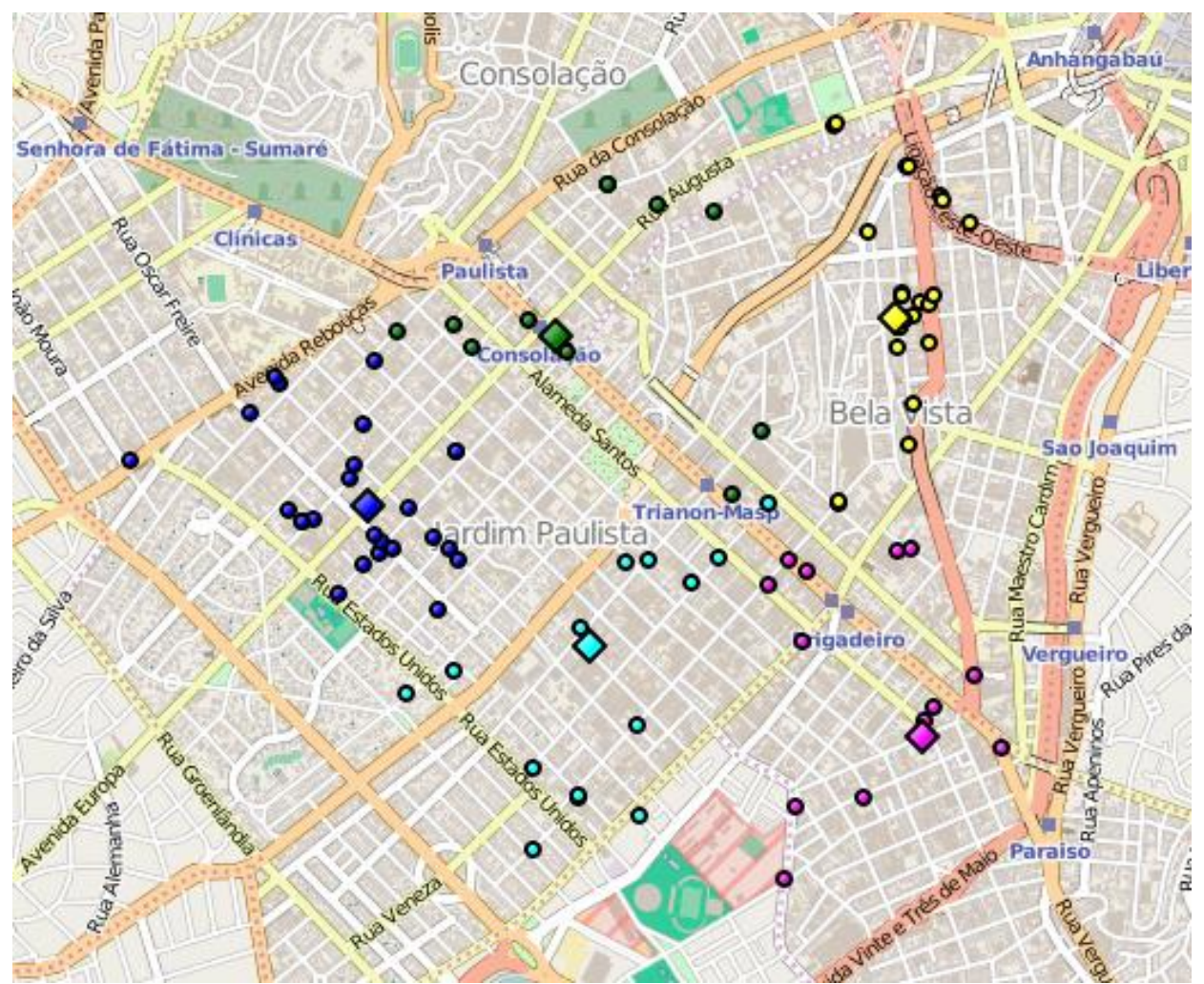

Figura C.4: Resultado do agrupamento para $\mathrm{k}=5$ com distâncias reais.

A Figura C.1 e a Figura C.2 mostram os resultados de agrupamentos para 3 grupos com distâncias euclidianas e distâncias reais, respectivamente. Os pontos no mapa representam os restaurantes e estão coloridos de acordo com o grupo em que foram alocados. O ponto representado por um quadrado representa o restaurante que é centroide do grupo. Observando as figuras, é possível identificar algumas diferenças no resultado final dos grupos formados e dos centroides. No caso, a diferença mais significativa é dos pontos que foram alocados no grupo rosa pelas distâncias euclidianas, mas que pelas distâncias reais foram alocados no grupo azul. Eles realmente estão geograficamente mais próximos do centroide em que foram alocados na Figura C.1, porém devido à configuração da rede viária e a barreira que algumas vias arteriais representam, faz mais sentido eles serem alocados a outro centroide, como acontece na Figura C.2.

A Figura C.3 e a Figura C.4 mostram os resultados para uma configuração final de 5 grupos. Comparando as Figuras C.3 e C.4 com as Figuras C.1 e C.2, percebese que a diferença de resultados para alocação baseada em distâncias reais e distâncias euclidianas é maior para $\mathrm{k}=5$ do que para $\mathrm{k}=3$. A tendência observada é que quanto maior o número de grupos, maior a diferença de resultados entre os dois tipos de distâncias. 
Outra diferença relevante para se observar entre a Figura C.3 e Figura C.4 é que na Figura C.3 os grupos formados nitidamente delimitam espaços geográficos separados. Já na Figura C.4, existem regiões do mapa onde os pontos estão coloridos com diversas cores. Isto se dá devido ao padrão de conectividade da rede viária que não está necessariamente diretamente associada ao espaço físico em que estão localizados os pontos a serem ligados.

Os grupos formados pelo k-means na Figura C. 1 a e na Figura C.4 estão de acordo com o esperado para a região. As diferenças de configuração nos agrupamentos refletem as limitações impostas pela malha viária local na qual as restrições de mão de direção e conversões são abundantes. Além disso, a região também contempla obstáculos para a circulação como túneis e viadutos, que acabam atuando como barreiras geográficas. As maiores limitações deste método são: a dificuldade de quantificar os resultados para comparação com resultados de outras regiões, já que a análise é feita de forma visual e qualitativa e a quantidade de pontos alocados em cada grupo não é necessariamente homogênea. Além disso, todas as distâncias em redes foram calculadas através de OSM, portanto não são totalmente confiáveis. 


\section{ANEXO D: ANÁlISE DO ACESSO À ÁREA DE ENTREGA UTILIZANDO ROTEIRIZAÇÃO}

Para analisar outras etapas da distribuição urbana além da circulação entre os pontos de entrega, foi desenvolvido um método que inclui um processo de roteirização e contempla potenciais locais de centro de distribuição. O procedimento e os resultados obtidos estão neste Anexo.

Começando pelo acesso ao distrito de entrega, pressupõe-se que o local do centro de distribuição, a área de atendimento do veículo, bem como seus pontos de parada são conhecidos. O primeiro passo da análise é identificar qual é o trajeto de ida e de volta do veículo. A ida tem origem no centro de distribuição de destino no primeiro local de entrega e a volta tem origem no último local de entrega e destino no centro de distribuição. Para a identificação desses trajetos é necessário definir a rota percorrida pelo veículo e nesta análise foi utilizada a ferramenta de otimização de rotas da Google Maps Directions API. Dados um ponto de origem, um ponto de destino e pontos intermediários de parada, a API do Google retorna o sequenciamento dos pontos intermediários que garante a rota de menor tempo de acordo com a média histórica de tempos de viagem do local.

A solicitação da API é feita colocando o centro de distribuição como ponto de origem e destino da rota, os locais de entrega entram como pontos intermediários. A partir do resultado do sequenciamento dos pontos intermediários, é possível extrair o primeiro e último locais a serem atendidos pelo veículo e, portanto, é possível definir as origens e destinos dos trajetos de line-haul.

O próximo passo consiste em extrair as velocidades médias para esses trajetos ao longo do dia e esse processo também é realizado através da Google Maps Directions API. Neste passo, coloca-se como dados de entrada na solicitação da API a origem e o destino de acordo com os trajetos de line-haul já identificados e um horário de saída específico a fim de se obter o tempo de viagem com maior precisão. Os tempos de viagens retornados são calculados de acordo com um modelo de previsão baseado em dados reais do local, por isso que quando se especifica um horário de saída o resultado tem mais precisão do que quando o tempo de viagem é calculado de acordo com uma média geral. Com os resultados de distância e tempo 
de viagem fornecidos pela API é possível calcular a velocidade média dos trajetos desejados. Este procedimento é repetido para horários de saída variando de $0 \mathrm{~h}$ a $23 \mathrm{~h}$, ou seja, são calculadas 24 velocidades médias respectivas ao horário de saída para cada trajeto, possibilitando a elaboração de perfis de velocidade e a visualização da variação das velocidades médias ao longo do dia.

A análise das velocidades médias dos deslocamentos entre pontos de entrega é realizada de maneira análoga à análise do line-haul, ou seja, determina-se as origens e destinos de cada trecho da rota e em seguida solicita-se cada trecho individualmente 24 vezes à API do Google, modificando em cada solicitação o horário de saída desejado a fim de se obter um panorama da variação das velocidades médias ao longo do dia. Porém, diferentemente da análise de line-haul que necessita da definição de pontos de origem e destino específicos devido à sua natureza que envolve deslocamentos mais distantes, a análise de distâncias locais pode ser vista como uma velocidade média de deslocamento dentro de uma região, no caso o distrito de entrega conhecido.

No caso de pontos e sequenciamento de entrega conhecidos, pode-se solicitar à $\mathrm{API}$ apenas os trechos conhecidos e com horários precisos de saída que correspondem ao horário que foi considerada a saída do centro de distribuição mais os tempos de viagem dos trechos anteriores. Caso a etapa de otimização da rota não tenha sido feita, é possível solicitar os tempos e distâncias de viagem para as $24 \mathrm{~h}$ do dia para a construção de matrizes origem-destino, na qual todos os pontos dentro do distrito de entrega são origens e destinos, a fim de se criar um panorama das velocidades médias de circulação dentro de uma região ao longo do dia.

A fim de simular os dados necessários para a realização da análise, foi definida a Zona Máxima de Restrição de Circulação (ZMRC) da cidade de São Paulo como distrito de entrega e foram gerados três conjuntos de 20 pontos aleatórios dentro da região para simular três conjuntos de pontos de entrega. Note que os três conjuntos de pontos de entrega não representam três distritos de entrega distintos neste caso, foram apenas gerados três conjuntos para comparar os resultados e verificar se há influência significativa nos mesmos devido a distribuição espacial aleatória dos pontos. Estes conjuntos foram gerados através do comando de geração de pontos aleatórios dentro de um polígono do software QGIS. E, além disso, foram 
selecionados quatro pontos em quatro rodovias diferentes (Dutra, Anhanguera, Castelo Branco e Raposo Tavares) conhecidos por serem locais de centros de distribuição existentes para simular os locais de centro de distribuição.

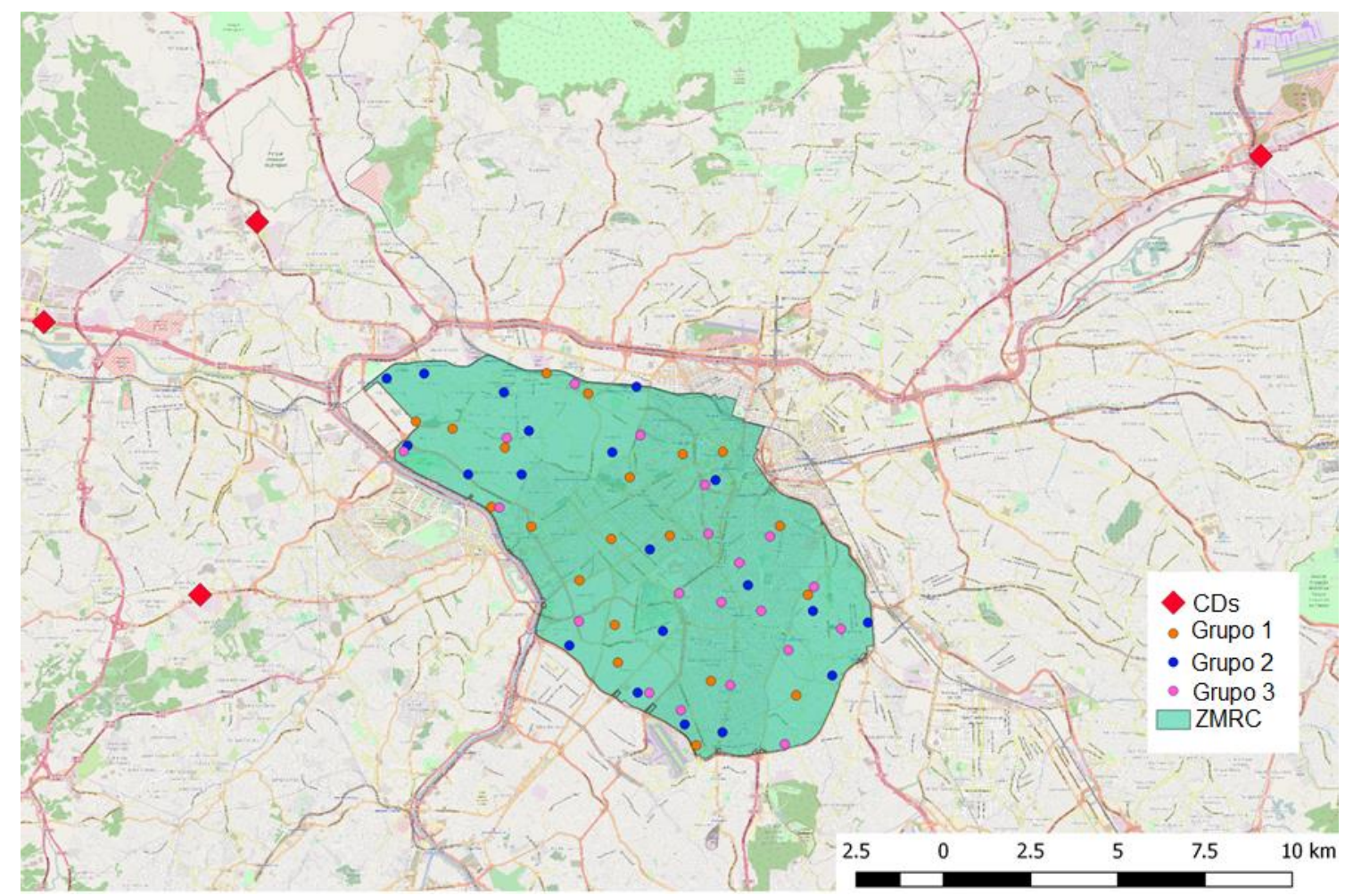

Figura D.1: Dados de entrada para a análise de velocidades: distrito de entrega, locais de entrega e locais dos centros de distribuição.

Na Figura D.1 pode-se observar um mapa com a localização dos pontos de entrega e centros de distribuição. Como são considerados três grupos de pontos de entregas e quatro locais de centro de distribuição, serão analisadas 12 rotas fictícias no total. 


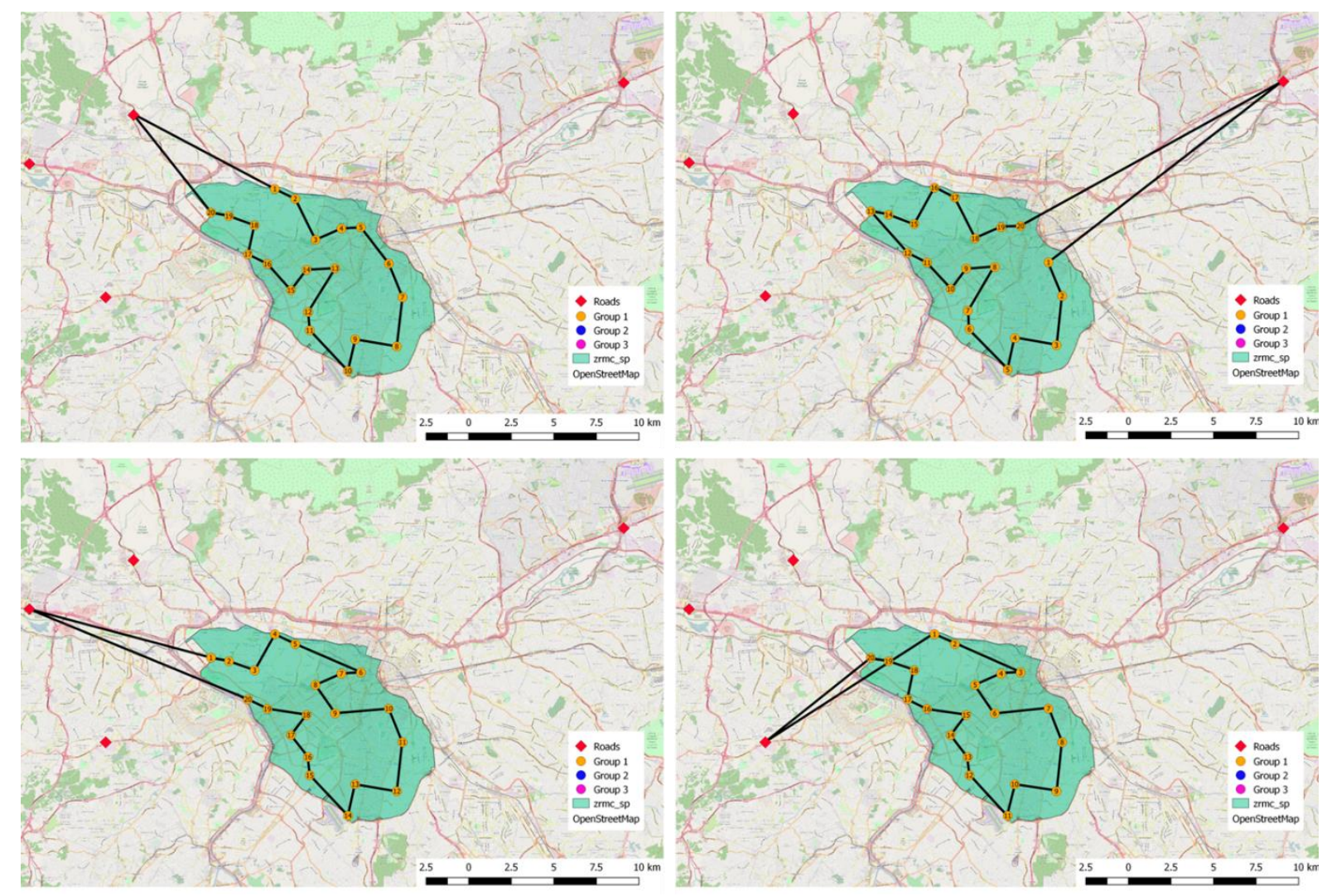

Figura D.2: Resultado do sequenciamento das rotas para o grupo de pontos 1.

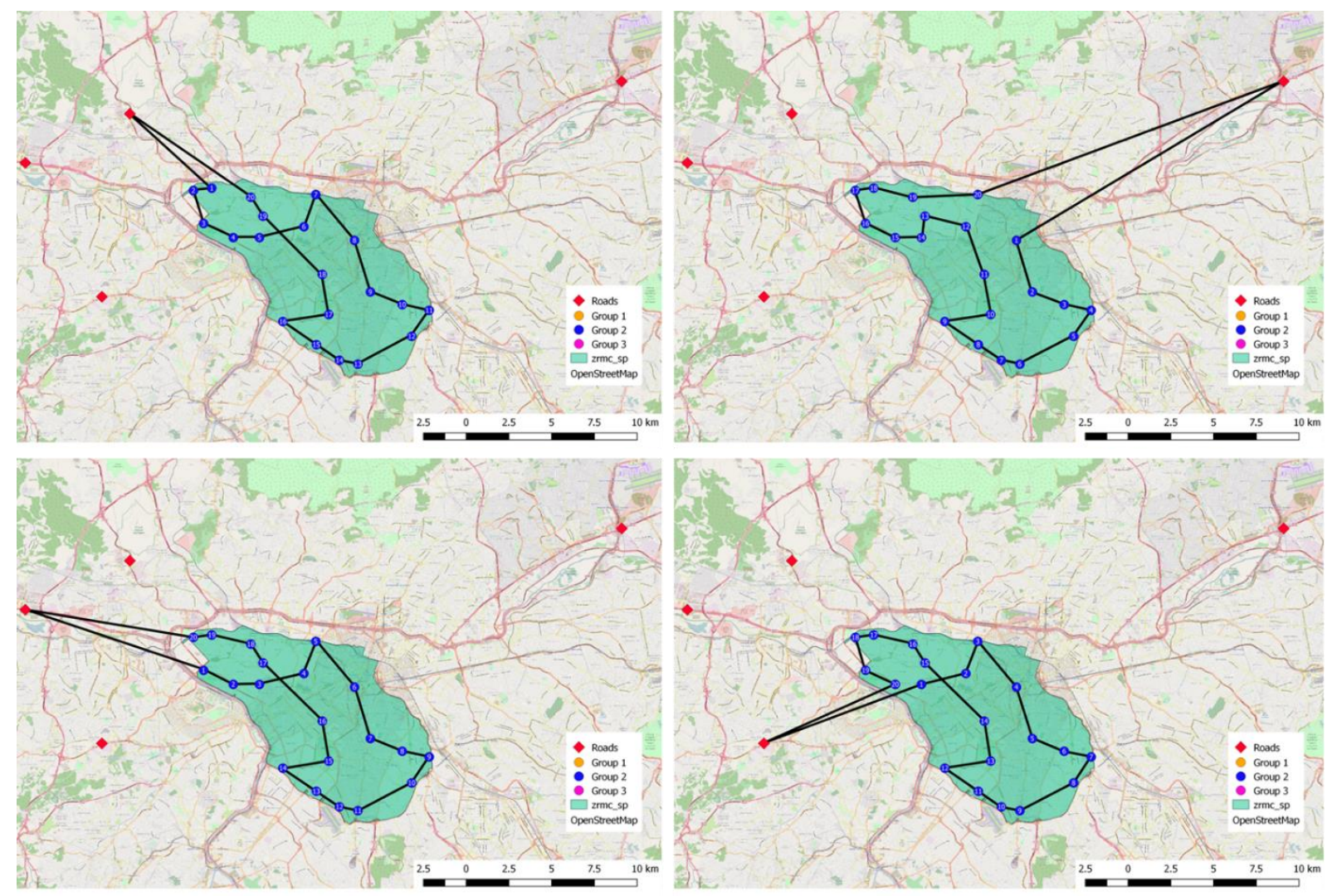

Figura D.3: Resultado do sequenciamento das rotas para o grupo de pontos 2. 

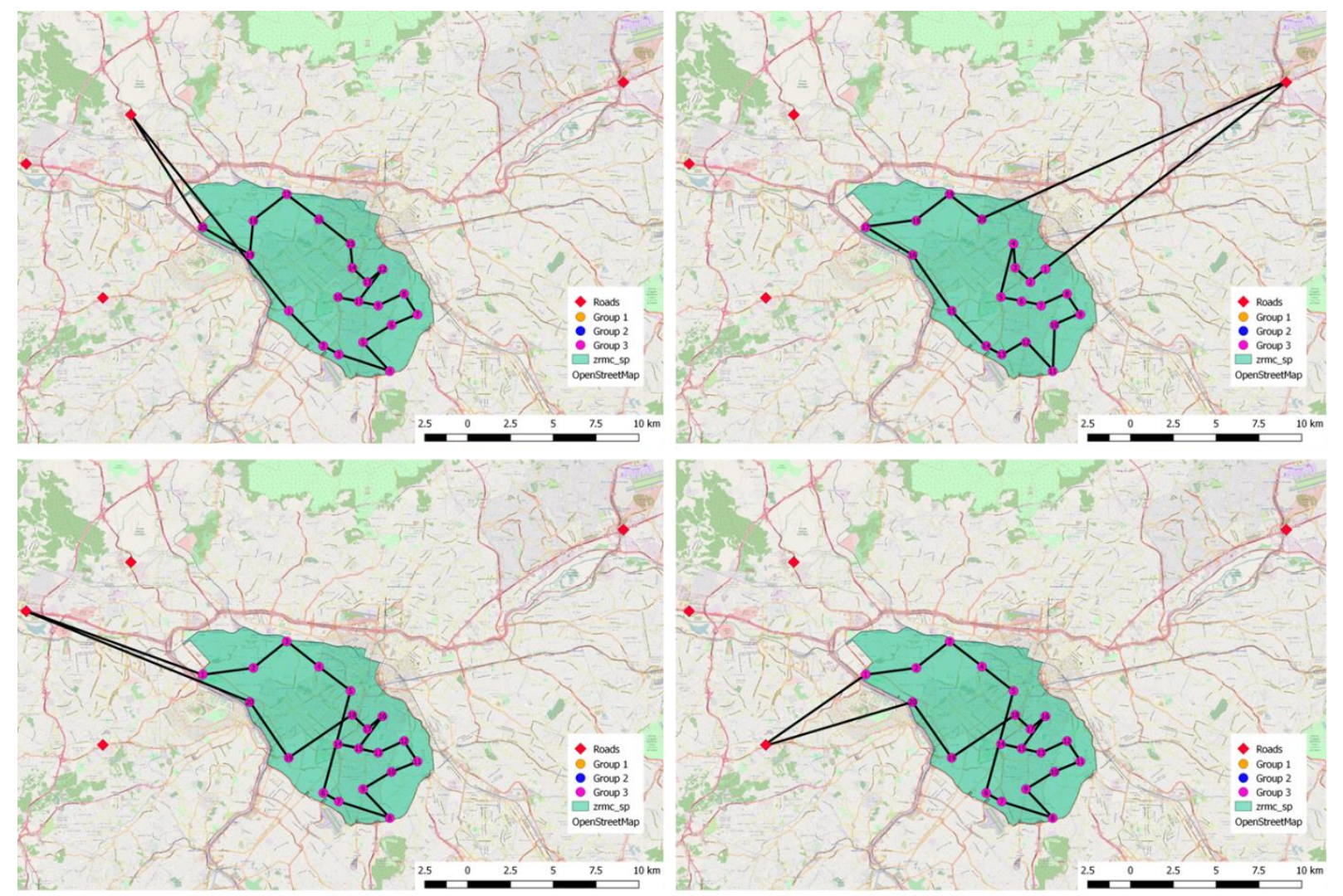

Figura D.4: Resultado do sequenciamento das rotas para o grupo de pontos 3.

A Figura D.2 a e Figura D.4 mostram o resultado de sequenciamento de pontos obtidos pela ferramenta de otimização de rota da Google Maps Directions API. Notase que cada combinação de grupo de ponto e local de centro de distribuição é considerada uma rota. Com a informação de sequenciamento em mãos, é possível passar para a segunda etapa do método que consiste na extração dos tempos de viagem para cada trecho da rota considerando horários de início da rota de hora em hora a partir do centro de distribuição. Os resultados finais serão apresentados de acordo com três etapas: a primeira consiste no primeiro trecho, com origem no centro de distribuição e destino no primeiro ponto de entre a segunda etapa é representada através das médias dos valores obtidos para os trechos entre pontos de entrega e, por fim, a terceira etapa que consiste no último trecho da rota, cuja origem é o último ponto atendido e o destino o centro de distribuição. Sendo assim, como discutido anteriormente, as etapas 1 e 3 representam os trechos de line-haul e a etapa 2 representa a circulação local dentro do distrito de entrega. As Tabelas D.1, D.2 e D.3 a seguir mostram os resultados obtidos para cada etapa respectivamente. 
Tabela D.1: Resultados da etapa 1 - line-haul.

\begin{tabular}{ccccc}
\hline & Local do CD & $\begin{array}{c}\text { Distância } \\
(\mathrm{km})\end{array}$ & $\begin{array}{c}\text { Velocidade } \\
\text { Média }(\mathrm{km} / \mathrm{h})\end{array}$ & $\begin{array}{c}\text { Índice de } \\
\text { "Retilinidade" }\end{array}$ \\
\hline \multirow{3}{*}{ Conjunto 1 } & Anhanguera & 22,15 & 45,45 & 1,51 \\
& Dutra & 40,41 & 44,14 & 1,20 \\
& Castelo & 17,40 & 42,79 & 1,24 \\
& Raposo & 11,71 & 38,97 & 1,64 \\
\hline \multirow{3}{*}{ Conjunto 2 } & Anhanguera & 22,22 & 49,29 & 1,24 \\
& Dutra & 40,56 & 44,85 & 1,19 \\
& Castelo & 14,59 & 43,93 & 1,19 \\
& Raposo & 11,17 & 33,72 & 1,58 \\
\hline \multirow{3}{*}{ Conjunto 3 } & Anhanguera & 23,79 & 46,61 & 1,31 \\
& Dutra & 40,89 & 42,86 & 1,25 \\
& Castelo & 17,92 & 39,20 & 1,30 \\
& Raposo & 11,73 & 27,65 & 1,60 \\
\hline
\end{tabular}

Tabela D.2: Resultados da etapa 2 - circulação local

\begin{tabular}{ccccc}
\hline & Local do CD & $\begin{array}{c}\text { Distância } \\
\text { Total }(\mathrm{km})\end{array}$ & $\begin{array}{c}\text { Velocidade } \\
\text { Média }(\mathrm{km} / \mathrm{h})\end{array}$ & $\begin{array}{c}\text { Índice de } \\
\text { "Retilinidade" } \\
\text { Médio }\end{array}$ \\
\hline \multirow{3}{*}{ Conjunto 1 } & Anhanguera & 81,97 & 22,33 & 1,75 \\
& Dutra & 100,58 & 24,56 & 1,73 \\
& Castelo & 78,79 & 21,15 & 1,46 \\
& Raposo & 75,65 & 19,75 & 1,47 \\
\hline \multirow{3}{*}{ Conjunto 2 } & Anhanguera & 91,92 & 23,96 & 1,71 \\
& Dutra & 105,90 & 26,51 & 1,70 \\
& Castelo & 84,53 & 22,27 & 1,53 \\
Conjunto 3 & Raposo & 81,79 & 21,52 & 1,51 \\
& Anhanguera & 87,80 & 25,60 & 1,83 \\
& Dutra & 103,38 & 27,33 & 1,69 \\
& Castelo & 91,23 & 25,15 & 1,46 \\
\hline & Raposo & 81,79 & 23,66 & 1,49 \\
\hline
\end{tabular}


Tabela D.3: Resultados da etapa 3 - line-haul.

\begin{tabular}{ccccc}
\hline & Local do CD & $\begin{array}{c}\text { Distância } \\
(\mathrm{km})\end{array}$ & $\begin{array}{c}\text { Velocidade } \\
\text { Média }(\mathrm{km} / \mathrm{h})\end{array}$ & $\begin{array}{c}\text { Índice de } \\
\text { "Retilinidade" }\end{array}$ \\
\hline \multirow{3}{*}{ Conjunto 1 } & Anhanguera & 22,15 & 59,13 & 2,87 \\
& Dutra & 40,41 & 51,09 & 2,25 \\
& Castelo & 17,40 & 58,61 & 1,24 \\
& Raposo & 11,71 & 33,84 & 1,20 \\
\hline \multirow{3}{*}{ Conjunto 2 } & Anhanguera & 22,22 & 57,40 & 2,51 \\
& Dutra & 40,56 & 55,17 & 2,10 \\
& Castelo & 14,59 & 43,74 & 1,46 \\
Conjunto 3 & Raposo & 11,17 & 37,27 & 1,31 \\
\hline & Anhanguera & 23,79 & 56,04 & 2,86 \\
& Dutra & 40,89 & 55,60 & 2,06 \\
& Castelo & 17,92 & 55,11 & 1,25 \\
& Raposo & 11,73 & 40,10 & 1,30 \\
\hline
\end{tabular}

Pelos resultados das Tabelas D.1, D.2 e D.3, percebe-se as velocidades médias das etapas de line-haul são consideravelmente maiores que as de circulação local. Isso é esperado, pois o acesso aos locais de entrega a partir do centro de distribuição, e vice-versa, envolvem distâncias consideravelmente maiores que as distâncias entre pontos de entrega, e também têm trajetos que percorrem por mais tempo rodovias e vias expressas cujos limites de velocidade são superiores aos das vias locais onde predominam os trajetos locais. Além disso, observa-se que os valores de índice de "retilinidade" são maiores no retorno ao centro de distribuição do que no acesso à cidade. Isso se deve ao fato da seleção dos locais fictícios de centros de distribuição estarem na margem da pista da rodovia com sentido para cidade, fazendo com que os caminhos de retorno envolvam distâncias maiores.

Para completar a análise, são gerados os perfis de velocidades para cada etapa. As Figuras D.5, D.6 e D.7 representam os perfis de velocidade para a etapa 1 dos conjuntos de pontos 1, 2 e 3, respectivamente. Analogamente, as Figuras D.8, D.9 e D.10 correspondem aos perfis da etapa 2 para os três conjuntos e as Figuras D.11, D.12 e D.13 da etapa 3. 


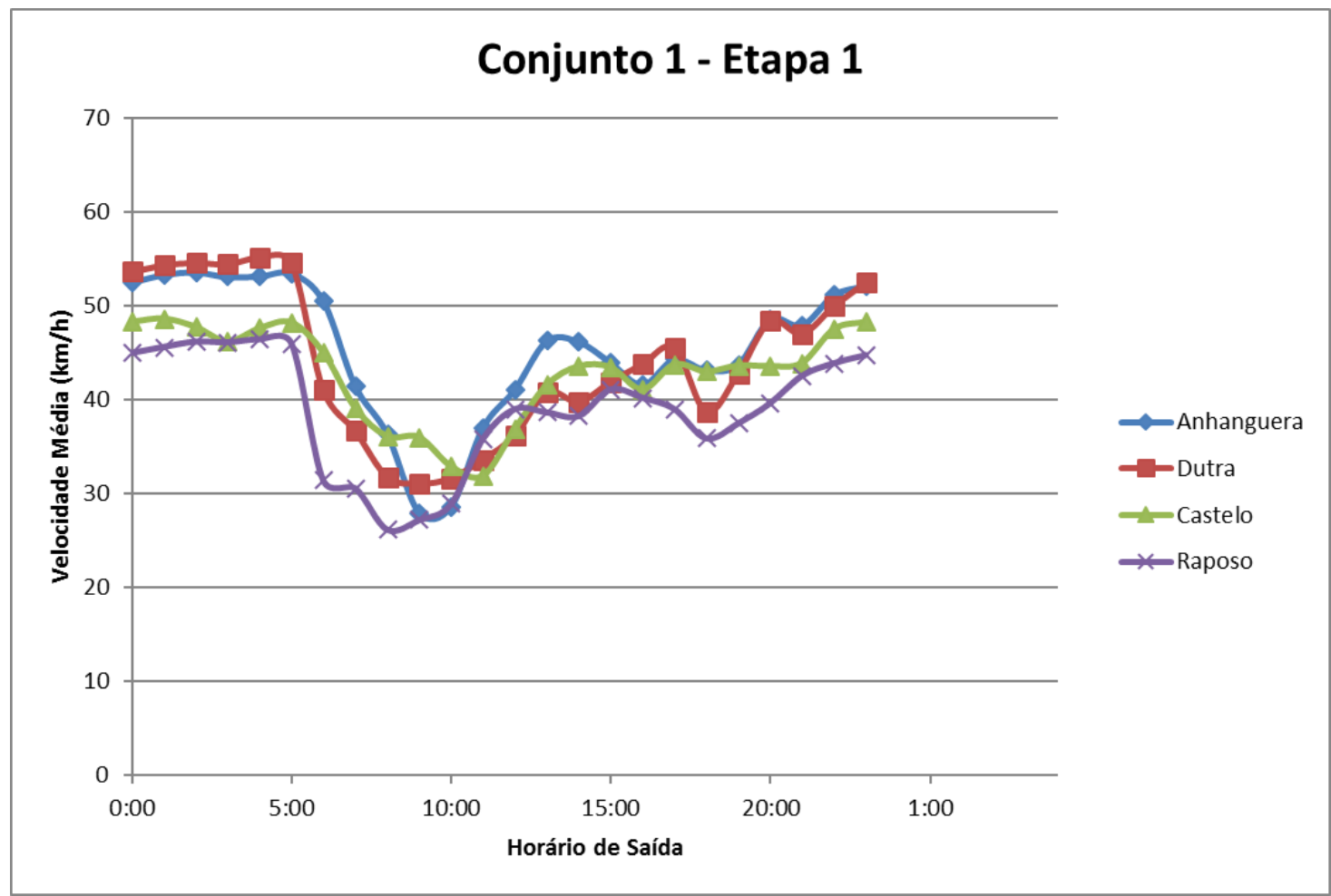

Figura D.5: Perfis de velocidade para etapa de line-haul até o local de entrega para o grupo de pontos 1 .

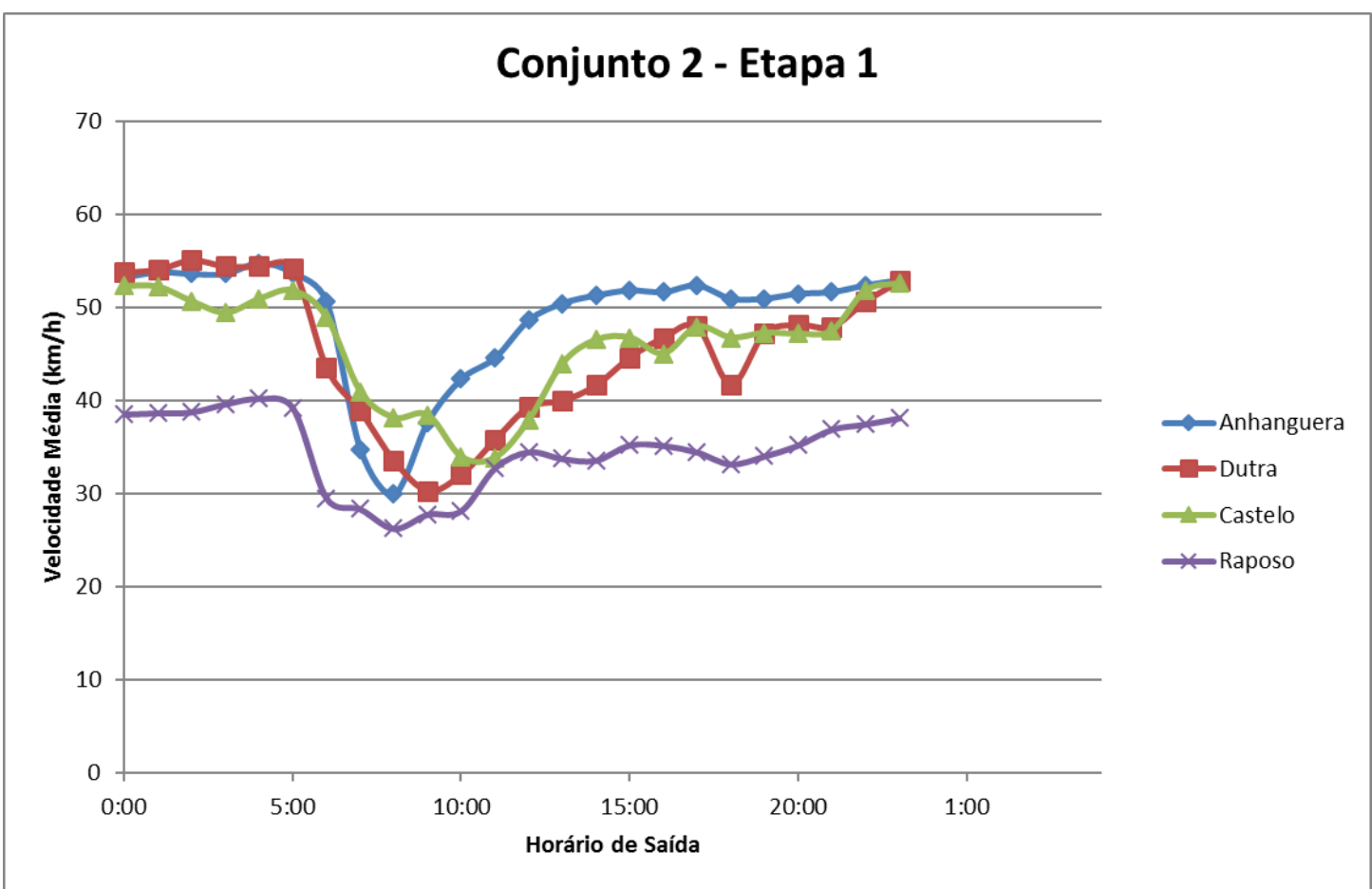

Figura D.6: Perfis de velocidade para etapa de line-haul até o local de entrega para o grupo de pontos 2 . 


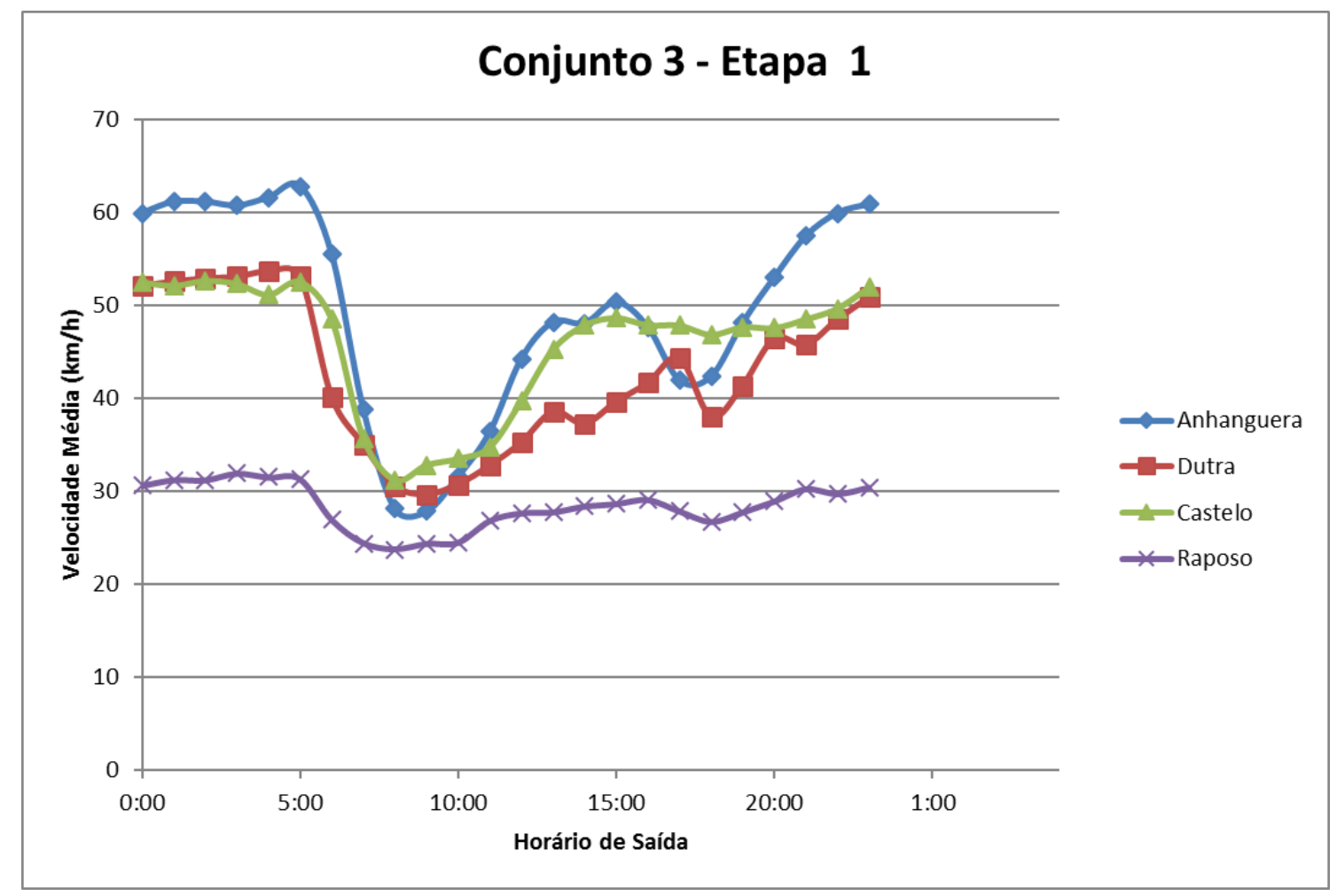

Figura D.7: Perfis de velocidade para etapa de line-haul até o local de entrega para o grupo de pontos 3 .

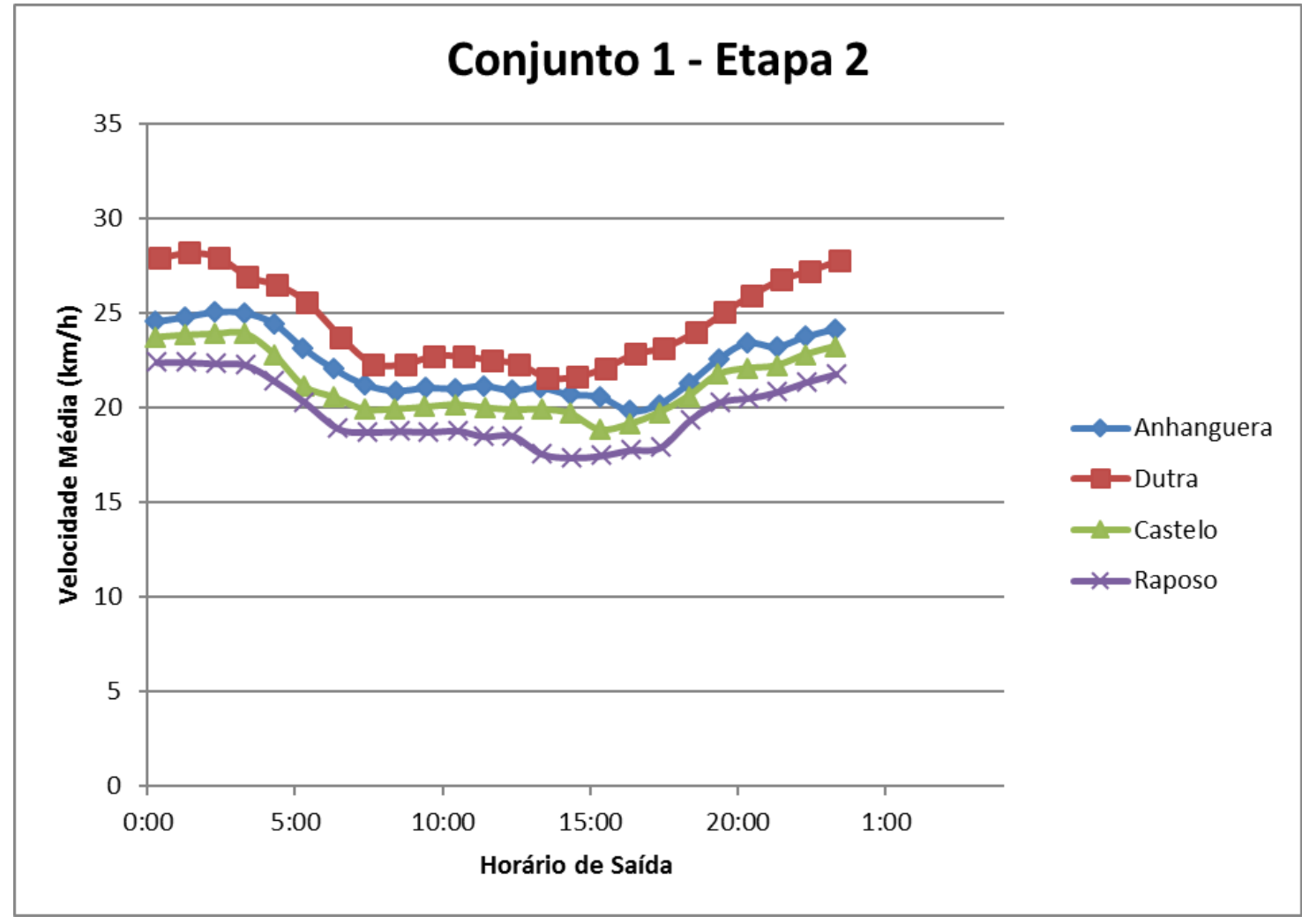

Figura D.8: Perfis de velocidade para etapa de circulação entre locais de entrega para o grupo de pontos 1 . 


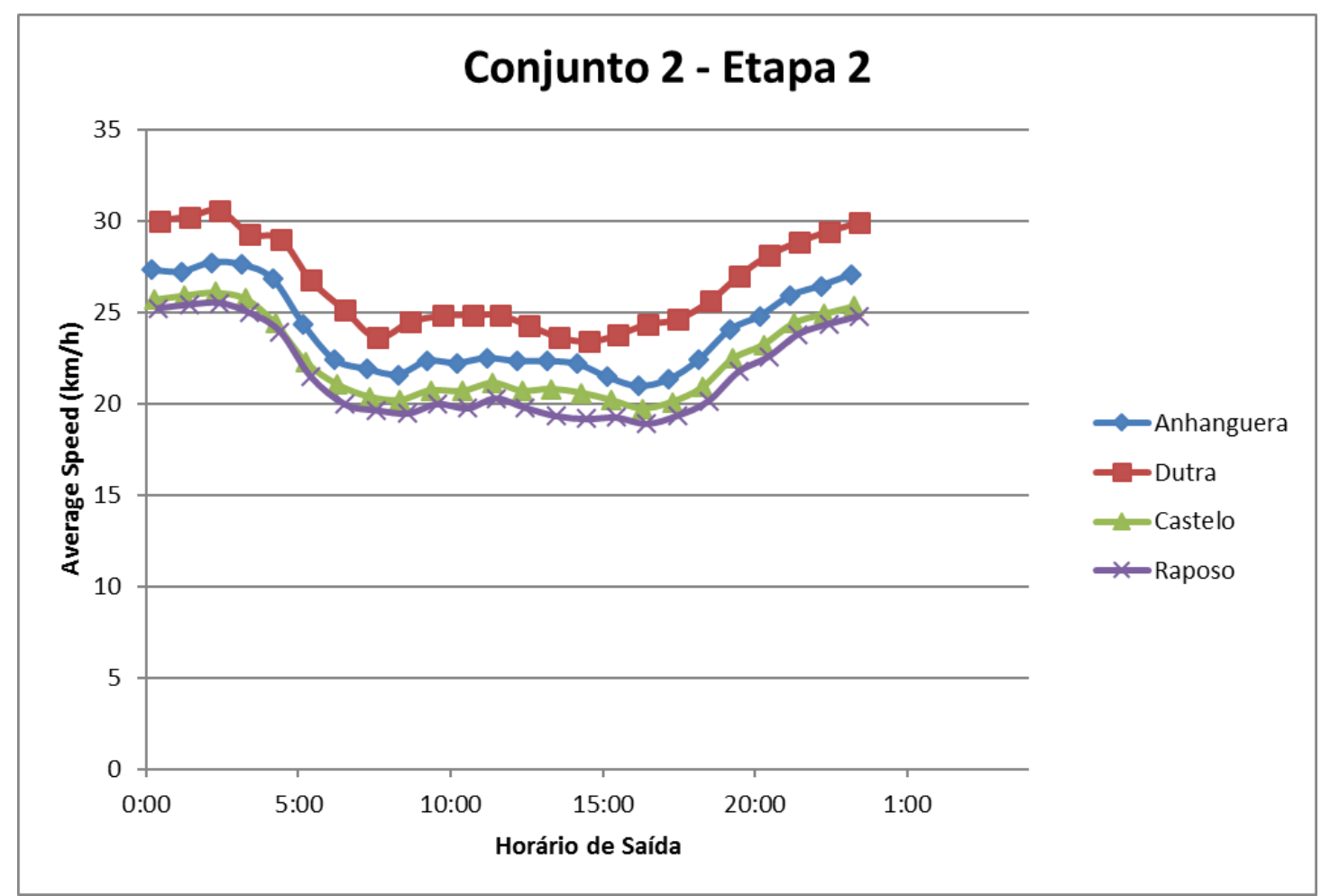

Figura D.9: Perfis de velocidade para etapa de circulação entre locais de entrega para o grupo de pontos 2 .

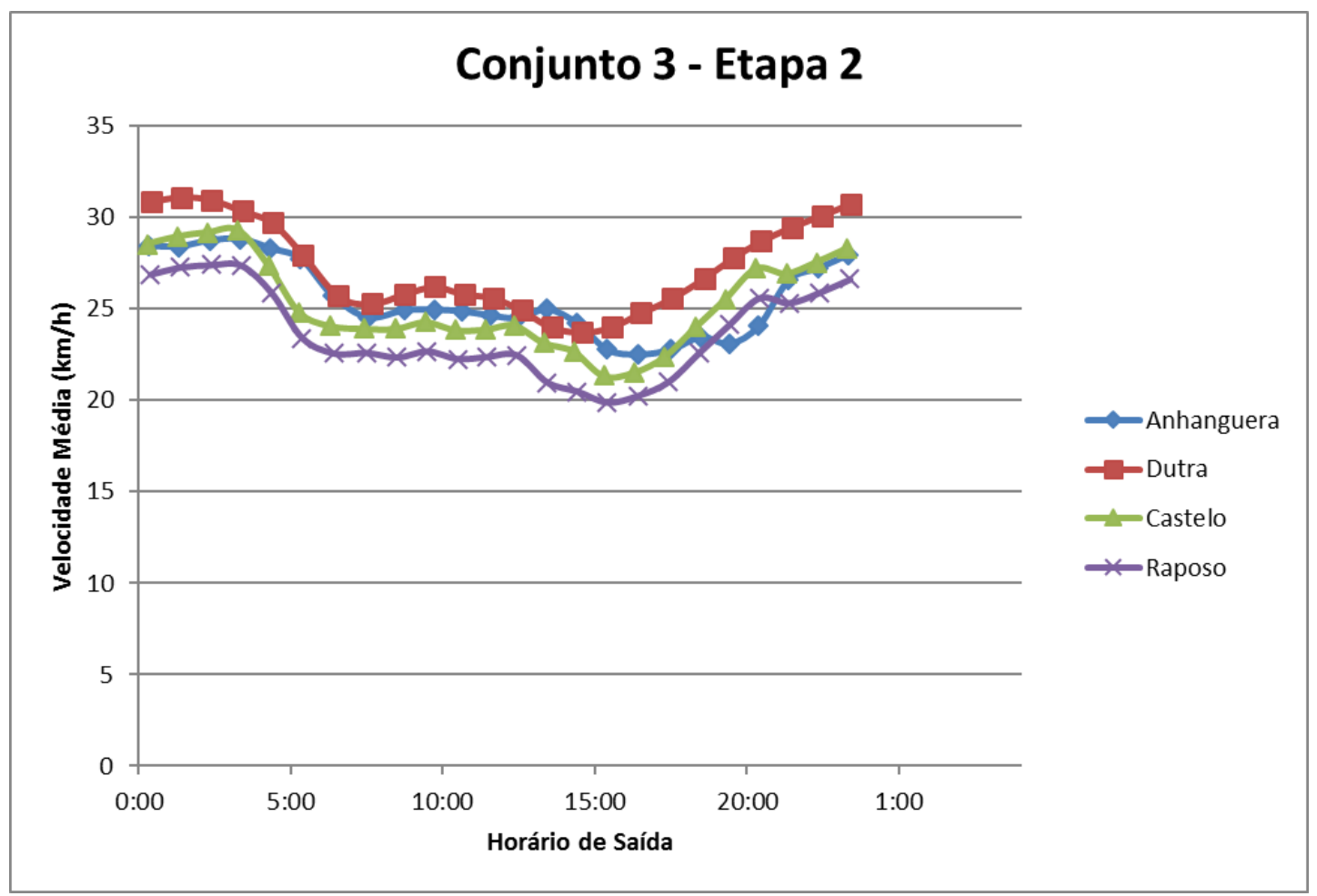

Figura D.10: Perfis de velocidade para etapa de circulação entre locais de entrega para o grupo de pontos 3 . 


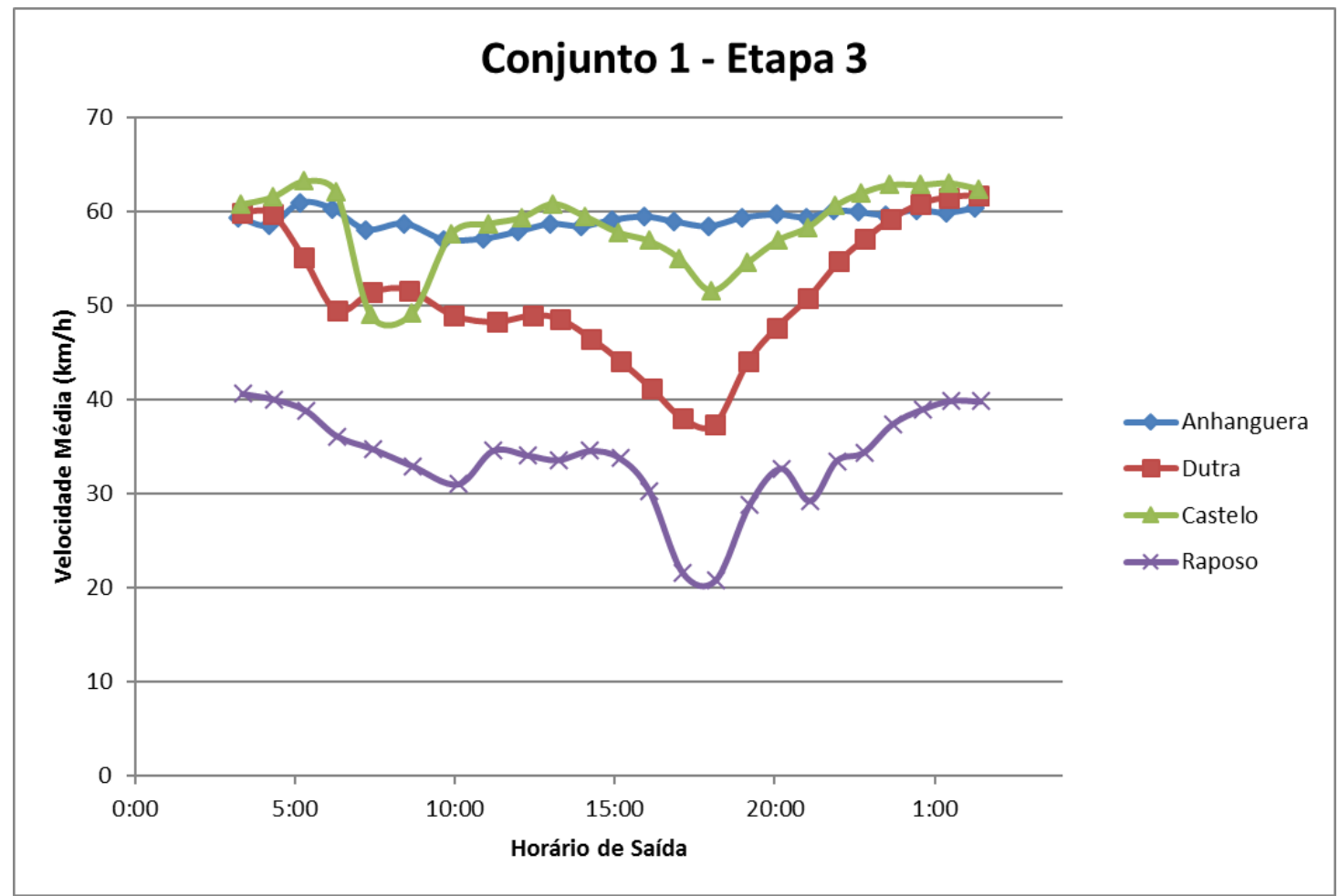

Figura D.11: Perfis de velocidade para etapa de line-haul de retorno para o centro de distribuição para o grupo de pontos 1 .

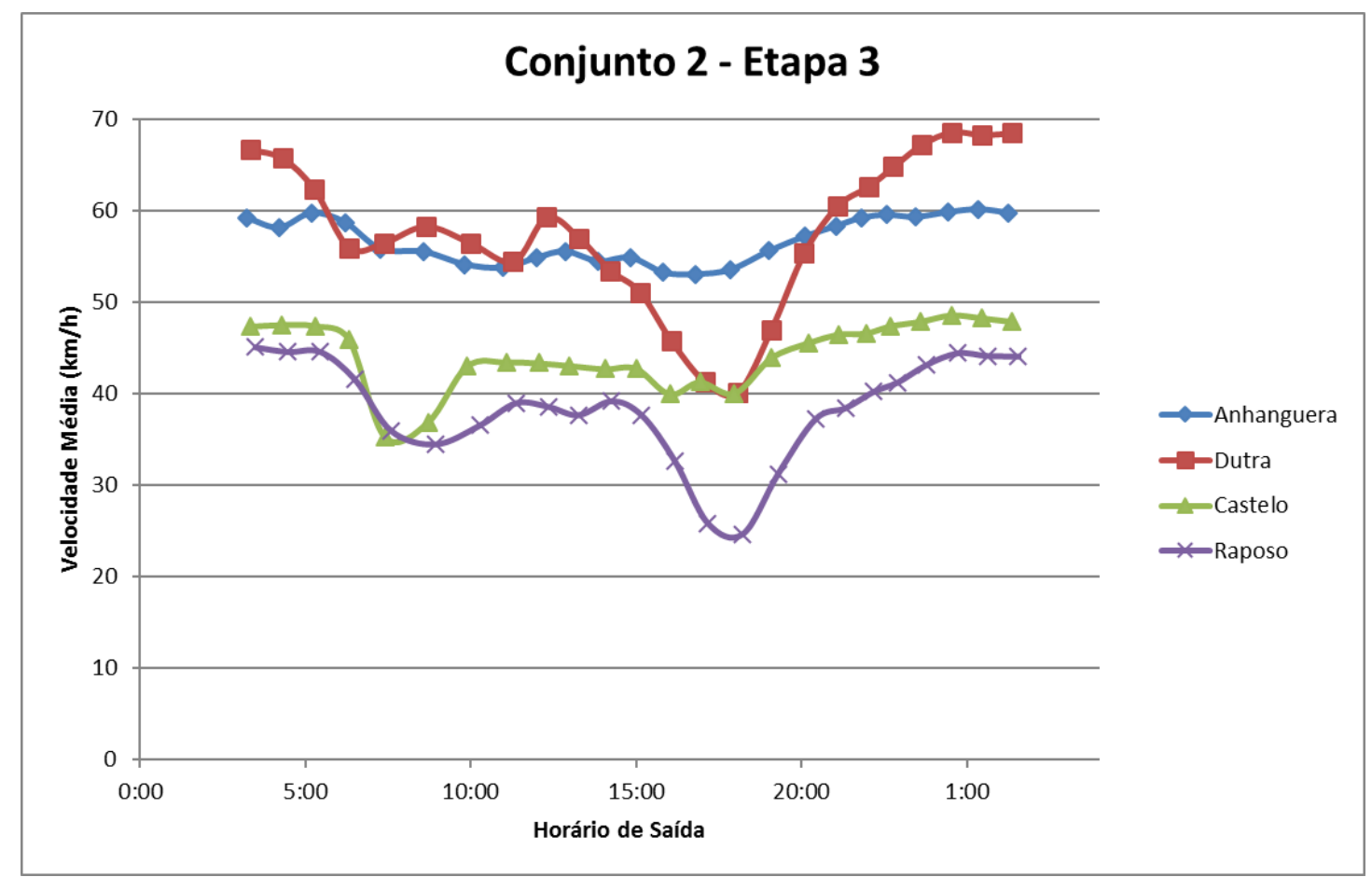

Figura D.12: Perfis de velocidade para etapa de line-haul de retorno para o centro de distribuição para o grupo de pontos 2 . 


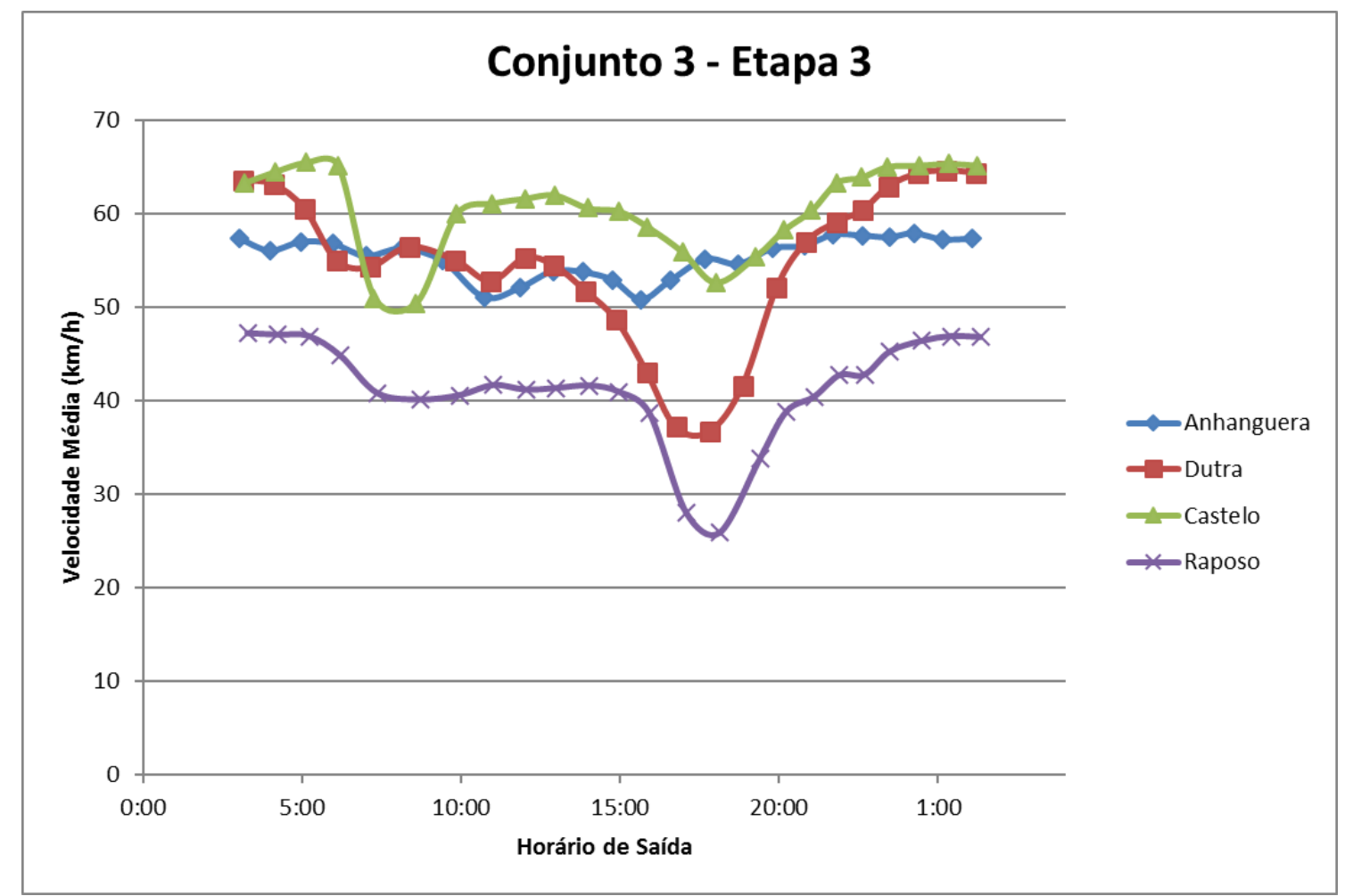

Figura D.13: Perfis de velocidade para etapa de line-haul de retorno para o centro de distribuição para o grupo de pontos 3.

Observando os gráficos de perfis de velocidade da Figura D.5 e da Figura D.13, percebe-se que as velocidades nas etapas 1 e 3 possuem uma maior variação que na etapa 2. Além disso, percebe-se que os deslocamentos com sentido centro da etapa 1 sofrem mais os impactos do trânsito congestionado no período da manhã e os deslocamentos sentido interior da etapa 3 sofrem mais impactos dos congestionamentos no período da tarde. Outro fator que chama a atenção é que as velocidades médias referentes ao centro de distribuição localizado na rodovia Raposo Tavares são menores para todos os conjuntos de pontos ao longo do dia todo.

A abordagem descrita nesta seção possui limitações consideráveis. Primeiro, o sequenciamento dos pontos de entrega utilizando a API do Google Maps não pode ser realizado para um número de pontos maior que 23 , que é o limite aceito pela ferramenta. 


\section{ANEXO E: COMPARAÇÃO DE RESULTADOS - GOOGLE MAPS X OPEN STREET MAP}

Este anexo sumariza o procedimento utilizado para a extração das distâncias em rede utilizando a base de mapas aberta Open Street Map (OSM), os resultados obtidos e a comparação com os resultados do Google Maps.

A computação das rotas em rede é automatizada em Python através das bibliotecas OSMnx e NetworkX (Hagberg et al., 2008). A biblioteca OSMnx permite o acesso aos dados da base do OSM e a biblioteca NetworkX permite computar caminhos em rede. Este teste utilizou dados de entrada no mesmo formato que são descritos na seção 3.1 deste trabalho, ou seja, um shapefile definindo a área de estudo e um arquivo csv listando as coordenadas geográficas dos pontos aleatórios que serão usados como origens e destinos na análise.

Um grande limitante do uso desta ferramenta é que, diferentemente da API do Google Maps, a biblioteca NetworkX calcula caminhos mínimos entre nós da rede apenas, o que quer dizer que, deve-se identificar qual o nó mais próximo dos pontos de origem e destino para computar o caminho mínimo em rede entre eles. Sendo assim, é necessário utilizar o comando da biblioteca OSMnx que realiza esta tarefa.

O segundo passo do algoritmo é computar os caminhos mínimos entre as origens e os destinos. Como não há limitação de número de solicitações para o uso destas bibliotecas, há poucas desvantagens em computar a matriz de distâncias completa entre todos os pontos aleatórios gerados. Principalmente porque o objetivo desta etapa é testar os resultados da ferramenta e compará-las com os resultados provenientes do Google Maps, e para tal é interessante computar caminhos em diversas faixas de distâncias dentro do contexto urbano, a fim de identificar a consequente variação dos resultados.

O procedimento foi realizado em áreas nas cidades de São Paulo, Rio de Janeiro e Bogotá. Foi gerado um conjunto de pontos aleatórios para cada cidade e foram computadas as distâncias em rede entre todos os pontos através do OSM e do Google Maps. Para cada par origem e destino foram atribuídos dois Índices de 
"Retilinidade" (IR); um para a distância obtida pelo OSM $\left(I R_{O S M}\right)$ e outro para a distância obtida pela API do Google Maps $\left(I R_{G M}\right)$.

O percentual de variação entre os IRs foi calculado segundo a seguinte fórmula:

$$
\frac{I R_{G M}-I R_{O S M}}{I R_{G M}} \times 100
$$

As Figuras E.1, E.2 E E.3 contém os gráficos gerados desta análise. O eixo x representa a distância linear entre origem e destino e o eixo y a variação percentual observada para o IR.

Analisando os gráficos das Figuras E.1, E.2 e E.3 percebe -se uma tendência a menores variações do IR para maiores distâncias. Esse comportamento é esperado devido a maneira que as distâncias em rede são calculadas pelo OSM, com as origens e destinos sendo nós da rede. Além disso, percebe-se que em Bogotá observam-se variações muito maiores para distâncias entre 4 e $8 \mathrm{~km}$. O motivo para tal resultado inesperado foi investigado. A Figura E.4 mostra um exemplo de caminho entre dois pontos, o traço vermelho representa o caminho do Google Maps o azul o caminho do OSM. Visualmente, não há dúvidas que a alternativa fornecida pelo Google Maps é mais eficiente e adequada para ligar os dois pontos. Portanto, pressupõe-se que há alguma falha na base do OSM para Bogotá, já que diferenças como essa foram observadas para diversos pares de pontos.

Por fim, a Tabela E.1 resume a porcentagem de observações (pares origem e destino) que estão em determinada faixa de variação de IR. Percebe-se que nas 3 cidades analisadas, menos da metade dos pares origem e destino apresentam variação no IR menor que 10\%. Este resultado reforça a pouca confiabilidade da base OSM. 


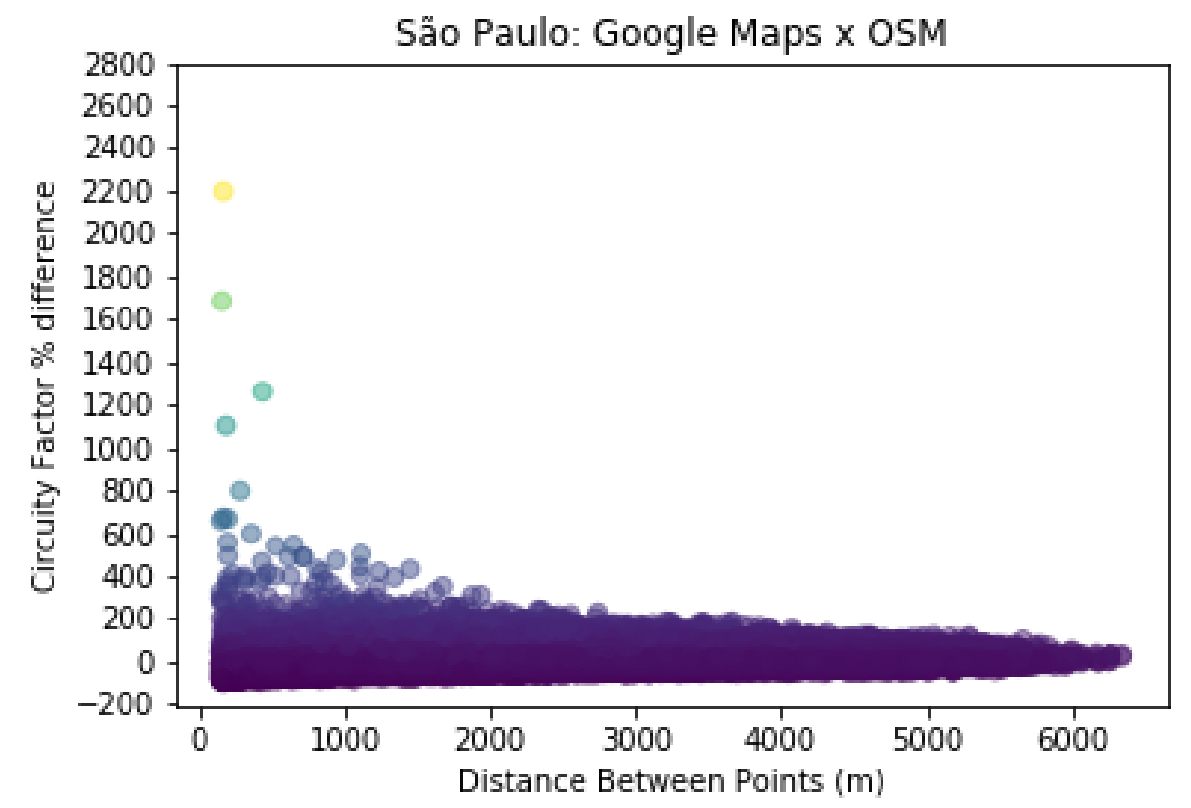

Figura E.1: Variação do IR Google Maps x OSM em São Paulo.

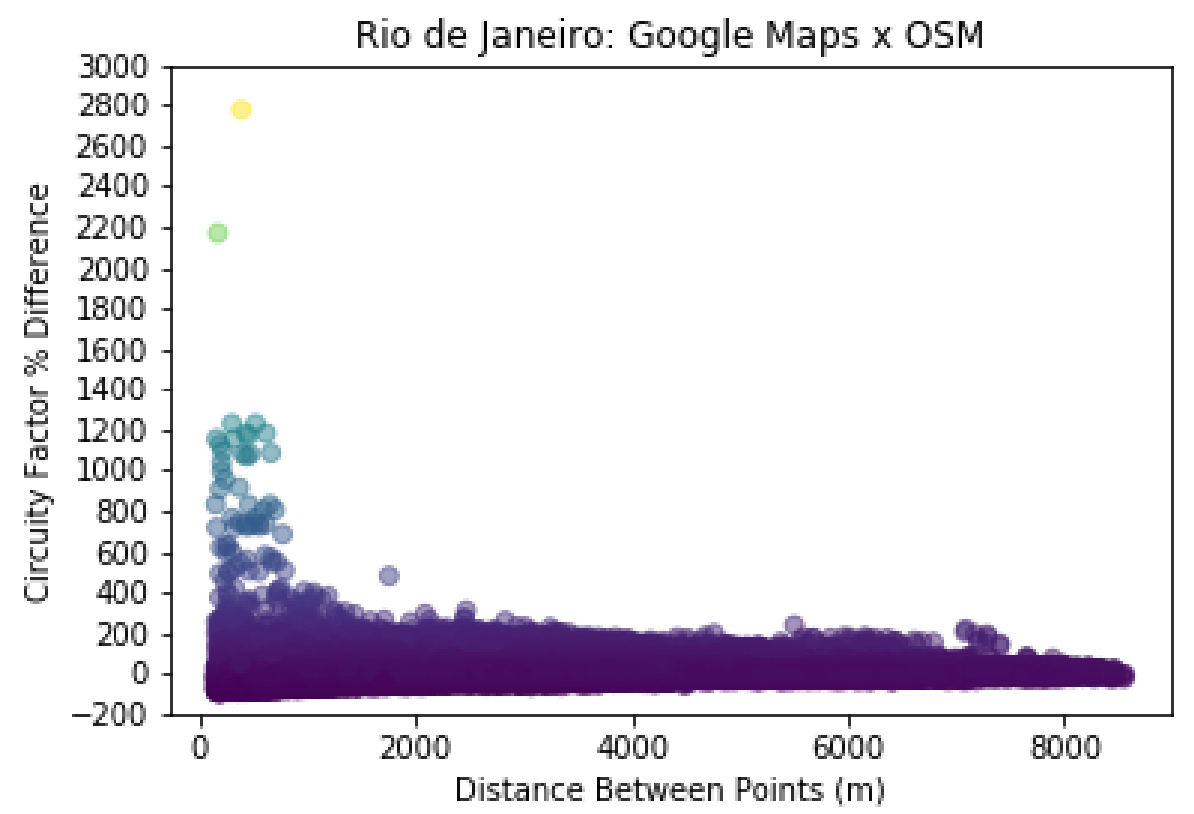

Figura E.2: Variação do IR Google Maps x OSM no Rio de Janeiro. 


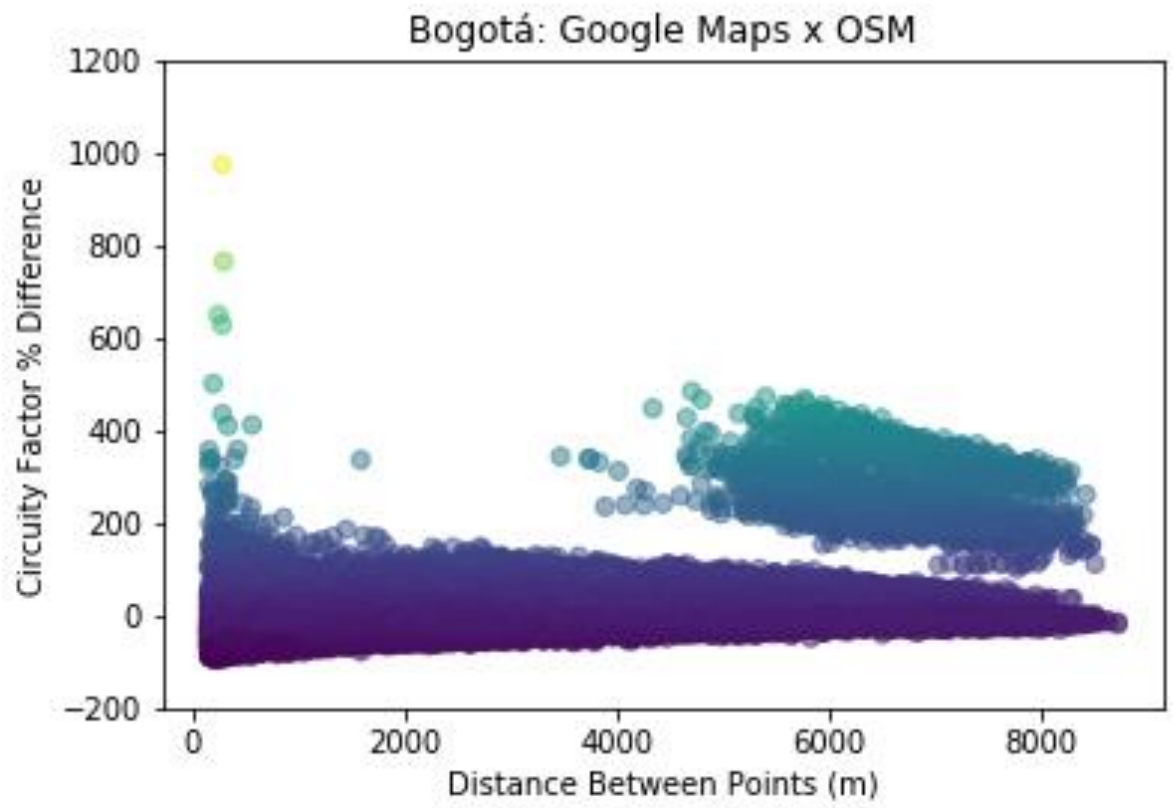

Figura E.3: Variação do IR Google Maps x OSM em Bogotá.

- Tabela E.1: Porcentagem (\%) de observações em cada variação de IR.

\begin{tabular}{cccc}
\hline Variação \% de IR & São Paulo & Rio de Janeiro & Bogotá \\
\hline Até 100\% & 98,5 & 97,0 & 97,9 \\
Até 50\% & 92,4 & 86,3 & 91,0 \\
Até 40\% & 87,9 & 80,4 & 86,3 \\
Até 30\% & 79,6 & 71,5 & 78,8 \\
Até 20\% & 64,1 & 57,9 & 66,1 \\
Até 10\% & 36,9 & 34,4 & 41,8 \\
\hline
\end{tabular}




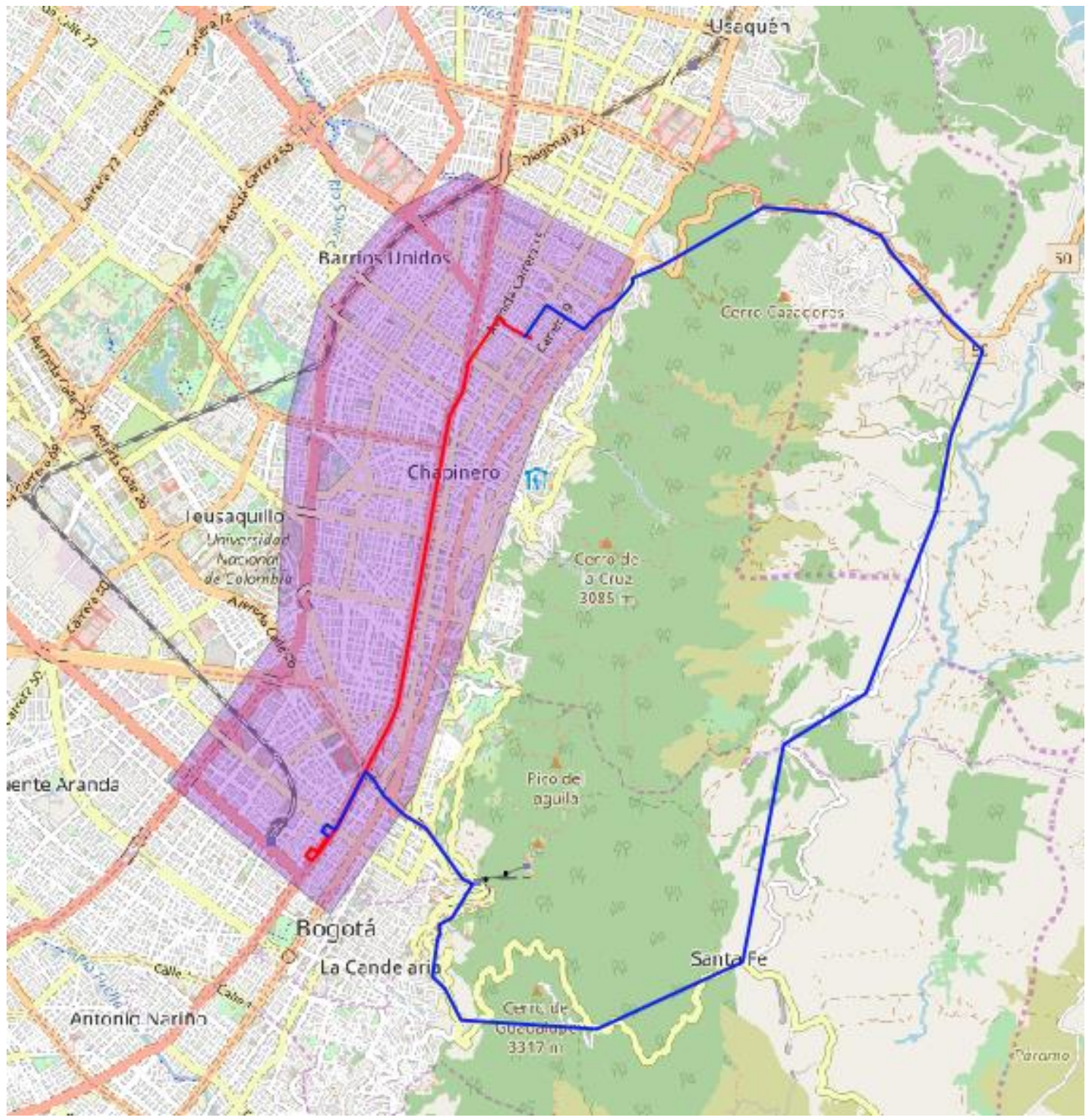

Figura E.4: Exemplo de caminhos em Bogotá. 